\title{
ALTERNATIVAS DE USOS FINAIS DA ELETRICIDADE DESLOCADA DA COCÇÃO ELÉTRICA NA COLÔMBIA
}

\begin{abstract}
Dissertação apresentada ao Programa Interunidades de Pós-Graduaçã̀o em Energia (IEE-USP, EPUSP, FEA-USP, IFUSP) da Universidade de São Paulo para obtenção do lítulo de Mestre em Energia.
\end{abstract}

620.98:537(861)

A473a

São Paulo

D-PIPGE/USP"

1994

e. 3 


\title{
ALTERNATIVAS DE USOS FINAIS DA ELETRICIDADE DESLOCADA DA COCÇÃO ELÉTRICA NA COLÔMBIA
}

\begin{abstract}
Dissertação apresentada ao Programa Interunidades de Pós-Graduação em Energia (IEE-USP, EPUSP, FEA-USP, IFUSP) da Universidade de São Paulo para obtenção do título de Mestre em Energia.
\end{abstract}

Área de Concentração:

Área interdisciplinar de Energia

Orientadores:

Dr. Roberto Hukai

Dr. Prof. Otavio Mielnik

São Paulo

1994 
A Rosalba, Adriana e Rosana. 


\section{AGRADECIMENTOS}

Aos professores Roberto Hukai e Otavio Mielnik por suas orientações e sugestões na elaboração deste trabalho.

À International Energy Initiative (IEI) pelo apoio financeiro.

À Empresa Interconexión Eléctrica S.A. (ISA) da Colômbia pela minha liberação e apoio integral para a realização deste trabalho.

A todas as pessoas e instituições que de uma ou outra forma colaboraram na realização desta dissertação. 


\section{LISTA DE ABREVIATURAS E SIGLAS}

RESUMO

\section{ABSTRACT}

1 INTRODUÇÃO

1.1 Definição do Problema

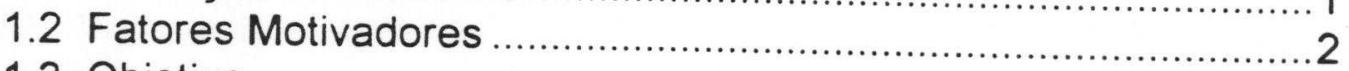

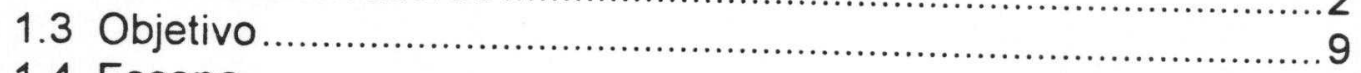

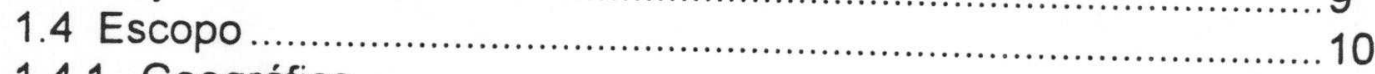

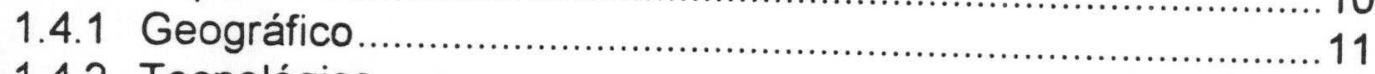

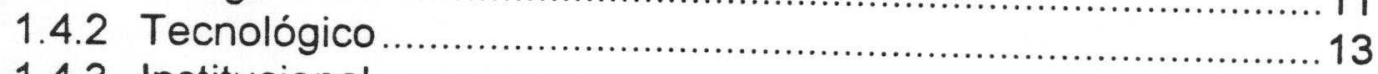

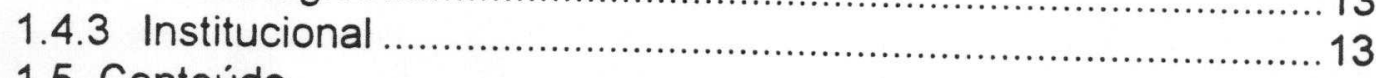

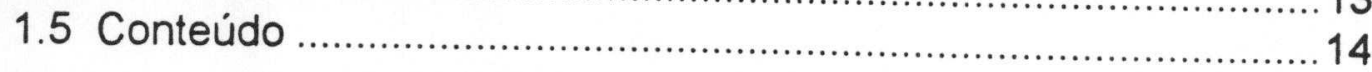

2 A COCÇÃO ELÉTRICA NA COLÔMBIA

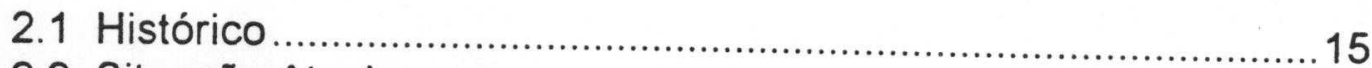

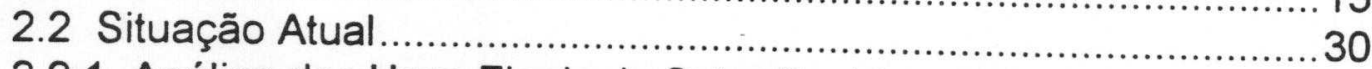

2.2.1 Análise dos Usos Finais do Setor Residencial ...........................31

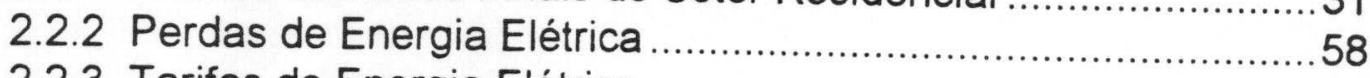

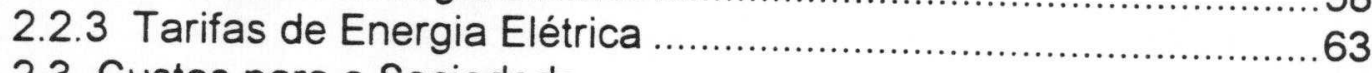

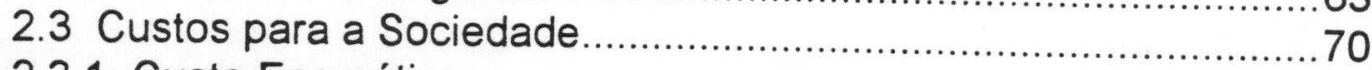

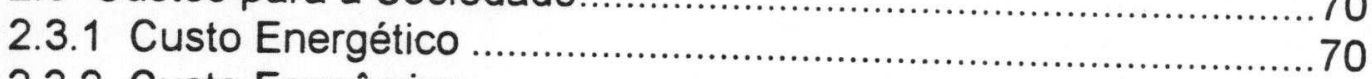

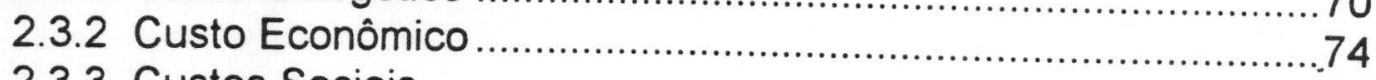

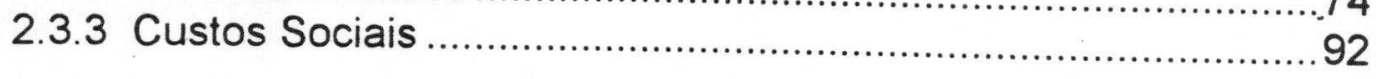

3. ALTERNATIVAS DE SUBSTITUIÇÃO 98

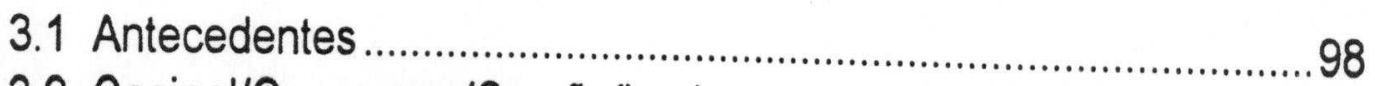

3.2 Cocinol/Querosene/Carvão/Lenha............................................. 100

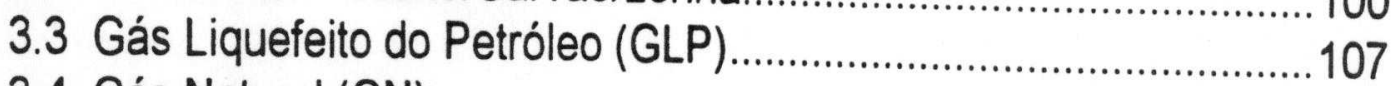

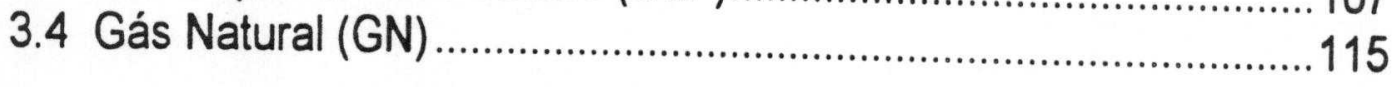

\section{A PROBLEMÁTICA DOS USOS FINAIS DA ELETRICIDADE} DESLOCADA DA COCÇÃO

4.1 Antecedentes

4.2 Eletrificação do Setor Ferroviário

4.3.1 Projetos de Eassa (STM)........... 142

4.3.1 Projetos de Eletrificação de STM em Santafé de Bogotá ...........149

4.3.2 Projetos de Eletrificação de STM em Medellin .............................172

4.4 Crescimento Vegetativo da Demanda. 
5.1 Conclusões

5.2 Recomendações

REFERÊNCIAS BIBLIOGRÁFICAS

LISTA DE FIGURAS

LISTA DE TABELAS 


\begin{tabular}{ll} 
Abreviaturas & \\
bbl & Barril (42 galons) \\
BOMT & Build, Operate, Maintain and Transfer \\
CIF & Cost, Insurance and Freight \\
Col\$ & Pesos colombianos (moeda nacional) \\
DSM & Demand Side Management \\
FOB & Free on Board \\
f.C. & Fator de carga \\
GLP & Gás Liquefeito do Petróleo \\
GN & Gás Natural \\
MMCol\$ & Milhões de pesos colombianos \\
MMm & Milhões de metros cúbicos \\
MMBTU & Gás Natural Comprimido \\
GPC & Giga pé cúbico \\
IPC & Litro dice de preços ao consumidor \\
\hline
\end{tabular}


MMUS\$ Milhões de dólares americanos

m.s.n.m. Metros sobre o nivel do mar

PIB Produto Interno Bruto

ppb Partes por bilhão

ppm Partes por milhão

STM Sistema de Transporte de Massa

Tcal Tera $\left(10^{12}\right)$ calorias

TIR Taxa interna de retorno

ton Toneladas métricas

US\$ Dólares americanos

VLT Veículo Leve sobre Trilhos

VPL Valor presente líquido

Siglas

ACIEM Asociación Colombiana de Ingenieros Electricistas, Electrónicos, Mecánicos y Afines

BID Banco Interamericano de Desenvolvimento

BIRD Banco Internacional de Reconstrução e Desenvolvimento

BM Banco Mundial 
Comissão das Comunidades Europeias

CIDI Centro de Investigaciones para el Desarrollo Integral

CISPROQUIM Centro de Información de Seguridad sobre Productos Químicos

CNE Comisión Nacional de Energía

COLGAS Compañia Colombiana de Gas

CONFIS Consejo Nacional de Política Fiscal

CONPES Consejo Nacional de Política Económica y Social

CORPES Corporación Regional de Política Económica y Social

CRE Comisión de Regulación Energética

CVC Corporación Autonóma Regional del Cauca

DANE Departamento Administrativo Nacional de Estadística

DNP Departamento Nacional de Planeación

ECOPETROL Empresa Colombiana de Petróleos

EDTU Empresa Distrital de Transporte Urbano

EEPPM Empresas Públicas de Medellín

EMCALI Empresas Municipales de Cali

ESMAP Energy Sector Management Assistance Program

ETMVA Empresa de Transporte Masivo del Valle de Aburrá

FERROVIAS Empresa Colombiana de Vías Férreas 
ISA Interconexión Eléctrica S.A.

JICA Japan International Cooperation Agency

JNT Junta Nacional de Tarifas

METROSALUD Instituto Metropolitano de Salud de Medellín

MIT Massachusetts Institute of Technology

MME Ministerio de Minas y Energía

MOPT Ministerio de Obras Públicas y Transporte

OLADE Organización Latinoamericana de Energía

SIE Sistema de Información Energética

SIEE Sistema de Información Económica Energética

STF Sociedad Colombiana de Transporte Ferroviario

UPB Universidad Pontificia Bolivariana

UPME Unidad de Planeamiento Minero Energética

UV Universidad del Valle 


\section{RES U M O}

Esta dissertação analisa, do ponto de vista técnico, econômico e social, diferentes alternativas de usos finais para a eletricidade deslocada da cocção elétrica no setor residencial da Colômbia.

Neste trabalho mostra-se que o cozimento e preparo de alimentos por meio da eletricidade, tem um custo social elevado. Discute-se, portanto, o papel de diversos energéticos substitutos da eletricidade nesse uso final.

Analisaram-se projetos de eletrificação no setor de transportes. Os resultados mostram que, a curto prazo, existem opções interessantes do ponto de vista técnico, econômico e ambiental de eletrificação de transporte de massa nas grandes cidades (Santafé de Bogotá e Medellín).

Contudo, determinou-se que provavelmente as reduções de demanda de eletricidade pelo setor residencial na Colômbia redundarão no adiamento do aumento de oferta e não na conquista de novos e importantes mercados para a eletricidade. 


\section{A B S TRACT}

This dissertation analyses, various end-use alternatives for the electricity saved from electric cooking in Colombia; technical, economic and social issues were studied.

This document shows that preparation of food, using electricity has a high social cost. Therefore, discussion about the role of several types of energy that could substitute electricity in that end-use was made.

There were also analyzed some projects of electrification in the transport sector. The results show that in a short range period of time there are interesting options of massive transport electrification in the largest cities of Colombia (Santafe de Bogota and Medellin) taking into consideration, technical, economic and environmental aspects.

However, it was determined that reductions on electricity demand of the residential sector will be more likely reflected in a delay of increasing supply than of new and large electricity market formation. 


\section{INTRODUÇÃO}

\subsection{Definição do Problema}

O problema a ser estudado nesta dissertação está relacionado com uma análise de usos finais alternativos para a eletricidade que, atualmente, está sendo utilizada em forma generalizada no preparo de alimentos (cocção) para uso residencial e que poderia ser substituida por outros energéticos mais eficientes para esta finalidade.

O uso da eletricidade na cocção doméstica de alimentos representa para o Setor Elétrico Colombiano um ônus de crítica importância, pois implica superdimensionar o sistema para atender o serviço de uma maneira confiável. Isto se traduz em altos custos econômicos e socio-politicos para o país, dificilmente sustentáveis num futuro próximo.

Levanta-se nesta dissertação uma análise sobre a possivel movimentação com eletricidade de uma parte da frota de veículos para transporte coletivo, como parte da solução dos problemas decorrentes do consumo de derivados do petróleo no setor de transportes: déficit de gasolina, outorga de subsídios, poluição ambiental, baixas eficiências, congestionamentos nas principais cidades do país, etc..

A dissertação, então, explora o sinergismo existente entre os setores de transporte e elétrico ao considerar uma análise conjunta dos seus problemas. 


\subsection{Fatores Motivadores}

Em $1991^{1}$, as vendas de eletricidade na Colômbia foram de 27.375 GWh. O setor de maior participação foi o residencial, com $47,3 \%$ de tais vendas. $O$ setor industrial, que na maioria dos paises é tipicamente o maior consumidor, teve uma participação de 30,6\% (ISA, 1993a). Este comportamento torna a Colômbia como um caso especial de estrutura de mercado de eletricidade a nivel mundial.

Deve-se salientar que as cifras acima mostradas correspondem a vendas e não ao consumo real dos setores, para o qual teria de incluir as perdas associadas a cada setor.

As perdas de energia elétrica em 1991 foram de $21 \%$ da demanda (vendas + perdas + consumo próprio). Incluindo-se o consumo próprio de $715 \mathrm{GWh}$, pode-se então dizer que para cada $100 \mathrm{GWh}$ produzidos, efetivamente só 72,6 GWh são faturados.

Ora, o setor residencial é considerado como o setor de maior responsabilidade por estas perdas, e especialmente pelas perdas não técnicas ${ }^{2}$. Esta questão leva a que, sob o ponto de vista do consumo de eletricidade, este setor seja ainda mais preponderante.

Esta característica da estrutura do mercado da eletricidade na Colômbia responde várias questōes pertinentes à indústria elétrica. Por exemplo, a eletricidade é amplamente usada para os diferentes usos finais no setor

1 Em diferentes partes da dissertação vão-se apresentar dados relacionados com o ano 1991 ao invés de 1992 devido ao comportamento atípico deste último ano por causa do racionamento de energia elétrica que o país viveu entre 1992 e 1993.

2 As perdas não técnicas para o pais estão estimadas em $40 \%$ do total das perdas (técnicas + não técnicas), mas existem concessionárias que as responsabiiizam por mais de $70 \%$ das perdas nos seus mercados atendidos. 
residencial : iluminação, geladeiras, aquecimento de água, acondicionamento de ar, cocção. Este último uso é o mais intensivo em eletricidade, em especial nas grandes cidades do pais (Santafé de Bogotá, Medellín e Santiago de Cali). Também, a percentagem do serviço elétrico para usuários residenciais é alta devido aos programas de eletrificação rural impulsionados em governos passados. Além disso, existem usuários que têm características de consumo do tipo industrial (micro-indústrias) ou comercial (por exemplo. micro-empresas) mas estão registrados como usuários de tipo residencial. 0 setor industrial não está suficientemente desenvolvido e existem claras ineficiências no uso da eletricidade (em especial os setores residencial e comercial).

A desvantagem para o pais, decorrente da atual estrutura de consumo da eletricidade, é resultante da estrutura tarifária que prevaleceu nas últimas décadas. A Figura 1.1 mostra os valores relativos das tarifas com relação aos custos marginais médios de longo prazo (CMLP) da eletricidade. Como pode-se ver, a tarifa média do setor residencial foi somente $44 \%$ do CMLP que, em outras palavras, significa que o serviço da eletricidade está sendo altamente subsidiado.

Obviamente, esta situação representa para as empresas de serviço elétrico uma condição financeiramente adversa aos seus interesses. Aliás, a "sobrevivência" das empresas tem ocorrido com um esquema de subsídios cruzados entre os setores comercial, industrial e os setores residencial e público.

O esquema anterior tem características administrativas internas e não tem uma conceituação formal legal. Ainda assim, nenhuma empresa do setor elétrico, na Colômbia consegue apresentar uma condição satisfatória para suas finanças (Figura 1.2). 
Figura 1.1

Comparação entre Tarifas Setoriais e Custos Marginais de Longo Prazo (CMLP)

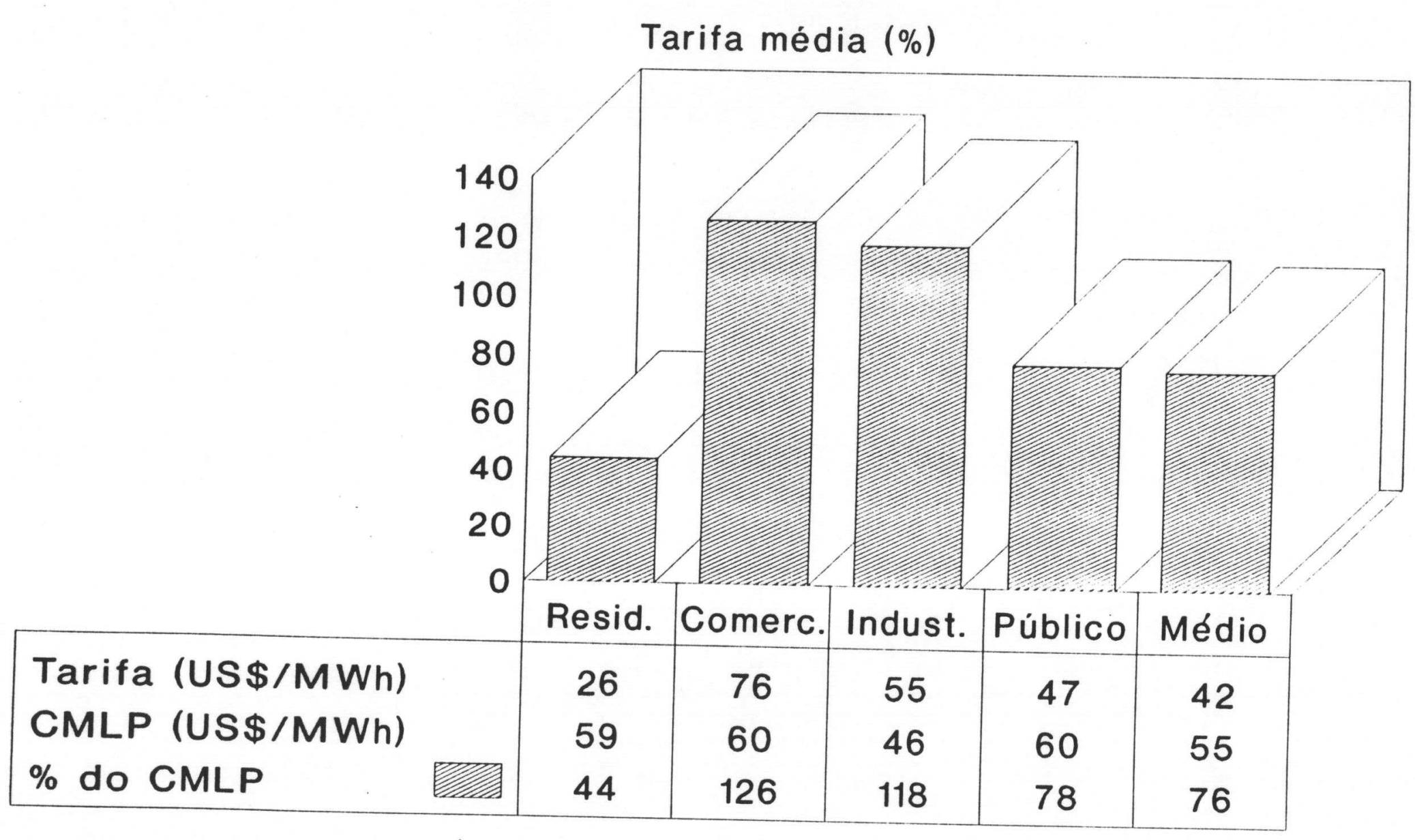

Fonte: ISA, 1993a

Valores em dólares de dezembro de 1990 
Figura 1.2

Comparação entre Tarifas e Custos Marginais de Longo Prazo (CMLP) por Empresas e para o Sistema Nacional

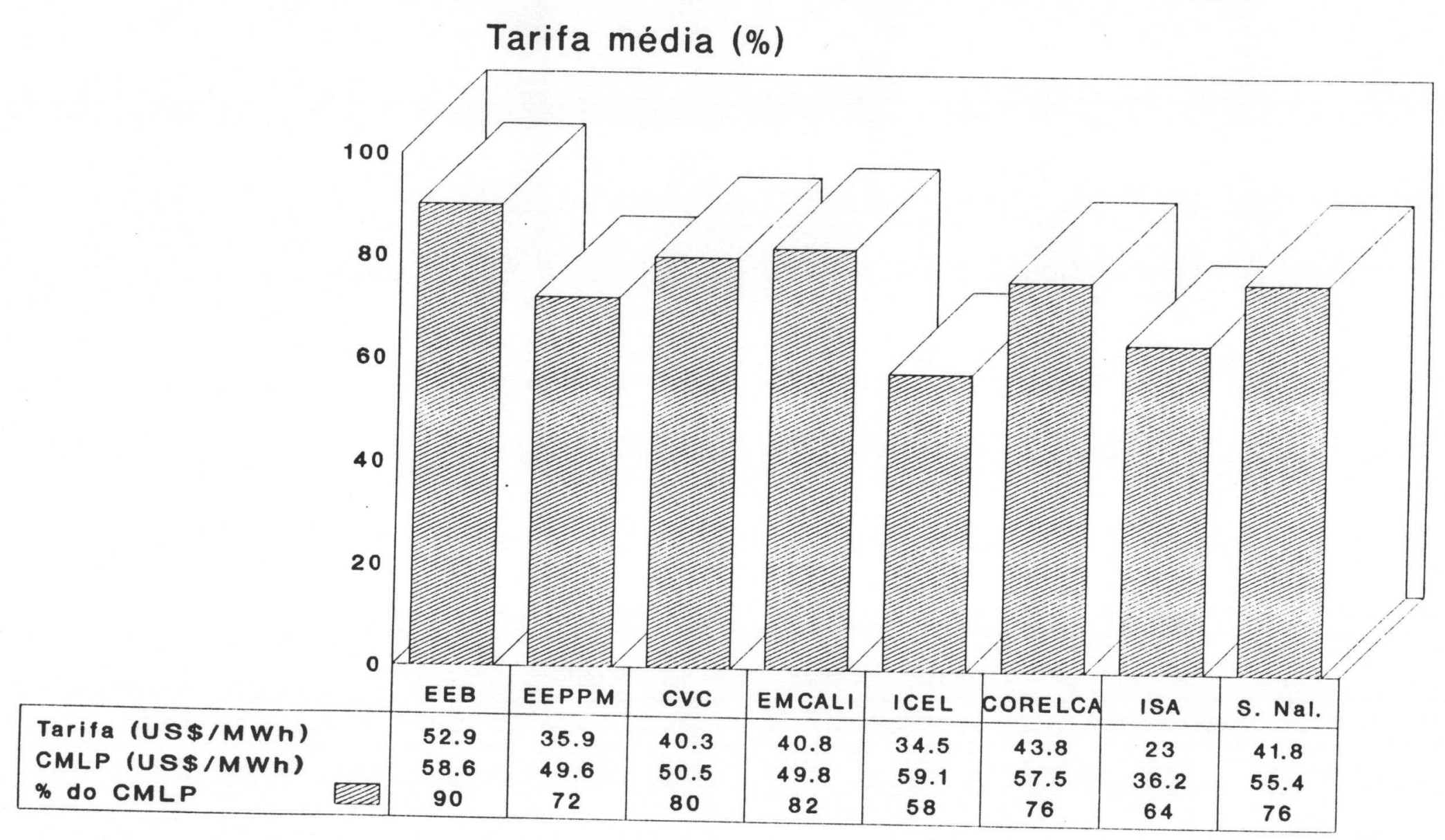

Fonte: ISA, 1993a

Valores em dólares de dezembro de 1990 
Para solucionar tal crise, o setor elétrico propôs ao Governo Central, através da Junta Nacional de Tarifas (JNT), uma política de atualização de tarifas no setor residencial, procurando levá-las ao custo econômico de produção, isto é, que a tarifa fosse igual ao CMLP. Atualmente, com a criação da Comissão de Regulamentação Energética (CRE) e a extinção da JNT, o controle e desenho do esquema tarifário passou a ser competência dessa nova entidade.

Essa medida, à primeira vista, óbvia, teria repercussões financeiras e políticas muito sensiveis para a sociedade, o que provavelmente impediria sua execução imediata. Aliás, as últimas resoluções da CRE visam ajustar as tarifas num horizonte que vai até 1995 . Também não solucionaria o problema de ponta de potência do setor residencial que necessita de um sistema super dimensionado e, por consequência, ocioso, devido ao baixo fator de carga desse setor (por volta de 65\%).

Outra alternativa que o Governo propôs e que atualmente está em andamento, é o programa de Massificação do Uso de Gás ${ }^{3}$, cujo objetivo é precisamente o de "promover uma matriz de consumo de energia mais eficiente e conveniente para o país, mediante a substituição de recursos energéticos de àlto custo, inicialmente por gás liquefeito do petróleo (GLP) e logo depois pela massificação do uso do gás natural (GN)". Este programa não está sendo liderado pelo setor elétrico mas sim, diretamente, pela Empresa Colombiana de Petróleos (ECOPETROL).

O programa de Massificação do Uso de Gás, embora implique numa diminuição nas vendas de eletricidade pelas concessionárias de energia elétrica, não tem provocado resistências muito fortes na sua aplicação. A razão

3 Departamento Nacional de Planeación, 1993. Estrategia para el Desarrollo del Programa de Gas. Doc. MINMINAS-ECOPETROL-DNP-2646-UINF-DIMEN. Santafé de Bogotá, 18 de marzo de 
é simples: como foi comentado anteriormente, a conjuntura financeira é tão crítica que qualquer medida que vise um adiamento de novos investimentos é bem-vinda.

Esta dissertação visa apresentar uma estratégia na qual as empresas do setor elétrico possam sair ainda mais beneficiadas pelo programa de massificação de gás. A idéia é estudar a viabilidade de criação de um novo mercado para o setor, aproveitando parte da energia que seria liberada do setor residencial devido à substituição de eletricidade usada na cocção e aquecimento de água.

Parte deste estudo objetiva de analisar a viabilidade da eletricidade participar como um vetor energético adicional dentro da matriz de consumo do setor de transportes.

Há outros interesses dentro do setor de transportes que motivam também esta análise. Atualmente, o país passa por um defícit crônico de gasolina, apesar da Colômbia ser um exportador de cru. As importações desse derivado são crescentes ao longo do tempo e começa a ser discutida a onerosa construção de uma nova refinaria. Em 1992, por exemplo, foram importados $13.026 \mathrm{kbbl}$ de gasolina, algo como $30 \%$ da demanda interna. Infelizmente nenhum programa de conservação, racionalização ou substituição da gasolina tem sido considerado.

O congestionamento generalizado de tráfego que se apresenta em cidades como Santafé de Bogotá e Medellin, além de sérios problemas de poluição atmosférica e as dificuldades financeiras que existem para expandir a atual rede viária dessas cidades, são também razões válidas para se pensar em medidas que contribuam para amenizar esse problema. 
Uma vantagem que existe em torno da conceituação desta idéia de eletrificação do transporte de massa, é que essas cidades são, por sua vez, os maiores mercados potenciais para o programa de massificação do uso de gás.

$\mathrm{Na}$ Colômbia começaram a se abrir novos espaços para o investimento privado em projetos de infra-estrutura e outros ativos atualmente em poder do Estado, como resultado da mudança de prioridade do Governo Central, agora concentrada na questão social, isto é, nas áreas de saúde, educação, cultura, lazer, esportes e atenção aos grupos vulneráveis da população (indígenas, minorias étnicas, crianças, idosos) (DNP, 1993a). O setor ferroviário colombiano é um exemplo de aplicação dessa política, já que a sua recente privatização abriu horizontes para um subsetor atrasado tecnologicamente, com uma pobre infra-estrutura física implantada e uma lamentável gestão administrativa. Deste modo, a modernização das máquinas e equipamentos e a eletrificação das linhas são fatores considerados nas análises desta dissertação.

\subsection{Objetivo}

Constitue-se em objetivo maior deste estudo, mostrar a conveniência de substituir a energia elétrica por outros tipos de energéticos no uso final da cocção doméstica na Colômbia e analisar usos alternativos para a eletricidade deslocada desse uso final, que possam resultar em maiores benefícios sociais, econômicos e ambientais para o país.

Para cumprir esse objetivo, foram realizados os seguintes trabalhos:

- Diagnosticar as deficiências que existem na Colômbia no campo energético, especialmente nos setores elétrico e de transportes.

- Mostrar as características e a situação atual da cocção elétrica no país. 
- Analisar os custos econômicos, sociais e energéticos envolvidos no uso da eletricidade para cocção.

- Analisar alternativas de solução a esse problema, usando-se de combustiveis substitutos.

- Analisar as vantagens e desvantagens do ponto de vista econômico, ambiental, técnico e sócio-político de utilizar a eletricidade deslocada para: (a) eletrificação de ferrovias; (b) eletrificação do transporte de massa em grandes cidades, ou (c) deixar que o crescimento vegetativo da demanda absorva os excedentes de energia elétrica.

- Apresentar conclusões e recomendações que possam ajudar as autoridades nacionais a tomar decisões sobre uma possivel implementação das alternativas propostas ou para definir um projeto específico que mereça um estudo detalhado. Também, pretende-se trazer à tona fatos de interesse até agora desconhecidos para os diferentes atores sociais envolvidos.

\subsection{Escopo}

Esta dissertação está vinculada a um contexto nacional, que é precisamente o problema da má alocação de recursos na maioria das regiões do país. Um problema que afeta ou atinge por restringir os recursos necessários a outros problemas sociais.

Contudo, o estudo está restrito a algumas questões de tipo geográfico, tecnológico, econômico e institucional. 


\subsubsection{Geográfico}

O "Programa de Massificação do Uso do Gás na Colômbia", em realidade é um programa que objetiva aumentar substancialmente a penetração do uso de GN ou GLP nas principais cidades, em especial as cidades localizadas na região Andina ${ }^{4}$ da Colômbia. O Mapa da Figura 1.4 mostra a localização dessas cidades no território nacional. A análise do uso de fontes energéticas alternativas tal que a eletricidade para cocção visa, então, enfocar com maior atenção e grau de detalhe os mercados potenciais mais proeminentes, que é o caso de cidades como Santafé de Bogotá, Medellín, Cali e o "eixo cafeeiro" 5 . Análises mais gerais são feitas para as demais regiōes e para a zona rural, com um consumo bastante significativo de lenha para uso doméstico.

No caso de eletrificação do transporte de massa, a atenção está dirigida às maiores cidades do país, na seguinte ordem: Santafé de Bogotá (6.314.305 habitantes), Cali (1.783.546 habitantes) e Medellín (1.698.777 habitantes) ${ }^{6}$. Aliás, os problemas mais agudos de transporte estão nessas cidades.

A rede ferroviária nacional é analisada em forma global, porém, as linhas que operam atualmente e o seu plano de expansão estão relativamente bem definidos. Desta forma podem-se identificar trechos que mereceriam um estudo posterior mais aprofundado.

4 Colômbia está geograficamente dividida em cinco regiões: A região Andina (zona central), caracterizada pela presença da cadeia montanhosa dos Andes em forma de três cordilheiras denominadas Ocidental, Central e Oriental ; a região Caribe (zona norte); a região Pacifica (zona ocidental); a Orinoquia (zona oriental) e a Amazônia.

50 "eixo cafeeiro" é formado pelos Departamentos (divisão política colombiana) altamente produtores de café no pais: Caldas, Quindio e Risaralda.

6 Considerando os municipios associados à área metropolitana da cidade de Medellín, a população é de aproximadamente 2.500 .000 habitantes, segundo o censo do DANE (Departamento Administrativo Nacional de Estadistica) de 1993. 
iIB B F

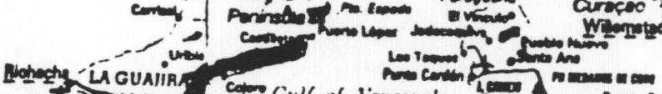

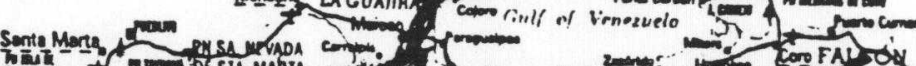

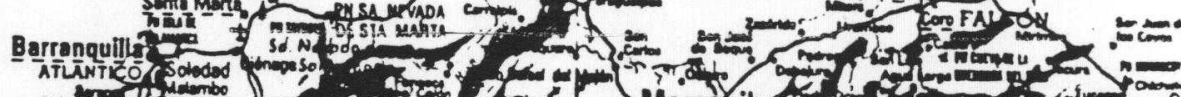

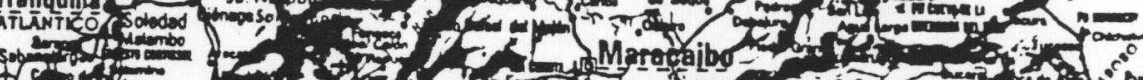

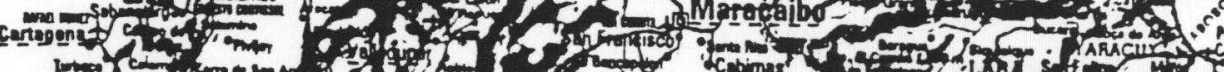

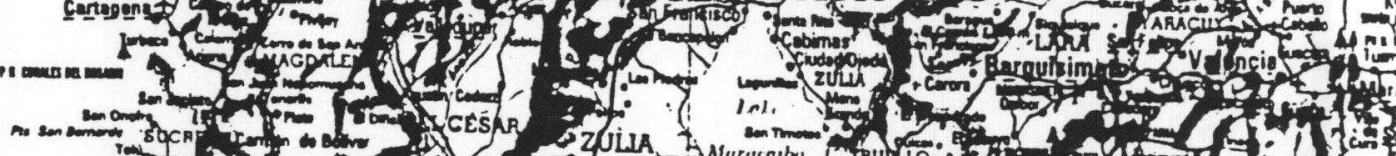

Istomus of Paname

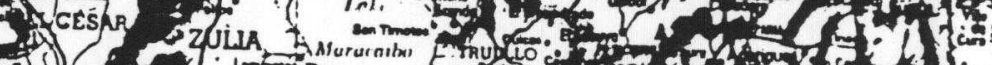
Finer

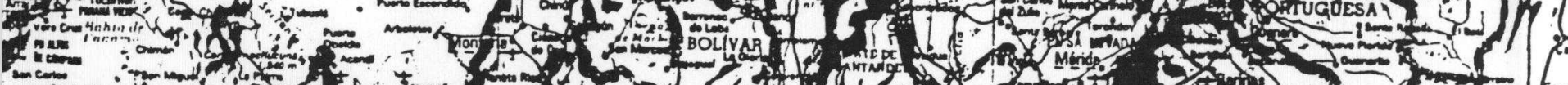

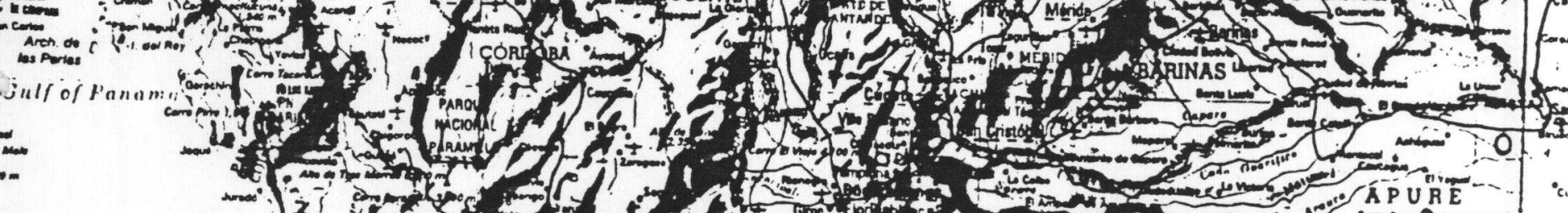

$\rightarrow$

1.000 -

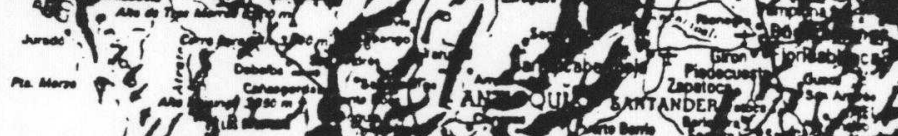

S il toce

IFIC P. $\int f$ and

$i A N$ Bumention

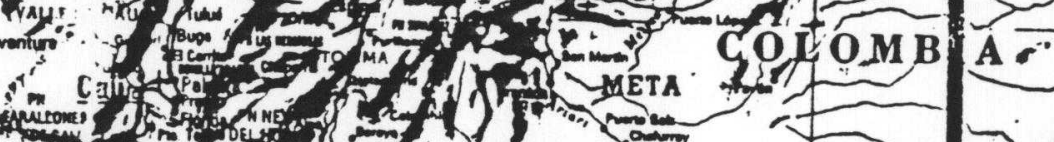
(n) (n) and 20

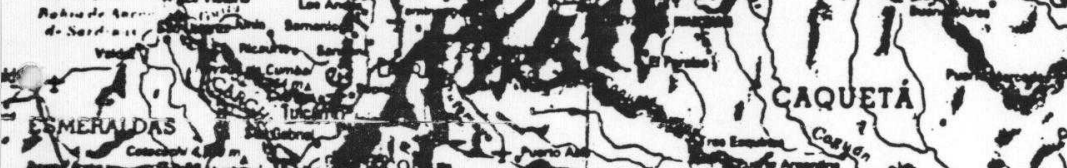

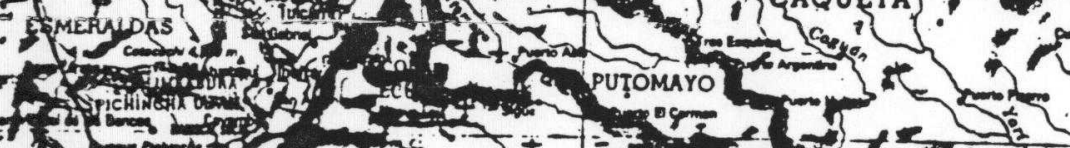

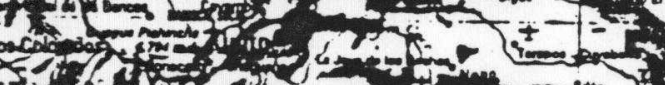

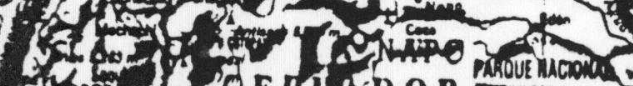

2. 3 on at 20

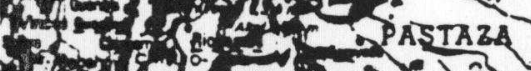
Sn of $\mathrm{F}$ finting

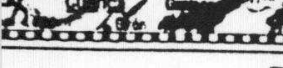
B $76^{\circ}$ , 200

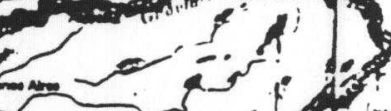

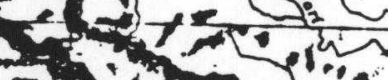
: gusinis

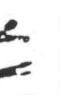




\subsubsection{Tecnológico}

Com relação ao programa de substituição de energia elétrica na cocção, são estudados o potencial dos mercados, os impactos e as alternativas energéticas, fundamentado na atual estrutura de projetos de gasodutos, empresas de distribuição de gás formadas ou em vias de criação e as reservas de GN disponíveis no pais.

A eficiência dos aparelhos usados na cocção, tanto aqueles que funcionam a gás quanto os que operam com energia elétrica, é um tópico que se trata na dissertação. Todavia, a classe de aparelhos considerados são basicamente aqueles de produção nacional.

As alternativas analisadas para a eletrificação do transporte de massa, são os tróleibus, os veículos leves sobre trilhos (VLT) ou pré-metro, trens rápidos metropolitanos (metrô) e trens suburbanos.

A eletrificação de ferrovias é discutida do ponto de vista dos requisitos da tecnologia atual de trens elétricos.

\subsubsection{Institucional}

Para este caso, são examinadas as opções institucionais que se poderiam ter para implementar efetivamente os projetos apresentados na dissertação.

Obviamente, e dentro do processo de abertura econômica que se vive na Colômbia, oportunidades vindas do setor privado são analisadas. 


\subsection{Conteúdo}

Esta dissertação consta de quatro capítulos principais, conclusões e bibliografia. Os três capítulos a seguir, apresentam o desenvolvimento das análises dos problemas levantados neste capitulo introdutório. O Capitulo 2, destina-se especialmente a tratar do problema relacionado ao uso de eletricidade para cocção na Colômbia. O Capítulo 3 analisa o papel que os diversos tipos de energéticos poderiam exercer como substitutos da eletricidade na cocção. O Capítulo 4 apresenta a segunda abordagem da dissertação, na qual se apresenta uma análise dos usos alternativos para a eletricidade deslocada da cocção. 


\section{A COCÇÃO ELÉTRICA NA COLÔMBIA}

Neste capítulo apresentam-se detalhes que caracterizam o uso da energia na Colômbia e principalmente da eletricidade.

Para dar uma visão global da problemática e estrutura energética da Colômbia, apresenta-se inicialmente no item 2.1 uma análise da evolução histórica do consumo de energia na Colômbia.

No item 2.2, realiza-se uma análise crítica da situação atual da estrutura de consumo energético, mas já com um enfoque bem mais específico para a cocção elétrica.

Os custos que a atual estrutura de consumo de eletricidade para cocção implica para a sociedade, são analisados no item 2.3.

\subsection{Histórico}

Em geral, o aproveitamento dos recursos naturais não renováveis e hídricos com fins energéticos, requerem a execução de projetos de considerável monta, que unicamente são viáveis dentro de políticas setoriais de longo prazo. Assim sendo, o setor energético tem uma significância e incidência notórias na economia nacional, pelos recursos de investimento que demanda o seu desenvolvimento e pelos efeitos da mesma em relação às transferências de recursos, exportações, importaçōes, geração de emprego, capacidade de poupança e definição de processos e tecnologias. Aliás, em 1990, 9,7\% das receitas correntes do país foram geradas no setor minero-energético (MENA; MME, 1990a).

A década dos anos 80 é chamada de "a década perdida" para a América Latina, devido aos crescimentos negativos das economias na maioria dos 
países da região e aos processos hiper-inflacionários apresentados nesses paises (MENA; MME, 1990a).

O caso da Colômbia, pode-se dizer que foi uma das exceções. O Produto Interno Bruto (PIB) aumentou em forma real nessa década a um ritmo médio anual de $3,2 \%$ e o PIB per capita cresceu ao $1 \%$ anualmente. A inflação anual não superou os $28 \%$. (MENA;MME, 1990a). No entanto, o PIB cresceu nas décadas do 60 e 70 a taxas superiores aos $5 \%$ anualmente (UPME;MME, 1994).

Basicamente, esses resultados são devidos às políticas macro-econômicas delineadas com relação às questões de controle monetário, cambiário e fiscal Essas políticas tem-se sustentado em duas estratégias: por um lado, a questão fiscal, monetária e cambial, com fins de substituição de importações; e por outro lado, o desenvolvimento de projetos de certa envergadura, destinados a gerar um fluxo importante de divisas. Estes projetos, basicamente a cargo do Estado, relacionaram-se fundamentalmente com a utilização de recursos naturais não renováveis.

Existe outra variável para explicar a evolução do uso e produção da énergia na Colômbia. $O$ crescimento demográfico também diminuiu nas últimas décadas de taxas ainda maiores que $3 \%$ nos 60 para $1,7 \%$ ao ano nos princípios dos anos 90 (UPME;MME, 1994). Segundo as projeções do Departamento Administrativo Nacional de Estatística (DANE), estimam-se taxas anuais médias de crescimento da população total do país para o período 1992-2000 de $1,56 \%$. A população passaria, então, de 33.413 .414 habitantes para $37.816 .292,37 \%$ desses, concentrados nas 13 maiores cidades colombianas ?.

7 As 13 maiores cidades colombianas, segundo população, são: Santafé de Bogotá, Santiago de Cali, Medellin, Barranquilla, Cartagena, Cúcuta, Bucaramanga, Pereira, Ibagué, Manizales, Santa Marta,
Neiva e Armenia. 
A Figura 2.1 e a Tabela 2.1 ilustram a evolução da demanda de energia por setores na Colômbia em Tcal (1012 calorias) para o período 1975-1992. A taxa de crescimento média anual da demanda total foi de $3,1 \%$, ao passar de 160.718 Tcal para 268.666 Tcal nesses 17 anos.

Figura 2.1

Evolução da Demanda de Energia Final na Colômbia 1975-1992

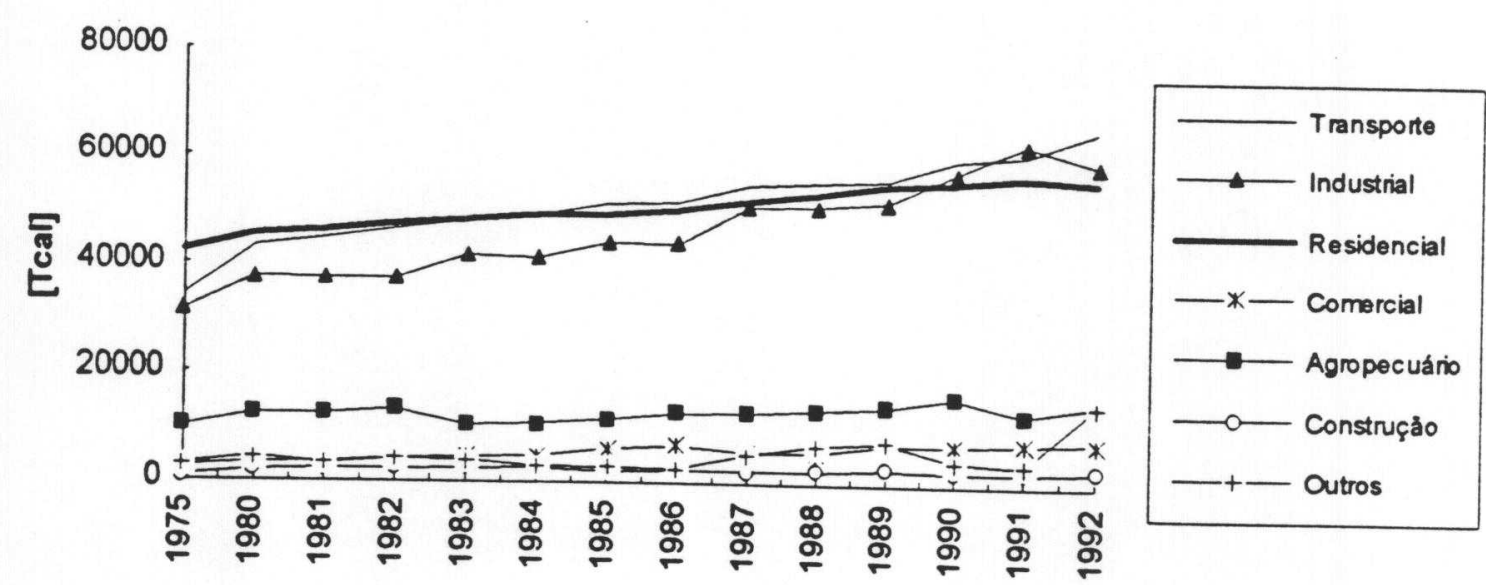

Fonte:MME, Memorias al Congreso Nacional, 1991, 1992 e 1993. MME-UPME, 1994.

Entretanto, a produção aumentou a taxas anuais médias de 5,9\%, explicável pelas exportaçōes de cru e carvão que se iniciaram no quinquênio 1985-1990. De fato, as exportaçōes (em termos de Tcal) cresceram nesses cinco anos a um ritmo médio anual de $34,7 \%$.

As taxas de crescimento anuais entre 1981 e 1992 da demanda de energia dos diferentes setores de consumo são apresentados na Figura 2.2 e na Tabela 2.3. 
TABELA 2.1

DEMANDA DE ENERGIA FINAL NA COLOMBIA.

(Tcal)

\begin{tabular}{|c|c|c|c|c|c|c|c|c|c|c|c|c|c|c|}
\hline SETOR & \multicolumn{14}{|c|}{ ANO } \\
\hline Residencial & $\begin{array}{ll}1975 \\
423650\end{array}$ & 1980 & 1981 & 1982 & 1983 & 1984 & 1985 & 1986 & 1987 & 1988 & 1989 & 1990 & 1991 & 1992 \\
\hline Comercial & $\begin{array}{r}42365.0 \\
2654.0\end{array}$ & 45356.4 & 46180.9 & 47453.4 & 48310.5 & 49152.7 & 49273.2 & 50107.6 & 51951.3 & 53284.8 & 55121.6 & 55747.0 & 56750.7 & 5594 \\
\hline Industrial & 31376.0 & $\begin{array}{r}3351.9 \\
37484.7\end{array}$ & $\begin{array}{r}3602.6 \\
37361.6\end{array}$ & $\begin{array}{r}4146.5 \\
37313 .\end{array}$ & 4639.3 & 4891.5 & 6251.7 & 6932.0 & 5811.8 & 5865.2 & 7353.4 & 7384.0 & 7793.1 & 820 \\
\hline Tran & 34269.0 & 43392.0 & 44835.7 & 46444.6 & $\begin{array}{l}41837.0 \\
48135.6\end{array}$ & $\begin{array}{l}41327.2 \\
49223 .\end{array}$ & 44104.1 & 44013.8 & 50979.2 & 51140.6 & 52049.8 & 57521.0 & 62863.0 & 59154 \\
\hline uário & 10049.0 & 12369.8 & 12477.7 & 13190.1 & 10541.1 & $\begin{array}{l}49223.1 \\
10871.7\end{array}$ & $\begin{array}{l}51193.9 \\
11588.7\end{array}$ & 51570.7 & 54858.8 & 55451.2 & 55997.0 & 59757.0 & 60930.5 & 65553 \\
\hline ução & 901.0 & 1959.6 & 2245.9 & 2390.3 & 2520.5 & 2594.6 & $\begin{array}{r}11588.7 \\
2075.5\end{array}$ & $\begin{array}{r}12766.2 \\
2251.6\end{array}$ & 12910.9 & 13532.5 & 14229.3 & 16014.0 & 13007.1 & 14890 \\
\hline utr & 3144.0 & 4462.1 & 3306.4 & 4139.5 & 4047.0 & 2886.4 & 2771.7 & $\begin{array}{l}2251.6 \\
2659.7\end{array}$ & $\begin{array}{l}2295.1 \\
5245.0\end{array}$ & $\begin{array}{l}2405.4 \\
71707\end{array}$ & 2753.1 & 2443.0 & 2507.6 & 2761 \\
\hline Total & 24758.0 & 8376.5 & 150010.8 & 155078.1 & 160031.0 & & & & & & $7852.9 \mid$ & 4511.0 & 3775.8 & 14957 \\
\hline
\end{tabular}

\begin{tabular}{|l|r|r|r|r|r|r|r|r|r|r|r|}
\hline 155078.1 & 160031.0 & 160947.2 & 167258.8 & 170301.6 & 184052.1 & 188859.4 & 195357.1 & 203377.0 & 207627.8 & 221471.9 \\
\hline
\end{tabular}

TABELA 2.2

PARTICIPAÇÃO SETORIAL NA DEMANDA DE ENERGIA FINAL NA COLOMBIA
(Porcentagem)

\begin{tabular}{|c|c|c|c|c|c|c|c|c|c|c|c|c|c|c|}
\hline \multirow[b]{2}{*}{ SETOR } & \multicolumn{14}{|c|}{$\begin{array}{c}\text { ANO } \\
1085\end{array}$} \\
\hline & 1975 & 1980 & 1981 & 1982 & 1983 & 1984 & 1985 & 1986 & 1987 & 1988 & 1989 & 1990 & 1991 & 1992 \\
\hline Residencial & $34.0 \%$ & $30.6 \%$ & $30.8 \%$ & $30.6 \%$ & $30.2 \%$ & $30.5 \%$ & $29.5 \%$ & $29.4 \%$ & $28.2 \%$ & $28.2 \%$ & $28.2 \%$ & $27.4 \%$ & $27.3 \%$ & $25.3 \%$ \\
\hline Comercial & $2.1 \%$ & $2.3 \%$ & $2.4 \%$ & $2.7 \%$ & $2.9 \%$ & $3.0 \%$ & $3.7 \%$ & $4.1 \%$ & $3.2 \%$ & $3.1 \%$ & $3.8 \%$ & $3.6 \%$ & $3.8 \%$ & $3.7 \%$ \\
\hline Industrial & $25.1 \%$ & $25.3 \%$ & $24.9 \%$ & $24.1 \%$ & $26.1 \%$ & $25.7 \%$ & $26.4 \%$ & $25.8 \%$ & $27.7 \%$ & $27.1 \%$ & $26.6 \%$ & $28.3 \%$ & $30.3 \%$ & $26.7 \%$ \\
\hline Transporte & $27.5 \%$ & $29.2 \%$ & $29.9 \%$ & $29.9 \%$ & $30.1 \%$ & $30.6 \%$ & $30.6 \%$ & $30.3 \%$ & $29.8 \%$ & $29.4 \%$ & $28.7 \%$ & $29.4 \%$ & $29.3 \%$ & $29.6 \%$ \\
\hline Agropecuário & $8.1 \%$ & $8.3 \%$ & $8.3 \%$ & $8.5 \%$ & $6.6 \%$ & $6.8 \%$ & $6.9 \%$ & $7.5 \%$ & $7.0 \%$ & $7.2 \%$ & $7.3 \%$ & $7.9 \%$ & $6.3 \%$ & $6.7 \%$ \\
\hline Construção & $0.7 \%$ & $1.3 \%$ & $1.5 \%$ & $1.5 \%$ & $1.6 \%$ & $1.6 \%$ & $1.2 \%$ & $1.3 \%$ & $1.2 \%$ & $1.3 \%$ & $1.4 \%$ & $1.2 \%$ & $1.2 \%$ & $1.2 \%$ \\
\hline Outros & $2.5 \%$ & $3.0 \%$ & $2.2 \%$ & $2.7 \%$ & $2.5 \%$ & $1.8 \%$ & $1.7 \%$ & $1.6 \%$ & $2.8 \%$ & $3.8 \%$ & $4.0 \%$ & $2.2 \%$ & $1.8 \%$ & $6.8 \%$ \\
\hline Total & $100.0 \%$ & $100.0 \%$ & $100.0 \%$ & $100.0 \%$ & $100.0 \%$ & $100.0 \%$ & $100.0 \%$ & $100.0 \%$ & $100.0 \%$ & $100.0 \%$ & $100.0 \%$ & $100.0 \%$ & $100.0 \%$ & $100.0 \%$ \\
\hline
\end{tabular}

Fonte: Cálculos do autor com base nos dados da Tabela 2.1 
Figura 2.2

Taxas de Crescimento Anual da Demanda Final

de Energia Setorial na Colômbia

1981-1992

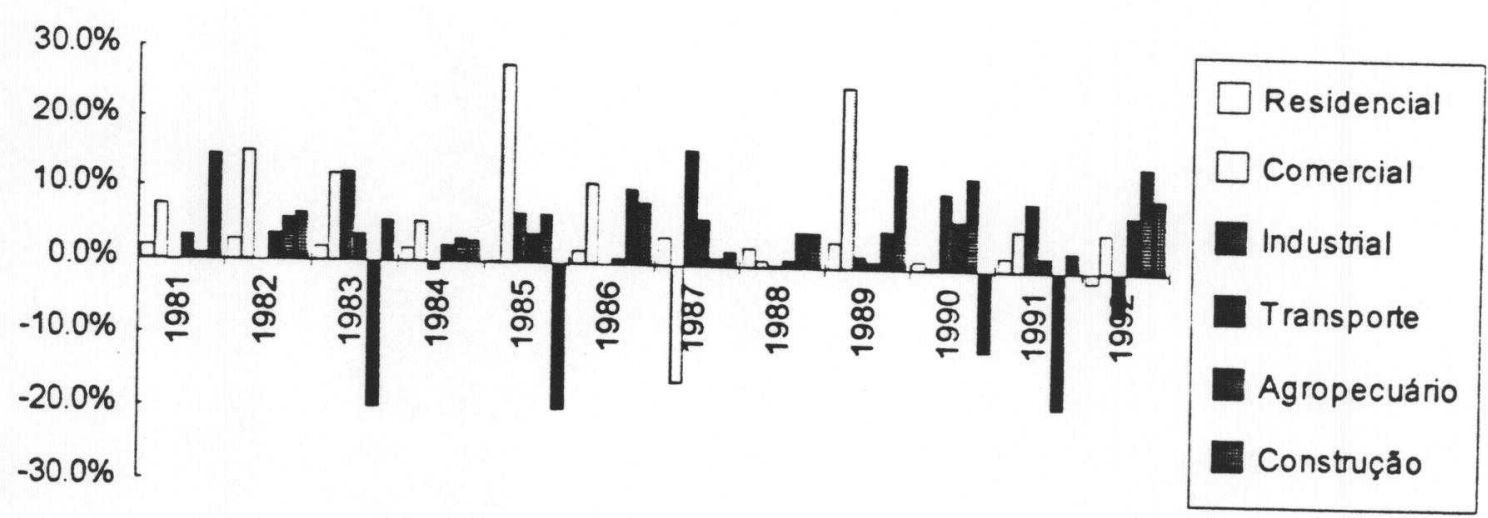

Fonte: Cálculos do autor com base em dados do MME

Os setores mais energo-intensivos são o setor de transportes, o setor industrial e o setor residencial. A evolução da participação desses setores na demanda total de energia apresentou mudanças durante 0 periodo considerado de 1975 até 1992, ilustrado na Figura 2.3 e tabulado na Tabela 2.2.

Figura 2.3

Evolução da Participação Relativa no Consumo Energético dos Principais Setores Consumidores. 1975-1992

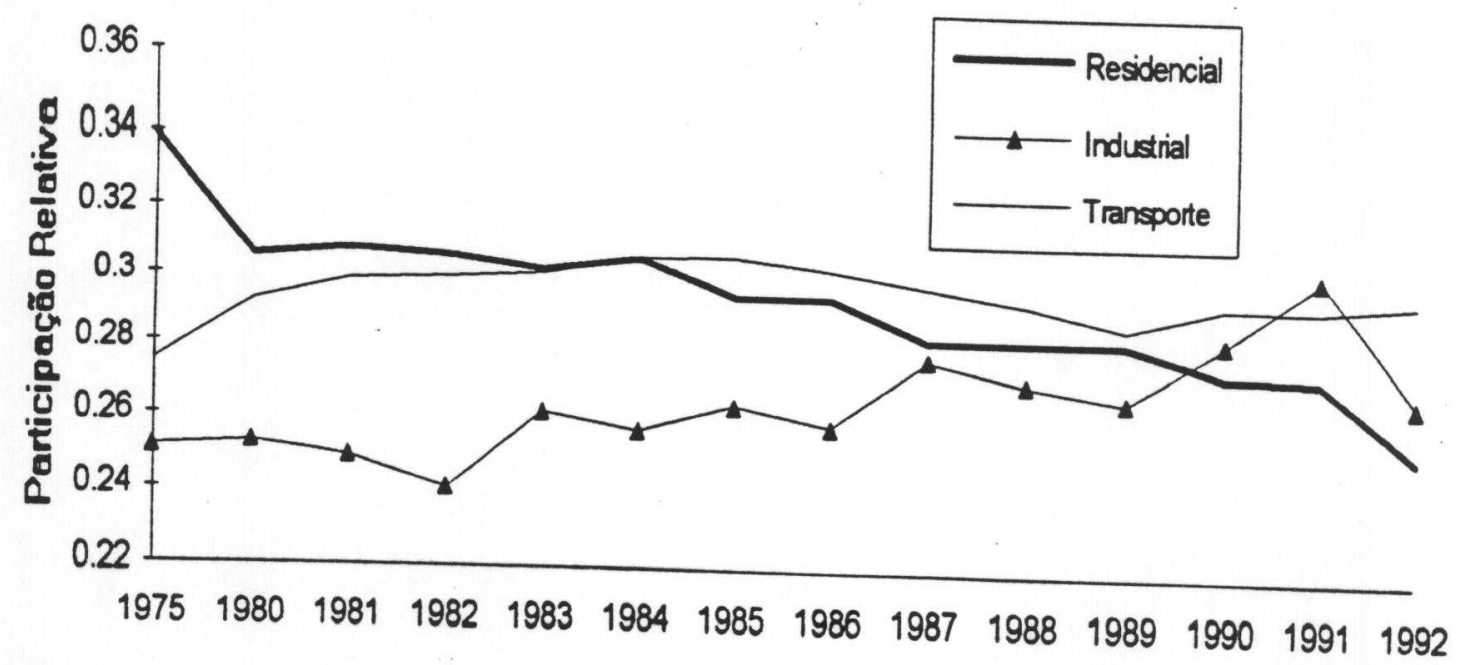

Fonte: Cálculos do autor com base em dados do MME. 
TABELA 2.3

TAXAS DE CRESCIMENTO ANUAL DA DEMANDA DE ENERGIA FINAL NA COLOMBIA.
(Porcentagem)

\begin{tabular}{|c|c|c|c|c|c|c|c|c|c|c|c|c|c|c|}
\hline \multirow[b]{2}{*}{ SETOR } & \multicolumn{14}{|c|}{ ANO } \\
\hline & 1975 & 1980 & 1981 & 1982 & 1983 & 1984 & 1985 & 1986 & 1987 & 1988 & 1989 & 1990 & 1991 & 1992 \\
\hline Residencial & - & - & $1.8 \%$ & $2.8 \%$ & $1.8 \%$ & $1.7 \%$ & $0.2 \%$ & $1.7 \%$ & $3.7 \%$ & $2.6 \%$ & $3.4 \%$ & $1.1 \%$ & $1.8 \%$ & $-1.4 \%$ \\
\hline Comercial & - & - & $7.5 \%$ & $15.1 \%$ & $11.9 \%$ & $5.4 \%$ & $27.8 \%$ & $10.9 \%$ & $-16.2 \%$ & $0.9 \%$ & $25.4 \%$ & $0.4 \%$ & $5.5 \%$ & $5.3 \%$ \\
\hline Industrial & - & - & $-0.3 \%$ & $-0.1 \%$ & $12.1 \%$ & $-1.2 \%$ & $6.7 \%$ & $-0.2 \%$ & $15.8 \%$ & $0.3 \%$ & $1.8 \%$ & $10.5 \%$ & $9.3 \%$ & $-5.9 \%$ \\
\hline Transporte & - & - & $3.3 \%$ & $3.6 \%$ & $3.6 \%$ & $2.3 \%$ & $4.0 \%$ & $0.7 \%$ & $6.4 \%$ & $1.1 \%$ & $1.0 \%$ & $6.7 \%$ & $2.0 \%$ & $7.6 \%$ \\
\hline Agropecuário & - & - & $0.9 \%$ & $5.7 \%$ & $-20.1 \%$ & $3.1 \%$ & $6.6 \%$ & $10.2 \%$ & $1.1 \%$ & $4.8 \%$ & $5.1 \%$ & $12.5 \%$ & $-18.8 \%$ & $14.5 \%$ \\
\hline Construção & - & - & $14.6 \%$ & $6.4 \%$ & $5.4 \%$ & $2.9 \%$ & $-20.0 \%$ & $8.5 \%$ & $1.9 \%$ & $4.8 \%$ & $14.5 \%$ & $-11.3 \%$ & $2.6 \%$ & $10.1 \%$ \\
\hline Outros & - & - & $-25.9 \%$ & $25.2 \%$ & $-2.2 \%$ & $-28.7 \%$ & $-4.0 \%$ & $-4.0 \%$ & $97.2 \%$ & $36.9 \%$ & $9.4 \%$ & $-42.6 \%$ & $-16.3 \%$ & $296.2 \%$ \\
\hline Total & - & E & $1.1 \%$ & $3.4 \%$ & $3.2 \%$ & $0.6 \%$ & $3.9 \%$ & $1.8 \%$ & $8.1 \%$ & $2.6 \%$ & $3.4 \%$ & $4.1 \%$ & $2.1 \%$ & $6.7 \%$ \\
\hline
\end{tabular}

Fonte: Cálculos do autor com base nos dados da Tabela 2.1

TABELA 2.4

DEMANDA DE ENERGIA ÚTIL NA COLOMBIA.

(Tcal)

\begin{tabular}{|c|c|c|c|c|c|c|c|c|c|c|c|c|c|c|}
\hline \multirow[b]{2}{*}{ SETOR } & \multicolumn{14}{|c|}{ ANO } \\
\hline & 1975 & 1980 & 1981 & 1982 & 1983 & 1984 & 1985 & 1986 & 1987 & 1988 & 1989 & 1990 & 1991 & 1992 \\
\hline Residencial & ND & 11314.5 & 11681.2 & 12494.3 & 12938.3 & 13475.9 & 13660.9 & 14090.8 & 15043.9 & 15785.2 & 16697.9 & 15528.7 & 14425.1 & 14291.1 \\
\hline Comercial & ND & 2644.1 & 2835.2 & 3251.7 & 3715.5 & 3957.1 & 4981.7 & 5564.0 & 4503.0 & 4544.4 & 5335.2 & 3984.6 & 2756.4 & 4024.2 \\
\hline Industrial & ND & 25499.2 & 25452.2 & 25537.0 & 28507.8 & 28217.9 & 29972.7 & 29946.1 & 34398.7 & 34663.1 & 35298.1 & 37623.1 & 39603.2 & 39839.0 \\
\hline Transporte & ND & 7213.5 & 7447.6 & 7684.7 & 8013.7 & 8138.2 & 8369.0 & 8385.1 & 9043.2 & 9371.4 & 9482.6 & 10418.4 & 10927.9 & 10191.1 \\
\hline Agropecuário & ND & 2597.3 & 2610.3 & 2732.6 & 2576.5 & 2511.6 & 2667.3 & 2934.3 & 3020.1 & 3698.0 & 3864.0 & 4412.7 & 3636.1 & 3864.1 \\
\hline Construção & ND & 1357.8 & 1430.2 & 1469.3 & 1387.6 & 1411.7 & 1202.8 & 1267.7 & 1677.6 & 1681.6 & 1807.8 & 1535.6 & 4781.0 & 1658.6 \\
\hline Outros & ND & 1891.1 & 1444.0 & 1755.8 & 1486.5 & 1083.1 & 1039.9 & 1046.9 & 2065.3 & 2329.7 & 2426.6 & 697.0 & 0.0 & 11624.7 \\
\hline Total & ND & 52517.5 & 52900.7 & 54925.4 & 58625.9 & 58795.5 & 61894.3 & 63234.9 & 69751.8 & 72073.4 & 74912.2 & 74200.0 & 76129.7 & 85492.8 \\
\hline
\end{tabular}

Fonte: MENA;MME. Memoria al Congreso Nacional: Anexo Histórico. 1990b e NULE;MME. Memoria al Congreso Nacional. 1993. 
setor residencial deixou de ser o maior consumidor de energia final já em 1985 e, conforme tendência apresentada, continua perdendo participação relativa para os outros setores. Em 1992, este setor consumiu uma quarta parte da energia final do pais em contraste com 1975, onde a participação era superior a um terço do total. Supondo-se a continuação dessa tendência ${ }^{8}$, estariamos começando o novo século com uma participação de $23 \%$ para o setor residencial e $31 \%$ para o setor industrial. Porém, se for feita uma análise do ponto do vista da demanda, assim como está proposta nesta dissertação, pode-se demonstrar que convém modificar essa estrutura, acelerando-se a redução da participação do setor residencial no consumo total de energia final, através de um conjunto de estratégias adequadas para essa finalidade.

Este fenômeno é explicado principalmente pela redução do consumo de energia não comercial (em especial a lenha e carvão de lenha) nas áreas rurais, substituida em grande parte por eletricidade (UPME;MME, 1994). A diminuição do crescimento demográfico também ajudou a amenizar as taxas de incremento de demanda residencial de energia. Todavia, é de se esperar que este setor chegue a algum ponto de saturação como conseqüência do aumento de serviço elétrico na zona rural. Em 1990, $80 \%$ da população nacional já tinha acesso à eletricidade comparado com $40 \%$ de cobertura em 1970 (CNE, 1992). Igualmente, segundo os resultados do censo de 1993, $73,82 \%$ da população total do país mora em zona urbana.

Basicamente, os ganhos de eficiência do uso da energia final em escala nacional foram devidos ao deslocamento de energéticos menos eficientes no setor residencial por eletricidade e gás natural (GN) ou gás liquefeito do petróleo (GLP) (Figura 2.4 e Tabelas 2.4 e 2.5). 8 Tendências ajustadas a projeçôes exponenciais $\left(y=b m^{x}\right)$ com coeficientes de determinação $\left(r^{2}\right)$ de
0,92 e 0,63 para o setor residencial e industrial respectivamente. 


\section{TABELA 2.5}

EFICIÉNCIA NO USO ENERGÉTICO NA COLOMBIA. (Energia útil/Energia final)
(Porcentagem)

\begin{tabular}{|c|c|c|c|c|c|c|c|c|c|c|c|c|c|c|}
\hline \multirow[b]{2}{*}{ SETOR } & \multicolumn{14}{|c|}{ ANO } \\
\hline & 1975 & 1980 & 1981 & 1982 & 1983 & 1984 & 1985 & 1986 & 1987 & 1988 & 1989 & 1990 & 1991 & 1992 \\
\hline Residencial & - & $24.9 \%$ & $25.3 \%$ & $26.3 \%$ & $26.8 \%$ & $27.4 \%$ & $27.7 \%$ & $28.1 \%$ & $29.0 \%$ & $29.6 \%$ & $30.3 \%$ & $27.9 \%$ & $25.4 \%$ & $25.5 \%$ \\
\hline Comercial & - & $78.9 \%$ & $78.7 \%$ & $78.4 \%$ & $80.1 \%$ & $80.9 \%$ & $79.7 \%$ & $80.3 \%$ & $77.5 \%$ & $77.5 \%$ & $72.6 \%$ & $54.0 \%$ & $35.4 \%$ & $49.0 \%$ \\
\hline Industrial & - & $68.0 \%$ & $68.1 \%$ & $68.4 \%$ & $68.1 \%$ & $68.3 \%$ & $68.0 \%$ & $68.0 \%$ & $67.5 \%$ & $67.8 \%$ & $67.8 \%$ & $65.4 \%$ & $63.0 \%$ & $67.3 \%$ \\
\hline Transporte & - & $16.6 \%$ & $16.6 \%$ & $16.5 \%$ & $16.6 \%$ & $16.5 \%$ & $16.3 \%$ & $16.3 \%$ & $16.5 \%$ & $16.9 \%$ & $16.9 \%$ & $17.4 \%$ & $17.9 \%$ & $15.5 \%$ \\
\hline Agropecuário & - & $21.0 \%$ & $20.9 \%$ & $20.7 \%$ & $24.4 \%$ & $23.1 \%$ & $23.0 \%$ & $23.0 \%$ & $23.4 \%$ & $27.3 \%$ & $27.2 \%$ & $27.6 \%$ & $28.0 \%$ & $25.9 \%$ \\
\hline Construção & - & $69.3 \%$ & $63.7 \%$ & $61.5 \%$ & $55.1 \%$ & $54.4 \%$ & $58.0 \%$ & $56.3 \%$ & $73.1 \%$ & $69.9 \%$ & $65.7 \%$ & $62.9 \%$ & $60.1 \%$ & $60.1 \%$ \\
\hline Outros & - & $42.4 \%$ & $43.7 \%$ & $42.4 \%$ & $36.7 \%$ & $37.5 \%$ & $37.5 \%$ & $39.4 \%$ & $39.4 \%$ & $32.4 \%$ & $30.9 \%$ & $15.5 \%$ & $0.0 \%$ & $77.7 \%$ \\
\hline Total & - & $35.4 \%$ & $35.3 \%$ & $35.4 \%$ & $36.6 \%$ & $36.5 \%$ & $37.0 \%$ & $37.1 \%$ & $37.9 \%$ & $38.2 \%$ & $38.3 \%$ & $37.5 \%$ & $36.7 \%$ & $38.6 \%$ \\
\hline
\end{tabular}


O resultado foi uma diminuição na intensidade energética do país ao passar de

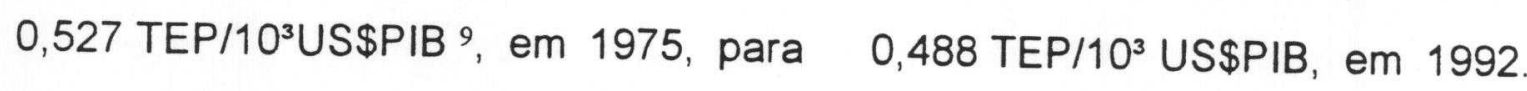
Outros estudos (UPME;MME, 1994) apontam que caso se considerasse unicamente a energia comercial, a intensidade energética em 1975 seria inferior à de 1992, mais precisamente $0,386 \mathrm{TEP} / 10^{3}$ US\$PIB frente a $0,397 \mathrm{TEP} / 10^{3}$ US\$PIB respectivamente.

Figura 2.4

Evolução da Eficiência Energética dos Principa is Setores de Consumo Colombianos. 1980-1992

(energia útil/energia final)

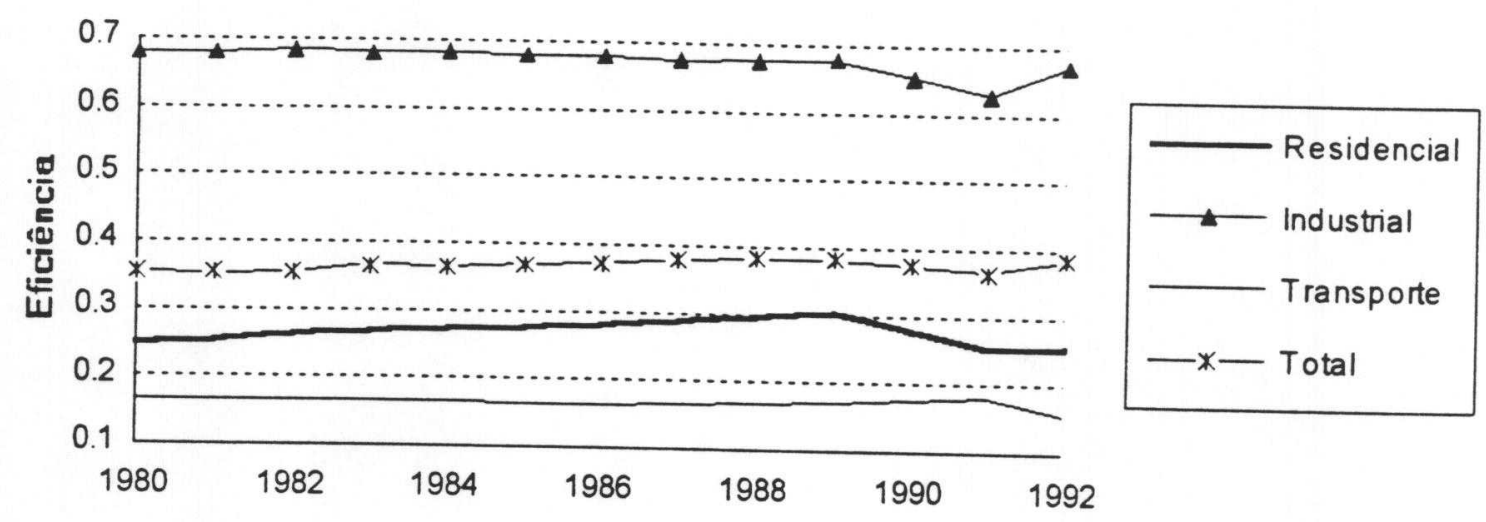

Fonte: Cálculos do autor com base em dados do MME.

O setor de transportes apresentou uma participação no consumo energético nacional relativamente estável entre 1980 até 1992 , variando numa faixa de $29 \%$ (1989) a 31\% (1985). É interessante mostrar que esse setor foi sempre o maior consumidor de energia final na Colômbia desde 1985, com exceção de 1991 quando perdeu para o setor industrial. A demanda do setor de transportes é dominada principalmente pelo tamanho e consumo específico da frota veicular do pais que por sua vez depende de variáveis econômicas (PIB)

9 Intensidades calculadas para uma base de PIB em dólares americanos constantes de 1992, usando como deflator para a moeda local, o índice de preços ao consumidor nacional, e a taxa representativa de câmbio em 31 de dezembro de 1992 (Col\$738/US\$). 
e demográficas. Uma análise mais aprofundada sobre a questão energética deste setor é apresentada no Capitulo 4 desta dissertação.

Dentro desta visão global, convém analisar o caso do setor elétrico, pois a eletricidade representa, atualmente, a segunda maior fonte energética do setor residencial, depois da lenha.

\section{Figura 25}

\section{Evolução da Participação dos Energéticos no Cansumo de} Energia Fral Residencial
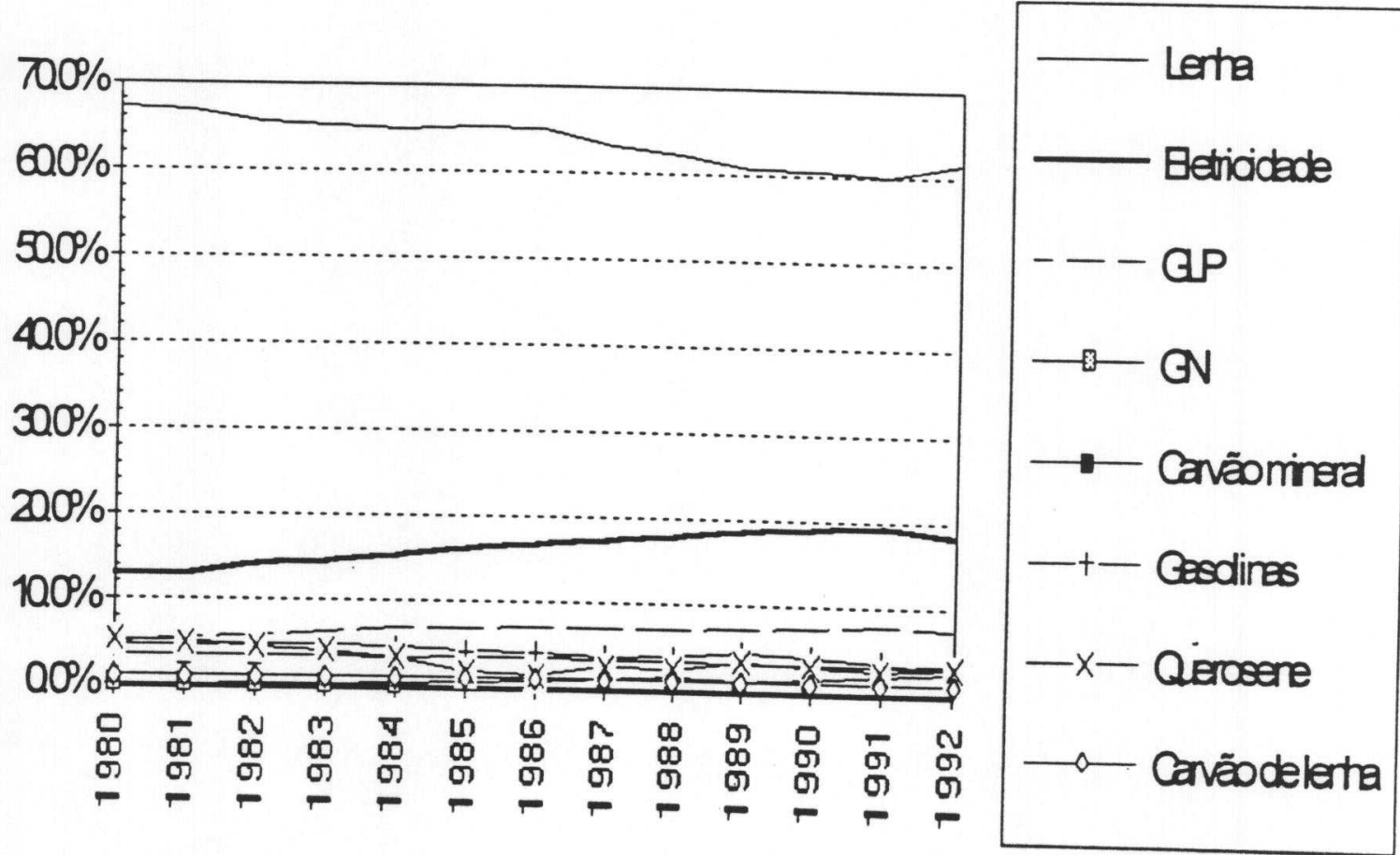

Fonte: Cálculos do autor com base em dados do MME.

Antes do Governo incentivar os programas de eletrificação rural na Colômbia, a eletricidade não tinha uma participação tão significativa no consumo total de energia. De fato, em 1975, a energia consumida em forma de eletricidade correspondeu a $8,3 \%$ do total, comparado com 70,6\% da lenha. Já para 1992 , as diferenças eram bem menores, pois dentro da estrutura da matriz de consumo de energia do setor residencial, $18,4 \%$ foram gastos na forma de eletricidade e $61,4 \%$ em lenha (Figura 2.5 e Tabela 2.7). Porém, se fosse 
considerado o valor da demanda de eletricidade racionado em 1992, estimado por ISA em $5.183 \mathrm{GWh}$ (13,9\% da demanda esperada), a energia elétrica estaria participando com $24,4 \%$ das 60.404 Tcal que teriam sido consumidas pelo setor residencial ${ }^{10}$.

A evolução da demanda de energia elétrica ${ }^{11}$ entre 1975 e 1992 é apresentada na Figura 2.6 e Tabela 2.8.

Figura 2.6

Evolução Histórica da Demanda de Eletricidade na Colômbia

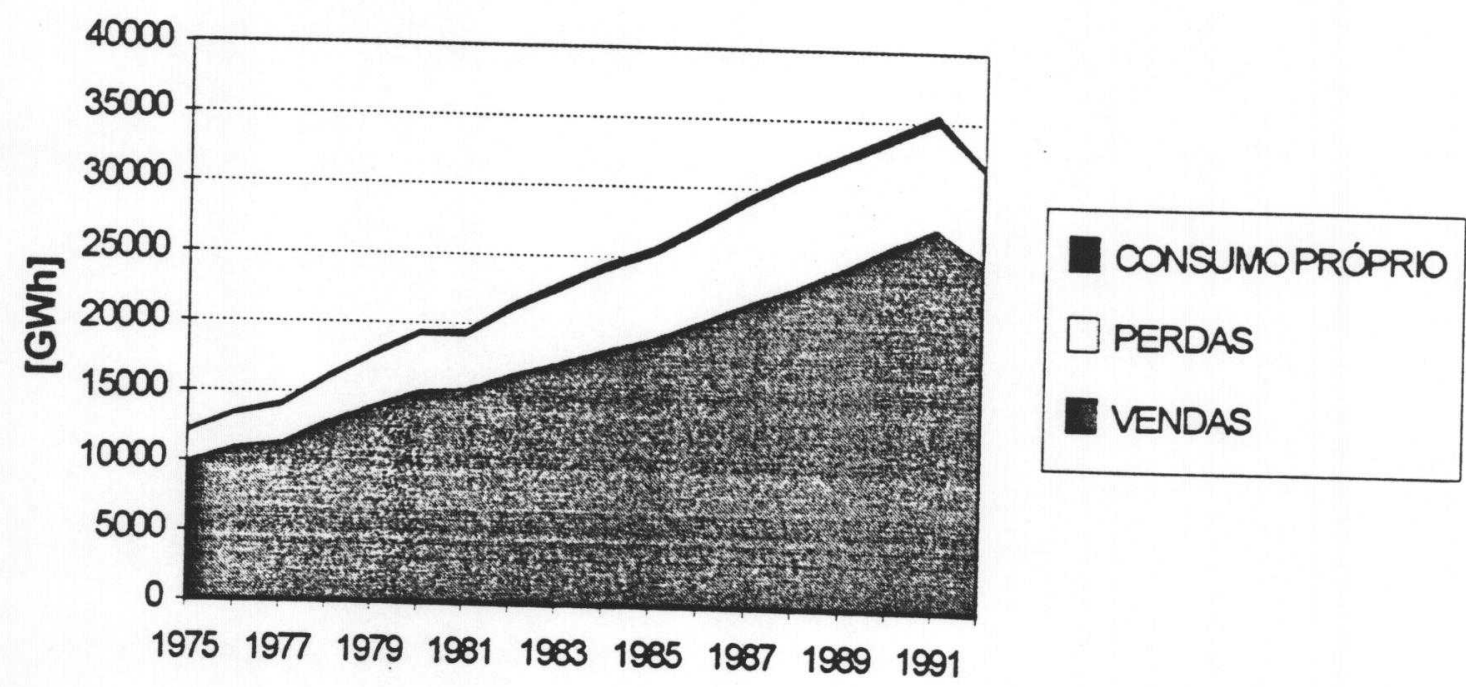

Fonte: ISA, 1993 10 Em sentido estrito, dever-se-ia considerar que parte das necessidades de energia elétrica racionada
foram supridas com outros tipos de energéticos como GN, GLP e querosene na zona urbana e lenha,
carvão de lenha, carvão mineral e querosene carvão de lenha, carvão mineral e querosene na zona rural.

11 Demanda de energia elétrica $=$ vendas + consumo próprio + perdas. 
TABELA 2.6

EVOLUÇÃO DO CONSUMO DE ENERGÉTICOS NO SETOR RESIDENCIAL 1980-1992 (Tcal)

\begin{tabular}{|c|c|c|c|c|c|c|c|c|c|c|c|c|c|}
\hline \multirow[t]{2}{*}{ ENERGÉTICO } & \multicolumn{13}{|c|}{ ANO } \\
\hline & 1980 & 1981 & 1982 & 1983 & 1984 & 1985 & 1986 & 1987 & 1988 & 1989 & 1990 & 1991 & 1992 \\
\hline GN & 27,2 & 45,1 & 111,8 & 146,0 & 191,5 & 323,4 & 368,9 & 595,7 & 861,9 & 647,1 & 862,0 & 1142,1 & 1351,9 \\
\hline Carvâo mineral & 1643,9 & 1661,4 & 1689,4 & 1697,8 & 1695,9 & 1734,2 & 1753,7 & 1772,6 & 1792,1 & 1807,0 & 1821,0 & 1836,9 & 1846,0 \\
\hline Lenha & 30481,6 & 30804,1 & 31123,1 & 31473,4 & 31785,8 & 32112,0 & 32517,0 & 32785,2 & 33134,4 & 33426,0 & 34377,0 & 34034,4 & 34351,2 \\
\hline Eletricidade & 5893,6 & 5989,0 & 6807,8 & 7093,3 & 7584,3 & 8015,8 & 8483,3 & 9096,4 & 9584,7 & 10302,8 & 10807,0 & 11048,9 & 10304,5 \\
\hline GLP & 2235,4 & 2594,5 & 2743,1 & 3070,3 & 3383,7 & 3421,8 & 3541,9 & 3700,7 & 3822,9 & 3962,1 & $8880(1)$ & 4416,4 & 4218,0 \\
\hline Gasolinas & 2132,6 & 2182,6 & 2321,7 & 2308,2 & 2263,1 & 2171,6 & 2074,6 & 1972,4 & 2112,4 & 2515,5 & nd & 2075,0 & 1546,7 \\
\hline Querosene & 2415,7 & 2375,1 & 2118,4 & $.1971,6$ & 1686,2 & 919,8 & 781,2 & 1410,9 & 1346,0 & 1817,6 & nd & 1532,8 & 1653,1 \\
\hline Carvâo de lenha & 526,5 & 529,1 & 538,2 & 549,9 & 562,2 & 574,6 & 587,0 & 617,5 & 630,5 & 643,5 & nd & 664,3 & 676,0 \\
\hline TOTAL & 45356,5 & 46180,9 & 47453,5 & 48310,5 & 49152,7 & 49273,2 & 50107,6 & 51951,4 & 53284,9 & 55121,6 & 56747,0 & 56750,8 & 55947,4 \\
\hline
\end{tabular}

(1) Esse dado corresponde ao consumo de todos os derivados do Petróleo nesse ano

Fonte: MENA;MME. Memoria al Congreso Nacional: Anexo Histórico, 1990a e UPME;MME, 1994

TABELA 2.7

EVOLUÇÃO DA PARTICIPAÇÃO DOS ENERGÉTICOS NO CONSUMO RESIDENCIAL 1980-1992 (Porcentagem)

\begin{tabular}{|c|c|c|c|c|c|c|c|c|c|c|c|c|c|}
\hline \multirow[t]{2}{*}{ ENERGÉTICO } & \multicolumn{13}{|c|}{ ANO } \\
\hline & 1980 & 1981 & 1982 & 1983 & 1984 & 1985 & 1986 & 1987 & 1988 & 1989 & 1990 & 1991 & 1992 \\
\hline GN & $0,1 \%$ & $0,1 \%$ & $0,2 \%$ & $0,3 \%$ & $0,4 \%$ & $0,7 \%$ & $0,7 \%$ & $1,1 \%$ & $1,6 \%$ & $1,2 \%$ & $1,5 \%$ & $2,0 \%$ & $2,4 \%$ \\
\hline Carvâo mineral & $3,6 \%$ & $3,6 \%$ & $3,6 \%$ & $3,5 \%$ & $3,5 \%$ & $3,5 \%$ & $3,5 \%$ & $3,4 \%$ & $3,4 \%$ & $3,3 \%$ & $3,2 \%$ & $3.2 \%$ & $3,3 \%$ \\
\hline Lenha & $67,2 \%$ & $66,7 \%$ & $65,6 \%$ & $65,1 \%$ & $64,7 \%$ & $65,2 \%$ & $64,9 \%$ & $63,1 \%$ & $62,2 \%$ & $60,6 \%$ & $60,6 \%$ & $60,0 \%$ & $61,4 \%$ \\
\hline Eletricidade & $13,0 \%$ & $13,0 \%$ & $14,3 \%$ & $14,7 \%$ & $15,4 \%$ & $16,3 \%$ & $16,9 \%$ & $17,5 \%$ & $18,0 \%$ & $18,7 \%$ & $19,0 \%$ & $19,5 \%$ & $18,4 \%$ \\
\hline GLP & $4,9 \%$ & $5,6 \%$ & $5,8 \%$ & $6.4 \%$ & $6,9 \%$ & $6,9 \%$ & $7.1 \%$ & $7.1 \%$ & $7,2 \%$ & $7,2 \%$ & $7,5 \%$ & $7,8 \%$ & $7,5 \%$ \\
\hline Gasolinas & $4,7 \%$ & $4,7 \%$ & $4,9 \%$ & $4,8 \%$ & $4,6 \%$ & $4,4 \%$ & $4,1 \%$ & $3,8 \%$ & $4,0 \%$ & $4,6 \%$ & $4.1 \%$ & $3,7 \%$ & $2,8 \%$ \\
\hline Querosene & $5,3 \%$ & $5,1 \%$ & $4,5 \%$ & $4,1 \%$ & $3,4 \%$ & $1,9 \%$ & $1,6 \%$ & $2,7 \%$ & $2,5 \%$ & $3,3 \%$ & $3.0 \%$ & $2,7 \%$ & $3,0 \%$ \\
\hline Carvăo de lenha & $1,2 \%$ & $1,1 \%$ & $1,1 \%$ & $1,1 \%$ & $1,1 \%$ & $1,2 \%$ & $1,2 \%$ & $1,2 \%$ & $1,2 \%$ & $1,2 \%$ & $1,2 \%$ & $1,2 \%$ & $1,2 \%$ \\
\hline TOTAL & $100 \%$ & $100 \%$ & $100 \%$ & $100 \%$ & $100 \%$ & $100 \%$ & $100 \%$ & $100 \%$ & $100 \%$ & $100 \%$ & $100 \%$ & $100 \%$ & $100 \%$ \\
\hline
\end{tabular}

Fonte: cálculos do autor com base nos dados da Tabela 2.6 
TABELA 2.8

EVOLUÇÃO DO CONSUMO DE ELETRICIDADE NA COLÓMBIA 1975-1992 (GWh)

\begin{tabular}{|c|c|c|c|c|c|c|c|c|c|c|c|c|c|c|c|c|c|c|}
\hline \multirow[b]{2}{*}{ ITEM } & \multicolumn{18}{|c|}{ ANO } \\
\hline & 1975 & 1976. & 1977 & 1978. & 1979 & 1980 & 1981 & 1982 & 1983 & 1984 & 1985 & 1986. & 1987 & 1988 & 1989 & 1990 & 1991 & 1992 \\
\hline VENDAS & 9902 & 11023 & 11392 & 12883 & 14012 & 15159 & 15327 & 16466 & 17275 & 18252 & 19109 & 20420 & 21793 & 22958 & 24482 & 26048 & 27375 & 25209 \\
\hline Residencial & 4207 & 4655 & 4878 & 5686 & 6432 & 7092 & 7224 & 7923 & 8272 & 8779 & 9293 & 9849 & 10378 & 11086 & 11809 & 12488 & 12962 & 11696 \\
\hline Comercial & 1294 & 1428 & 1539 & 1707 & 1787 & 1901 & 1853 & 1959 & 2043 & 2012 & 2112 & 2446 & 2244 & 2281 & 2450 & 2575 & 2695 & 2424 \\
\hline Industrial & 3257 & 3706 & 3715 & 4122 & 4387 & 4537 & 4519 & 4719 & 4901 & 5286 & 5449 & 6130 & 6679 & 7008 & 7482 & 7880 & 8389 & 8041 \\
\hline Público & 716 & 781 & 799 & 829 & 920 & 1041 & 1147 & 1170 & 1299 & 1343 & 1380 & 1437 & 1611 & 1544 & 1636 & 1740 & 1826 & 2573 \\
\hline Iluminação pública & 216 & 220 & 237 & 255 & 276 & 349 & 370 & 392 & 406 & 450 & 483 & 508 & 524 & 659 & 766 & 825 & 888 & (1) \\
\hline Năo desagregados & 182 & 203 & 197 & 245 & 160 & 180 & 160 & 191 & 207 & 217 & 234 & 258 & 270 & 264 & 273 & 203 & 0 & 0 \\
\hline Outros & 30 & 30 & 27 & 39 & 50 & 59 & 54 & 112 & 147 & 165 & 158 & 92 & 87 & 116 & 66 & 337 & 615 & 475 \\
\hline CONSUMO PRÓPRIO & 184 & 242 & 278 & 321 & 358 & 407 & 419 & 509 & 575 & 590 & 595 & 572 & 587 & 623 & 601 & 648 & 715 & 370 \\
\hline PERDAS & 2106 & 2275 & 2513 & 2985 & 3504 & 3915 & 3773 & 4574 & 5223 & 5746 & 6034 & 6559 & 7113 & 7571 & 7492 & 7385 & 7496 & 6405 \\
\hline DEMANDA TOTAL & 12192 & 13540 & 14183 & 16189 & 17874 & 19481 & 19519 & 21549 & 23073 & 24588 & 25738 & 27551 & 29493 & 31152 & 32575 & 34081 & 35586 & 31984 \\
\hline
\end{tabular}

(1) Valor incluído nas vendas para o setor público nesse ano

Fonte: ISA, 1993a.

TABELA 2.9

EVOLUÇĀO DA PARTICIPAÇÃO SETORIAL NAS VENDAS DE ELETRICIDADE NA COLÓMBIA 1975-1992

\begin{tabular}{|c|c|c|c|c|c|c|c|c|c|c|c|c|c|c|c|c|c|c|}
\hline \multirow[b]{2}{*}{ ITEM } & \multicolumn{18}{|c|}{ ANO } \\
\hline & 1975 & 1976 & 1977 & 1978 & 1979 & 1980 & 1981 & 1982 & 1983 & 1984 & 1985 & 1986 & 1987 & 1988 & 1989 & 1990 & 1991 & 1992 \\
\hline Residencial & $42.5 \%$ & $42.2 \%$ & $42.8 \%$ & $44.1 \%$ & $45.9 \%$ & $46.8 \%$ & $47.1 \%$ & $48.1 \%$ & $47.9 \%$ & $48.1 \%$ & $48.6 \%$ & $48.2 \%$ & $47.6 \%$ & $48.3 \%$ & $48.2 \%$ & $47.9 \%$ & $47.3 \%$ & $46.4 \%$ \\
\hline Comercial & $13.1 \%$ & $13.0 \%$ & $13.5 \%$ & $13.3 \%$ & $12.8 \%$ & $12.5 \%$ & $12.1 \%$ & $11.9 \%$ & $11.8 \%$ & $11.0 \%$ & $11.1 \%$ & $10.5 \%$ & $10.3 \%$ & $9.9 \%$ & $10.0 \%$ & $9.9 \%$ & $9.8 \%$ & $9.6 \%$ \\
\hline Industrial & $32.9 \%$ & $33.6 \%$ & $32.6 \%$ & $32.0 \%$ & $31.3 \%$ & $29.9 \%$ & $29.5 \%$ & $28.7 \%$ & $28.4 \%$ & $29.0 \%$ & $28.5 \%$ & $30.0 \%$ & $30.6 \%$ & $30.5 \%$ & $30.6 \%$ & $30.3 \%$ & $30.6 \%$ & $31.9 \%$ \\
\hline Público e llum. Púb. & $9.4 \%$ & $9.1 \%$ & $9.1 \%$ & $8.4 \%$ & $8.5 \%$ & $9.2 \%$ & $9.9 \%$ & $9.5 \%$ & $9.9 \%$ & $9.8 \%$ & $9.7 \%$ & $9.5 \%$ & $9.8 \%$ & $9.6 \%$ & $9.8 \%$ & $9.8 \%$ & $9.9 \%$ & $10 \%$ \\
\hline Năo desagregados & $1.8 \%$ & $1.8 \%$ & $1.7 \%$ & $1.9 \%$ & $1.1 \%$ & $1.2 \%$ & $1.0 \%$ & $1.2 \%$ & $1.2 \%$ & $1.2 \%$ & $1.2 \%$ & $1.3 \%$ & $1.2 \%$ & $1.1 \%$ & $1.1 \%$ & $0.8 \%$ & $0.0 \%$ & $0.0 \%$ \\
\hline Outros & $0.3 \%$ & $0.3 \%$ & $0.2 \%$ & $0.3 \%$ & $0.4 \%$ & $0.4 \%$ & $0.4 \%$ & $0.7 \%$ & $0.9 \%$ & $0.9 \%$ & $0.8 \%$ & $0.5 \%$ & $0.4 \%$ & $0.5 \%$ & $0.3 \%$ & $1.3 \%$ & $2.2 \%$ & $1.9 \%$ \\
\hline TOTAL & $100.0 \%$ & $100.0 \%$ & $100.0 \%$ & $100.0 \%$ & $100.0 \%$ & $100.0 \%$ & $100.0 \%$ & $100.0 \%$ & $100.0 \%$ & $100.0 \%$ & $100.0 \%$ & $100.0 \%$ & $100.0 \%$ & $100.0 \%$ & $100.0 \%$ & $00.0 \%$ & $100.0 \%$ & $0.0^{\circ}$ \\
\hline
\end{tabular}

Fonte: Cálculos do autor com base nos dados da Tabela 2.8 
Entre 1975 e 1980, a demanda esteve crescendo a $10 \%$ ao ano enquanto, entre 1981 e 1991 cresceu aos 6\% anuais. Isto é equivalente a mostrar que segundo as tendências do quinquênio 1975-1980, a demanda duplicar-se-ia cada 7 anos e para a década 1981-1991 a duplicação seria cada 12 anos.

O racionamento de energia elétrica em $1981^{12}$ coincide com a mudança da tendência de crescimento de $10 \%$ anualmente. A explicação pode ser encontrada principalmente nas intensas campanhas por parte das empresas do setor elétrico incentivando os usuários a economizar energia o que, presumivelmente tiveram algum sucesso.

A visão do planejamento elétrico de longo prazo sempre foi "ofertista", daí a super-capacidade de geração após 1985, o que levou à crise financeira das empresas e à demora na entrada em operação das usinas programadas para os últimos anos, identificada como uma das causas estruturais do passado racionamento (UPME;MME, 1994). No item 2.2 analisa-se mais detidamente esse fato, de acordo com a ótica do lado da demanda desta dissertação.

O interessante é mostrar que, na estrutura do consumo da eletricidade, o setor residencial é o seu principal responsável. Na Figura 2.7 e na Tabela 2.9, encontram-se a evolução da composição das vendas do setor elétrico para os diferentes setores de consumo durante 1975 até 1992.

Como se pode ver, a composição das vendas de eletricidade não tem variado muito durante os últimos dez anos, mostrando sempre um setor de consumo predominantemente residencial. Esse setor teve sua menor participação, durante o periodo considerado (1975-1992), em 1975 com 42,2\%. Em 1985 alcançaria seu maior valor, $48,6 \%$, que é $15 \%$ maior que a participação observada em 1975. 12 As restrições de oferta de eletricidade ocorreram durante os períodos de racionamento de 1977,1981
e entre 2 de março de 1992 e 1 de abril de 1993 . 
A estrutura do mercado da eletricidade na Colômbia é um caso atípico. $\mathrm{Na}$ Tabela 2.10 apresentam-se valores comparativos para diferentes paises que mostram grandes divergências na estrutura do mercado elétrico quando comparadas às da Colômbia. Em paises desenvolvidos, PERRY (1987) indica que a participação do setor de consumo residencial, também, não supera os $30 \%$.

Figura 2.7

Evolução do Porcentual Setorial das Vendas de Eletricicade na Colômbia. 1975-1992

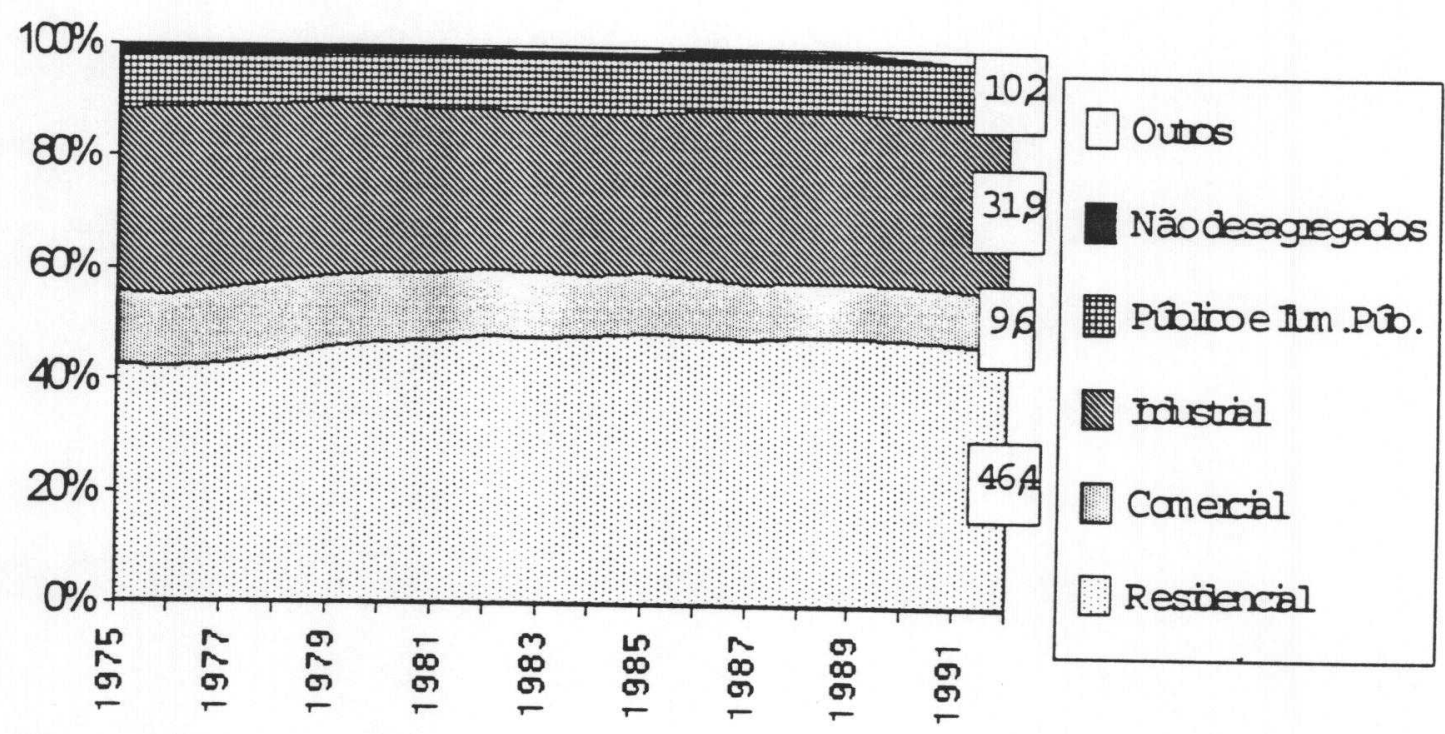

Fonte: Cálculos do autor com base em dados de ISA.

Para se chegar a esses niveis, o pais teve que destinar uma quantidade muito grande dos seus recursos, per se exíguos, para o setor elétrico. PERRY (1987), nota, por exemplo, que houve periodos nos quais a Colômbia destinou entre $35 \%$ e $40 \%$ do total de investimento público, unicamente para esse setor. 
Tabela 2.10

Participação do Setor Residencial no Total de Consumo de Eletricidade (Ano 1992)

\begin{tabular}{|l|c|}
\hline \multicolumn{1}{|c|}{ PAÍS } & PARTICIPAÇÃO (\%) \\
\hline Colômbia & $43,6 \%$ \\
Argentina & $42,3 \%$ \\
Bolivia & $58,6 \%$ \\
Brasil & $23,4 \%$ \\
Chile & $29,9 \%$ \\
México & $37,2 \%$ \\
Peruador & $39,1 \%$ \\
Venezuela & $38,6 \%$ \\
\hline
\end{tabular}

Fonte: OLADE-SIEE, 1994

\subsection{Situação Atual}

Na seção anterior foi apresentada uma visão geral e histórica da situação energética colombiana. Neste item, porém, analisa-se com cuidado as características da cocção residencial sob o ponto de vista dos usos finais.

Também, é discutido o problema das perdas de energia elétrica e a questão tarifária para o setor residencial. 


\subsubsection{Análise dos Usos Finais do Setor Residencial}

As principais variáveis explicativas do consumo de energia para o setor residencial estão relacionadas com a renda familiar que é uma característica muito típica em todos os paises (BÔA NOVA, 1985), condiçōes geográficas (clima) e acesso a energéticos substitutos.

Para se determinar os consumos por uso final da energia no setor residencial, precisam-se conhecer os hábitos característicos dos usuários com relação à intensidade que eles dão aos seus equipamentos e à frequência de uso dos aparelhos. Estas questões são objetos de um estudo de usos finais, efetuado por meio de enquetes e medições diretas.

$\mathrm{Na}$ Colômbia, já foram feitos alguns trabalhos com relação ao tema, com diferentes escopos metodológicos e resultados. Dos estudos mais recentes podem-se citar os seguintes: (1) trabalho coordenado pelo Sistema de Informação Energética (SIE) do Ministério de Minas e Energia da Colômbia em 1990 13; (2) o estudo apresentado pela então Comissão Nacional de Energia (CNE) em $1992^{14}$, elaborado por um grupo de consultores nacionais e internacionais dentro do Programa ESMAP (Energy Sector Management Assistance Program) do Banco Mundial (BM); (3) o trabalho do Programa de Cooperação Técnica (EURCOLERG) da Comissão das Comunidades Europeias (CCE) em 1992 is e (4) um estudo realizado para a região sudoeste

13 SISTEMA DE INFORMACIÓN ENERGÉTICA, MME. Usos y Consumos de Energia en los Sectores Residencial Rural, Comercial e Industria. Santafé de Bogotá, mar. 1990.

14 COMISIÓN NACIONAL DE ENERGIA. Estudio de Eficiencia Energética en los Sectores Residencial, Comercial y Oficial; Informe Final. Programa ESMAP. Santafé de Bogotá, junio de 1992.

15 EURCOLERG. Gestión de Carga Eléctrica: Resumen Ejecutivo. Santafé de Bogotá, nov. 1992. 
do pais pela Corporação Autônoma Regional do Cauca (CVC), as Empresas Municipais de Cali (EMCALI) e a Universidade do Valle (UV) em 199316

A análise do setor residencial no primeiro estudo teve como principal finalidade a de atualizar o trabalho de J. L. Calabrese, feito entre 1981 e 1982, para o Estudo Nacional de Energia (ENE) sobre energias não comerciais.

Nesta pesquisa foi amplamente analisada a questão da cocção para a zona rural do país, mostrando que esse uso final é o mais energo-intensivo. Também, demonstra que na zona rural, ao invés da zona urbana, as energias não comerciais são as de maior utilização.

Porém, mostra como nas áreas de cafeicultura dos Departamentos de Antioquia, Risaralda, Caldas e Quindio 17, a eletricidade representa uma fonte energética importante, diferindo dos outros energéticos. Os resultados desse estudo explicam a aplicação de programas intensivos de eletrificação rural.

Contudo, o autor considera que, se 0 aumento de cobertura do serviço de eletricidade contribuiu para o aumento do consumo de energia elétrica, a hipótese levantada nesse estudo não explicaria por quê em outras. zonas do pais, que também experimentaram um aumento de cobertura elétrica, não ocorreu um consumo similar.

As explicaçōes para este fenômeno devem ser procuradas diretamente nos hábitos de consumo dos usuários e não somente como um problema de acessibilidade a energéticos ou de oferta. Parte das razões desta particularidade nos Departamentos cafeeiros podem ser encontradas nos seus costumes de alimentação. Por exemplo, para a fabricação das tradicionais

16 CVC; EMCALI; UV. Proyecto Demanda y Oferta de Energéticos en el Suroccidente Colombiano: Informe de Encuesta de Hogares Sector Residencial. Santiago de Cali, ene. 1993.

17 Departamentos localizados na zona central ou região andina da Colômbia. 
arepas ${ }^{18}$ os usuários encontraram a eletricidade como um energético bastante cômodo que poderia substituir eficientemente as brasas que Ihe proporcionava o carvão, quer de lenha, quer mineral. Essa emulação dificilmente pode ser conseguida com outro tipo de energético, questão que impõe barreiras à penetração de substitutos energéticos para essa tarefa. É, portanto, um tema a ser analisado no Capítulo 3 desta dissertação.

O estudo coordenado pela CNE é bem mais amplo no seu escopo, porém, a análise dos usos finais do setor residencial foi dirigido só para as quatro maiores cidades do país: Santafé de Bogotá, Medellin, Santiago de Cali e Barranquilla que, em conjunto, concentram $60 \%$ do consumo total de eletricidade. Este estudo será continuamente utilizado, pois o autor considera que os resultados obtidos neste último trabalho são bastante consistentes.

O trabalho desenvolvido dentro do programa EURCOLERG teve uma aplicação mais específica para a cidade de Bucaramanga (região nordeste). Determinaram-se as curvas de carga por uso final a partir de medições e enquetes, visando selecionar alternativas técnicas que permitissem modificar a curva de carga global do sistema analisado. No entanto, já existe uma penetração de GN (encanado) em $86 \%$ dos lares dessa cidade o qual é destinado principalmente para a cocção de alimentos e por essa razão, este uso final não foi considerado.

O quarto estudo referido também teve um escopo geográfico limitado para uma única região, mas, diferente do anterior, o uso final cocção foi amplamente discutido. A região sudoeste do país, que compreende a cidade de Santiago de Cali (segunda cidade colombiana), demanda grandes quantidades de

18 As arepas são espécies de pães feitos com milho cozido e amassado em forma de disco que logo são
assadas para lhes dar consistência. 
energia elétrica para a cocção de alimentos, devido à ausência de disponibilidade de energéticos substitutos.

Este estudo é útil no sentido de comparação com o trabalho da CNE, igual que algumas pesquisas especificas que as Empresas Públicas de Medellin (EEPPM) fizeram há alguns anos.

Dos estudos anteriores, infere-se que uma análise para o uso final cocção só pode ser abordado se é respeitado o fato da variabilidade do consumo segundo a região geográfica considerada. Em primeira instância, a desagregação inicial poderia ser: zona urbana e zona rural ${ }^{19}$. Uma subdivisão apropriada para a zona urbana seria determinada pela possibilidade de acesso a energéticos substitutos da eletricidade e os niveis de renda familiar. Para a zona rural, a subdivisão depende de vários fatores como: a região à qual pertence um usuário, se este mora ou não na zona central do município, se a zona é carbonifera, se está eletrificado, etc.. Esta estrutura para a zona rural já demonstrou sua validade quando utilizada na metodologia do estudo para o SIE em 1990 em que se produziram resultados estatisticamente representativos (SIE, 1990).

\section{Zona Urbana}

A utilização da energia e o uso de energéticos nas zonas urbanas depende de fatores geográficos (principalmente o clima), os niveis de renda familiar e a disponibilidade de acesso a diversos energéticos.

A variável geográfica que define o clima na Colômbia é a altitude. As cidades da região andina apresentam clima de montanha e aquelas da região atlântica,

19 Para guardar homegeneidade, o conceito de zona rural que se usará nesta dissertação é a definida pelo DANE, correspondente a todos os municípios com menos de 10.000 habitantes e a zona fora da
área central dos municípios de mais de 10.000 habitantes. 
clima de litoral ou de planície. Nestas duas regiões concentra-se a maior parte da população colombiana. Das quatro cidades analisadas no estudo da $\mathrm{CNE}$, Santafé de Bogotá ( 2.600 m.s.n.m) é uma cidade de clima frio, Medellín (1500 m.s.n.m) e Santiago de Cali (1.000 m.s.n.m) têm um clima médio e Barranquilla é de clima quente.

Os niveis de renda na zona urbana, para efeitos de análises, são agrupados em "estratos sócio-econômicos". A estratificação visa estabelecer um critério de classificação dos usuários segundo as suas capacidades econômicas (rendas familiares), a partir de parâmetros indiretos objetivos e de simples aplicação (CNE, 1992). Atualmente, estão definidos seis estratos: 1) BaixoBaixo, 2) Baixo, 3) Médio-Baixo, 4) Médio, 5) Médio-Alto e 6) Alto. (Vide Tabela 2.13)

Os parâmetros utilizados nesta classificação e as suas respectivas ponderações são mostrados na Tabela 2.11.

Tabela 2.11

Parâmetros e Fatores de Ponderação Utilizados para Estratificação SócioEconômica na Colômbia

\begin{tabular}{|l|c|}
\hline \multicolumn{1}{|c|}{ Parâmetro } & Ponderação \\
\hline Alocação espacial & $25 \%$ \\
Fachadas & $30 \%$ \\
Zonas verdes e de lazer & $15 \%$ \\
Garagens & $20 \%$ \\
Vias de acesso & $5 \%$ \\
Serviços públicos & $5 \%$ \\
\hline
\end{tabular}

Fonte: CNE, 1992. 
Uma revisão das metodologias de estratificação, por parte do Departamento Nacional de Planeación (DNP), é considerada no Decreto Presidencial No. 2220 de 5 de novembro de 1993. A nova metodologia, deverá ser adotada pelos municípios e Distritos até 31 de dezembro deste ano (1994), para a zona urbana, e até 31 de julho de 1995 no caso das zonas rurais. Todavia, conservam-se como fatores de estratificação os apresentados anteriormente.

Uma distribuição percentual dos usuários residenciais segundo o estrato sócio-econômico apresenta-se na Tabela 2.12 e na Figura 2.8.

Tabela 2.12

Distribuição Percentual dos Usuários Residenciais Segundo Estrato Sócio-Econômico

\begin{tabular}{|l|r|r|r|r|}
\hline \multicolumn{1}{|c|}{ ESTRATO } & S. DE BOGOTÁ & MEDELLÍN & S. DE CALI & BARRANQUILLA \\
\hline Baixo Baixo & 0.99 & 1.93 & 6.43 & 24.40 \\
Baixo & 28.15 & 32.20 & 37.47 & 39.22 \\
Médio baixo & 40.80 & 39.95 & 29.18 & 18.91 \\
Médio & 18.30 & 14.62 & 6.55 & 6.62 \\
Médio alto & 8.15 & 8.32 & 15.87 & 5.11 \\
Alto & 3.61 & 2.97 & 4.50 & 5.75 \\
\hline Total & 100.0 & 100.0 & 100.0 & 100.0 \\
\hline
\end{tabular}

Fonte: Anuario de Estadísticas Básicas del Sector Eléctrico, dic. 1991. apud CNE, 1992. 
Figura 28

Histogramas de Freqüência Relativa dos Usuários Residenciais

Segundo Estrato Sócio-Econômico

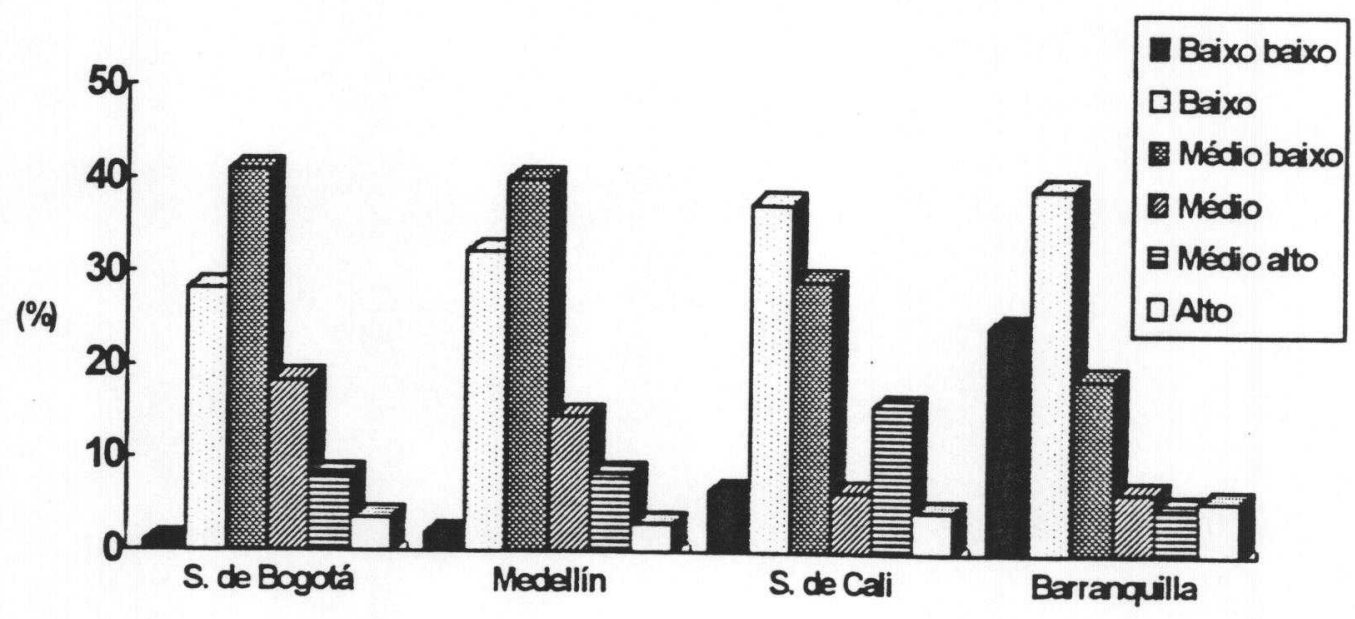

Barranquilla chama a atenção com relação à distribuição relativa dos consumidores de energia elétrica. Para os primeiros dois estratos, correspondentes aos grupos humanos de menores recursos, já existe um acúmulo de $63,6 \%$. Valor muito superior ao apresentado para as cidades de Santafé de Bogotá e Medellín com 29,1\% e 34\% respectivamente. A cidade de Santiago de Cali, embora não atinja esse patamar, mostra uma cifra também alta, de $44 \%$. Caso se considere os três primeiros estratos, o acumulado para as cidades de Santafé de Bogotá, Medellín, Santiago de Cali e Barranquilla é, respectivamente, $69,9 \%, 74,1 \%, 73,1 \%$ e $82,5 \%$.

Esta assimetria na distribuição relativa dos usuários segundo o estrato sócioeconômico, mostra que $70 \%$ ou mais do mercado residencial atendido pelas principais concessionárias do pais, corresponde a consumidores de baixos recursos, cujas rendas familiares não superam em média, os 5,4 salários mínimos 20 legais (Tabela 2.13).

20 O salário mínimo mensal em janeiro de 1994 para todo o território nacional era de Col\$ 98.700 , equivalente a US\$ 123. 
Tabela 2.13

Nivel de Renda Familiar Segundo Estrato Sócio-Econômico

\begin{tabular}{|l|c|c|}
\hline \multicolumn{1}{|c|}{ ESTRATO } & RENDA FAMILIAR & RENDA FAMILIAR \\
& $(1993$ US $\$)$ & (No. SALÁRIOS MINIMOS) \\
\hline 1.Baixo Baixo & $R<123$ & $R<1$ \\
2. Baixo & $123 \leq R<332,1$ & $1 \leq R<2,7$ \\
3. Médio baixo & $332,1 \leq R<664,2$ & $2,7 \leq R<5,4$ \\
4. Médio & $664,2 \leq R<1.328,4$ & $5,4 \leq R<10,8$ \\
5. Médio alto & $1.328,4 \leq R<1.992,6$ & $10,8 \leq R<16,2$ \\
6. Alto & $R \geq 1.992,6$ & $R \geq 16,2$ \\
\hline
\end{tabular}

Fonte: Hidrotec, 1986 apud GUHL et al,1993 e cálculos do autor

O terceiro fator que define a utilização de energia na zona urbana é a disponibilidade ou acesso aos diferentes energéticos. Nas Tabelas 2.14 a 2.17 são tabuladas as participações dos diferentes energéticos nos seis estratos sócio-econômicos para as quatro cidades consideradas.

Tabela 2.14

Distribuição Percentual do Consumo (Tcal) Residencial de Energéticos Segundo o Estrato Sócio-Econômico para a Cidade de Santafé de Bogotá.

\begin{tabular}{|c|c|c|c|c|c|}
\hline \multirow{2}{*}{ ESTRATO } & \multicolumn{5}{|c|}{ ENERGÉTICOS UTILIZADOS } \\
\cline { 2 - 6 } & Eletricidade & GLP & GN & COCINOL & LENHA \\
\hline 1 & $66,22 \%$ & $10,05 \%$ & $2,46 \%$ & $20,84 \%$ & $0,44 \%$ \\
2 & $38,93 \%$ & $14,74 \%$ & $6,78 \%$ & $39,50 \%$ & $0,05 \%$ \\
3 & $47,87 \%$ & $18,79 \%$ & $5,79 \%$ & $27,55 \%$ & $0,00 \%$ \\
4 & $70,60 \%$ & $27,88 \%$ & $0,55 \%$ & $0,97 \%$ & $0,00 \%$ \\
5 & $77,00 \%$ & $22,51 \%$ & $0,00 \%$ & $0,49 \%$ & $0,00 \%$ \\
6 & $92,94 \%$ & $7,06 \%$ & $0,00 \%$ & $0,00 \%$ & $0,00 \%$ \\
\hline
\end{tabular}

Fonte: CNE, 1992 
Tabela 2.15

Distribuição Percentual do Consumo (Tcal) Residencial de Energéticos Segundo o Estrato Sócio-Econômico para a Cidade de Medellín

\begin{tabular}{|c|c|c|c|c|c|}
\hline \multirow{2}{*}{ ESTRATO } & \multicolumn{5}{|c|}{ ENERGÉTICOS UTILIZADOS } \\
\cline { 2 - 6 } & ELETRICID. & GLP & QUEROSENE & $\begin{array}{c}\text { CARVÁO } \\
\text { MINERAL }\end{array}$ & LENHA \\
\cline { 2 - 6 } & $99,83 \%$ & $0,00 \%$ & $0,16 \%$ & $0,00 \%$ & $0,01 \%$ \\
2 & $99,46 \%$ & $0,11 \%$ & $0,29 \%$ & $0,06 \%$ & $0,07 \%$ \\
3 & $99,42 \%$ & $0,47 \%$ & $0,08 \%$ & $0,01 \%$ & $0,01 \%$ \\
4 & $98,76 \%$ & $0,18 \%$ & $0,00 \%$ & $0,04 \%$ & $1,02 \%$ \\
5 & $99,92 \%$ & $0,06 \%$ & $0,00 \%$ & $0,00 \%$ & $0,00 \%$ \\
6 & $99,98 \%$ & $0,02 \%$ & $0,00 \%$ & $0,00 \%$ & $0,00 \%$ \\
\hline \multirow{2}{*}{ MÉDIA } & $99,56 \%$ & $0,26 \%$ & $0,11 \%$ & $0,03 \%$ & $0,04 \%$ \\
\hline
\end{tabular}

Fonte: CNE, 1992

Tabela 2.16

Distribuição Percentual do Consumo (Tcal) Residencial de Energéticos Segundo o Estrato Sócio-Econômico para a Cidade de Santiago de Cali.

\begin{tabular}{|c|c|c|c|c|}
\hline \multirow{2}{*}{ ESTRATO } & \multicolumn{4}{|c|}{ ENERGÉTICOS UTILIZADOS } \\
\cline { 2 - 5 } & ELETRICID. & GLP & $\begin{array}{c}\text { GASOLINA } \\
\text { BRANCA }\end{array}$ & QUEROSENE \\
\hline & & & $0,00 \%$ & $1,31 \%$ \\
2 & $95,16 \%$ & $3,52 \%$ & $0,11 \%$ & $1,13 \%$ \\
3 & $95,30 \%$ & $3,45 \%$ & $1,15 \%$ \\
4 & $94,01 \%$ & $4,67 \%$ & $0,17 \%$ & $0,84 \%$ \\
5 & $96,09 \%$ & $2,11 \%$ & $0,96 \%$ & $0,00 \%$ \\
6 & $99,76 \%$ & $0,24 \%$ & $0,00 \%$ & $0,00 \%$ \\
\hline \multirow{2}{*}{ MÉDIA } & $100,00 \%$ & $0,00 \%$ & $0,00 \%$ & $0,80 \%$ \\
& $96,31 \%$ & $2,74 \%$ & $0,14 \%$ & \\
\hline
\end{tabular}

Fonte: CNE, 1992 
Tabela 2.17

Distribuição Percentual do Consumo (Tcal) Residencial de Energéticos Segundo o Estrato Sócio-Econômico para a Cidade de Barranquilla

\begin{tabular}{|c|c|c|c|c|c|}
\hline \multirow{2}{*}{ ESTRATO } & \multicolumn{5}{|c|}{ ENERGÉTICOS UTILIZADOS } \\
\cline { 2 - 6 } & ELETRICID. & GLP & GN & COCINOL & QUEROSENE \\
\hline 1 & $43,75 \%$ & $48,68 \%$ & $7,56 \%$ & $0,00 \%$ & $0,00 \%$ \\
2 & $62,77 \%$ & $2,42 \%$ & $14,50 \%$ & $14,54 \%$ & $5,76 \%$ \\
3 & $59,12 \%$ & $8,72 \%$ & $24,57 \%$ & $0,00 \%$ & $7,59 \%$ \\
4 & $67,37 \%$ & $7,21 \%$ & $22,85 \%$ & $0,00 \%$ & $2,58 \%$ \\
5 & $43,59 \%$ & $0,00 \%$ & $56,41 \%$ & $0,00 \%$ & $0,00 \%$ \\
6 & $50,87 \%$ & $1,65 \%$ & $47,48 \%$ & $0,00 \%$ & $0,00 \%$ \\
\hline & & & & & $3,86 \%$ \\
MÉDIA & $51,87 \%$ & $9,31 \%$ & $33,25 \%$ & $1,71 \%$ & \\
\hline
\end{tabular}

Fonte: CNE. 1992

Nas cidades de Medellín e Santiago de Cali observa-se uma dependência quase total sobre a eletricidade, independente do estrato sócio-econômico do consumidor. Essa característica vai estar presente, também, na maioria dos Departamentos do oeste colombiano. As razões, estão diretamente relacionadas com a acessibilidade a energéticos substitutos e à inexistência de uma "cultura do gás" que explica a baixa penetração do GLP nessas regiōes.

Em Santafé de Bogotá, porém, o GLP tem uma participação bem significativa, com exceção do estrato 6 (alto). O cocinol (gasolina aditivada com corante e odorizante para efeitos de segurança) é bastante representativo para os estratos baixos (1 a 3) da população bogotana, todavia, como será explicado no próximo capítulo, este combustivel deve desaparecer a curto prazo. Similarmente, o consumo de GN é representativo só para os estratos 1 até 3,0 qual é conseqüência de programas específicos de extensão de redes domiciliárias de gás para estes setores da população por parte da empresa Gas Natural S.A. (COCK, 1991).

Barranquilla, como várias das cidades da região atlântica da Colômbia, estão assistidas por sistemas de distribuição domiciliária de GN, porém, ao invés de 
Santafé de Bogotá, o enfoque de penetração desse combustivel visou atender aos usuários de maiores recursos. Daí se explica o fato das altas participações do GN nos estratos 5 e 6 nessa cidade. 0 cocinol, como em Santafé de Bogotá, deve desaparecer do contexto de uso residencial.

Cidades como Bucaramanga (nordeste), Neiva (sul) e Villavicencio (leste) já estão servidas por sistemas de distribuição de GN encanado, aproveitando as jazidas deste combustivel nesses territórios.

A nivel nacional, para o setor urbano, a eletricidade participa com $44 \%$ das 20.733,9 Tcal demandadas pelo setor residencial. O GLP é o segundo energético, com $18 \%$. A lenha, entretanto, conserva ainda uma participação relevante de $14 \%$ (Figura 2.9 ).

Figura 2.9

Participação Energética no Setor Residencial Urbano Colombiano 1992

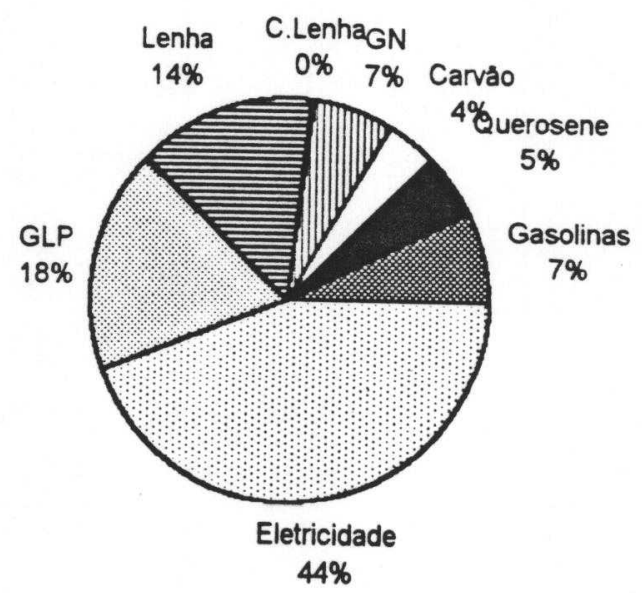

Fonte: NULE, G. Memorias al Congreso Nacional. MME, 1993.

A nivel nacional, portanto, a participação da eletricidade na zona urbana é menor que qualquer das médias das quatro cidades estudadas. Santafé de Bogotá e Barranquilla seriam as cidades que mais se aproximam à média nacional $(44 \%)$, pois a eletricidade representa $52 \%$ da energia consumida no setor residencial. 
Dos estudos de usos finais realizados nessas cidades, pode-se estabelecer como esta sendo utilizada a eletricidade. Os resultados encontrados no estudo da CNE são apresentados nas Tabelas 2.18 a 2.25. As Tabelas 2.18 a 2.21, mostram a distribuição percentual do consumo por uso final e as Tabelas 2.22 a 2.25 mostram os valores correspondentes em unidades físicas.

Em Santafé de Bogotá, observa-se que a participação da eletricidade na cocção aumenta conforme o estrato sócio-econômico do usuário. Igualmente 0 consumo de energia elétrica para aquecimento de água é significativo para todos os estratos, excetuando o "baixo baixo" que corresponde às faixas de miséria da cidade. Em compensação, o consumo em acondicionamento de ar é nulo. Uma temperatura média anual de $14^{\circ} \mathrm{C}$ para a cidade de Santafé de Bogotá (JICA, 1992), explica esse comportamento.

Os altos consumos de energia elétrica em cocção e aquecimento de água para os três estratos mais altos $(4,5$ e 6$)$, estão afins com a alta participação da eletricidade (maior que $70 \%$ ) com relação ao resto de energéticos para o uso residencial. Nesses estratos, a cocção e o aquecimento de água demandam, em média, entre $66 \%$ e $69 \%$ da energia elétrica consumida.

Ainda que os consumos absolutos por aquecimento de água e cocção para os estratos 4, 5 e 6 são, em termos analíticos, praticamente iguais, as suas curvas de carga são bem diferentes.

O aquecimento de água também poderia utilizar um energético diferente da eletricidade. Mas, devido à forma de utilização e características dos equipamentos (quase em sua totalidade do tipo acumuladores), existem oportunidades técnicas de se fazer uma gestão da demanda sobre este uso final, onde a sua utilização seria feita só para os periodos fora de ponta, onde os custos marginais de fornecimento elétrico são bem menores. 
TABELA 2.18

USOS FINAIS DA ELETRICIDADE NO SETOR RESIDENCIAL EM S. DE BOGOTÁ PORCENTUAIS DE CONSUMO PARA UM USUÁRIO MÉDIO

\begin{tabular}{|c|c|c|c|c|c|c|c|}
\hline ESTRATO & ILUMIN. & COCÇAO & AQUE. AGUA & GELADEIRA & AR CONDIC. & OUTROS & TOTAL \\
\hline 1 & 27.5 & 28.1 & 3.5 & 20.5 & 0.0 & 20.4 & 100.0 \\
\hline 2 & 29.9 & 23.4 & 15.8 & 19.0 & 0.0 & 12.0 & 100.0 \\
\hline 3 & 24.8 & 23.3 & 12.5 & 30.5 & 0.0 & 9.0 & 100.0 \\
\hline 4 & 19.0 & 34.6 & 26.0 & 13.9 & 0.0 & 6.5 & 100.0 \\
\hline 5 & 15.4 & 33.6 & 32.2 & 13.7 & 0.0 & 5.1 & 100.0 \\
\hline 6 & 14.6 & 37.8 & 31.1 & 10.2 & 0.0 & 5.7 & 100.0 \\
\hline MÉDIA & 20.3 & 30.2 & 22.1 & 19.1 & 0.0 & 8.3 & 100.0 \\
\hline
\end{tabular}

Fonte: CNE, 1992

TABELA 2.19

USOS FINAIS DA ELETRICIDADE NO SETOR RESIDENCIAL EM MEDELLÍN PORCENTUAIS DE CONSUMO PARA UM USUÁRIO MÉDIO

\begin{tabular}{|c|c|c|c|c|c|c|c|}
\hline ESTRATO & ILUMIN. & COCÇAO & AQUE. AGUA & GELADEIRA & AR CONDIC. & OUTROS & TOTAL \\
\hline 1 & 10.63 & 65.18 & 1.73 & 21.12 & 0.00 & 1.35 & 100 \\
\hline 2 & 10.76 & 61.32 & 2.92 & 22.61 & 0.00 & 6.39 & 100 \\
\hline 3 & 9.84 & 51.89 & 9.24 & 22.64 & 0.00 & 6.39 & 100 \\
\hline 4 & 10.58 & 37.37 & 23.72 & 22.10 & 0.00 & 6.23 & 100 \\
\hline 5 & 11.15 & 32.59 & 30.09 & 19.11 & 0.00 & 7.06 & 100 \\
\hline 6 & 10.31 & 28.75 & 37.87 & 12.74 & 0.00 & 10.33 & 100 \\
\hline MÉDIA & 10.38 & 48.87 & 13.64 & 21.59 & 0.00 & 5.53 & 100 \\
\hline
\end{tabular}

Fonte: CNE, 1992 
TABELA 2.20

USOS FINAIS DA ELETRICIDADE NO SETOR RESIDENCIAL EM S. DE CALI PORCENTUAIS DE CONSUMO PARA UM USUÁRIO MÉDIO

\begin{tabular}{|c|r|r|r|r|r|r|r|}
\hline ESTRATO & \multicolumn{1}{|c|}{ ILUMIN. } & \multicolumn{1}{c|}{ COCÇAO } & AQUE. AGUA & GELADEIRA & AR CONDIC. & OUTROS & TOTAL \\
\hline 1 & 10.23 & 49.70 & 0.00 & 26.08 & 7.67 & 6.33 & 100 \\
2 & 10.12 & 45.23 & 0.23 & 29.50 & 8.73 & 6.20 & 100 \\
3 & 11.05 & 40.94 & 0.87 & 31.11 & 8.69 & 7.32 & 100 \\
4 & 11.91 & 47.59 & 0.81 & 26.22 & 14.54 & 8.94 & 100 \\
5 & 10.44 & 32.89 & 5.86 & 25.85 & 18.37 & 6.59 & 100 \\
6 & 8.04 & 37.29 & 16.84 & 17.50 & 16.65 & 3.69 & 100 \\
\hline MÉDIA & 10.32 & 40.59 & 3.21 & 27.69 & 11.72 & 6.48 & 100 \\
\hline
\end{tabular}

Fonte: CNE, 1992

TABELA 2.21

USOS FINAIS DA ELETRICIDADE NO SETOR RESIDENCIAL EM BARRANQUILLA PORCENTUAIS DE CONSUMO PARA UM USUÁRIO MÉDIO

\begin{tabular}{|c|r|r|r|r|r|r|r|}
\hline ESTRATO & ILUMIN. & \multicolumn{1}{c|}{ COCÇAOO } & AQUE. AGUA & GELADEIRA & AR CONDIC. & OUTROS & TOTAL \\
\hline 1 & 17.26 & 10.82 & 0.00 & 50.47 & 10.00 & 11.46 & 100 \\
2 & 17.82 & 23.30 & 0.00 & 32.60 & 18.23 & 8.06 & 100 \\
3 & 11.62 & 5.93 & 0.00 & 41.46 & 32.80 & 8.18 & 100 \\
4 & 13.07 & 15.91 & 0.00 & 32.84 & 31.29 & 6.89 & 100 \\
5 & 12.43 & 5.16 & 0.00 & 28.22 & 44.87 & 9.31 & 100 \\
6 & 11.24 & 20.53 & 0.00 & 20.74 & 35.85 & 11.63 & 100 \\
\hline MÉDIA & 14.19 & 15.23 & 0.00 & 33.92 & 27.68 & 8.98 & 100 \\
\hline
\end{tabular}

Fonte: CNE, 1992 
TABELA 2.22

USOS FINAIS DA ELETRICIDADE NO SETOR RESIDENCIAL EM S. DE BOGOTÁ CONSUMOS MÉDIOS POR USUÁRIO (kWh/mês)

\begin{tabular}{|c|r|r|r|r|r|r|r|}
\hline ESTRATO & ILUMIN. & COCÇAO & AQUE. AGUA & GELADEIRA & AR CONDIC. & OUTROS & TOTAL \\
\hline 1 & 53.9 & 55.1 & 6.8 & 40.3 & 0.0 & 40.0 & 196.0 \\
2 & 71.4 & 55.9 & 37.6 & 45.5 & 0.0 & 28.6 & 239.0 \\
3 & 70.3 & 66.1 & 35.6 & 86.6 & 0.0 & 25.4 & 284.0 \\
4 & 66.0 & 119.9 & 90.4 & 48.2 & 0.0 & 22.6 & 347.0 \\
5 & 70.4 & 153.2 & 146.7 & 62.4 & 0.0 & 23.2 & 456.0 \\
6 & 89.3 & 231.7 & 190.5 & 62.7 & 0.0 & 35.0 & 613.0 \\
\hline MÉdIA & 63.7 & 94.7 & 69.3 & 59.7 & 0.0 & 25.9 & 313.4 \\
\hline
\end{tabular}

Fonte: Cálculos do autor com base em dados da CNE, 1992.

TABELA 2.23

USOS FINAIS DA ELETRICIDADE NO SETOR RESIDENCIAL EM MEDELLIN CONSUMOS MÉDIOS POR USUÁRIO (kWh/més)

\begin{tabular}{|c|r|r|r|r|r|r|r|}
\hline ESTRATO & ILUMIN. & COCÇAO & AQUE. AGUA & GELADEIRA & AR CONDIC. & OUTROS & - TOTAL \\
\hline 1 & 27.1 & 166.2 & 4.4 & 53.9 & 0.0 & 3.4 & 255.0 \\
2 & 31.5 & 179.7 & 8.6 & 66.2 & 0.0 & 18.7 & 293.0 \\
3 & 35.7 & 188.4 & 33.5 & 82.2 & 0.0 & 23.2 & 363.0 \\
4 & 41.5 & 146.5 & 93.0 & 86.6 & 0.0 & 24.4 & 392.0 \\
5 & 53.9 & 157.4 & 145.3 & 92.3 & 0.0 & 34.1 & 483.0 \\
6 & 73.5 & 205.0 & 270.0 & 90.8 & 0.0 & 73.7 & 713.0 \\
\hline MÉDIA & 37.5 & 176.8 & 49.3 & 78.1 & 0.0 & 20.0 & 361.7 \\
\hline
\end{tabular}

Fonte: Cálculos do autor com base em dados da CNE, 1992. 
TABELA 2.24

USOS FINAIS DA ELETRICIDADE NO SETOR RESIDENCIAL EM S. DE CALI CONSUMOS MÉDIOS POR USUÁRIO (kWh/mês)

\begin{tabular}{|c|r|r|r|r|r|r|r|}
\hline ESTRATO & ILUMIN. & COCÇAO & AQUE. AGUA & GELADEIRA & AR CONDIC. & OUTROS & TOTAL \\
\hline 1 & 22.2 & 107.9 & 0.0 & 56.6 & 16.7 & 13.7 & 217.1 \\
2 & 30.2 & 135.2 & 0.7 & 88.2 & 26.1 & 18.5 & 298.9 \\
3 & 31.6 & 116.9 & 2.5 & 88.9 & 24.8 & 20.9 & 285.6 \\
4 & 35.9 & 143.6 & 2.4 & 79.1 & 43.9 & 27.0 & 301.7 \\
5 & 39.6 & 124.7 & 22.2 & 98.0 & 69.6 & 25.0 & 379.1 \\
6 & 56.7 & 263.2 & 118.9 & 123.5 & 117.5 & 26.0 & 705.8 \\
\hline MÉdIA & 33.2 & 130.5 & 10.3 & 89.1 & 37.7 & 20.8 & 321.6 \\
\hline
\end{tabular}

Fonte: Cálcullos do autor com base em dados da CNE, 1992.

TABELA 2.25

USOS FINAIS DA ELETRICIDADE NO SETOR RESIDENCIAL EM BARRANQUILLA CONSUMOS MÉDIOS POR USUÁRIO (kWh/mês)

\begin{tabular}{|c|r|r|r|r|r|r|r|}
\hline ESTRATO & ILUMIN. & COCÇAO & AQUE. AGUA & GELADEIRA & AR CONDIC. & OUTROS & TOTAL \\
\hline 1 & 19.2 & 12.0 & 0.0 & 56.1 & 11.1 & 12.7 & 111.1 \\
2 & 30.9 & 40.4 & 0.0 & 56.5 & 31.6 & 14.0 & 173.4 \\
3 & 28.0 & 14.3 & 0.0 & 99.9 & 79.0 & 19.7 & 240.9 \\
4 & 40.8 & 49.7 & 0.0 & 102.5 & 97.7 & 21.5 & 312.2 \\
5 & 45.0 & 18.7 & 0.0 & 102.1 & 162.4 & 33.7 & 361.9 \\
6 & 65.7 & 120.1 & 0.0 & 121.3 & 209.7 & 68.0 & 584.8 \\
\hline MÉDIA & 32.0 & 34.3 & 0.0 & 76.4 & 62.4 & 20.2 & 225.3 \\
\hline
\end{tabular}

Fonte: Cálculos do autor com base em dados da CNE, 1992. 
Também, existem estudos no pais que demonstram que existe uma duração ótima para o tempo em que os acumuladores deveriam estar ligados à rede elétrica. Por exemplo, foi determinado que 2 horas é o tempo mais conveniente para um acumulador de 71 l (20 gal), ser usado por uma familia de 5 pessoas com um consumo diário total de água quente de $84 \mathrm{I}$ e 101,4 kWh por mês (ISA; CIDI, 1992). Ademais, determinou-se que existem também alternativas para aumentar a eficiência dos acumuladores caso usar isolantes de melhor qualidade.

Outra razão, desta vez de mercado, para se continuar usando acumuladores de tanque elétricos, é a baixissima oferta de outro tipo de aquecedores de água. Aliás, HACEB, principal empresa produtora de eletrodomésticos da Colômbia, retém o $90 \%$ do mercado de aquecedores de água, produzindo em sua totalidade aquecedores do tipo acumulador elétrico.

Além disso, o uso final de aquecimento de água não tem a mesma intensidade para o território nacional inteiro nem para todos os estratos sócio-econômicos e às vezes é até inexistente.

As razōes anteriores, mostram que o problema com esse uso final não é tão grave quanto o problema com a cocção.

Para a cidade de Medellín, os resultados mostram que, em valores absolutos, o consumo de energia elétrica para cocção independe do estrato do usuário. Estatisticamente, o valor esperado $\mu$ é de $176,8 \mathrm{kWh} / \mathrm{mês}$ com desvio padrão $\sigma$ de $12 \%$.

As Empresas Públicas de Medellín (EEPPM), concessionária de energia elétrica que atende o mercado desta cidade, fez um estudo baseado em enquetes e mediçōes para o setor residencial que resultou em uma estrutura de consumo por usos finais como mostra a Tabela 2.26. 
Tabela 2.26

Estrutura de Consumo de Energia Elétrica para a Cidade de Medellin, Segundo Avaliação das Empresas Públicas de Medellín

\begin{tabular}{|c|c|c|c|c|}
\hline \multirow{2}{*}{ ESTRATO } & \multicolumn{4}{|c|}{ PARTICIPAÇ் ÁO } \\
\cline { 2 - 5 } & COCÇÃO & AQUEC. ÁGUA & ILUMINAÇÃO & OUTROS \\
\hline 1 & $57 \%$ & $1 \%$ & $7 \%$ & $35 \%$ \\
2 & $54 \%$ & $1 \%$ & $7 \%$ & $38 \%$ \\
3 & $47 \%$ & $5 \%$ & $7 \%$ & $41 \%$ \\
4 & $39 \%$ & $17 \%$ & $7 \%$ & $37 \%$ \\
5 & $34 \%$ & $24 \%$ & $7 \%$ & $35 \%$ \\
6 & $22 \%$ & $29 \%$ & $8 \%$ & $41 \%$ \\
\hline
\end{tabular}

Fonte: EEPPM. s.d.

Em forma geral, os resultados para cocção, são parecidos aos encontrados no estudo da CNE. O estudo das EEPPM tinha um objetivo mais especifico, pois seus resultados apoiariam a criação da unidade de gás dessa entidade, visando oferecer no futuro o GN para os atuais usuários da eletricidade. Por esta razão, o escopo do trabalho esteve dirigido para os usos finais cocção e aquecimento de água.

O caso de Santiago de Cali é também similar com o de Medellin, no que tange à cocção elétrica. Porém, uma altitude sobre o nivel do mar de $1.000 \mathrm{~m}$ e uma temperatura média de $22^{\circ} \mathrm{C}$ explicam o porquê de consumo por aquecimento de água não seja tão significativo.

$\mathrm{Na}$ Tabela 2.27 apresentam-se os resultados encontrados recentemente para essa cidade a partir de um estudo elaborado pelas concessionárias de energia Corporación Autónoma Regional del Cauca (CVC) e Empresas Municipales de Cali (EMCALI) e a Universidad del Valle (UV), (CVC; EMCALI; UV, 1993).

Alguns destes valores divergem bastante do estudo da CNE. Isto demonstra a alta incerteza envolvida no levantamento de dados. Nem para este estudo, nem para o trabalho da $\mathrm{CNE}$, são apresentados resultados com confiança estatistica. 
Tabela 2.27

Estrutura de Consumo de Energia Elétrica para a Cidade de Santiago de Cali, Segundo Estudo CVC-EMCALI-UV

\begin{tabular}{|c|r|r|r|r|r|r|}
\hline \multirow{2}{*}{ ESTRATO } & \multicolumn{5}{|c|}{ PARTICIPAÇÃO } \\
\cline { 2 - 7 } & COCÇÃO & $\begin{array}{c}\text { AQUEC. } \\
\text { AGUA }\end{array}$ & ILUMINAÇÃO & GELADEIRA & $\begin{array}{c}\text { AR (1) } \\
\text { CONDIC. }\end{array}$ & OUTROS \\
\hline 1 & $40,38 \%$ & $0,00 \%$ & $2,60 \%$ & $33,05 \%$ & $5,12 \%$ & $18,85 \%$ \\
2 & $28,86 \%$ & $6,09 \%$ & $2,70 \%$ & $35,44 \%$ & $4,45 \%$ & $22,46 \%$ \\
3 & $27,08 \%$ & $9,81 \%$ & $5,26 \%$ & $29,78 \%$ & $7,86 \%$ & $20,21 \%$ \\
4 & $28,09 \%$ & $25,25 \%$ & $3,56 \%$ & $22,94 \%$ & $2,15 \%$ & $18,01 \%$ \\
5 & $22,48 \%$ & $34,69 \%$ & $3,24 \%$ & $19,80 \%$ & $3,77 \%$ & $16,02 \%$ \\
6 & $8,00 \%$ & $48,75 \%$ & $1,32 \%$ & $6,07 \%$ & $30,96 \%$ & $4,90 \%$ \\
\hline
\end{tabular}

(1) Inclui ventiladores

Fonte: CVC; EMCALI; UV, 1993

Outro aspecto que motivaria uma atualização desses dados, seria a ocorrência do último racionamento de energia elétrica que o país viveu entre 2 de março de 1992 e 1 de abril de 1993. A restrição de oferta de eletricidade modificou nesse período os hábitos de consumo dos usuários, principalmente com relação à utilização de energéticos substitutos da energia elétrica para a cocção. A demanda de GLP, por exemplo, experimentou um aumento súbito durante 0 racionamento que não se conseguiu cobrir devido às limitações de abastecimento do combustivel no território nacional. Também não é conhecido - grau de conscientização da população com relação ao uso racional e eficiente da energia. Porém, as novas políticas tarifárias, advindas após a ocorrência da emergência elétrica, parecem estar fazendo eco nos usuários para uma mudança de atitude com a utilização da energia elétrica.

O caso da cidade de Barranquilla é diferente do resto das cidades do interior onde ainda não existe um programa de difusão de consumo de gás, quer GLP, quer GN.

Praticamente existe somente um consumo apreciável de energia elétrica para fins de cocção de alimentos para o estrato 6. Esses resultados estão diretamente relacionados com o fato da penetração do GN encanado para usuários de altas rendas e o uso de GLP entre os estratos mais baixos. As 
altas temperaturas nesta região portuária, entretanto, incrementam os consumos de outros usos finais como em geladeiras e ar condicionado.

Uma limitação importante que se tem apresentado na maioria dos estudos de usos finais na Colômbia está relacionada com a ausência de estudos sobre as curvas de carga horária para cada uso final.

Os estudos de caracterização da carga para as cidades de Medellín e Barranquilla, feitos em 1990 e 1991 (ISA; EEPPM, 1990 e ISA; CORELCA, 1991) permitiram determinar as curvas de carga típicas para cada categoria de consumo (industrial, comercial, residencial, público e iluminação pública), mas não chegaram ao detalhe de análise por usos finais.

É importante notar que, dispôr de informaçōes sobre o comportamento dos usuários até os usos finais, é uma valiosa ajuda para definir estruturas tarifárias e para estabelecer programas de administração da demanda (demand side management -DSM-) através de estratégias técnicas e econômicas, visando a modificação da curva de carga para um tipo de usuário. Os resultados podem levar a substanciais reduções nos custos de fornecimento da eletricidade, beneficiando tanto o usuário quanto a concessionária.

No caso da cocção, tem-se demonstrado em alguns estudos (CVC; EMCALl; UV, 1993) que este uso final tem uma relevante ingerência no valor da demanda de ponta dos sistemas elétricos. Para o sistema interligado colombiano, a ponta máxima acontece às 19:00 horas e uma ponta secundária às 11:00 horas (Figura 2.10). Para alguns subsistemas elétricos, a ponta das 11:00 horas é maior ou tão similar quanto a ponta das 19:00 horas. Este é o caso dos sistemas de CVC (sudoeste colombiano) e EEPPM (região centro) que atendem os mercados das cidades de Santiago de Cali (através de vendas em bloco a EMCALI) e Medellín respectivamente. 
Figura 2.10

Curva de Carga Diária Típica do Sistema Elétrico Colombiano (1)

MW

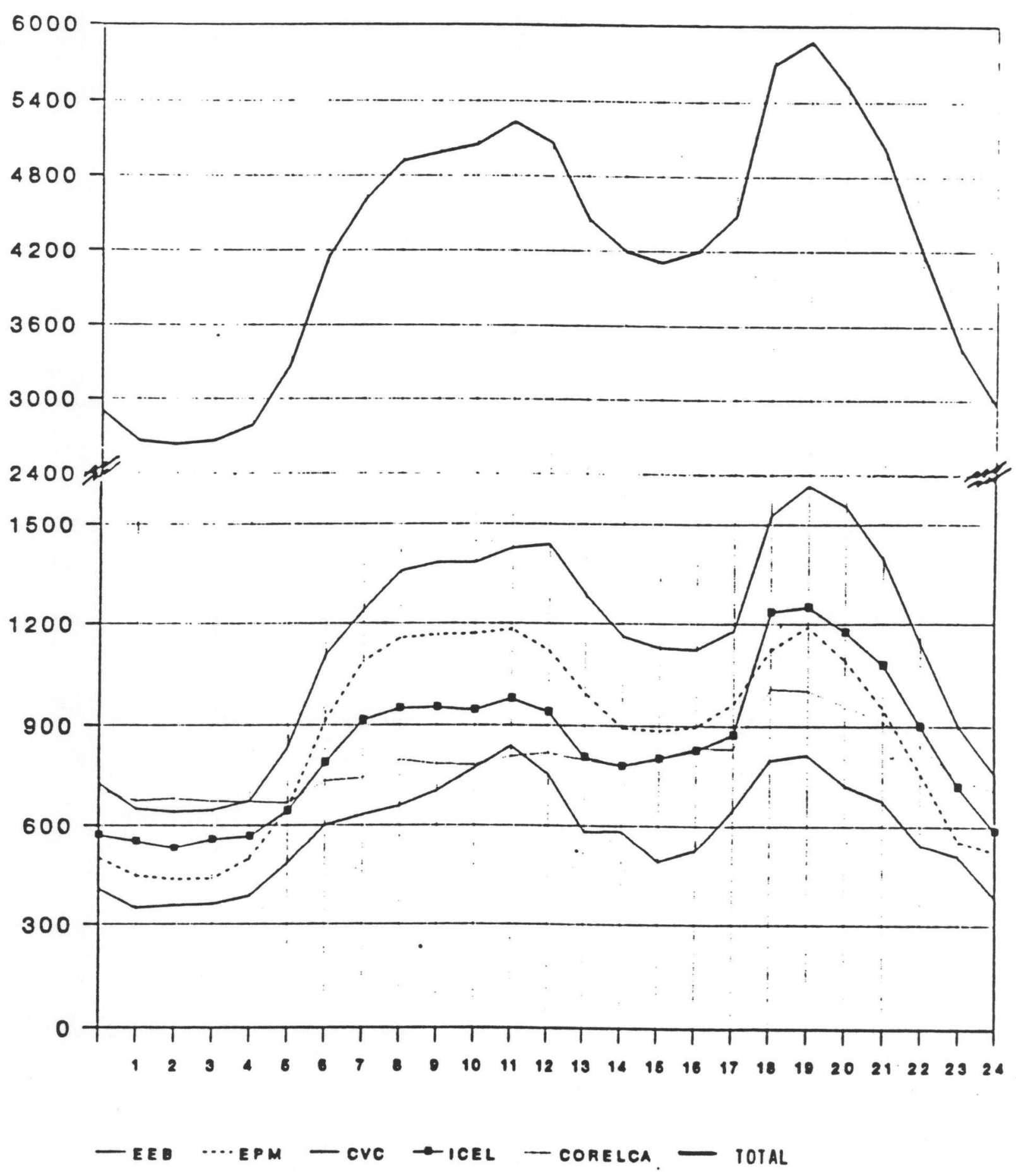

(1) Curva correspondente ao dia 20 de novembro (quarta-feira) de 1991.

Fonte: ISA. 1993a. 
O estudo levado a cabo pela CVC, EMCALI e UV mostra que os picos de consumo de energia elétrica para cocção acontecem às 6:00 horas (café da manhã), 11:00 horas (almoço) e 19:00 horas (jantar). Portanto, o fator de coincidência do uso final cocção é unitário, isto é, a sua responsabilidade no pico da demanda é igual à razão entre a demanda pico em cocção e a demanda máxima do sistema.

As curvas de carga para cocção elétrica encontradas no estudo da CVC, EMCALI e UV são ilustradas nas Figuras 2.11 a 2.16. Os valores mostrados são em função do número de usuários que, para uma hora em particular teriam ligados seus fogões. Em Santiago de Cali o pico máximo absoluto de demanda que acontece às 11:00 horas é por causa da altíssima concentração do uso da eletricidade para cocção (almoço). As análises realizadas neste estudo concluem que este fenômeno "tem resposta na estrutura espacial compacta da cidade, onde os tempos de viagem trabalho-lar não superam os 30 minutos em média e tornam difícil pensar em uma alternativa diferente na hora de decidir onde almoçar".

A existência da "jornada continua" 21 em vários lugares de trabalho para cidades como Medellín e Santafé de Bogotá e os problemas de congestionamento do tráfego, explicariam o fato da inexistência desse fenômeno nessas cidades.

As potências efetivas por usuário dependem do tipo de refeição e do estrato. A Tabela 2.28 mostra os resultados encontrados para a cidade de Santiago de Cali.

21 Chamada assim porque os intervalos de tempo que se usam para o almoço não superam uma hora. 
Figura 2.11

Curva de Distribuição Percentual Diária de Usuários da Cocção Elétrica em Santiago de Cali para o Estrato Sócio-Econômico 1.

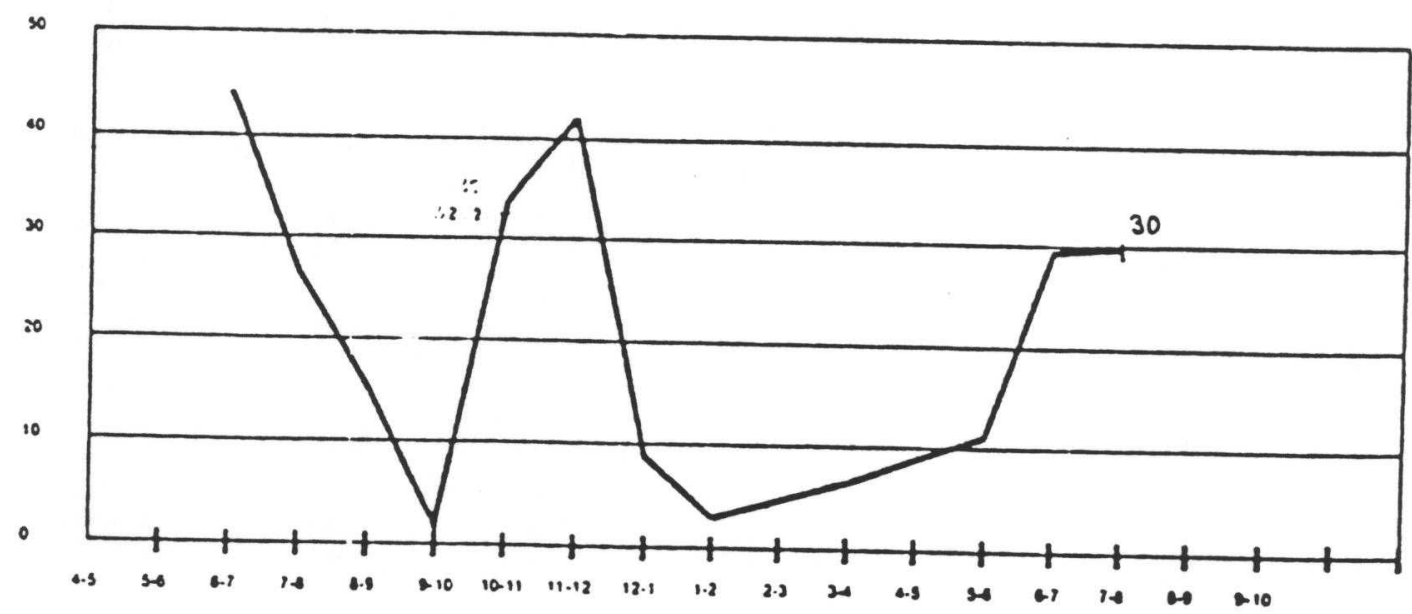

Fonte: CVC; EMCALI; UV, 1993

Figura 2.12

Curva de Distribuição Percentual Diária de Usuários da Cocção Elétrica em Santiago de Cali para o Estrato Sócio-Econômico 2.

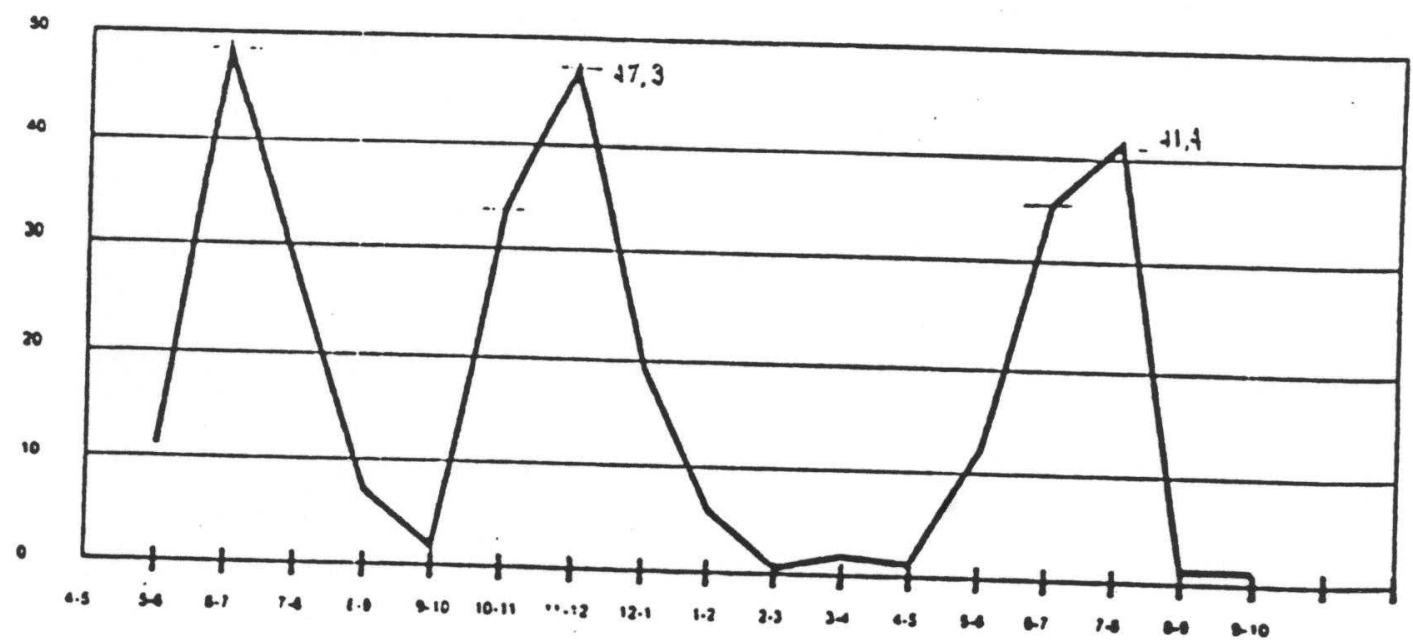

Fonte: CVC; EMCALI; UV, 1993 
Figura 2.13

Curva de Distribuição Percentual Diária de Usuários da Cocção Elétrica em Santiago de Cali para o Estrato Sócio-Econômico 3.

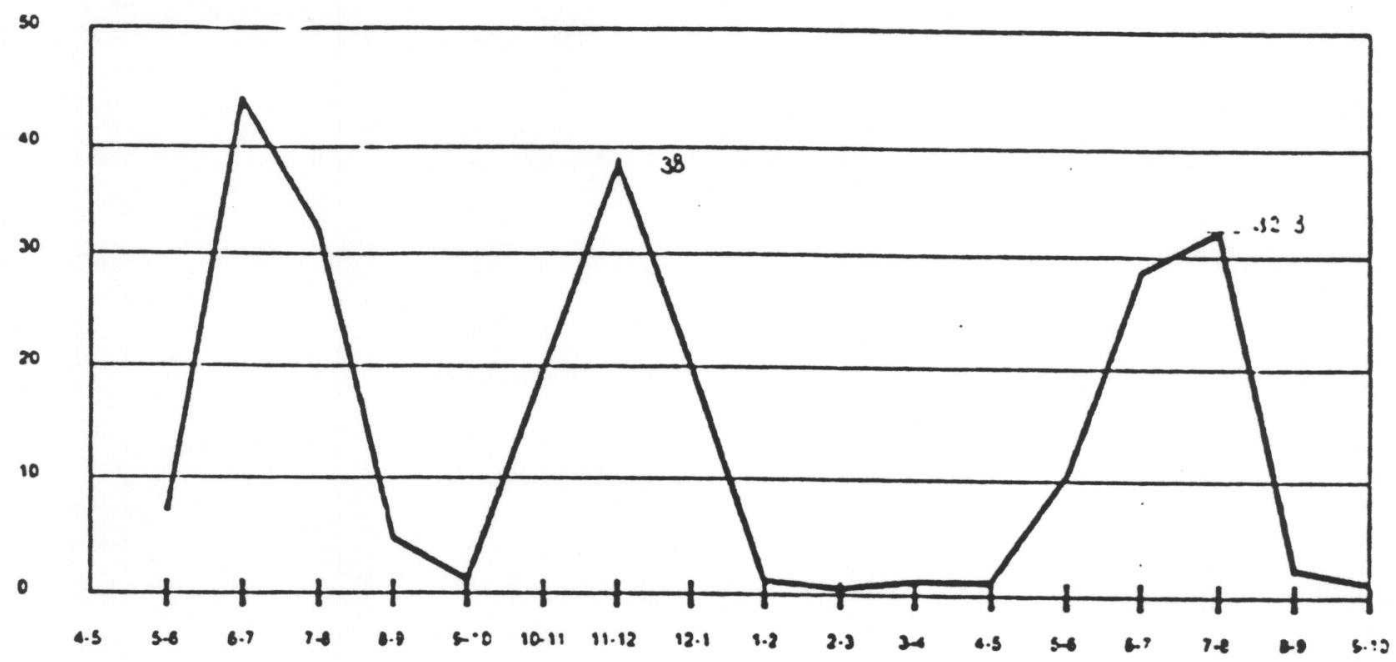

Fonte: CVC; EMCALI; UV, 1993

Figura 2.14

Curva de Distribuição Percentual Diária de Usuários da Cocção Elétrica em Santiago de Cali para o Estrato Sócio-Económico 4.

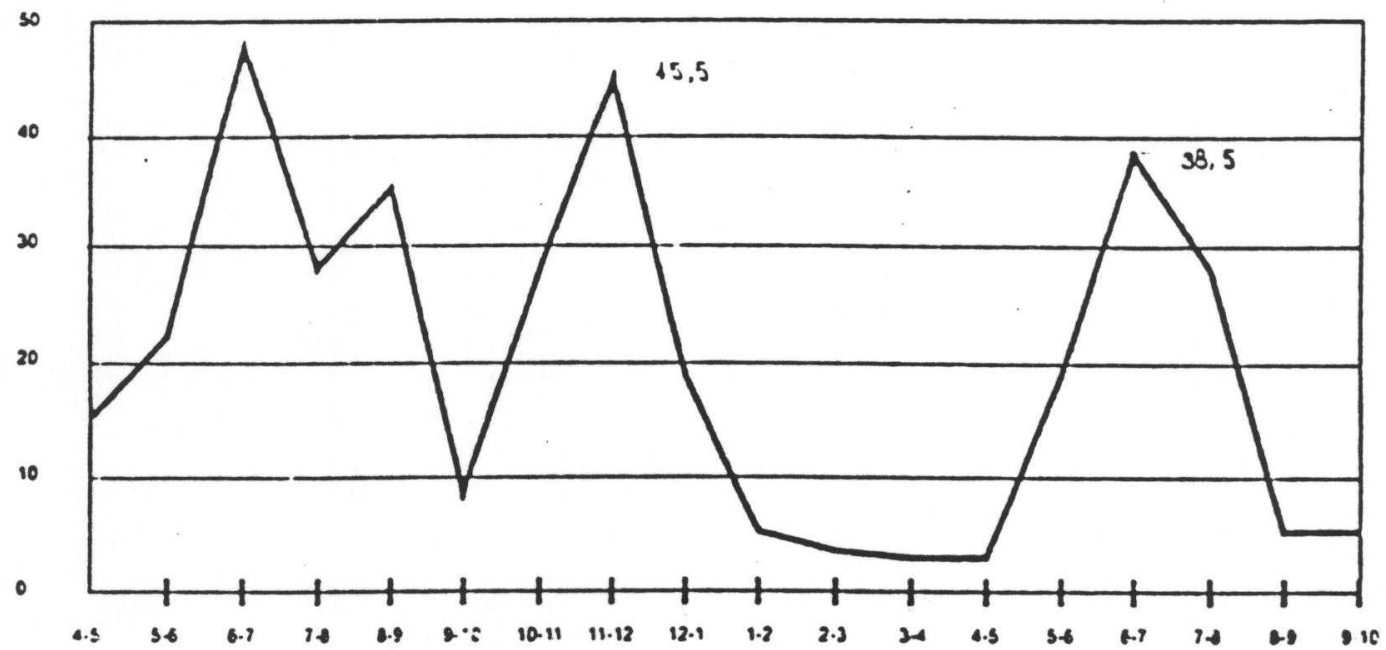

Fonte: CVC; EMCALI; UV, 1993 
Figura 2.15

Curva de Distribuição Percentual Diária de Usuários da Cocção Elétrica em Santiago de Cali para o Estrato Sócio-Econâmico 5.

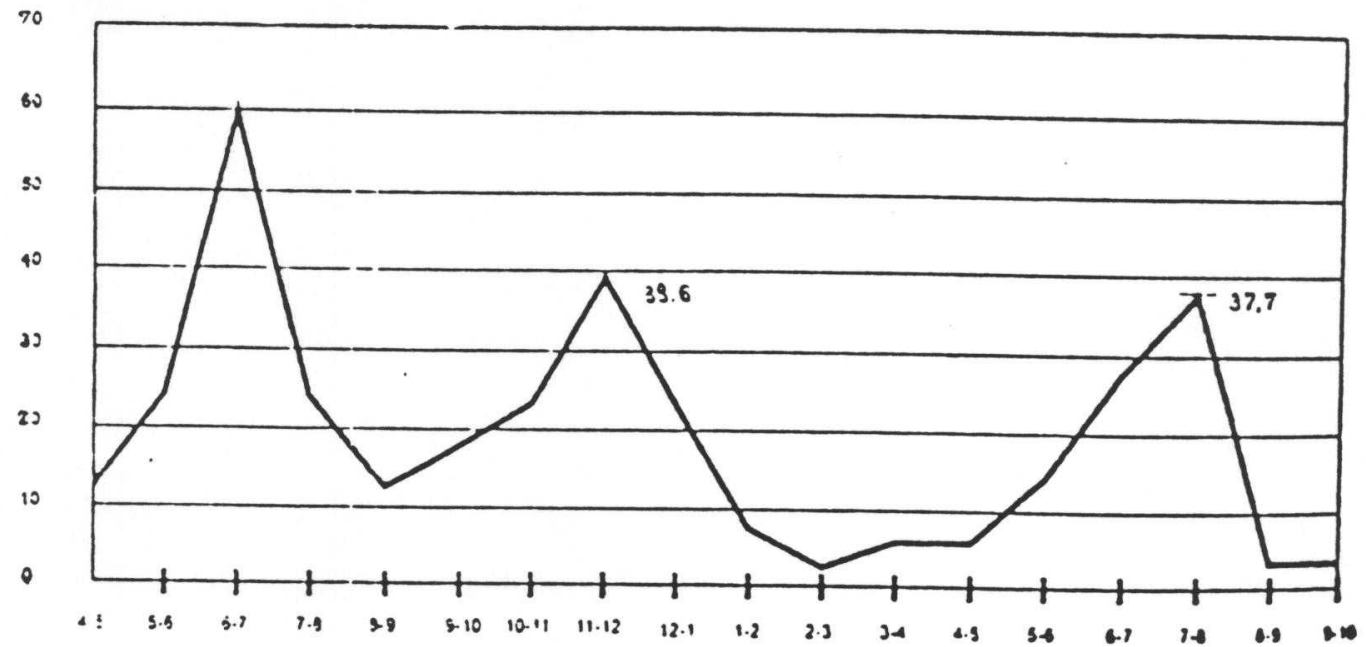

Fonte: CVC; EMCALI; UV, 1993

Figura 2.16

Curva de Distribuição Percentual Diária de Usuários da Cocção Elétrica em Santiago de Cali para o Estrato Sócio-Económico 6.

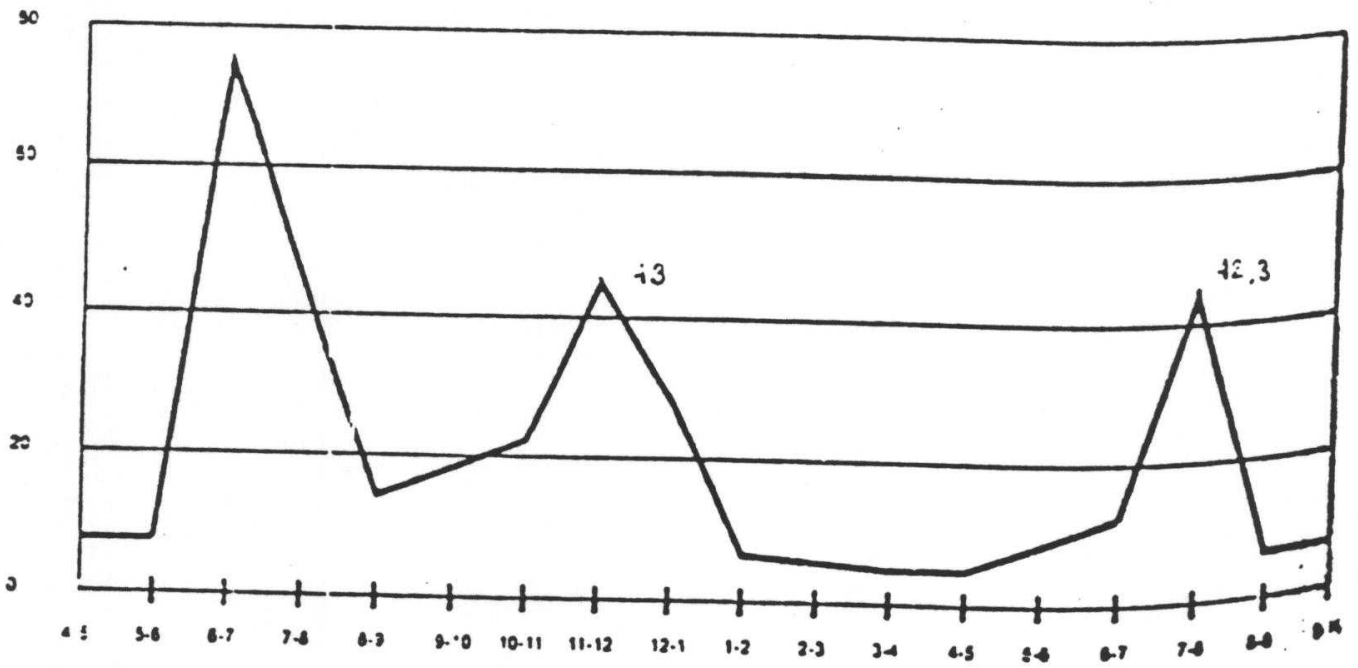

Fonte: CVC; EMCALI; UV, 1993 
Tabela 2.28

Potências Efetivas Instaladas para o Atendimento da Cocção Elétrica por Usuário em Santiago de Cali

(kW)

\begin{tabular}{|l|c|c|c|c|c|c|}
\hline \multirow{2}{*}{ REFEIÇÃO } & \multicolumn{7}{|c|}{ ESTRATO } \\
\cline { 2 - 7 } & 1 & 2 & 3 & 4 & 5 & 6 \\
\hline Café da manhã & 1.04 & 0.70 & 0.79 & 0.96 & 0.97 & 1.38 \\
Almoço & 1.23 & 0.93 & 1.10 & 1.21 & 1.22 & 1.67 \\
Jantar & 1.02 & 0.71 & 0.76 & 1.01 & 1.07 & 1.67 \\
\hline
\end{tabular}

Fonte: CVC; EMCALI; UV, 1993

Com base nas curvas de carga das Figuras 2.11 a 2.16 e na Tabela 2.28, pode-se determinar, então, a potência máxima diversificada, com relação às pontas do sistema nacional, utilizada para cocção por um usuário médio de cada um dos diferentes estratos. Os resultados são mostrados na Tabela 2.29 abaixo.

Tabela 2.29

Potências Máximas Diversificadas para Cocção Elétrica por Usuário Médio em Santiago de Cali (kW)

\begin{tabular}{|c|c|c|c|c|c|c|}
\hline PONTA DO & \multicolumn{7}{|c|}{ ESTRATO } \\
\cline { 2 - 7 } SISTEMA & 1 & 2 & 3 & 4 & 5 & 6 \\
\hline $11: 00$ & 0.50 & 0.44 & 0.42 & 0.55 & 0.47 & 0.72 \\
$19: 00$ & 0.30 & 0.29 & 0.24 & 0.39 & 0.40 & 0.71 \\
\hline
\end{tabular}

Fonte: Cálculos do autor com base em dados de CVC; EMCALI; UV, 1993

\section{Zona Rural}

A estrutura de consumo de energéticos para o setor rural em 1992, identificou a lenha como a sua principal fonte de energia, responsável por $89,1 \%$ das necessidades energéticas do setor residencial das áreas rurais do país. $\mathrm{A}$ eletricidade, entretanto, foi a segunda fonte em importância participando com $3,2 \%$. das $35.213,5$ Tcal totais consumidas (Figura 2.17 ).

A porcentagem da população colombiana que mora na zona rural, segundo os resultados do Censo de população de 1993 , é de $26,2 \%$, mas consome $63 \%$ 
de toda a energia utilizada para fins residenciais no pais. Essa situação devese ao fato da ampla utilização da lenha, destinada para o uso final cocção sob condições de eficiência muito baixas.

Caso se considere apenas os energéticos comerciais, o consumo energético residencial da Colômbia em 1992 seria de 20.920 Tcal, 84,7\% localizado na zona urbana e $15,3 \%$ na zona rural.

Figura 2.17

Participação Energética no Setor Residencial Rural Colombiano 1992

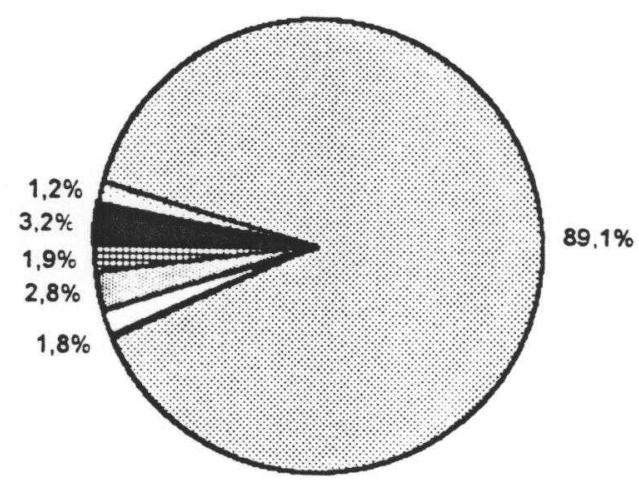

- Eletricidade D GLP ه Lenha 口 Carvão lenha प GN - Canão min - Querosene 日 Gasolinas

Fonte: NULE, G. Memorias al Congreso Nacional 1992-1993. MME.

Um estudo detalhado sobre os tipos de energéticos utilizados para cocção na zona rural da Colômbia elaborado para o Sistema de Informação Energética (SIE) do MME em 199022 encontrou os seguintes resultados:

- A lenha é o combustível de uso único em veredas da maioria dos Departamentos onde não existe carvão mineral. 22 SIE. Usos y Consumos de Energía en los Sectores Residencial Rural, Comércio e Industria. Santafé
de Bogotá, 1990. 
- Em regiões de cafeicultura, porém, a eletricidade tem um uso muito significativo.

- Nas zonas carboníferas, o uso de carvão mineral diminuiu, sendo substituído por lenha, eletricidade ou derivados do petróleo. A razão, encontra-se no fato da dificuldade de ignição desse mineral comparado com os outros energéticos.

- Nas zonas centrais das pequenas cidades, existe maior variedade de combustiveis. O uso de GLP vem aumentando notavelmente nos lugares onde há acesso a esse energético.

\subsubsection{Perdas de Energia Elétrica}

As perdas de energia elétrica na Colômbia são, desde há vários anos, um problema bastante complicado devido à magnitude e ao aumento destas ao longo dos anos. Já, desde inícios dos 80 , começaram a se desenhar medidas de controle das perdas de eletricidade a partir de estudos específicos ou de estimativas direta 23. Contudo, só em 1985, com o financiamento do Banco Interamericano de Desenvolvimento (BID) foi definido um programa prioritário de redução de perdas, inicialmente sob coordenação de ISA.

Nos estudos que foram realizados, foi identificado que as áreas de distribuição apresentavam a maior parte das perdas elétricas e observou-se a falta de planejamento para a expansão desses sistemas (OLADE, 1990). Até hoje, ainda persiste esse problema, porém, significativas reduções dos índices de

23 Os dois estudos mais importantes sobre perdas de energia desenvolvidos foram o "Estudio de Pérdidas de Energía en el Sector Eléctrico Colombiano" contratado por ISA e elaborado por SISTECOM Ltda. em 1981 e o "Plan Maestro de Distribución", também contratado pelo setor
elétrico e terminado em 1982. 
perdas foram obtidos durante os últimos anos. Aliás, o maior índice de perdas na Colômbia, 24,3\%, foi atingido em 1988.

Os índices de perdas de energia na Colômbia são calculados mensalmente, mas, para propósitos de análises e acompanhamento, os balanços são agregados em períodos de 12 meses (o que se denomina "ano corrido") e daí se determina o índice para o acúmulo anual. (ISA, 1994)

Em dezembro de 1992, o indice de perdas de energia elétrica (acúmulo anual) para o sistema elétrico colombiano foi de $19,8 \%$. Como a demanda de energia é definida como a somatória das vendas, o consumo próprio (auto-consumo em usinas, subestaçōes elétricas, etc.) e as perdas, então, a eletricidade que não foi vendida ou gasta pelo próprio setor foi de $24,7 \%$. Isto é, para cada $100 \mathrm{MWh}$ gerados, 24,7 MWh perderam-se em forma fisica (perdas técnicas) ou por deficiências no faturamento (perdas não-técnicas).

Caso forem tomadas apenas as vendas de eletricidade como base de comparação, as perdas em 1992 de 6.405 GWh, equivaleriam a 25,4\% das receitas operacionais do setor, pois as vendas ao consumidor final nesse ano foram de $25.209 \mathrm{GWh}$. Em outros termos, para cada 1.000 unidades de energia produzidas, só 746 são faturadas.

Todavia, 1992 foi um ano atípico para o setor elétrico devido ao racionamento de energia elétrica que começou em março daquele ano. As restrições de oferta de eletricidade, apresentadas com maior força no setor residencial, fizeram cair os índices de perdas durante aquele ano. Porém, após o retorno da normalidade (abril de 1993), os índices de perdas novamente têm mostrado uma tendência a aumentos (Figura 2.18). 0 índice de perdas para 0 ano corrido dez/92-nov/93 foi de $22,5 \%$. 
Figura 2.18

Evolução do İ́dice de Perdas do Sistema Elétrico Colombiano

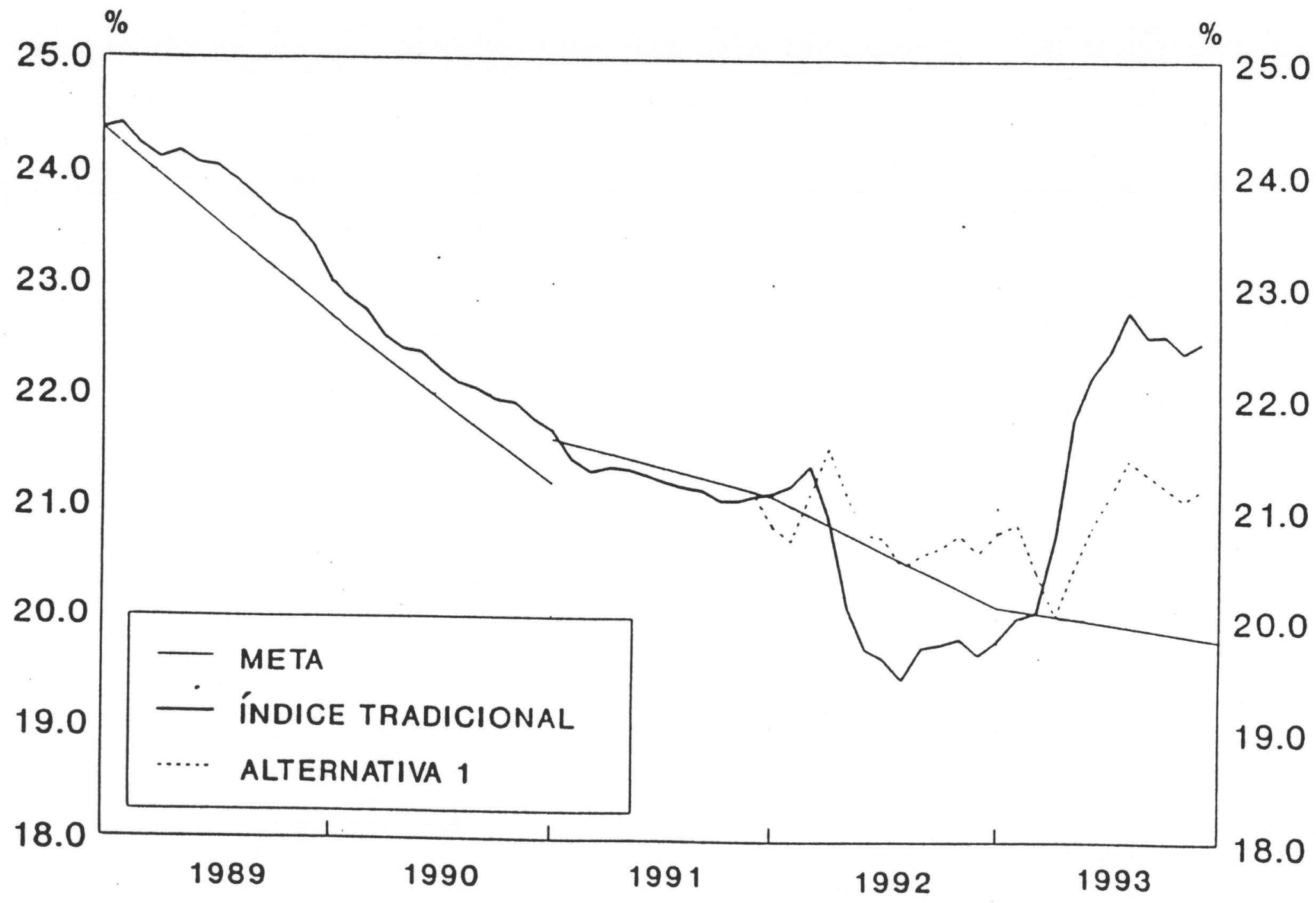

NOTA: A curva definida como "Alternativa l" é uma proposta de modificação da metodologia de cálculo do indice de perdas para o acumulado anual do sistema. Fonte: ISA. 1994. 
É importante diferenciar entre consumo e vendas de eletricidade. As vendas de eletricidade têm a ver com os montantes de faturamento que as concessionárias cobram de seus subscritores ${ }^{24}$ pelo uso da energia elétrica. 0 consumo, entretanto, é a quantidade de energia elétrica efetivamente gasta pelos usuários. O consumo sempre é maior ou igual às vendas, devido aos erros de medição e faturamento e roubos, ligações ilícitas etc.. A diferença entre o consumo efetivo e a energia faturada corresponde ao valor das perdas não técnicas.

O setor residencial por estar servido de energia elétrica ao nivel de distribuição, último escalão da cadeia elétrica, é responsável pelas perdas produzidas em transmissão e subtransmissão causadas pelo transporte da energia consumida em baixa tensão.

As perdas não técnicas estão localizadas basicamente no subsistema de distribuição. Avaliações das concessionárias realizadas no final dos anos 90 , determinaram que esse tipo de perdas está localizado principalmente no setor residencial 25. Por exemplo, a Empresa de Energia de Bogotá (EEB), estima que o setor residencial é responsável por $62 \%$ das perdas não técnicas no seu sistema; EEPPM as estima em 77\%; EMCALI em $70 \%$ e a Eletrificadora del Atlántico (ELECTRANTA) que atende o mercado de Barranquilla, em $74 \%$.

A Figura 2.19 mostra de modo desagregado a estimativa de perdas para as principais concessionárias da Colômbia.

24 Subscritores são aqueles usuários que assinaram um contrato legal com a concessionária de energia elétrica, gozando assim dos direitos e deveres fixados nas regulamentações.

25 A partir das avaliações entregues pelas concessionárias ao Comité de Perdas do Setor Elétrico Colombiano que é coordenado por ISA. 
Figura 2.19

Desagregação Estimada das Perdas de Energia Elétrica na Colômbia em 1992

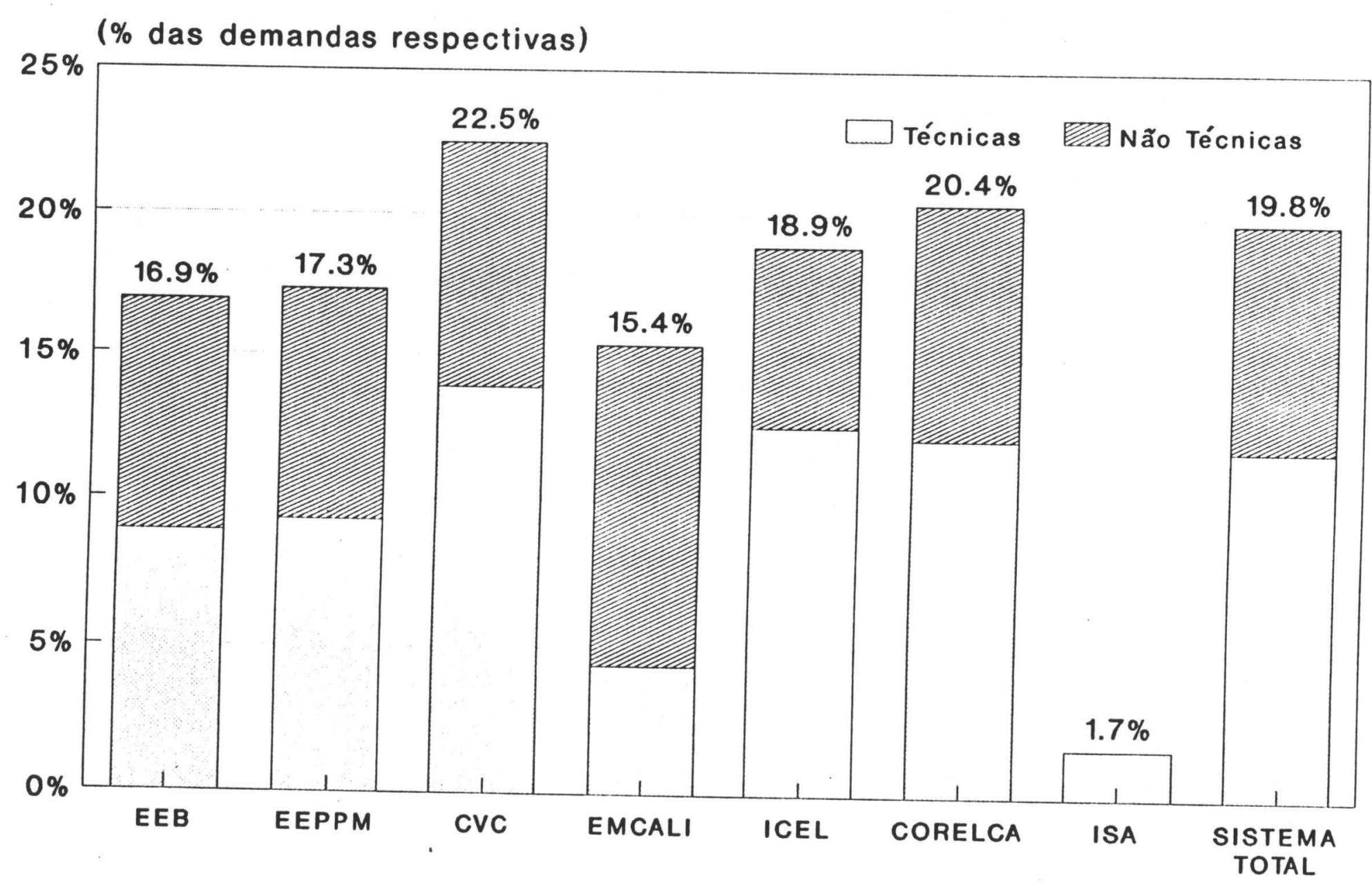

Fonte: ISA, 1993a 


\subsubsection{Tarifas de Energia Elétrica}

O sistema tarifário colombiano foi definido pela extinta Junta Nacional de Tarifas (JNT), organismo de ordem nacional dependente do Departamento Nacional de Planeación (DNP). A sua função era de definir e determinar a estrutura e os níveis tarifários dos serviços públicos (água, eletricidade, gás, telefones e saúde pública).

Com a criação da Comisión de Regulación Energética (CRE), a definição de tarifas para o setor energético passou a ser de competência desta nova entidade.

Para o caso de tarifas de eletricidade do setor residencial, a estrutura tarifária é caraterizada por três componentes: o nível de consumo, o nível sócioeconômico e a região à qual pertencem os usuários. Como foi explicado no item 2.2.2, o nível sócio-econômico dos usuários é determinado a partir de seis estratos (classes) denominados assim:

$\begin{array}{ll}\text { Estrato 1 } & \text { Baixo-baixo } \\ \text { Estrato 2 } & \text { Baixo } \\ \text { Estrato 3 } & \text { Médio-baixo } \\ \text { Estrato 4 } & \text { Médio } \\ \text { Estrato 5 } & \text { Médio-alto } \\ \text { Estrato 6 } & \text { Alto }\end{array}$

Para uma faixa de consumo determinada, o nivel tarifário é também diferenciado. Atualmente (1994), a estrutura tarifária define cinco faixas e um encargo fixo. As faixas são determinadas pelo consumo mensal em $\mathrm{kWh}$ :

Faixa 1

Faixa 2

0-200 kWh

Faixa 3 $201-400 \mathrm{kWh}$

Faixa 4 401-800 kWh

Faixa 5 801-1600 kWh mais de $1600 \mathrm{kWh}$

À guisa de exemplo, considere-se este caso: se o consumo de energia elétrica de um mês dado para um usuário do estrato "i" e da região "j" foi de 700 kWh, o valor que esse usuário deve pagar seria assim: 
Encargo fixo para o estrato i+ $200 \times$ nivel tarifário para a faixa de consumo 1 do estrato i da região $j+$ $200 \times$ nivel tarifário para a faixa de consumo 2 do estrato i da região $j+$ 300 x nivel tarifário para a faixa de consumo 3 do estrato $i$ da região $j$

Evidencia-se, então, que o sistema tarifário colombiano tem uma estrutura complexa, tratando de embutir critérios políticos e econômicos na sua definição. Políticos, porque intenta-se proteger os usuários de menores recursos evitando impôr niveis tarifários impopulares. Econômicos, porque considera as diferenças dos custos de fornecimento de eletricidade para os diversos usuários espalhados ao longo do território nacional e tem em conta o fato de custos crescentes à medida que a demanda se incrementa.

A Tabela 2.30 mostra os niveis tarifários vigentes em 31 de dezembro de 1993 para o setor residencial em algumas regiões do país. As regiōes estão definidas pela área de cobertura das diversas concessionárias que operam na Colômbia. Algumas delas, têm um mercado concentrado, atendendo as maiores cidades, outras têm um mercado mais disperso porque oferecem o serviço para um Departamento (divisão poítica da Colômbia) inteiro ou para vários deles.

Se comparados com os custos econômicos, os niveis tarifários para o setor residencial na Colômbia são inferiores. Esses subsídios são particularmente notórios nos estratos baixos e médios.

A Tabela 2.31 mostra os custos econômicos de referência de energia e potência a nivel de distribuição (tensões inferiores a $1 \mathrm{kV}$ ) por regiōes. Os custos de referência foram obtidos a partir do cálculo dos Custos Incrementais Médios de Longo Prazo (CIMLP) tanto para o sistema de geração e transmissão quanto de distribuição. Os CIMLP servem de aproximação para o Custo Marginal de Longo Prazo (CMLP). (ISA, 1986). 
TABELA 2.30

TARIFAS DE ENERGIA ELÉTRICA NA COLOMBIA (Cent US $\$ / \mathrm{kWh} / \mathrm{mês}$ ) VALORES EM CENTAVOS DE DÓLAR DE DEZEMBRO DE 1993 (1)

\begin{tabular}{|c|c|c|c|c|c|c|c|}
\hline \multirow[t]{2}{*}{ REGIẢO } & \multirow[t]{2}{*}{ ESTRATO } & \multirow[t]{2}{*}{ CARGO FIXO } & \multicolumn{5}{|c|}{ FAIXAS DE CONSUMO (kWh/mês) } \\
\hline & & & $0-200$ & $201-400$ & $401-800$ & $801-1600$ & $>1600$ \\
\hline \multirow{4}{*}{ Bogota } & $\begin{array}{l}1 \\
2\end{array}$ & $\begin{array}{l}22,11 \\
57,61\end{array}$ & $\begin{array}{l}1,24 \\
1,24\end{array}$ & $\begin{array}{l}3,79 \\
3,79\end{array}$ & $\begin{array}{l}8,34 \\
8,34\end{array}$ & $\begin{array}{l}12,52 \\
12,52\end{array}$ & $\begin{array}{l}17,65 \\
17,65\end{array}$ \\
\hline & $\begin{array}{l}3 \\
4\end{array}$ & $\begin{array}{l}151,41 \\
317,56\end{array}$ & 1,24 & 3,79 & 8,34 & 12,52 & 17,65 \\
\hline & 5 & $\begin{array}{l}317,56 \\
651,19\end{array}$ & 1,24 & 3,79 & 8,34 & 12,52 & 17,65 \\
\hline & 6 & $1.018,33$ & $\begin{array}{l}7,91 \\
2,86\end{array}$ & $\begin{array}{r}8,59 \\
859\end{array}$ & $\begin{array}{l}10,50 \\
10,50\end{array}$ & $\begin{array}{l}12,52 \\
12,50\end{array}$ & 17,65 \\
\hline \multirow[t]{5}{*}{ c/marca } & 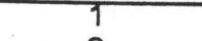 & 22,11 & 1,52 & 4,02 & $\frac{70,50}{7.06}$ & $\begin{array}{l}12.52 \\
11,93\end{array}$ & $\begin{array}{ll}17,65 \\
2,98\end{array}$ \\
\hline & 2 & 57,61 & 1,52 & 4,02 & 7,06 & 11,93 & 12,98 \\
\hline & $\begin{array}{l}3 \\
4\end{array}$ & 151,41 & 1,52 & 4,02 & 7,06 & 11,93 & 12,98 \\
\hline & $\begin{array}{l}4 \\
5\end{array}$ & 317,56 & 1,52 & 4,02 & 7,06 & 11,93 & 12,98 \\
\hline & $\begin{array}{l}5 \\
6\end{array}$ & 651,19| & 5,73 & 8,59 & 10,50 & 11,93 & 12,98 \\
\hline \multirow[t]{6}{*}{ Medelin } & $\frac{6}{1}$ & $1.018,33$ & 6,68 & 8,59 & 10,50 & 11,93 & 12,98 \\
\hline & $\begin{array}{l}1 \\
2\end{array}$ & 22,11 & 1,64 & 3,10 & 5,37 & 10,14 & 14,78 \\
\hline & 3 & 57,61 & 1,64 & 3,10 & 5,37 & 10,14 & 14,78 \\
\hline & 4 & $\begin{array}{l}151,41 \\
317,56\end{array}$ & 1,64 & 3,10 & 5,37 & 10,14 & 14,78 \\
\hline & 5 & 651,19 & 1,64 & 3,10 & 5,37 & 10,14 & 14,78 \\
\hline & 6 & $1.018,33$ & $\begin{array}{l}4,86 \\
5,68\end{array}$ & $\begin{array}{l}7,30 \\
7,30\end{array}$ & 8,11 & 10,14 & 14,78 \\
\hline \multirow{6}{*}{ Antioquia } & 7 & 22,19 & 1,64 & $\frac{7,30}{3,10}$ & 8,11 & 10,14 & 14,78 \\
\hline & 2 & 57,61 & 1.64 & $\begin{array}{l}3,10 \\
3,10\end{array}$ & 5,37 & 10,14 & 14,78 \\
\hline & 3 & 151,41 & 164 & $\begin{array}{l}3,10 \\
3,10\end{array}$ & 5,37 & 10,14 & 14,78 \\
\hline & 4 & 317,56 & 1,64 & $\begin{array}{l}3,70 \\
3,10\end{array}$ & 5,37 & 10,14 & 14,78 \\
\hline & 5 & 651,19 & 4.86 & 3,700 & 5,37 & 10,14 & 14,78 \\
\hline & 6 & $1.018,33$ & 5,68 & 7,30 & 8,11 & 10,14 & 14,78 \\
\hline \multirow[t]{6}{*}{ Caldas } & 9 & 22,17 & 1.97 & $\begin{array}{ll}7,30 \\
4,66\end{array}$ & 8,11 & 10,14 & 14,78 \\
\hline & 2 & 57,61 & 1,97 & $\begin{array}{l}4,66 \\
466\end{array}$ & 6,33 & 12,86 & 12,86 \\
\hline & 3 & 151,41 & 1,97 & $\begin{array}{l}4,00 \\
4,66\end{array}$ & 6,33 & 12,86 & 12,8 \\
\hline & 4 & 317,56 & 1.97 & $\begin{array}{l}4,00 \\
4,66\end{array}$ & 6,33 & 12,86 & 12 \\
\hline & 5 & 651,19 & 617 & $\begin{array}{l}4,66 \\
9266\end{array}$ & 6,33 & 12, & 12,86 \\
\hline & 6 & $1.018,33$ & 7.20 & $\begin{array}{l}9,26 \\
9,26\end{array}$ & 10,29 & 12,86 & 12,86 \\
\hline \multirow{6}{*}{ Call } & 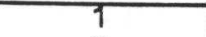 & 22,11 & 1,71 & $\frac{9,26}{6,26}$ & 10,29 & 12,86 & 12,86 \\
\hline & 2 & 57,61 & 171 & $\begin{array}{l}6,26 \\
626\end{array}$ & 8,90 & 10,46 & 14,78 \\
\hline & 3 & 151,41 & 171 & 6,26 & 8,9 & 10,46 & 14,78 \\
\hline & 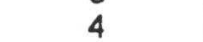 & 317,56 & 1 $1>1$ & 6,26 & 8,90 & 10,46 & 14,78 \\
\hline & 5 & 651,19 & $\begin{array}{l}7,7 \\
5,02\end{array}$ & 6,26 & 8,90 & 10,46 & 14,7 \\
\hline & 6 & $1.018,33$ & $\begin{array}{l}5,02 \\
5,85\end{array}$ & 75 & 9,20 & 10,46 & 14,78 \\
\hline \multirow[t]{6}{*}{ CVC } & 1 & 22,17 & $\begin{array}{l}3,85 \\
, 771\end{array}$ & $\begin{array}{ll}7,53 \\
526\end{array}$ & 9,20 & 10,46 & 14,78 \\
\hline & 2 & 57,61 & 1,71 & $\begin{array}{l}6,26 \\
626\end{array}$ & 8,90 & 10,46 & 14,78 \\
\hline & 3 & 151,41 & 1,71 & $\begin{array}{l}0,20 \\
6,26\end{array}$ & 8,90 & 10,46 & 14,78 \\
\hline & 4 & 317,56 & 1,71 & 6,26 & $\begin{array}{l}8,90 \\
890\end{array}$ & 10,46 & 14,78 \\
\hline & 5 & 651,19 & 5.02 & 753 & 8,90 & 10,46 & 14,78 \\
\hline & 6 & $1.018,33$ & 586 & 753 & 8,90 & 10,46 & 14,78 \\
\hline \multirow{6}{*}{ B/quilla } & 1 & 22,11 & & $\frac{7,03}{576}$ & 8,90 & 10,46 & 14,78 \\
\hline & 2 & 57,61 & 210 & $\begin{array}{l}5,10 \\
5,76\end{array}$ & 9,75 & 12,03 & 13,13 \\
\hline & 3 & 151,41 & 2,10 & 5,16 & 9,7 & 12, & 13,13 \\
\hline & 4 & 317,56 & 2,10 & $\begin{array}{l}5,76 \\
576\end{array}$ & 9,75 & 12,03 & 13,13 \\
\hline & 5 & 651,19 & 5,77 & $\begin{array}{l}5,10 \\
866\end{array}$ & 9,75 & 12,03 & 13,13 \\
\hline & 6 & $1.018,33$ & 6.73 & $\begin{array}{l}8,66 \\
8,66\end{array}$ & $\begin{array}{l}10,58 \\
10,58\end{array}$ & 12,03 & 13,13 \\
\hline
\end{tabular}

(1)

As unidades originais, em pesos colombianos, foram deflacionadas a $2,23 \%$ /mês entre jun/91 e set/93 e a $2 \%$ /mês para os meses restantes. A taxa representativa de câmbio em 31-12-93 era Col\$ 802.71/US\$

Fonte: $\quad$ Cálculos do autor com base em dados da JNT de junho de 1991. 
TABELA 2.31

CUSTOS DE REFERÊNCIA PARA USUÁRIOS A NIVEL DE DISTRIBUIÇÃO SECUNDÁRIA (< 1 kV)

(cent US $\$$ de dezembro de 1993) (1)

\begin{tabular}{|l|c|c|c|}
\hline \multirow{2}{*}{ REGIÃO } & \multicolumn{3}{|c|}{ CUSTOS } \\
\cline { 2 - 4 } & $\begin{array}{c}\text { ENERGIA } \\
\text { (Cent US\$/kWh) }\end{array}$ & $\begin{array}{c}\text { POTENCIA } \\
\text { (Cent US\$/kW-ano) }\end{array}$ & $\begin{array}{c}\text { EQUIVALENTE } \\
\text { (Cent US\$/kWh) }\end{array}$ \\
\hline Medellín & 4,23 & $20.871,28$ & 7,95 \\
Antioquia & 4,57 & $23.658,26$ & 9,03 \\
Caldas & 4,57 & $23.658,26$ & 9,80 \\
Cali & 4,56 & $23.658,26$ & 8,57 \\
CVC & 4,49 & $23.658,26$ & 8,67 \\
Bogotá & 4,73 & $23.658,26$ & 8,65 \\
C/marca & 4,57 & $23.658,26$ & 9,56 \\
Atlántico & 4,52 & $22.642,67$ & 8,13 \\
\hline NACIONAL & 4,55 & $22.809,33$ & 8,70 \\
\hline
\end{tabular}

(1) As unidades originais, em pesos colombianos (Col\$) de junho de 1993, foram deflacionadas segundo o indice de custos do setor elétrico em $1993(20,8 \%)$. A taxa representativa de câmbio em 31-12-93 era Col\$ 802.71/US\$

Fonte: Cálculos do autor com base em dados da CRE, 1993. 
O sistema tarifário que se deseja implantar na Colômbia é uma tarifa baseada nos custos marginais ou tarifa integrada. Nesta modalidade, tanto o nivel como a estrutura das tarifas são estabelecidas guardando a maior coerência possivel com os custos marginais. Além disso, leva em consideração outros princípios básicos de tarifação (eficiência, eqüidade, justiça social, equilibrio financeiro, simplicidade e estabilidade) e os objetivos atribuidos ao setor elétrico (BITU; BORN, 1994). Neste sistema, a tarifa de referência é a base para a definição da estrutura tarifária.

Para se conseguir o principio de equilíbrio financeiro, as tarifas devem gerar receitas capazes de cobrir os custos, permitir uma rentabilidade razoável para o capital investido e garantir a expansão do sistema elétrico. Atualmente, esse princípio não se dá na Colômbia e é talvez o problema mais sério do sistema elétrico.

A Resolução 090 de 1990 da JNT definiu metas de niveis tarifários que deveriam ser atingidas pelas concessionárias mediante um plano de ajuste gradual. A Resolução 070 de 1993 do mesmo organismo, fez uma atualização e eliminou uma faixa de consumo da estrutura tarifária. Os apectos mais importantes dessas resoluções são os seguintes:

Definições:

- Consumo de Subsistência: até $200 \mathrm{kWh} / \mathrm{mês}$

- Consumo básico: a diferença entre $800 \mathrm{kWh} / \mathrm{mês}$ e o consumo de subsistência

- Consumo Intermédio: entre 801 e 1600 kWh/mês

- Consumo superior: mais de $1600 \mathrm{kWh} / \mathrm{mês}$

As metas percentuais do custo de referência são 


$\begin{array}{lcccc}\text { ESTRATO } & \begin{array}{c}\text { CONSUMO DE } \\ \text { SUBSISTÉNCIA }\end{array} & \begin{array}{c}\text { CONSUMO } \\ \text { BÁSICO }\end{array} & \begin{array}{c}\text { CONSUMO } \\ \text { INTERMÉDIO }\end{array} & \begin{array}{c}\text { CONSUMO } \\ \text { SUPERIOR }\end{array} \\ \text { Baixo-baixo } & 35 \% & 100 \% & 120 \% & 140 \% \\ \text { Baixo } & 50 \% & 100 \% & 120 \% & 140 \% \\ \text { Médio-baixo } & 80 \% & 100 \% & 120 \% & 140 \% \\ \text { Médio } & 80 \% & 100 \% & 120 \% & 140 \% \\ \text { Médio-alto } & 90 \% & 100 \% & 120 \% & 140 \% \\ \text { Alto } & 90 \% & 100 \% & 120 \% & 140 \%\end{array}$

O sistema de tarifação integrado, portanto, deverá desmontar os subsidios para as faixas mais elevadas de consumo e simplificará a estrutura atual, eliminando a faixa de consumo 401-800 kWh/mês. Na Resolução 090 de 1990 ainda era considerado um subsidio para a faixa de $201-400 \mathrm{kWh} / \mathrm{mês}$. A subdivisão por estratos sócio-econômicos vai-se manter por considerar-se que é uma forma prática de favorecer os usuários de baixos recursos econômicos.

Uma comparação entre o nivel tarifário em dezembro de 1993 e os custos de referência é apresentada na Tabela 2.32. Para se calcular os valores das tarifas médias por kWh, utilizaram-se os dados das Tabelas 2.22 a 2.25 que mostram os consumos médios por estrato para as quatro principais cidades da Colômbia.

Os resultados mostram que as tarifas que o grosso da população está pagando, correspondentes aos usuários de menores recursos (estratos 1 a 4), estão bastante distanciadas do valor real de fornecimento da eletricidade. Só os estratos 5 e 6 têm tarifas médias acordes com o custo da eletricidade, como conseqüência de uma atualização feita para esses estratos há alguns anos. 
TABELA 2.32

COMPARAÇÃO PERCENTUAL ENTRE AS TARIFAS RESIDENCIAIS DE ELETRICIDADE E OS CUSTOS ECONÔMICOS DE REFERÊNCIA PARA A COLÔMBIA

(Valores em dólares de dezembro de 1993)

\begin{tabular}{|c|c|c|c|c|c|}
\hline REGIÁO & ESTRATO & $\begin{array}{c}\text { CONSUMO MÉDIO } \\
\text { (kWh/mês) }\end{array}$ & $\begin{array}{c}\text { CUSTO CONSUMO } \\
\text { (US\$/mês) }\end{array}$ & $\begin{array}{l}\text { TARIFA MEDIA } \\
\text { (Cent US\$/kWh) } \\
\end{array}$ & $\begin{array}{l}\text { TARIFA MEDIA / } \\
\text { CUSTO REFER. }\end{array}$ \\
\hline \multirow[t]{6}{*}{ Bogotá } & 1 & \begin{tabular}{|l|}
196,0 \\
\end{tabular} & 2,6 & 1,35 & $15,6 \%$ \\
\hline & 2 & 239,0 & 4,5 & 1,89 & $21,9 \%$ \\
\hline & 3 & 284,0 & 7.2 & 2,53 & $29.2 \%$ \\
\hline & 4 & 347,0 & 11,2 & 3,23 & $37.4 \%$ \\
\hline & 5 & 456,0 & 33,4 & 7,32 & $84,6 \%$ \\
\hline & 6 & 613,0 & 55,5 & 9,05 & $104,6 \%$ \\
\hline \multirow{6}{*}{ Medellin } & 1 & 255,0 & 5,2 & 2,04 & $25,7 \%$ \\
\hline & 2 & 293,0 & 6,7 & 2,30 & $29,0 \%$ \\
\hline & 3 & 363,0 & 9,9 & 2,72 & $34,2 \%$ \\
\hline & 4 & 392,0 & 12,4 & 3,17 & $39,9 \%$ \\
\hline & 5 & 483,0 & 37,6 & 7,78 & $97,9 \%$ \\
\hline & 6 & 713,0 & 61,5 & 8,63 & $108,6 \%$ \\
\hline \multirow[t]{6}{*}{ Cali } & 1 & 217,1 & 4,7 & 2,17 & $25,4 \%$ \\
\hline & 2 & 298,9 & 10,2 & 3,41 & $39,8 \%$ \\
\hline & 3 & 285,6 & 10,3 & 3,61 & $42,1 \%$ \\
\hline & 4 & 301,7 & 13,0 & 4,30 & $50,2 \%$ \\
\hline & 5 & 379,1 & 30,0 & 7.92 & $92,5 \%$ \\
\hline & 6 & 705,8 & 65,1 & 9,22 & $107,6 \%$ \\
\hline \multirow[t]{6}{*}{ Barranquilla } & 1 & 111,1 & 2,6 & 2,30 & $28,3 \%$ \\
\hline & 2 & 173,4 & 4,2 & 2,43 & $29,9 \%$ \\
\hline & 3 & 240,9 & 8.1 & 3,35 & $41,2 \%$ \\
\hline & 4 & 312,2 & 13,8 & 4,43 & $54,5 \%$ \\
\hline & 5 & 361,9 & 32,1 & 8,86 & $109,0 \%$ \\
\hline & 6 & 584,8 & 60,5 & 10,35 & $127,3 \%$ \\
\hline
\end{tabular}

Fonte: Cálculos do autor com base nos dados das Tabelas 2.22 a 2.25 e as Tabelas 2.30 e 2.31 


\subsection{Custos para a Sociedade}

Manter uma estrutura de consumo de energia elétrica como a apresentada nos itens anteriores pressupõe custos que a sociedade como um todo, e de uma maneira ou outra, deve pagar.

A seguir, será realizada uma análise com relação aos custos decorrentes da utilização de eletricidade para cocção. Esses custos vao ser analisados sob três aspectos: (1) $O$ energético. A idéia é determinar o que significa a cocção elétrica na estrutura energética não apenas para o país como um todo mas também para o consumidor individual. (2) 0 econômico. Basicamente aqui o objetivo é determinar a importância dos recursos monetários utilizados para estas finalidades tanto para a sociedade, como um todo, quanto para os agentes econômicos participantes. (3) $O$ social. A distribuição dos custos entre os diversos agentes da sociedade não é homogênea. A intenção é discutir a nivel qualitativo e quantitativo esse fato.

\subsubsection{Custo Energético}

No item 2.2 foi apresentada a situação atual relacionada com o uso final cocção residencial. Mostrou-se que na zona urbana do país, onde mora mais de $70 \%$ da população da Colômbia, a eletricidade atende $44 \%$ das necessidades energéticas do setor residencial.

Dessa eletricidade, segundo as estimativas apresentadas no balanço energético de 1992, preparado pelo Sistema de Informação Energética (SIE) do $\mathrm{MME}, 33 \%$ é destinada para fins de cocção. Em termos absolutos, são $3.514 \mathrm{GWh}$ que, somados às perdas técnicas até distribuição, estimadas em $60,1 \%$ das perdas totais, que para esse ano foram de $19,8 \%$ da demanda, fizeram que a quantidade de energia elétrica gerada para atender esse uso final na zona urbana fosse de 4.043,2 GWh. 
Essa cifra tem sentido se comparada com outras quantidades. Com relação à produção total de energia, isto equivale a $11,2 \%$, ou seja, $40,4 \%$ da geração termoelétrica do país. Além disso, essa energia teria sido suficiente para absorver $78 \%$ da estimativa de energia racionada nesse ano na Colômbia.

Esses números são ainda mais acentuadas em cidades como Medellín, Santiago de Cali e Santafé de Bogotá, onde a participação da cocção no consumo de eletricidade residencial é de $49 \%, 41 \%$ e $30 \%$ respectivamente (Tabelas 2.18 a 2.20).

Há um aspecto que é importante colocar. A potência máxima é o parâmetro que determina fundamentalmente o dimensionamento da infraestrutura elétrica em toda a sua cadeia (Geração-Transmissão-Distribuição).

Para o sub-sistema de geração, a capacidade instalada é superior à demanda máxima do sistema, devido à margem de reserva que todo o sub-sistema de geração deve ter para dar um adequado nível de confiabilidade de fornecimento. No caso de sistemas predominantemente hidraúlicos, como é o caso da Colômbia ( $80 \%$ do total instalado), a disponibilidade de potência das usinas, além de depender da capacidade dos geradores, depende também das condições hidrológicas, pois a capacidade de produção de potência de uma unidade é proporcional à queda disponivel elevada à potência 1,5 (BITU; BORN, 1994). Isso faz com que o sistema elétrico seja mais suscetível a riscos de déficit de potência.

As características de linhas de transmissão são definidas segundo os volumes de potência a transportar. Niveis de tensão, tipo de cabo, números de circuítos, necessidades de compensação reativa, etc., são diretamente influenciados por essa variável. Altos fatores de capacidade (a razão entre a potência média e a potência máxima) das linhas favorecem enormemente a sua economicidade, ainda mais agora em que o serviço de transmissão na 
Colômbia é visto como um negócio, no qual os usuários da rede deverão pagar um pedágio pela utilização da mesma.

Para o caso dos sistemas de distribuição, o dimensionamento do equipamento utilizado depende diretamente da magnitude da potência máxima, e é precisamente esse valor que deve ser avaliado no processo de planejamento deste subsistema elétrico (ISA, 1992a). Deve-se ter em conta que pelas características espaciais do sub-sistema de distribuição, é típico achar alimentadores primários atendendo uma única categoria de usuários, como os residenciais. Neste caso, é a demanda máxima do setor residencial que determina as especificações técnicas do alimentador e os transformadores de distribuição.

A contribuição da cocção para a ponta do sistema elétrico é alta, segundo resultado encontrado em Santiago de Cali (CVC; EMCALI; UV, 1993), porém, avaliações detalhadas sobre esta questão não existem na Colômbia.

Enfatiza-se aqui que o ônus para o sistema elétrico decorrente da utilização de eletricidade para cocção não deve ser visto apenas sob o ângulo da demanda de energia mas também da demanda de potência, especialmente para o subsistema de distribuição das concessionárias de energia elétrica das cidades onde é bastante notória a presença desse fenômeno de consumo. Os custos marginais de potência poderiam ser bem menores caso não houvesse o consumo de energia elétrica para cocção que aparece nas horas onde é mais caro o fornecimento de eletricidade, isto é, nos períodos de ponta.

É interessante trazer à tona o caso de Costa Rica. Estudos recentes nesse país (OLADE;CCE, 1993), mostram que a estrutura de consumo de energia elétrica é bem similar com a da Colômbia. Na Tabela 2.33 é feita uma comparação dos dois sistemas. 
A grande incidência do setor residencial no sistema elétrico desses paises, como conseqüência do extensivo uso da eletricidade para cocção, mostra como a modulação das suas curvas de carga são determinadas por este setor de consumo.

Os trabalhos de caracterização da carga por usos finais na Costa Rica, determinaram que a cocção elétrica era responsável por $20 \%$ da potência de ponta (das 10:00-12:00 horas) e por 12\% para a ponta das 17:30-19:30 horas, devido ao fato que neste último período está presente também a iluminação.

Tabela 2.33

Paralelo entre as Estruturas dos Sistemas Elétricos da Colômbia e da Costa Rica. Valores para o Ano de 1992.

\begin{tabular}{|l|c|c|}
\hline \multicolumn{1}{|c|}{ CARACTERÍSTICA } & COLÔMBIA & COSTA RICA \\
\hline Participação no consumo de energia & & \\
elétrica total dos setores: & $46,4 \%$ & $45,4 \%$ \\
- Residencial & $31,9 \%$ & $30,0 \%$ \\
- Industrial & $9,6 \%$ & $19,7 \%$ \\
- Comercial & & \\
Participação da cocção elétrica no & $33,0 \%$ & $30,0 \%$ \\
consumo residencial de en. elét. & $9: 00-12: 00$ e & $10: 00-12: 00$ e \\
Periodos de potência de ponta & $17: 30-20: 00$ & $17: 30-19: 30$. \\
& $60 \%$ & $61 \%$ \\
\hline
\end{tabular}

Fonte: ISA, 1993a; SIE, 1993; OLADE-CCE, 1993 e cálculos do autor.

Para a Colômbia, não existe ainda um estudo sobre a caracterização da curva de carga por usos finais. Porém, aproximações podem ser feitas a partir do valor do fator de carga (f.c.) para o uso final cocção.

O estudo da CNE (1992), em suas análises, estimou um f.c. de 50,5\% para o uso final "cocção". Entretanto, de acordo com os resultados das medições efetuadas para o estudo da CVC, EMCALI e a UV (1993), pode-se calcular um f.c. médio de $27,7 \%$ (Tabela 2.34). 
Tabela 2.34

Cálculo do Fator de Carga do Uso Final Cocção em Santiago de Cali

\begin{tabular}{|c|c|c|c|}
\hline ESTRATOS & $\begin{array}{c}\text { CONSUMO } \\
(\mathrm{kWh} / \mathrm{semana})\end{array}$ & $\begin{array}{c}\text { DEMANDA PICO } \\
(\mathrm{kW})\end{array}$ & $\begin{array}{c}\text { FATOR DE } \\
\text { CARGA }\end{array}$ \\
\hline 1 & 26,09 & 0,50 & $31,0 \%$ \\
2 & 17,94 & 0,44 & $24,3 \%$ \\
3 & 20,26 & 0,42 & $28,7 \%$ \\
4 & 28,49 & 0,55 & $30,8 \%$ \\
5 & 25,29 & 0,47 & $32,0 \%$ \\
6 & 30,14 & 0,72 & $24,9 \%$ \\
\hline MÉDIA & \multicolumn{3}{|l}{} \\
\hline
\end{tabular}

(1) Calculado usando como fatores de ponderação os dados da Tabela 2.12.

Fonte: Cálculos do autor com base nos dados da CVC;EMCALI; UV. 1993.

As cifras anteriores diferem muito entre si e as implicações por selecionar um ou outro valor, vão-se ver nos resultados dos cálculos da potência máxima demandada pela cocção, coincidente com a ponta do sistema. A partir dos $4.043,2 \mathrm{GWh}$ determinados anteriormente, a potência máxima coincidente devida à cocção elétrica seria de $914 \mathrm{MW}$ ou $1.666 \mathrm{MW}$ que correspondem a fatores de responsabilidade na ponta do sistema de $15 \%$ e $27 \%$, caso assumir um f.c. de $50,5 \%$ ou $27,7 \%$ respectivamente.

Para as três cidades com maior consumo absoluto de energia elétrica para cocção, a responsabilidade na ponta do sistema desse uso final, usando aqueles f.c., estaria entre $37 \%$ e $66 \%$ para Santafé de Bogotá, $60 \%$ e $95 \%$ para Medellín e entre 50\% e 92\% para Santiago de Cali. Nesta última cidade, a ponta máxima acontece às 11:00 horas e não às 19:00 horas como para os outros sistemas.

\subsubsection{Custo Econômico}

O fato de utilizar eletricidade para cocção no setor residencial tem custos que convenientemente repassados para os usuários não deveria produzir 
distorções na economia, pois o preço do energético ao mesmo nivel do seu custo real daria os sinais certos para os usuários usarem eficientemente esse recurso. Isso é o que sob a óptica marginalista, fundamentada na teoria do bem-estar e a escassez dos recursos, indica que os preços devem ser iguais aos seus custos marginais.

Contudo, como foi apresentado no item 2.2.3, os preços da eletricidade para o setor residencial estão longe de ser similares aos custos marginais de fornecimento, principalmente para os grupos de usuários de menores recursos.

Os custos marginais de fornecimento para os usuários são compostos pelos custos marginais de produção, de interconexão, repartição (sub-transmissão) e distribuição. Estes dois últimos com componentes por potência unicamente, pois o dimensionamento da infraestrutura desses sistemas é determinado pelos kW pico que vão carregar ao invés dos kWh (MUNASINGHE; WARFORD, 1982). Dai que o esforço ao sistema produzido pela cocção elétrica traduz-se em custos de capacidade instalada para as concessionárias de distribuição de energia elétrica. Na Colômbia, os custos marginais são calculados em forma aproximada a partir dos custos incrementais médios de longo prazo (CIMLP) para toda a cadeia do serviço elétrico (ISA, 1986).

Para um consumo de 3.514 GWh por cocção elétrica na zona urbana da Colômbia, um fator de carga de $27,7 \%$ e os custos marginais até distribuição secundária (tensões inferiores a $1 \mathrm{kV}$ ) para a média nacional que são de US\$45,53/MWh por energia e de US\$228,10/kW-ano por potência ${ }^{26}$, calculam-se custos anuais decorrentes da cocçāo elétrica na zona urbana do

26 Valores calculados a partir dos dados da CRE de custos de referência para o sistema nacional em junho de 1993. A atualização a dezembro de 1993 é feita de acordo com o índice de custos para 0 setor elétrico nesse ano $(20,84 \%)$ e utilizando uma taxa representativa de câmbio de Col\$802,71/US\$. 
país de MMUS $\$ 490,32$. Uma análise similar com um fator de carga de 50,5\% entrega valores de MMUS\$341,21.

Esse montante calculado é a quantidade de recursos que a sociedade como um todo está pagando anualmente pela utilização da eletricidade em cocção.

Porém, os usuários não estão recebendo os sinais adequados para que eles façam um uso eficiente dos recursos energéticos devido a que as tarifas de eletricidade são menores que os custos econômicos de fornecimento.

Como exercício podem-se calcular os montantes de subsídios que as quatro principais empresas na Colômbia dão aos usuários, segundo o nivel tarifário vigente (vide secção 2.3.2), consumos médios como os apresentados nas Tabelas 2.22 a 2.25 e uma distribuição de usuários segundo estrato sócioeconômico como a mostrada na Tabela 2.12. Os resultados são apresentados na Tabela 2.35 .

Essa grandeza de subsídios é a principal responsável da atual situação de insolvência do setor elétrico que pese aos sobre-custos nas tarifas para os setores comercial e industrial, não consegue balancear as finanças destas empresas com os subsídios cruzados.

Convém agora analisar a situação para um consumidor individual que usa a eletricidade para cocção. Os custos incorridos pela utilização de energia elétrica estão conformados pelos custos de capital investido, representado pelos equipamentos destinados para essa finalidade e os custos de operação, que seria o valor pago pelo consumo de eletricidade dos seus equipamentos.

Dentro dos custos de investimento, estaria presente o custo da conexão. Mas esse valor, como é cobrado atualmente, não depende da importância da carga senão do estrato sócio-econômico do novo subscritor. Daí que não seja coerente atribuir uma responsabilidade da cocção dentro desse montante. 
Tabela 2.35

Subsidios Anuais Implicítos nas Tarifas Residenciais de Energia Elétrica em Santafé de Bogotá, Medellin, Santiago de Cali e Barranquilla

(Valores em US\$ de dezembro de 1993)

\begin{tabular}{|c|c|c|c|c|c|}
\hline CIDADE & ESTRATO & $\begin{array}{l}\text { SUBSIDIO POR } \\
\text { USUÁRIO MÉDIO } \\
\text { CENÁRIO } 1 \text { (1) }\end{array}$ & $\begin{array}{l}\text { SUBSIDIO POR } \\
\text { USUÁRIO MÉDIO } \\
\text { CENÁRIO } 2 \text { (2) }\end{array}$ & $\begin{array}{c}\text { SUBSIDIO } \\
\text { TOTAL } \\
\text { CENÁRIO } 1 \text { (1) } \\
\end{array}$ & $\begin{array}{c}\text { SUBSIDIO } \\
\text { TOTAL } \\
\text { CENÁRIO } 2 \text { (2) } \\
\end{array}$ \\
\hline \multirow[t]{6}{*}{ S. de Bogotá } & 1 & US\$ 171,75 & US\$ 132,27 & US\$ 1.549 .371 & US\$ 1.193.245 \\
\hline & 2 & US\$193,81 & US\$ 103,83 & US\$ 49.712 .328 & US\$26.631.977 \\
\hline & 3 & US\$208,81 & US $\$ 41,53$ & US $\$ 77.628 .855$ & US\$ 15.439 .924 \\
\hline & 4 & US\$225,63 & US\$ $\$ 1,53$ & US\$ 37.623 .515 & US\$ 6.925 .260 \\
\hline & 5 & US\$ 72,70 & US\$20,77 & US\$ 5.399 .264 & US\$1.542.100 \\
\hline & 6 & -US\$29,10 & US $\$ 20,77$ & -US\$957.313 & US\$ 683.065 \\
\hline \multicolumn{4}{|l|}{ SUB-TOTAL } & US\$170.956.021 & US\$52.415.571 \\
\hline \multirow[t]{6}{*}{ Medellin } & 1 & US\$ 180,57 & US\$ 123,95 & US\$ 1.477.921 & US $\$ 1.014 .532$ \\
\hline & 2 & US $\$ 198,40$ & US $\$ 95,35$ & US\$27.092.526 & US\$ 13.020 .300 \\
\hline & 3 & US\$227,84 & US\$ 38,14 & US\$ 38.601 .059 & US\$ 6.461 .627 \\
\hline & 4 & US\$224,76 & US\$38,14 & US\$13.935.434 & US\$2.364.681 \\
\hline & 5 & US\$ 9,73 & US\$ 19,07 & US\$ 343.488 & US $\$ 672.850$ \\
\hline & 6 & -US\$58,29 & US\$ 19,07 & -US\$734.204 & US\$240.188 \\
\hline \multicolumn{4}{|l|}{ SUB-TOTAL } & US\$ 80.716 .223 & US\$23.774.178 \\
\hline \multirow[t]{6}{*}{ S. de Cali } & 1 & US\$ 166,57 & US\$ 133,65 & US\$ 2.592 .430 & US\$2.080.033 \\
\hline & 2 & US\$184,92 & US\$102,81 & US\$16.771.183 & US\$ 9.323 .941 \\
\hline & 3 & US\$169,99 & US\$ 41,12 & US\$12.006.069 & US\$2.904.431 \\
\hline & 4 & US\$154,50 & US\$ 41,12 & US\$2.449.436 & US\$ 651.954 \\
\hline & 5 & US\$29,30 & US\$20,56 & US\$ 1.125 .387 & US\$ 789.810 \\
\hline & 6 & -US\$55,49 & US $\$ 20,56$ & -US\$ 604.431 & US $\$ 223.954$ \\
\hline \multicolumn{4}{|l|}{ SUB-TOTAL } & US\$ 34.340 .073 & US\$ 15.974 .123 \\
\hline \multirow[t]{6}{*}{ Barranquilla } & 1 & us $\$ 77,71$ & us $\$ 70,42$ & US $\$ 4.500 .740$ & US $\$ 4.078 .845$ \\
\hline & 2 & US\$ 118,51 & US\$ 84,55 & US\$11.032.957 & US $\$ 7.871 .304$ \\
\hline & 3 & US\$ 138,11 & US\$ 39,01 & US\$ 6.199 .603 & US\$1.750.941 \\
\hline & 4 & US\$138,43 & US $\$ 39,01$ & US\$ 2.175 .380 & US\$ 612.968 \\
\hline & 5 & - US $\$ 31,92$ & US\$ 19,50 & -US\$387.197 & US\$ 236.576 \\
\hline & 6 & -US\$ 155,88 & US $\$ 19,50$ & -US\$2.127.603 & US\$266.206 \\
\hline \multicolumn{4}{|l|}{ SUB-TOTAL } & US\$21.393.879 & US\$14.816.841 \\
\hline
\end{tabular}

(1) O cenário 1 é definido sob o nível tarifário vigente em dezembro de 1993

(2) O cenário 2 é definido sob o nível tarifário meta, segundo as Resoluções 090 de 1991 e 070 de 1993 da JNT.

Fonte: Cálculos do autor 
Os equipamentos típicos utilizados para cocção numa residência são um fogão de uma ou várias chapas e um forno. Os modelos comercialmente disponíveis no país são em sua maioria ( $75 \%$ do mercado) produzidos por uma só fábrica (HACEB) e com preços que variam entre os US $\$ 13$ e US $\$ 392,4027$ para equipamentos com uma potência instalada de $1,1 \mathrm{~kW}$ até $8,1 \mathrm{~kW}$ respectivamente (ALVAREZ, 1994).

A seleção e compra desses equipamentos pelos usuários está muito relacionada com a sua capacidade econômica e o tamanho da familia. Contudo, para uma familia típica ( 5 pessoas) de nivel econômico médio, os modelos mais comuns adquiridos são fogões de 3 ou 4 lugares mais um forno. Os preços desses equipamentos estão em torno de US\$178 e US\$198, com uma vida útil estimada de 10 anos.

A responsabilidade da cocção no preço pago mensalmente por um usuário médio pelo uso da eletricidade é igual à percentagem desse uso final no total de consumo (vide Tabela 2.18 a 2.21). Dessa forma, os preços pagos por um usuário médio em cocção para as principais cidades do pais são as apresentadas na Tabela 2.36 .

Os custos totais anuais para um consumidor são, então, o valor anualizado do investimento (preço do aparelho) durante sua vida útil (10 anos) utilizando uma taxa atualização igual à taxa de rentabilidade média real na Colômbia $(3,3 \%)^{28}$ mais os custos de operação (custo da eletricidade num ano de consumo) e manutenção (peças de reposição). Esses valores são apresentados, para cada estrato sócio-econômico na Tabela 2.37.

27 Preços no mercado de revendedores em dólares de dezembro de 1993.

28 A taxa de rentabilidade média na Colômbia é definida pelo indicador DTF que é a média das taxas de captação das entidades financeiras. O DTF é expresso em juros anuais nominais a partir do valor por trimestre antecipado. Em 31 de dezembro de 1993 o DTF foi de $22,96 \%$ e a inflação acumulada anual de $22,6 \%$. Portanto, os juros efetivos anuais são de $26,67 \%$ e o custo real do capital foi de $3,3 \%$
e.a. 
Tabela 2.36

Custo Anual da Eletricidade Consumida em Cocção por um Usuário Médio em Santafé de Bogotá, Medellín, Santiago de Cali e Barranquilla

(Valores em US\$ de dezembro de 1993)

\begin{tabular}{|c|c|c|c|c|c|}
\hline CIDADE & ESTRATO & $\begin{array}{l}\text { CONSUMO } \\
\text { TOTAL } \\
\text { (kWh/ano) }\end{array}$ & $\begin{array}{c}\text { CUSTO DO } \\
\text { CONSUMO TOTAL } \\
\text { (US\$/ano) }\end{array}$ & $\begin{array}{c}\text { \% DEVOTADA } \\
\text { PARA } \\
\text { COCÇÃO } \\
\end{array}$ & $\begin{array}{c}\text { CUSTO DA ELEC. } \\
\text { EM COCÇÃO } \\
\text { (US\$/ano) }\end{array}$ \\
\hline \multirow[t]{6}{*}{ S. de Bogotá } & 1 & $2.352,00$ & US\$ 31,75 & $28,1 \%$ & US\$ 8,92 \\
\hline & 2 & $2.868,00$ & US\$ 54,34 & $23,4 \%$ & US $\$ 12,70$ \\
\hline & 3 & $3.408,00$ & US\$ 86,06 & $23,3 \%$ & US\$20.02 \\
\hline & 4 & $4.164,00$ & US $\$ 134,65$ & $34,6 \%$ & US $\$ 46,52$ \\
\hline & 5 & $5.472,00$ & US $\$ 400,74$ & $33,6 \%$ & US\$ 134,61 \\
\hline & 6 & $7.356,00$ & US\$ 665,56 & $37,8 \%$ & US\$251,51 \\
\hline \multirow[t]{6}{*}{ Medellin } & 1 & $3.060,00$ & US\$ 62,57 & $65,2 \%$ & US\$ 40,78 \\
\hline & 2 & $3.516,00$ & US\$ 80,97 & $61,3 \%$ & US\$ 49,65 \\
\hline & 3 & $4.356,00$ & US\$118,27 & $51,9 \%$ & US\$ 61,37 \\
\hline & 4 & $4.704,00$ & US $\$ 149,00$ & $37,4 \%$ & US\$ $\$ 5.68$ \\
\hline & 5 & $5.796,00$ & US\$ 450,79 & $32,6 \%$ & US\$146,91 \\
\hline & 6 & $8.556,00$ & US $\$ 738,11$ & $28,8 \%$ & US\$212.21 \\
\hline \multirow[t]{6}{*}{ S de Cali } & 1 & $2.605,20$ & US\$ 56,62 & $49,7 \%$ & US\$28,14 \\
\hline & 2 & $3.586,80$ & US $\$ 122,37$ & $45,2 \%$ & US\$ 55,35 \\
\hline & 3 & $3.427,20$ & US\$123,63 & $40,9 \%$ & US\$50,61 \\
\hline & 4 & $3.620,40$ & US\$ 155,67 & $47,6 \%$ & US\$74,08 \\
\hline & 5 & $4.549,20$ & US $\$ 360,45$ & $32,9 \%$ & US\$ 118,55 \\
\hline & 6 & $8.469,60$ & US $\$ 781,11$ & $37,3 \%$ & US\$291,28 \\
\hline \multirow[t]{6}{*}{ Barranquilla } & 1 & $1.333,20$ & US\$ 30,64 & $10,8 \%$ & US\$ 3,31 \\
\hline & 2 & $2.080,80$ & US\$50,59 & $23,3 \%$ & US\$11,79 \\
\hline & 3 & $2.890,80$ & US\$ 96,81 & $5,9 \%$ & US\$ 5,74 \\
\hline & 4 & $3.746,40$ & US\$166,01 & $15,9 \%$ & US\$26,41 \\
\hline & 5 & $4.342,80$ & US $\$ 384,83$ & $5,2 \%$ & US\$ 19,86 \\
\hline & 6 & $7.017,60$ & US\$726,15 & $20,5 \%$ & US\$ 149,08 \\
\hline
\end{tabular}

Fonte: Cálculos do autor com base nos dados da CNE,1992 e JNT, 1991. 
Tabela 2.37

Custos Totais Anualizados para um Usuário Médio Decorrentes da Cocção Elétrica em Santafé de Bogotá, Medellin, Santiago de Cali e Barranquilla (Valores em US\$ de dezembro de 1993)

\begin{tabular}{|c|c|c|c|c|c|}
\hline CIDADE & ESTRATO & $\begin{array}{l}\text { INVESTIMENTO } \\
\text { INICIAL (1) } \\
\text { (US\$) }\end{array}$ & $\begin{array}{c}\text { CUSTOS DE } \\
\text { OPERAÇÃO } \\
\text { (US\$/ano) }\end{array}$ & $\begin{array}{c}\text { CUSTO DE } \\
\text { MANUTENÇÃO } \\
\text { (US\$/ano) } \\
\end{array}$ & $\begin{array}{c}\text { CUSTO TOTAL } \\
\text { ANUALIZADO (2) } \\
\text { (US\$/ano) }\end{array}$ \\
\hline \multirow[t]{6}{*}{ S. de Bogotá } & 1 & US $\$ 22,40$ & US\$ 8,92 & US\$1,17 & US $\$ 12,76$ \\
\hline & 2 & US\$ 37,10 & US\$ 12,70 & US\$ 1,76 & US $\$ 18,88$ \\
\hline & 3 & US\$ 178,00 & US $\$ 20,02$ & US\$ 1,76 & US $\$ 42,97$ \\
\hline & 4 & US\$214,30 & US $\$ 46,52$ & US\$ 1,87 & US $\$ 73,90$ \\
\hline & 5 & US\$265,40 & US\$ 134,61 & US $\$ 2,46$ & US\$ 168,66 \\
\hline & 6 & US\$343,10 & US\$251,51 & US\$2,46 & US\$294,81 \\
\hline \multirow[t]{6}{*}{ Medellin } & 1 & US\$22,40 & US $\$ 40,78$ & US\$1,17 & US\$ 44,62 \\
\hline & 2 & US\$ 37,10 & US $\$ 49,65$ & US\$ 1,76 & US $\$ 55,83$ \\
\hline & 3 & US\$ 178,00 & US\$61,37 & US\$ 1,76 & US $\$ 84,32$ \\
\hline & 4 & US\$214,30 & US $\$ 55,68$ & US\$ 1,87 & US $\$ 83,06$ \\
\hline & 5 & US $\$ 265,40$ & US\$ 146,91 & US\$ 2,46 & US\$ 180,96 \\
\hline & 6 & US\$ 343,10 & US\$212,21 & US\$2,46 & US\$ 255,50 \\
\hline \multirow[t]{6}{*}{ S. de Cali } & 1 & US\$ 22,40 & US\$28,14 & US\$ 1,17 & US $\$ 31,98$ \\
\hline & 2 & US\$ 37,10 & US $\$ 55,35$ & US\$ 1,76 & US\$ 61,53 \\
\hline & 3 & US\$ 178,00 & US $\$ 50,61$ & US\$1,76 & US\$73,56 \\
\hline & 4 & US\$214,30 & US $\$ 74,08$ & US\$ 1,87 & US\$ 101,46 \\
\hline & 5 & US\$ 265,40 & US\$ 118,55 & US $\$ 2,46$ & US\$152,60 \\
\hline & 6 & US\$ 343,10 & US\$291,28 & US\$2,46 & US\$ $\$ 334,57$ \\
\hline \multirow{6}{*}{ Barranquilla } & 1 & US $\$ 22,40$ & us\$ 3,31 & US\$ 1,17 & US\$ 7,16 \\
\hline & 2 & US\$ 37,10 & US\$ 11,79 & US $\$ 1,76$ & US\$ 17,97 \\
\hline & 3 & US\$ 178,00 & US $\$ 5,74$ & US\$1,76 & US $\$ 28,69$ \\
\hline & 4 & US $\$ 214,30$ & US\$26,41 & US\$ 1,87 & US $\$ 53,79$ \\
\hline & 5 & US\$ 265,40 & US\$19,86 & US\$ 2,46 & US $\$ 53,90$ \\
\hline & 6 & US $\$ 343,10$ & US\$149,08 & US\$2,46 & US\$192,37 \\
\hline
\end{tabular}

(1) Valor comercial dos equipamentos utilizados em cocção na Colômbia, 1994.

(2) Avaliação realizada para uma vida econômica de 10 anos e uma taxa de desconto de 3,3\% (taxa média real de rentabilidade nacional em dezembro de 1993).

Fonte: Cálculos do autor com base nos dados da JNT, 1991; CNE,1992 e ALVAREZ, 1994. 
O elemento eletro-intensivo dos equipamentos utilizados na cocção são as resistências. Esta componente é quase em sua totalidade de origem nacional. Os principais fabricantes de resistências elétricas são Haceb, Cromaterm, Termoluz, Caloric e Ovelma (resistências industriais). Haceb praticamente concentra a maior parte do mercado (em torno de um $90 \%$, segundo entrevista realizada com a seç̧ão de resistências dessa fábrica em fevereiro de 1994) que, por sua vez, vende esses elementos para emsamblagem dos equipamentos das empresas concorrentes.

A evolução do crescimento do mercado pode ser acompanhado a partir dos volumes de produção de resistências elétricas de Haceb. (Figura 2.20)

Figura 2.20

Produção Anual de HACEB de Resistências Tubulares para

Fogões Elétricos

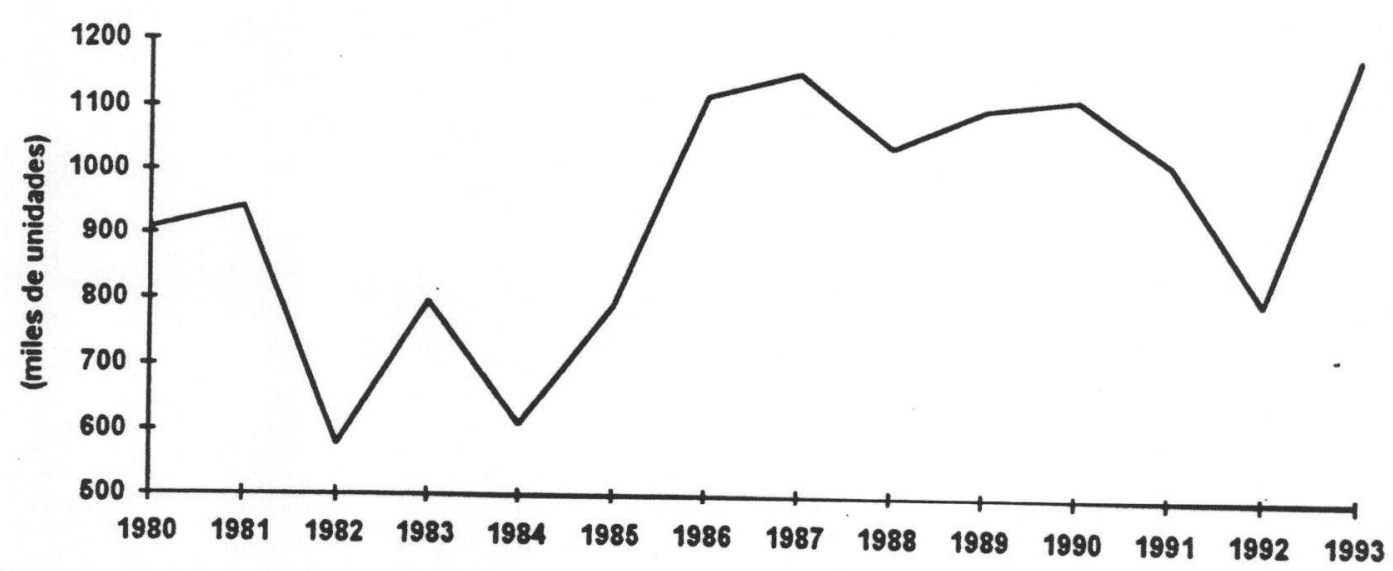

Fonte: Indústrias Haceb, Secção de Resistências, 1994.

O racionamento de energia em 1992 e parte de 1993 fez cair as vendas de equipamentos, mas aparentemente só foi um fenômeno circunstancial, pois os records de unidades produzidas obtiveram-se precisamente após esse periodo.

As características elétricas das resistências tubulares utilizadas nos equipamentos para coç̧ão de alimentos têm sido avaliadas em vários 
trabalhos, porém, condições mínimas devem ser cumpridas segundo a norma 2661 do Instituto Colombiano de Normas Técnicas (ICONTEC).

Com relação à vida útil mínima das resistências, a norma estabelece 1.000 ciclos de aquecimento-resfriamento, onde o ciclo é definido como um periodo de 80 minutos no qual 60 minutos está energizado o elemento e os seguintes 20 minutos está desligado. Segundo as provas de HACEB, o número médio máximo de ciclos tolerados pelas resistências nacionais está em torno de 5000 .

A eficiência das resistências deve ser superior a $55 \%$, de acordo com a norma 2661 do ICONTEC. Segundo HACEB, a eficiência de suas resistências é de $62 \%$ e a CNE (1992) no seu estudo utiliza uma eficiência de $55 \%$. No entanto, o autor realizou algumas provas de laboratório (11 de março de 1994) com a colaboração da Faculdade de Engenharia Mecânica da Universidade de Antioquia e foi determinada uma eficiência de $40,7 \%$. Esse valor é similar ao encontrado no estudo do Centro de Investigaciones para el Desarrollo Integral (CIDI) da Universidade Pontifícia Bolivariana (UPB) de Medellín para ISA, dentro do programa de sistema de qualidade do setor elétrico que coordena essa entidade (ISA; CIDI, 1992).

Nos laboratórios do CIDI, foi analisada a eficiência, sob diferentes condições de operação, dos seguintes fogões: fogão elétrico com resistência tubular, fogão elétrico com resistência do tipo placa (resistência importada) e fogão a gás (GLP). Para condições adequadas de uso dos equipamentos, as melhores eficiências encontradas foram de $42,1 \% ; 54,7 \%$ e $55 \%$ respectivamente.

Conforme a estes últimos dados, é possível calcular o custo por $k W(t)-h$ térmico útil segundo o tipo de tecnologia utilizado e o número de horas de utilização do equipamento. 
A idéia é encontrar o custo do serviço que o usuário demanda. Isto é, ele não requer energia elétrica como tal, senão os serviços que esta pode prover, como luz, calor, som, força motriz, etc. Para o caso da cocção, o usuário precisa calor para o cozimento dos alimentos, portanto o cálculo deve ser feito em relação ao custo de cada unidade de calor segundo o uso que ele faça do equipamento em média por ano.

Por sua vez, a análise pode ser efetuada do ponto do vista do pais (avaliação econômica) ou do ponto de vista do consumidor (avaliação financeira). No primeiro caso, o preço do energético é igual ao custo marginal de fornecimento. Do preço do aparelho deve ser descontado $14 \%$ do seu valor, que equivale à parcela de imposto (Imposto sobre o Valor Agregado, IVA) cobrado na Colômbia. A taxa de desconto utilizada é de $12 \%$, que é o custo de oportunidade amplamente utilizado no país.

Para a avaliação financeira, entretanto, a análise é feita com base em preços de mercado, o preço dos energéticos é valorado à tarifa atual e a taxa de atualização seria a taxa de rentabilidade média no país. Porém, o comportamento dos usuários mostra que estes são bem mais sensíveis ao investimento inicial do que aos custos totais na vida útil dos equipamentos. $\mathrm{Ou}$ seja, a taxa implícita de atualização dos usuários é maior que a taxa de atualização do mercado. Aliás, existem estudos que mostram que a taxa de desconto do consumidor aumenta exponencialmente conforme decresce a sua renda (REDDY, 1991).

Os resultados são apresentados nas Figuras 2.21 a 2.28 e nas Tabelas 2.38 e 2.39 . 
Figura 2.21

Avaliação Econômica do Custo por $k W(t)-h$ Útil na Cocção

Segundo Horas de Uso Diário e Equipamento Utilizado

Taxa de Desconto: $5 \%$

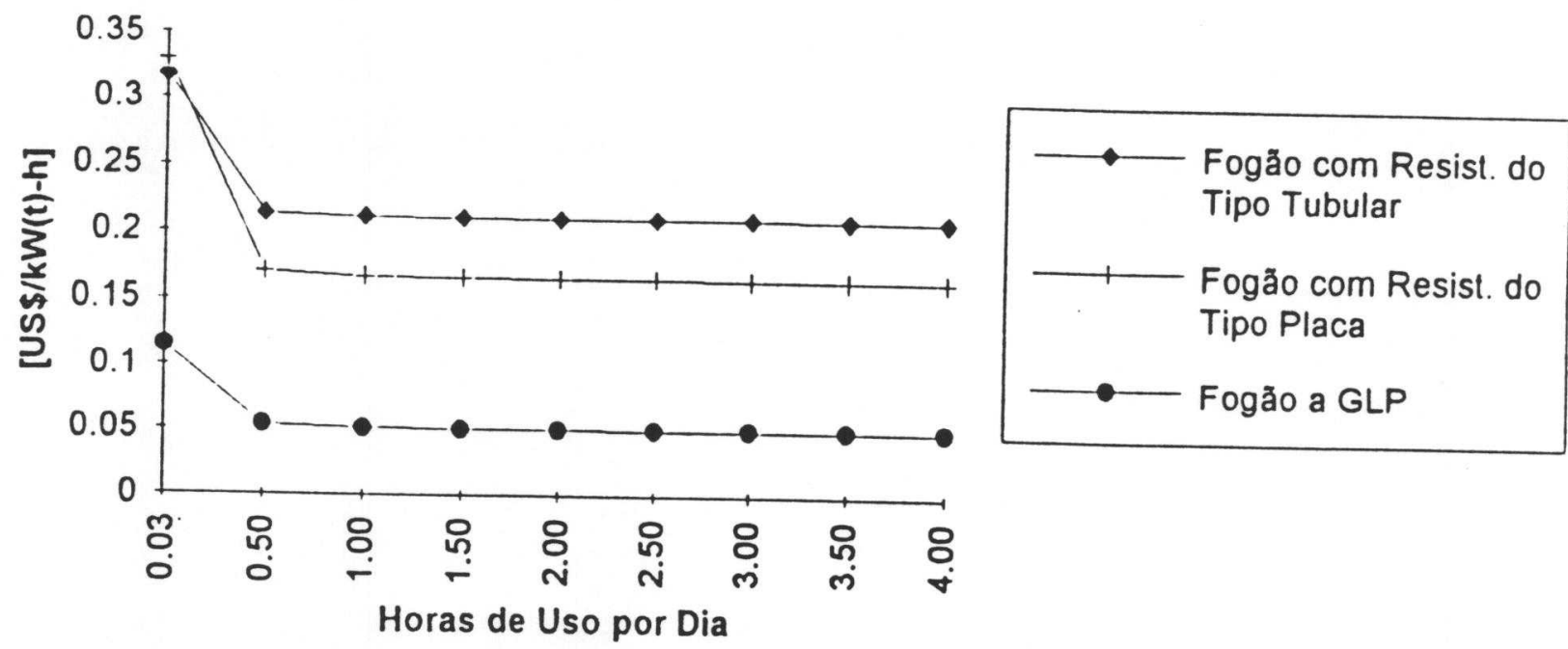

Figura 2.22

Avaliação Econômica do Custo por kW(t)-h Útil na Cocção

Segundo Horas de Uso Diário e Equipamento Utilizado

Taxa de Desconto: $8 \%$

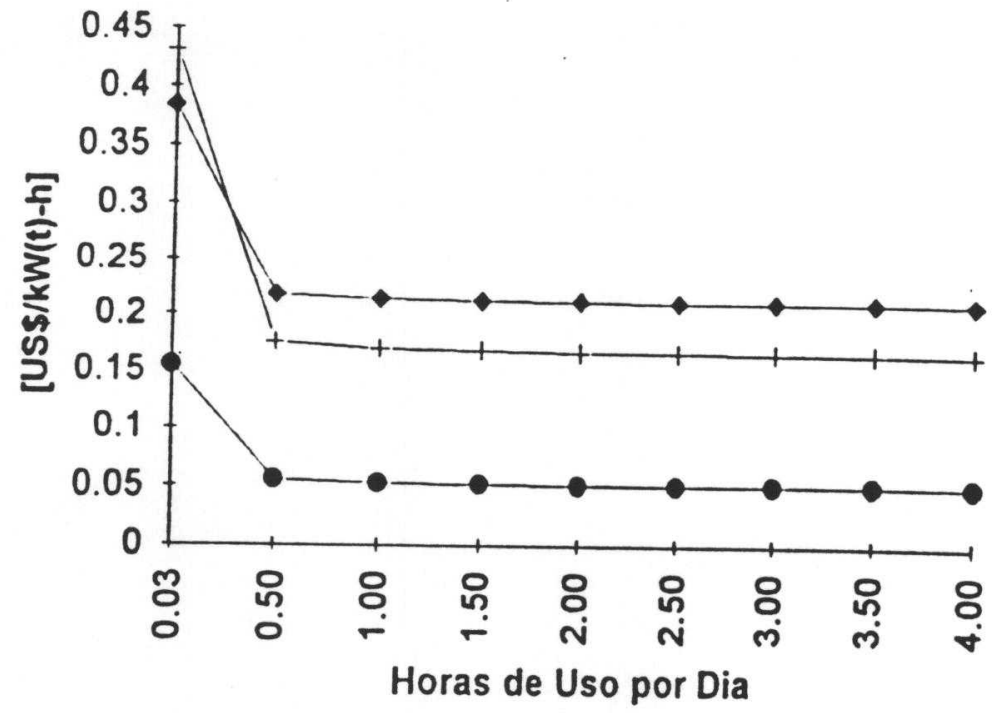

Fogão com Resist. do Tipo Tubular

Fogão com Resist. do Tipo Placa

$\longrightarrow$ Fogão a GLP

Fonte: Cálculos do autor 
Figura 2.23

Avaliaçăo Econômica do Custo por kW(t)-h Ủtil na Cocção

Segundo Horas de Uso Diário e Equipamento Utilizado

Taxa de Desconto: $12 \%$
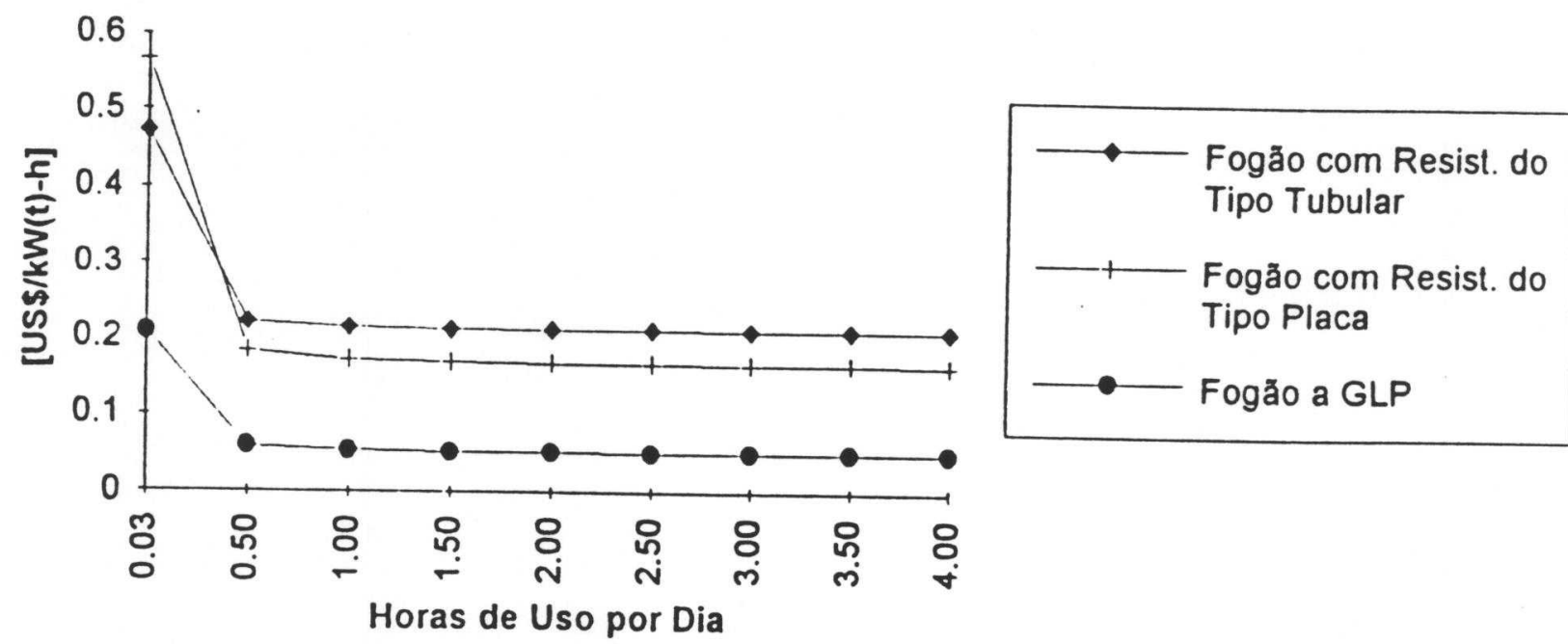

Figura 2.24

Avaliação Econômica do Custo por kW(t)-h Útil na Coç̧ão

Segundo Horas de Uso Diário e Equipamento Utilizado

Taxa de Desconto: $15 \%$
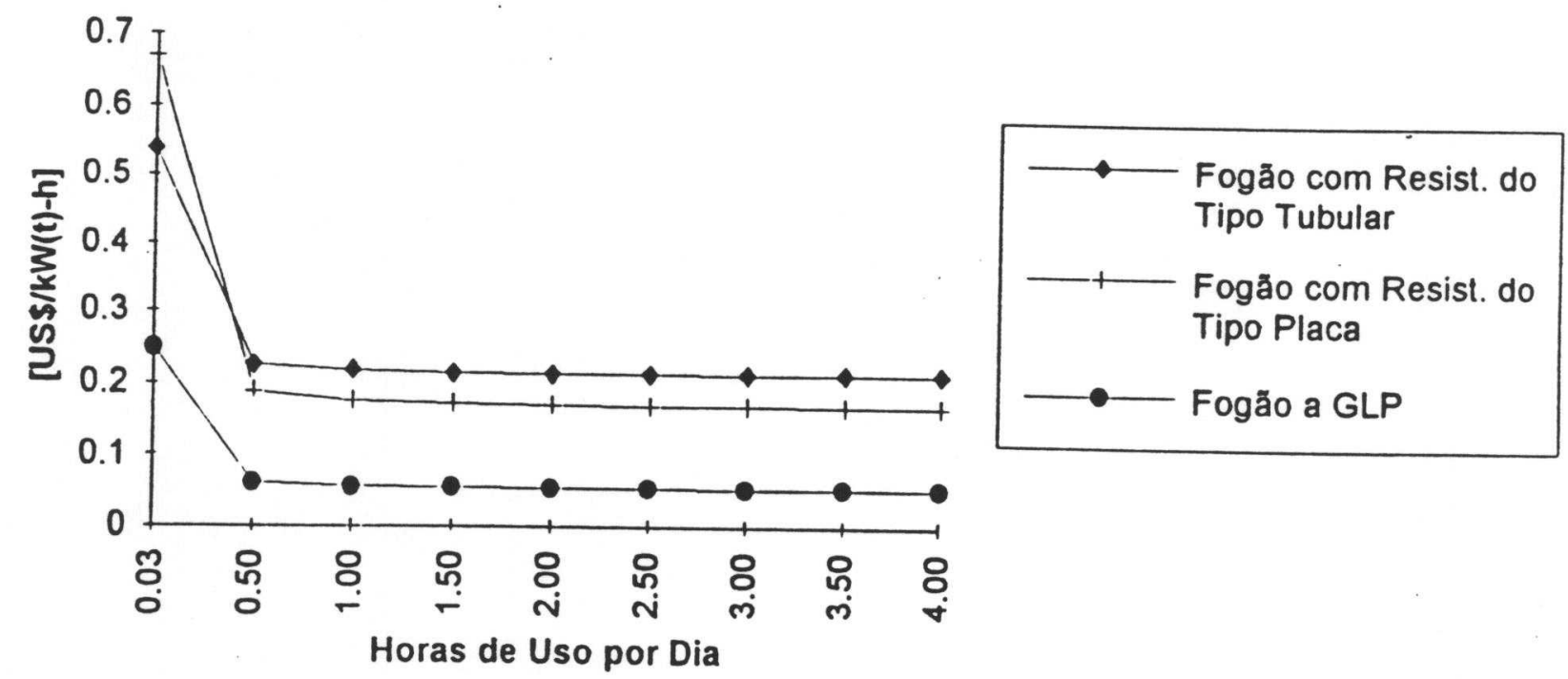

Fonte: Cálculos do autor 
Figura 2.25

Avaliação Financeira do Custo por $k W(t)-h$ Útil na Cocção Segundo Preço

da Eletricidade e Equipamento Utilizado

Taxa de Desconto: 3.3\%. Horas de Uso Diário: $4 \mathrm{~h}$.
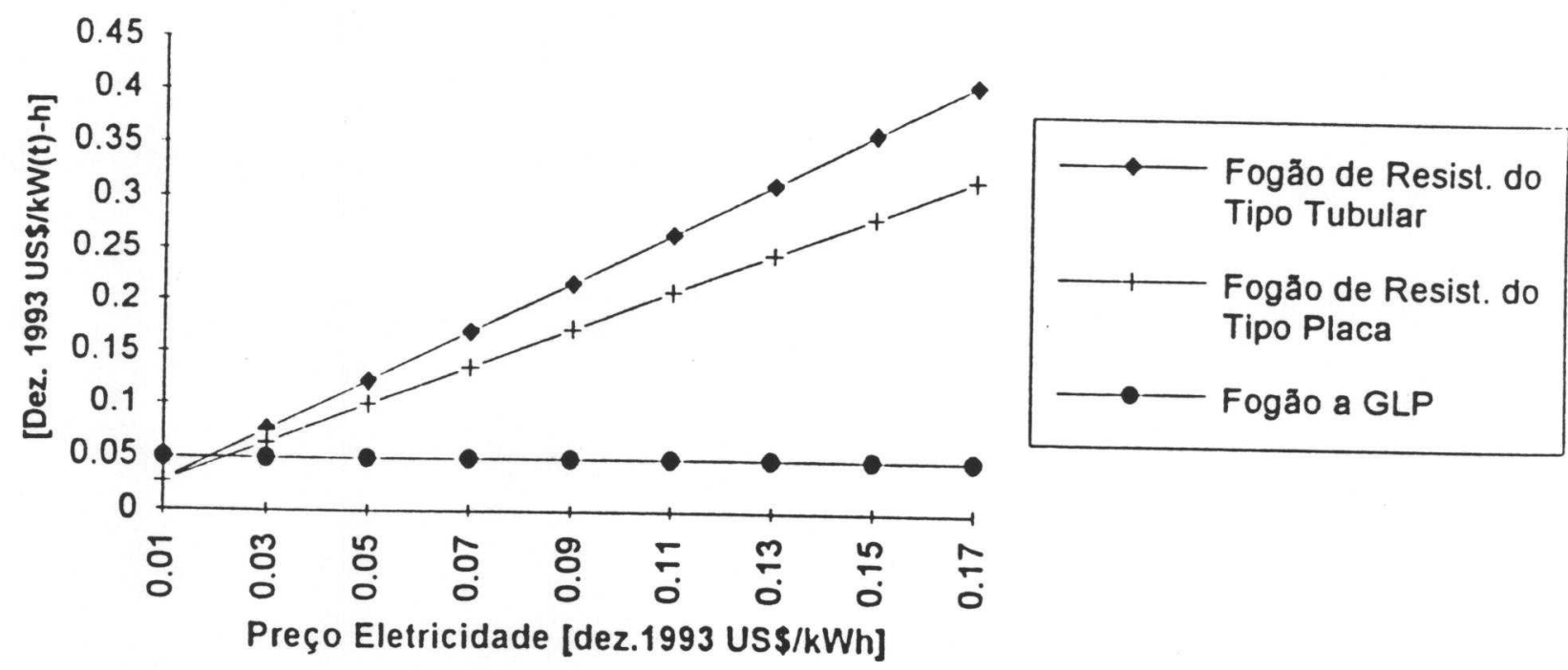

Figura 2.26

Avaliação Financeira do Custo por kW(t)-h Útil na Cocção Segundo Preço da Eletricidade e Equipamento Utilizado

Taxa de Desconto: 10\%. Horas de Uso Diário: $4 \mathrm{~h}$.
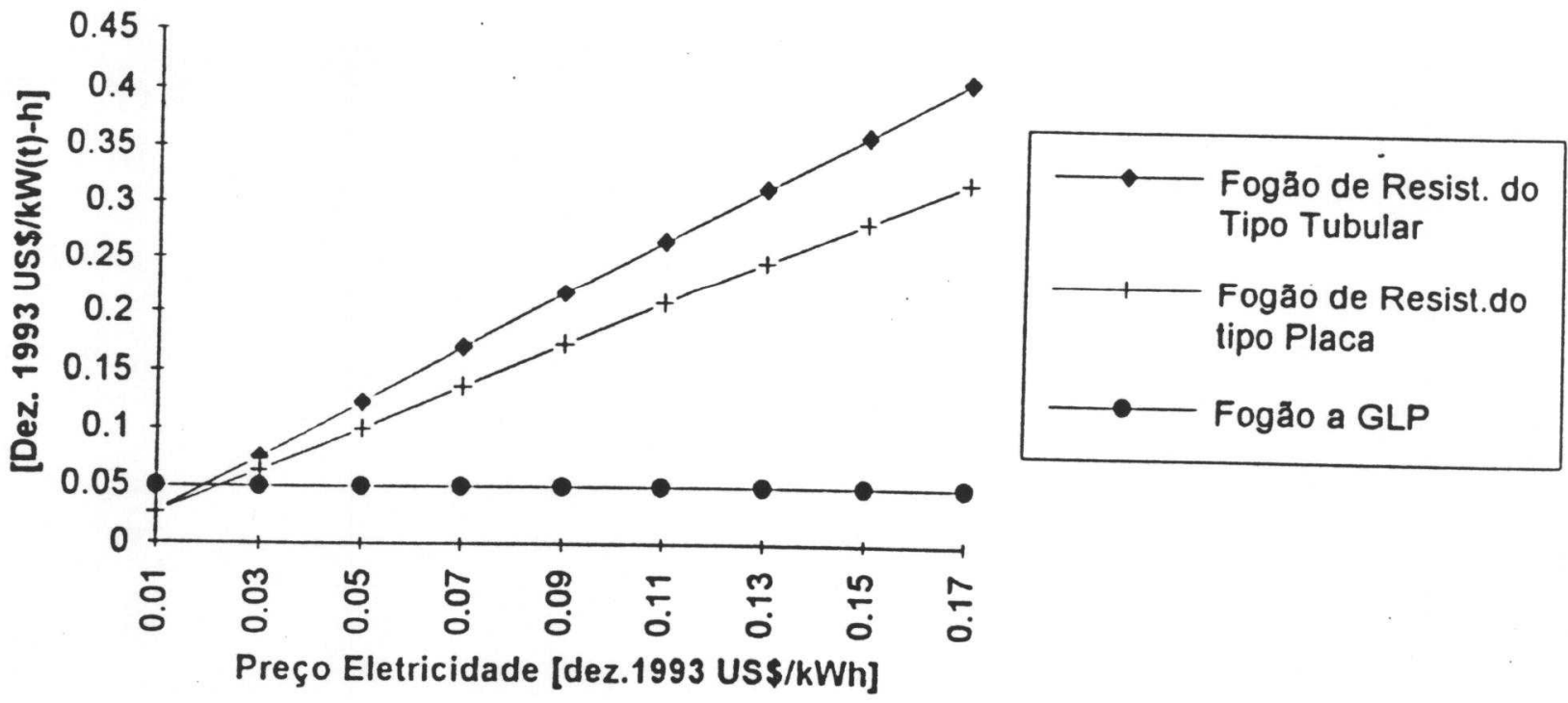

Fonte: Cálculos do autor 
Figura 2.27

Avaliação Financeira do Custo por $k W(t)-h$ Útil na Cocção Segundo Preço da Eletricidade e Equipamento Utilizado

Taxa de Desconto: 15\%. Horas de Uso Diário: $4 \mathrm{~h}$.

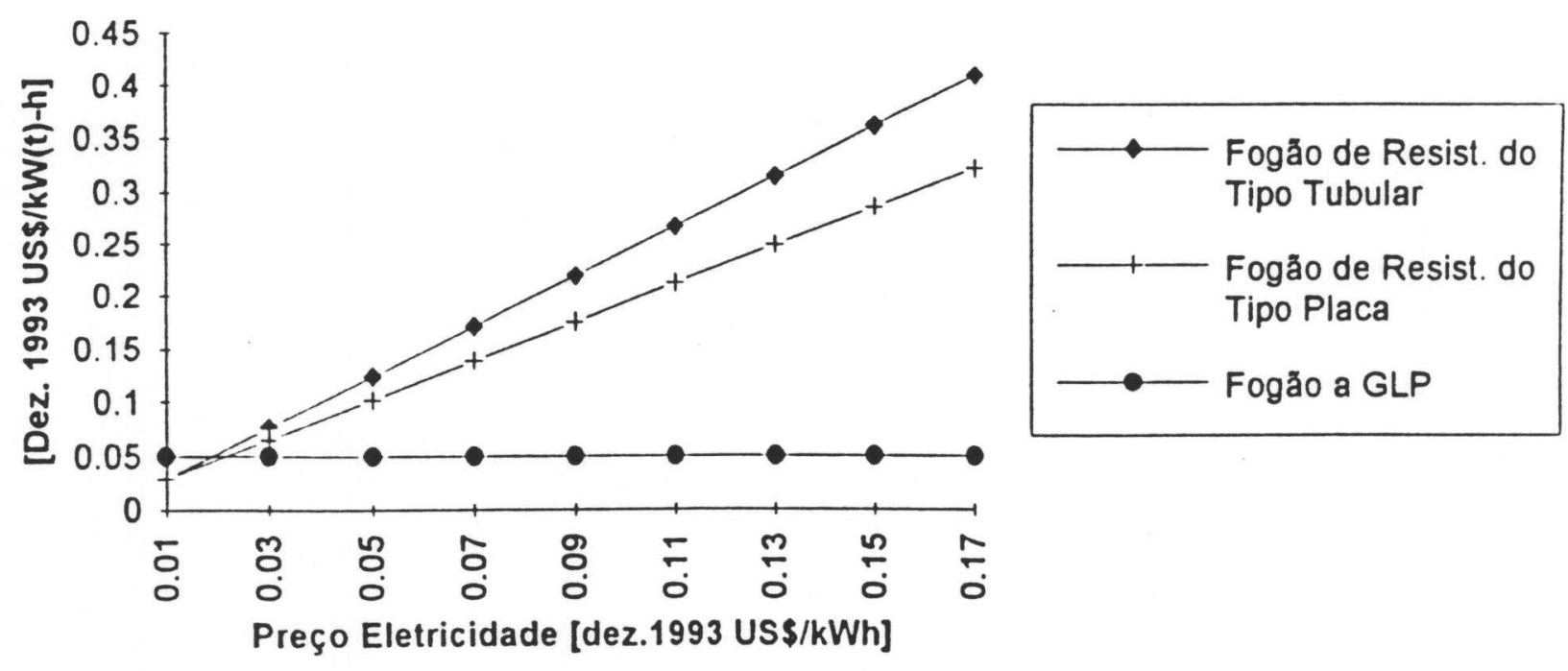

Figura 2.28

Avaliação Financeira do Custo por kW(t)-h Útil na Cocçåo Segundo Preço da Eletricidade e Equipamento Utilizado

Taxa de Desconto: $30 \%$. Horas de Uso Diário: $4 \mathrm{~h}$.
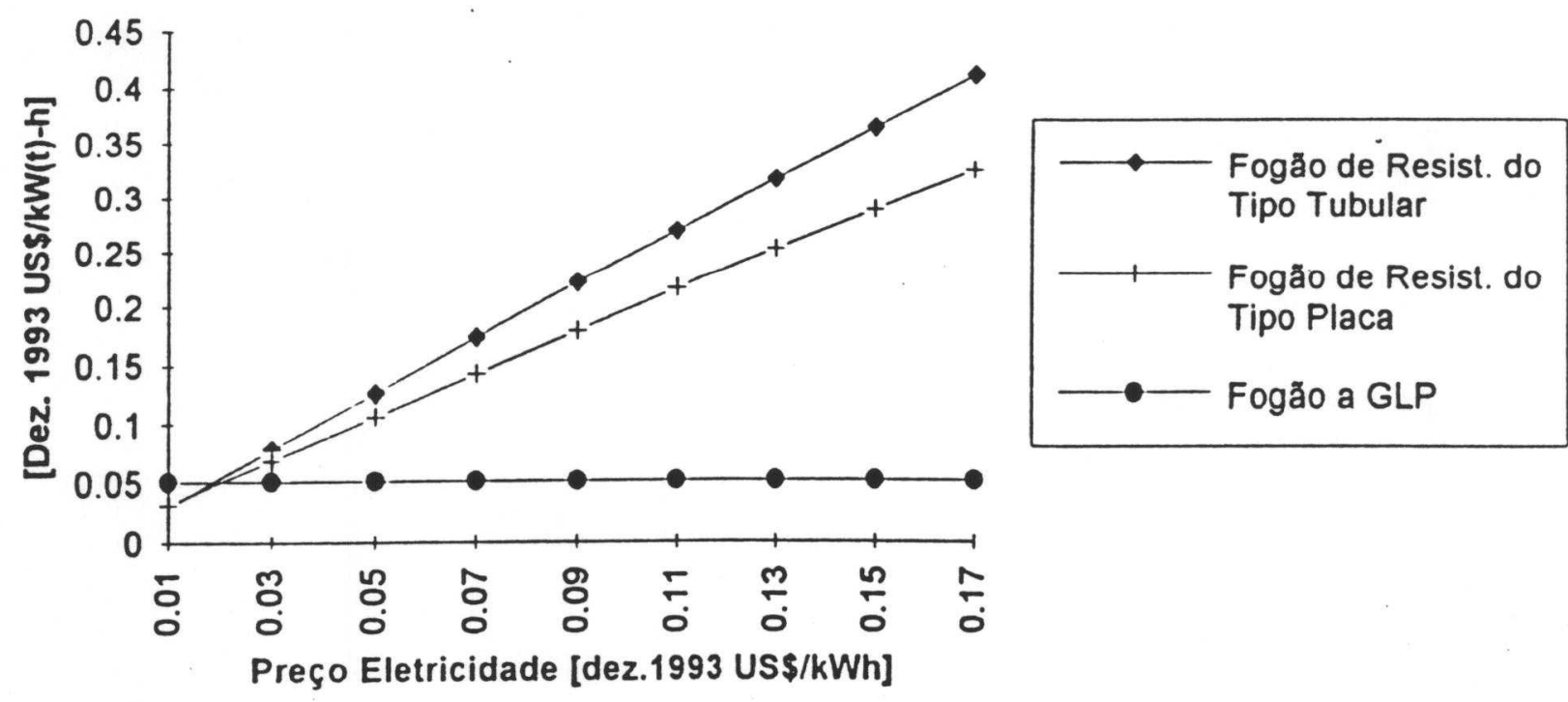

Fontc: Cálculos do autor 


\section{TABELA 2.38}

CÁLCULO ECONÓMICO DO CUSTO PELO SERVIÇO CALOR PARA COCÇÃO

(Valores em US\$ constantes de dezembro de 1993)

Dados dos Equipamentos:

\begin{tabular}{|c|c|c|c|c|c|c|}
\hline $\begin{array}{l}\text { TIPO DE } \\
\text { ELEMENTO }\end{array}$ & $\begin{array}{c}\text { Efic. } \\
k W(t) / k W(e) \\
\end{array}$ & $\begin{array}{l}\text { Potência } \\
{[\mathrm{kW}(\mathrm{e})]}\end{array}$ & $\begin{array}{l}\text { Custo } \\
\text { resist. } \\
\text { [US\$] }\end{array}$ & $\begin{array}{c}\text { Custo } \\
\text { aparelho } \\
\text { [US\$] }\end{array}$ & $\begin{array}{l}\text { Vida } \\
\text { resist. } \\
\text { [h] }\end{array}$ & $\begin{array}{c}\text { Vida } \\
\text { aparelho } \\
\text { [h] }\end{array}$ \\
\hline Fogão tubular (1) & $42,1 \%$ & 2,20 & US\$10,18 & US $\$ 10,74$ & 5.000 & 50.000 \\
\hline Fogão de placa (2) & $54,7 \%$ & 2,00 & US\$27,32 & US $\$ 10,74$ & 5.000 & 50.000 \\
\hline Fogão a gás (3) & $55,0 \%$ & 2,75 & US\$5,46 & US $\$ 15,08$ & 5.000 & 50.000 \\
\hline
\end{tabular}

(1) Resistência tubular nacional e uma carcaça

(2) Resistência plana importada e uma carcaça

(3) Regulador e uma carcaça. Para os cálculos, o regulador foi tratado como uma resistência

Potência fogão a gás: 9400 BTU/h. (3 412.7 BTU= 1 kWh)

Tarifa eletr. $=$ Tarifa GLP=

$$
\begin{aligned}
i & = \\
H D & =
\end{aligned}
$$

US $\$ 0,09$ [US\$/kW(e)h] (custo econômico de fornecimento) (Fonte: Tabela 2.31)
US $\$ 0,03$ [US\$/kWh equiv.] (valor do GLP importado + US $\$ 0,03$ [US $\$ / \mathrm{kWh}$ equiv.] (valor do GLP importado + custo transporte)(US\$7.90/MMBTU. Ecopetrol, 1993a.)
$12 \%$ (vai ser uma variavel) (taxa de desconto)

1 (vai ser uma variavel) (horas de uso por dia)

CÁlCULOS:

\begin{tabular}{rrrr}
\hline ITEM & TUBULAR & PLACA & \multicolumn{1}{c}{ GÁS } \\
\hline Nj_resis & 13,699 & 13,699 & 13,699 \\
Nj_carca & 136,986 & 136,986 & 136,986 \\
FRC_resis & 0,152 & 0,152 & 0,152 \\
FRC_carca & 0,120 & 0,120 & 0,120 \\
$\mathrm{~S}$ & 338,063 & 399,310 & 552,949 \\
$\mathrm{CI}$ & 0,008 & 0,014 & 0,005 \\
$\mathrm{CE}$ & 0,207 & 0,159 & 0,049 \\
$\mathrm{CT}$ & 0,215 & 0,173 & 0,054 \\
\hline
\end{tabular}

Vida útil em anos da resistência

Vida útil em anos da carcaça

Anualização equivalente dos custos de investimento Anualização equivalente dos custos de investimento

Quantidade de $\mathrm{kW}(\mathrm{t})-\mathrm{h}$ uteis produzidos ao ano

Custo anualizado de investimento por unidade de serviço

Custo energético por unidade de serviço

Custo total por unidade de serviço 
AVALIAÇÃO:

A) Custos do kW(t)-h útil para um Fogão Elétrico com Resistência Tubular:

\begin{tabular}{|c|c|c|c|c|c|c|c|c|c|c|}
\hline \multirow[t]{2}{*}{ REGIÁO } & \multirow{2}{*}{$\begin{array}{c}\text { TAXA DE } \\
\text { DESCONTO }\end{array}$} & \multirow{2}{*}{\multicolumn{6}{|c|}{ Custo do kW(t)-h segundo o Número de Horas de Uso Diário }} & \multirow[b]{3}{*}{3,00} & \multirow[b]{3}{*}{3,50} & \multirow[b]{3}{*}{4,00} \\
\hline & & & & & & & & & & \\
\hline \multirow{4}{*}{ Nivel Nacional } & & $\begin{array}{r}0,03 \\
0,317\end{array}$ & $\frac{0,50}{0,214}$ & 1,00 & 1,50 & 2,00 & 2,50 & & & \\
\hline & $\begin{array}{l}5 \% \\
8 \%\end{array}$ & 0,383 & $\begin{array}{l}0,214 \\
0,217\end{array}$ & 0,211 & 0,211 & 0,210 & 0,210 & 0,210 & 0,210 & 0,210 \\
\hline & $12 \%$ & 0.472 & $\begin{array}{l}0,217 \\
0,222\end{array}$ & 0,213 & 0,212 & 0,211 & 0,210 & 0,210 & 0,210 & 0,210 \\
\hline & $15 \%$ & 0,538 & 0,222 & 0,215 & 0,213 & 0,212 & 0,211 & 0,211 & 0,211 & 0,210 \\
\hline & & & & 0,211 & 0,214 & 0,213 & 0,212 & 0,211 & 0,211 & 0,211 \\
\hline
\end{tabular}

B) Custos do kW(t)-h útil para um Fogão Elétrico com Resistência de Placa

\begin{tabular}{|c|c|c|c|c|c|c|c|c|c|c|}
\hline \multirow[t]{2}{*}{ REGIĀO } & \multirow{2}{*}{$\begin{array}{c}\text { TAXA DE } \\
\text { DESCONTO }\end{array}$} & \multicolumn{6}{|c|}{ Custo do kW(t)-h segundo o Número de Horas de Uso Diário } & \multirow[b]{2}{*}{3,00} & \multirow[b]{2}{*}{3,50} & \multirow[b]{2}{*}{4,00} \\
\hline & & 0,03 & 0,50 & 1,00 & 1,50 & 2,00 & 2,50 & & & \\
\hline \multirow[t]{4}{*}{ Nivel Nacional } & $5 \%$ & 0,329 & 0,171 & 0,167 & 0,166 & 0,166 & 0,165 & 0,165 & 0,165 & 0,165 \\
\hline & $8 \%$ & 0,431 & 0,176 & 0,170 & 0,168 & 0,167 & 0,166 & 0,166 & 0,166 & 0,166 \\
\hline & $12 \%$ & 0,567 & 0,183 & 0,173 & 0,170 & 0,168 & 0,167 & 0,167 & 0,167 & 0,166 \\
\hline & $15 \%$ & 0,670 & 0,188 & 0,175 & 0,171 & 0,169 & 0,168 & 0,168 & 0,167 & 0,167 \\
\hline
\end{tabular}

C) Custos do $\mathrm{kW}(\mathrm{t})-\mathrm{h}$ útil para um Fogão a GLP

\begin{tabular}{|c|c|c|c|c|c|c|c|c|c|c|}
\hline \multirow[t]{2}{*}{ REGIẢO } & \multirow{2}{*}{$\begin{array}{l}\text { TAXA DE } \\
\text { DESCONTO }\end{array}$} & \multicolumn{6}{|c|}{ Custo do kW(t)-h segundo o Número de Horas de Uso Diário } & \multirow[b]{3}{*}{3,00} & \multirow[b]{3}{*}{3,50} & \multirow[b]{3}{*}{4,00} \\
\hline & & 0,03 & 0,50 & 1,00 & 1.50 & & & & & \\
\hline \multirow[t]{4}{*}{ Nível Nacional } & $5 \%$ & 0,115 & 0,053 & 0,051 & 0,051 & $\begin{array}{r}2,00 \\
0,051\end{array}$ & 2,50 & & & \\
\hline & $8 \%$ & 0,155 & 0,055 & 0,052 & 0,052 & $\begin{array}{l}0,051 \\
0,051\end{array}$ & 0,051 & 0,050 & 0,050 & 0,050 \\
\hline & $12 \%$ & 0,208 & 0,058 & 0,054 & 0,052 & 0,051 & 0,051 & 0,051 & 0,051 & 0,051 \\
\hline & $15 \%$ & 0,248 & 0,060 & 0055 & 0.053 & 0,052 & 0,051 & 0,051 & 0,051 & 0,051 \\
\hline & & & & & & 0,052 & 0,052 & 0,052 & 0,051 & 0,051 \\
\hline
\end{tabular}




\section{TABELA 2.39}

CÁLCULO FINANCEIRO DO CUSTO PELO SERVIÇO CALOR PARA A COCÇÃO

(Valores em US $\$$ constantes de dezembro de 1993)

Dados dos Equipamentos:

\begin{tabular}{|c|c|c|c|c|c|c|}
\hline $\begin{array}{l}\text { TIPO DE } \\
\text { ELEMENTO }\end{array}$ & $\begin{array}{c}\text { Efic. } \\
k W(t) / k W(e) \\
\end{array}$ & $\begin{array}{l}\text { Potência } \\
{[\mathrm{kW}(\mathrm{e})]}\end{array}$ & $\begin{array}{l}\text { Custo } \\
\text { resist. } \\
\text { [US\$] }\end{array}$ & $\begin{array}{c}\text { Custo } \\
\text { aparelho } \\
\text { [US\$] }\end{array}$ & $\begin{array}{c}\text { Vida } \\
\text { resist. } \\
\text { [h] }\end{array}$ & $\begin{array}{c}\text { Vida } \\
\text { aparelho } \\
\text { [h] }\end{array}$ \\
\hline Fogão tubular (1) & $42,1 \%$ & 2,20 & US\$ 11,61 & US $\$ 10,81$ & 5.000 & 20.000 \\
\hline Fogão de placa (2) & $54,7 \%$ & 2,00 & US\$ 37,37 & US\$ 10,81 & 5.000 & 20.000 \\
\hline Fogão a gás (3) & $55,0 \%$ & 2,75 & US\$ 6,23 & US\$ 17,19 & 5.000 & 20.000 \\
\hline
\end{tabular}

(1) Resistência tubular nacional e uma carcaça

(2) Resistência plana importada e uma carcaça

(3) Regulador e uma carcaça. Para os cálculos, o regulador foi tratado como uma resistência

Potência fogão a gás: 9400 BTU/h. (3 412.7 BTU= 1 kWh)

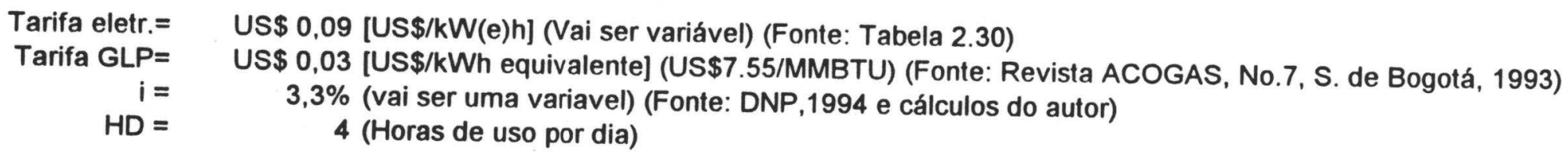

CÁLCULOS:

\begin{tabular}{lrrr}
\hline & TUBULAR & \multicolumn{1}{c}{ PLACA } & \multicolumn{1}{c}{ GÁS } \\
\hline Nj_resis & 3,425 & 3,425 & 3,425 \\
Nj_carca & 13,699 & 13,699 & 13,699 \\
FRC_resis & 0,314 & 0,314 & 0,314 \\
FRC_carca & 0,092 & 0,092 & 0,092 \\
S & 1352,252 & 1597,240 & 2211,797 \\
CI & 0,003 & 0,008 & 0,002 \\
CE & 0,207 & 0,159 & 0,047 \\
CT & 0,210 & 0,167 & 0,049 \\
\hline
\end{tabular}

Vida útil em anos da resistência

Vida útil em anos da carcaça

Anualização equivalente dos custos de investimento

Anualização equivalente dos custos de investimento

Quantidade de kW(t)-h uteis produzidos ao ano

Custo anualizado de investimento por unidade de serviço

Custo energético por unidade de serviço

Custo total por unidade de serviço 


\section{AVALIAÇÃO TABULAR:}

A) Custos do kW(t)-h útil para um Fogão Elétrico com Resistência Tubular:

\begin{tabular}{|c|c|c|c|c|c|c|c|c|c|c|}
\hline \multirow[t]{2}{*}{ REGIÁO } & \multirow[t]{2}{*}{$\begin{array}{c}\text { TAXA DE } \\
\text { DESCONTO }\end{array}$} & \multicolumn{5}{|c|}{ Custo do kW(t)-h segundo o Preço da eletricidade } & \multirow[b]{2}{*}{0,11} & \multirow[b]{2}{*}{0,13} & \multirow[b]{2}{*}{0,15} & \multirow[b]{2}{*}{0,17} \\
\hline & & 0,01 & 0,03 & 0,05 & 0,07 & 0,09 & & & & \\
\hline Cidades na & $3 \%$ & 0,027 & 0,075 & 0,122 & 0,170 & 0,217 & 0,265 & 0,312 & 0,360 & 0,407 \\
\hline \multirow[t]{3}{*}{ Colômbia } & $8 \%$ & 0,028 & 0,075 & 0,123 & 0,170 & 0,218 & 0,265 & 0,313 & 0,360 & 0,408 \\
\hline & $15 \%$ & 0,029 & 0,076 & 0,124 & 0,171 & 0,219 & 0,266 & 0,314 & 0,361 & 0,409 \\
\hline & $30 \%$ & 0,031 & 0,078 & 0,126 & 0,173 & 0,221 & 0,268 & 0,316 & 0,363 & 0,411 \\
\hline
\end{tabular}

B) Custos do $\mathrm{kW}(\mathrm{t})$-h útil para um Fogão Elétrico com Resistência de Placa

\begin{tabular}{|c|c|c|c|c|c|c|c|c|c|c|}
\hline \multirow[t]{2}{*}{ REGIÁO } & \multirow[t]{2}{*}{$\begin{array}{l}\text { TAXA DE } \\
\text { DESCONTO }\end{array}$} & \multicolumn{5}{|c|}{ Custo do kW(t)-h segundo o Preço da eletricidade } & \multirow[b]{2}{*}{0,11} & \multirow[b]{2}{*}{0,13} & \multirow[b]{2}{*}{0,15} & \multirow[b]{2}{*}{0,17} \\
\hline & & 0,01 & 0,03 & 0,05 & 0,07 & 0,09 & & & & \\
\hline Cidades na & $3 \%$ & 0,026 & 0,063 & 0,099 & 0,136 & 0,172 & 0,209 & 0,246 & 0,282 & 0,319 \\
\hline Colômbia & $8 \%$ & 0,027 & 0,064 & 0,100 & 0,137 & 0,173 & 0,210 & 0,247 & 0,283 & 0,320 \\
\hline & $15 \%$ & 0,029 & 0,065 & 0,102 & 0,138 & 0,175 & 0,212 & 0,248 & 0,285 & 0,321 \\
\hline & $30 \%$ & 0,032 & 0,069 & 0,105 & 0,142 & 0,178 & 0,215 & 0,252 & 0,288 & 0,325 \\
\hline
\end{tabular}

C) Custos do kW(t)-h útil para um Fogão a GLP

\begin{tabular}{|c|c|c|c|c|c|c|c|c|c|c|}
\hline \multirow[t]{2}{*}{ REGIÁO } & \multirow[t]{2}{*}{$\begin{array}{l}\text { TAXA DE } \\
\text { DESCONTO }\end{array}$} & \multicolumn{5}{|c|}{ Custo do $\mathrm{kW}(\mathrm{t})-\mathrm{h}$ segundo o Preço da eletricidade } & \multirow[b]{2}{*}{0,11} & \multirow[b]{2}{*}{0,13} & \multirow[b]{2}{*}{0,15} & \multirow[b]{2}{*}{0,17} \\
\hline & & 0,01 & 0,03 & 0,05 & 0,07 & 0,09 & & & & \\
\hline \multirow{4}{*}{ Colômbia } & $3 \%$ & 0,049 & 0,049 & 0,049 & 0,049 & 0,049 & 0,049 & 0,049 & 0,049 & 0,049 \\
\hline & $8 \%$ & 0,049 & 0,049 & 0,049 & 0,049 & 0,049 & 0,049 & 0,049 & 0,049 & 0,049 \\
\hline & $15 \%$ & 0,050 & 0,050 & 0,050 & 0,050 & 0,050 & 0,050 & 0,050 & 0,050 & 0,050 \\
\hline & $30 \%$ & 0,051 & 0,051 & 0,051 & 0,051 & 0,051 & 0,051 & 0,051 & 0,051 & 0,051 \\
\hline
\end{tabular}


Esses resultados demonstram que em termos de energia útil (aquela efetivamente utilizada pelo usuário), a cocção de alimentos realizada por meio de fogões elétricos de resistências tubulares (procedimento mais comum empregado na cocção elétrica na Colômbia, devido aos custos iniciais), não é uma alternativa economicamente eficiente se comparada com alternativas de fogões eficientes ou utilização de GLP.

\subsubsection{Custos Sociais}

Para avaliar as questões sociais envolvidas com o uso da eletridade na cocção devem-se identificar inicialmente os atores sociais que intervem nessa conjuntura.

Um primeiro grupo está formado pelos consumidores, quer de energia elétrica, quer de bens de consumo destinados à cocção elétrica. A cocção de alimentos é uma atividade não superflua é como tal independe do nível de renda familiar. As caracteristicas dos aparelhos utilizados para esses fins, porém, tem uma relação com o estrato sócio-econômico dos usuários.

Um segundo grupo de atores sociais corresponde aos produtores. de eletricidade ou distribuidores (concessionárias) e indústrias de eletrodomésticos. Para os primeiros, a cocção elétrica é uma carga financeira de grandes proporçōes, entretanto, os produtores de eletrodomésticos tem um mercado cativo (tanto do aparelho quanto das peças de reposição resistências- necessárias), como conseqüência da ausência de energéticos substitutos para alguns destes consumidores.

Outro tipo de ator social envolvido são as empresas de servicos. É basicamente aquele grupo de pequenas empresas do setor terciário da economia que participam em tarefas de manutenção, comercialização de insumos industriais, etc. 
Por último, estão os entes reguladores, conformados por instituições governamentais com escopo nacional, regional, departamental ou municipal. Os organismos com maior ingerência no setor são:

- Ministerio de Minas y Energia (MME)

- Comisión de Regulación Energética (CRE)

- Consejo Nacional de Politica Económica (CONPES)

- Consejo Nacional de Política Fiscal (CONFIS)

Existem outros organismos que também efetuam indiretamente ações de regulamentação:

- Instituto Colombiano de Normas Técnicas (ICONTEC).

- Ministerio de Medio Ambiente

- Instituto Nacional de Recursos Naturales (INDERENA)

Estes dois últimos organismos elaboram normas de controle ambiental e velam pelo cumprimento das mesmas. Todavia, os impactos ambientais envolvidos pela questão da cocção elétrica são muito pequenos, pois a energia elétrica gerada para cobrir as demandas deste uso final provém em quase $80 \%$, de usinas hidrelétricas, construidas na sua maior parte sob condiçōes topográficas e ambientais favoráveis.

Um assunto social importante para analisar é a questão tarifária no setor elétrico, não apenas na sua situação atual mas também para médio prazo, quando as metas tarifárias delineadas nas Resoluções 090 de 1991 e 070 de 1993 da JNT sejam atingidas. 
A porcentagem do orçamento familiar que deve ser destinado para adquisição de energia elétrica devido a um consumo médio por estrato sócio-econômico como o apresentado nas Tabelas 2.22 a 2.25 , para um nivel tarifário mostrado na Tabela 2.30, é calculado na Tabela 2.40. Nessa mesma Tabela apresentase para efeitos de comparação, a porcentagem do orçamento familiar caso se usar um nível tarifário igual ao definido como meta nas Resoluções acima referenciadas.

Observa-se em geral, que com a estrutura é nivel tarifário atual, a importância da fatura média de eletricidade mensal com relação às receitas familiares são mais ou menos homogêneas entre todos os estratos. As porcentagens do orçamento familiar destinado para essa parcela energética estão numa faixa de $1 \%$ até $8,3 \%$ (para o estrato 2 em Santiago de Cali).

Com o novo nivel tarifário, previsto como meta nas Resoluções 090/91 e 070/93 da JNT, aconteceram mudanças significativas nessas porcentagens. Para os estratos de menores recursos, a eletricidade será uma carga econômica muito mais sensivel, pois em alguns casos, o pagamento da fatura elétrica representará até $13,9 \%$ das rendas familiares. Entretanto,- para os estratos 5 e 6 (médio-alto e alto), as despesas por energia elétrica manterão uma proporção similar à atual ou vão-se reduzir com relação à sua capacidade econômica.

Uma análise interessante, no sentido de impacto social, é determinar as faturas de energia elétrica e suas porcentagens com relação ao orçamento familiar para uma redução marginal no consumo de eletricidade igual à parcela consumida em cocção (Tabela 2.41).

Obviamente, as despesas familiares em energia elétrica baixam, mas aparecerão novos gastos familiares pela utilização de energéticos substitutos. 
Nóte-se que em muitos casos, a proporção de redução da fatura de eletricidade é maior do que a proporção de redução de consumo, devido à estrutura tarifária operante na Colômbia (vide secção 2.2.3) que estabelece preços maiores por $\mathrm{kWh}$ para faixas incrementais de consumo. A conseqüência do alto consumo de eletricidade para cocção em Medellín e Cali, estas cidades mostram as maiores economias pela redução total do consumo em cocção. Porém, as reduções mais notórias aparecem nos estratos de menores recursos, o que é uma vantagem do ponto de vista social. 
Tabela 2.40

Parcela Familiar Orçamentária Devotada ao Pagamento da Fatura Elétrica Média Mensal em Santafé de Bogotá, Medellin, Santiago de Cali e Barranquilla (Valores em US\$ de dezembro de 1993)

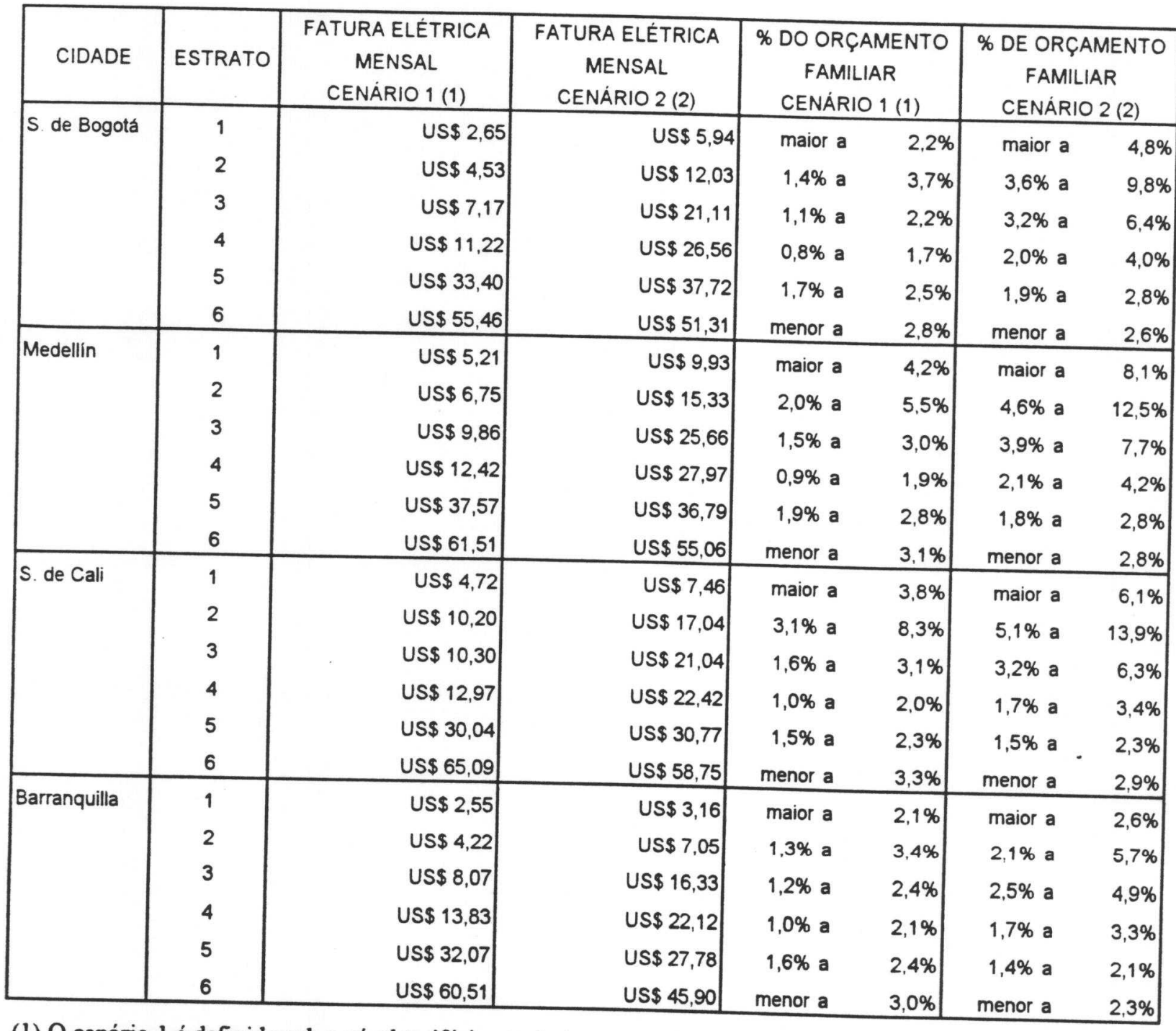

(1) O cenário 1 é definido sob o nivel tarifário atual vigente em 31 de dezembro de 1993.

(2) O cenário 2 é definido sob o nivel tarifário meta, segundo as Resoluções 090 de 1991 e 070 de 1993 da JNT.

Fonte: Cálculos do autor com base nos dados das Tabelas $2.13 ; 2.22$ a 2.25 e 2.30 . 
TABELA 2.41

EFEITO DA REDUÇÃO MARGINAL DE CONSUMO DE ELETRICIDADE

NA FATURA MÉDIA MENSAL DE ENERGIA ELÉTRICA RESIDENCIAL EM SANTAFÉ DE BOGOTÁ, MEDELLÍN, SANTIAGO DE CALI E BARRANQUILLA

(Valores em dólares de dezembro de 1993)

\begin{tabular}{|c|c|c|c|c|c|}
\hline REGIÃO & ESTRATO & $\begin{array}{l}\text { CONSUMO } \\
\text { MÉDIO } \\
\text { (kWh/mês) } \\
\end{array}$ & $\begin{array}{c}\text { REDUÇĀO NO } \\
\text { CONSUMO } \\
(\%) \\
\end{array}$ & $\begin{array}{l}\text { REDUÇĀO FATURA } \\
\text { DE ELETRICIDADE } \\
\text { CENÁRIO } 1 \text { (1) (\%) } \\
\end{array}$ & $\begin{array}{l}\text { REDUÇĀO FATURA } \\
\text { DE ELETRICIDADE } \\
\text { CENÁRIO } 2(2)(\%) \\
\end{array}$ \\
\hline \multirow[t]{6}{*}{ Bogotá } & 1 & 196,0 & 28,1 & 25,7 & 27.1 \\
\hline & 2 & 239,0 & 23,4 & 37,3 & 32,6 \\
\hline & 3 & 284,0 & 23,3 & 34,9 & 25,3 \\
\hline & 4 & 347.0 & 34,6 & 40,5 & 34,9 \\
\hline & 5 & 456,0 & 33,6 & 42,6 & 30,0 \\
\hline & 6 & 613,0 & 37,8 & 43,2 & 32,6 \\
\hline \multirow[t]{6}{*}{ Medellin } & 1 & 255,0 & 65,2 & 67,8 & 73,5 \\
\hline & 2 & 293,0 & 61,3 & 63,9 & 68,1 \\
\hline & 3 & 363,0 & 51,9 & 55,5 & 53,6 \\
\hline & 4 & 392,0 & 37.4 & 36,6 & 37.4 \\
\hline & 5 & 483,0 & 32,6 & 32,4 & 28,9 \\
\hline & 6 & 713,0 & 28,8 & 27,0 & 25,0 \\
\hline \multirow[t]{6}{*}{ Cali } & 1 & 217,1 & 49,7 & 55,7 & 54,5 \\
\hline & 2 & 298,9 & 45,2 & 66,8 & 56.9 \\
\hline & 3 & 285,6 & 40,9 & 57,3 & 42,0 \\
\hline & 4 & 301,7 & 47,6 & 54,6 & 45,3 \\
\hline & 5 & 379,1 & 32,9 & 31,3 & 28,7 \\
\hline & 6 & 705,8 & 37,3 & 37,2 & 32,7 \\
\hline \multirow[t]{6}{*}{ Barranquilla } & 1 & 111,1 & 10,8 & 22,3 & 10,1 \\
\hline & 2 & 173,4 & 23,3 & 33,7 & 21,5 \\
\hline & 3 & 240,9 & 5,9 & 7.0 & 6,5 \\
\hline & 4 & 312,2 & 15,9 & 16,4 & 16,0 \\
\hline & 5 & 361,9 & 5,2 & 4,6 & 4,4 \\
\hline & 6 & 584,8 & 20,5 & 20,3 & 17,4 \\
\hline
\end{tabular}

(1) Cálculos determinados para o nível tarifário vigente em 31-12-93

(2) Cálculos determinados para o nivel tarifário meta definido nas Resoluções 090/1991 e 070/1993 da JNT

Fonte: Cálculos do autor com base nos dados das Tabelas 2.30; 2.31 e 2.36 


\section{ALTERNATIVAS DE SUBSTITUIÇÃO}

Este capitulo visa analisar as possiveis alternativas de substituição da eletricidade utilizada na cocção por outros energéticos.

A análise é feita a partir de numerosos estudos realizados na Colômbia sobre o tema, abordando questões como potenciais de exploração dos energéticos, origem (quer importações, quer produção interna), vulnerabilidade no uso (confiabilidade do suprimento e na estabilidade do preço), acessibilidade por parte das diferentes classes sócio-econômicas da população, taxas de penetração, custos financeiros e econômicos, aspectos institucionais (regulamentações, políticas governamentais, etc.) e impactos ambientais.

Para facilitar a análise, definiram-se três grupos de energéticos substitutos: (1) Cocinol (gasolina)/Querosene/Carvão mineral/Lenha; (2) Gás Liquefeito do Petróleo (GLP) e (3) Gás Natural (GN).

\subsection{Antecedentes}

Há vários anos está-se pensando no problema de substituição da energia elétrica na cocção por energéticos mais baratos e eficientes. Em 1981, o Ministro das Minas e Energia (Carlos Rodado N.) já havia apresentado a conveniência econômica de construção do gasoduto La Guajira (zona setentrional)- Barrancabermeja (zona central) para substituir óleo combustivel, crus pesados e óleo diesel, devido à condição deficitária prevista para o complexo industrial pretroquímico de Barrancabermeja (CIB).

Em 1986, um grupo consultor elaborou o estudo "Bases para a Formulação de uma Política Energética na Colômbia". Esse trabalho serviu de pilar para o 
Governo definir o denominado "Programa do Gás para Mudança" que foi o primeiro objetivo de política energética daquela administração (PERRY, 1987). Contudo, o programa fundamentava-se em reservas de GN em La Guajira bastante otimistas e pouco convincentes, o que levou a postergar a decisão da construção do gasoduto-tronco devido às pressões políticas regionais ( $\mathrm{COCK}$, 1991).

O gás da Venezuela começou então a se vislumbrar como uma alternativa e chegou-se a estudar a viabilidade de construir um gasoduto desde aquele país até a Colômbia. No entanto, com as descobertas de petróleo e GN associado em Cusiana-Cupiagua (zona oriental da Colômbia), foi retomado o projeto de gasoduto La Guajira-Barranca. Aliás, recentemente, foi adjudicada a construção desse gasoduto à companhia Enron sob a modalidade de nonrecourse financing BOMT (Build, Operate, Maintain and Transfer).

Atualmente, o programa de massificação do uso de gás goza de ampla popularidade, segundo se infere das conclusões dos diferentes encontros e congressos celebrados sobre o tema (ACIEM, 1992 e REVISTA ACOGAS, 1993). Ecopetrol, instituição que lidera o programa, também está lihe dando toda a importância necessária e está incentivando ao setor privado a participar do projeto (RENDÓN, 1993).

Segundo estimativas do MME, em 1992 o consumo de energia final para cocção na zona urbana do pais apresentava uma estrutura como a apresentada na Figura 3.1.

A Figura 3.1 indica que em termos de energia final, não existe uma diferença muito grande entre a participação de cada energético no consumo residencial para cocção na zona urbana da Colômbia. Porém, os problemas envolvidos com a utilização de um ou outro energético são diferentes. No Capítulo 2 foi 
analisada a problemática da eletricidade. Neste Capítulo, entretanto, é discutida a possibilidade de que outros energéticos absorvam total ou parcialmente os $20,8 \%$ de participação que atualmente possui a eletricidade nesse uso final.

Figura 3.1

Participação dos Diferentes Energéticos no Consumo Final de Energia na Cocção Residencial em Zonas Urbanas da Colômbia (em Tcal)

(Ano 1992)

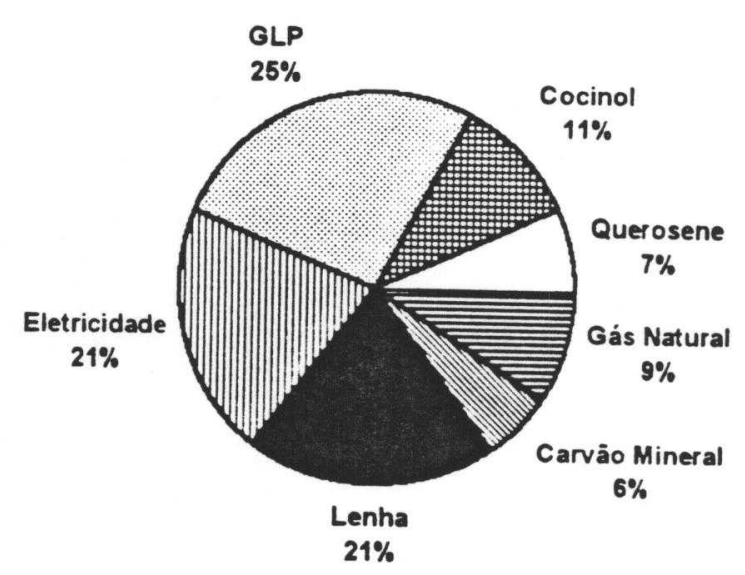

Fonte: Cálculos do autor com base em dados de NULE, G.; MME, 1993

\subsection{Cocinol/Querosene/Carvão/Lenha}

Estes quatro tipos de energéticos mostram um declínio na sua utilização para a cocção de alimentos no setor residencial, porém, os problemas e oportunidades suscitados com relação ao uso de alguns deles justificam a sua análise.

O cocinol é uma gasolina cujo consumo está concentrado em alguns setores da população de baixa renda na cidade de Santafé de Bogotá e nos Departamentos de Cundinamarca e Boyacá.

Em 1992, consumiram-se em média 3.473 bbl/d desse combustivel, mas é de se esperar que no futuro esta situação mude. Aliás, de 333.578 usuários que 
existiam, Ecopetrol conseguiu até dezembro de 1993 que 32.855 começacem a usar GN e 207.232, o GLP (REVISTA CARTA PETROLERA, No. 46, 1994).

Concebida inicialmente como uma idéia para ajudar os setores mais desfavorecidos da população, o fornecimento desse combustivel virou um grave problema, pois foi alvo de manipulação política, revendas não autorizadas, perdas de tempo pelas longas filas e, talvez o mais importante, o custo social pela insegurança do combustivel.

Em 1986, quando foi definido o programa de "Gás para Mudança" (PERRY, 1987), o MME reconhecia sua irresponsabilidade ao estimular o consumo de cocinol, pois segundo pesquisas desse tempo, demonstrava-se que $70 \%$ dos acidentes por queimaduras eram produzidos por este combustivel.

Pesquisas recentes elaboradas pela Ecopetrol, mostram que $46 \%$ dos acidentes causados por queimaduras acontecem em Santafé de Bogotá. Os relatórios das unidades hospitalares indicam que $55 \%$ delas são conseqüência do uso do cocinol, atingindo $70 \%$ dos casos para meninos de até 14 anos de idade (ECOPETROL, 1994b).

O programa de substituição de cocinol visa substituir o seu consumo pelo GLP, mediante a entrega de um fogão a gás, um tanque cheio de $40 \mathrm{lb}$, um regulador e três cupons para os primeiros consumos em troca do cupom familiar de cocinol (10 gal/mês). Os custos do programa estão totalmente assumidos pela Ecopetrol. Até dezembro de 1993, essa instituição tinha investido MMUS $\$ 13,4$ (REVISTA CARTA PETROLERA, No. 46, 1994).

Em termos energéticos, os $1.267,8 \mathrm{kbbl}$ de cocinol consumidos em 1992, implicam aumentar a oferta interna de GLP em 24,4\% (1.480,1 kbbl/ano) para poder substituir totalmente esse combustivel na cocção doméstica. 
O consumo de querosene para cocção em 1992 foi em média de $2.042 \mathrm{bbl} / \mathrm{d}$ na zona urbana. Contudo, é um combustível que só é utilizado por alguns usuários de baixa renda (vide Tabelas 2.14 a 2.17). Em termos de eficiência, o querosene apresenta menor eficiência que a eletricidade, o GLP e o GN. Além disso, é um energético incômodo no seu uso para cocção. Na zona rural, também não é um combustivel muito representativo segundo os resultados do estudo do SIE (1990).

Os cálculos realizados na Colômbia pela ECOPETROL (1993c) mostram os seguintes custos econômicos dos energéticos:
GN
Querosene:
3,40 US\$/MMBTU
Gasolina (cocinol)
5,10 US\$/MMBTU
GLP
5,10 US\$/MMBTU
7,90 US\$/MMBTU

O carvão, segundo as pesquisas realizadas no estudo do SIE (1990), não é um combustivel com boa aceitabilidade para cocção. Os usuários preferem utilizar eletricidade ou GLP, mesmo com a disponibilidade deste recurso, devido à dificuldade para iniciar a queima do mineral.

Contudo, existe uma empresa na zona carbonifera do Departamento de Antioquia que pretende produzir briquetes de carvão mineral, como mecanismo para incentivar o uso de carvão mineral nesta zona do pais, pois facilita consideravelmente a ignição. A empresa Bricarbón, com um investimento de MMUS $\$ 2,60$ e tecnologia chinesa, espera começar operações em janeiro de 1995, produzindo 10.000 ton, 20.000 ton para 1996 e 30.000 ton para 1997.

Este projeto já é uma realidade e mostra maiores vantagens do que projetos propostos há alguns anos baseados na gasificação do carvão (POVEDA, 1992), e que foram duramente criticados pela sua baixa economicidade (ACIEM, 1992). 
Mesmo sendo um projeto local, é interessante acompanhar a evolução que possa ter nos próximos anos. Essa região é consumidora de eletricidade e lenha para a cocção, portanto, a utilização deste energético, atualmente subutilizado, pode representar uma boa oportunidade para revitalizar socialmente as povoações envolvidas com a exploração do mineral, o qual encontra-se espalhado em muita parte do território nacional (Departamentos de La Guajira, El Cesar, Cundinamarca, Boyacá, Córdoba, Santander, Antioquia e Valle).

As 10.000 ton de briquetes poderiam substituir $13,8 \mathrm{GWh}$ de energia elétrica na cocção, que corresponderia ao consumo médio anual de mais de 136.000 familias da zona rural da Colômbia, segundo cálculos realizados com as estimativas do SIE (1990) de consumos médios familiares.

De forma similar, pode-se calcular que a quantidade de lenha economizada pelo uso desses briquetes seria da ordem de 25.000 ton, isto é, o consumo anual de quase 3.000 familias.

O carvão como tal, sem beneficiamento, tem um baixo custo econômico: US\$0,60/MMBTU para a zona urbana (ECOPETROL, 1993c). Porém, o valor agregado pelo procedimento necessário para convertê-lo em briquetes, aumentaria esse valor. Dados detalhados desses custos de produção não são conhecidos.

O estudo do SIE (1990), entretanto, identificou o carvão mineral como o energético mais econômico para a zona rural, mesmo em termos de energia final, seguido da lenha e do carvão vegetal. Os custos, em dólares de dezembro de 199329 , são de US $\$ 6,40 /$ Gcal, US $\$ 7,30 /$ Gcal e US $\$ 9,10 / G$ cal respectivamente.

29 Calcuiados a partir dos valores originais em pesos colombianos de dezembro de 1988, utilizando-se como deflator o índice de preços ao consumidor (IPC) e uma taxa de câmbio de Col\$802,71/US\$ (taxa representativa do mercado em 31 de dezembro de 1993). 
A penetração deste produto terá sucesso se a importância e a estabilidade do preço de venda for suficientemente competitivo com relação aos energétıcos substitutos. Um ponto a seu favor está no fato da comodidade de transporte. mas são necessárias campanhas (marketing) dirigidas aos potenciais usuários para permitir que os briquetes de carvão consigam obter a aceitação do público.

Do ponto de vista ambiental, os briquetes de carvão podem ajudar a diminuir o desmatamento, pois sua utilização seria muito importante na zona rural. altamente consumidora de lenha para fins de cocção e secagem de grãos ( $\mathrm{V} . \mathrm{g}$ café). Com relação à produção de $\mathrm{CO}_{2}$, podem-se obter reduções pela substituição de lenha, pois o poder calorifico desta última (3,6 Tcal/ton seca) é quase duas vezes menor do que o carvão nacional $(6,5 \mathrm{Tcal} / \mathrm{ton})$. Ademais. as eficiências de conversão com carvão mineral $(7,7 \%)$ também são superiores do que as obtidas com lenha $(5,5 \%)$ (SIE, 1990). Felizmente, os teores de enxofre do carvão colombiano são muito baixos. Estudos do JICA (Japan International Cooperation Agency) (1992), determinaram que esses valores estão em torno de $0,6 \%$ em peso.

Finalmente, cabe analisar o caso da lenha, principal energético da zona rural do pais. Em 1992, estima-se que no setor residencial foram consumidas 8.714 .700 ton na zona rural e 827.300 ton na zona urbana (NULE; MME, 1993). Em forma relativa, esses consumos finais representaram $89,1 \%$ do total de consumo residencial rural e $14,4 \%$ do total de consumo residencial urbano, para o uso final cocção.

No item 2.1, mostrou-se que a evoluçăo histórica deste energético indica uma tendência de redução da participação da lenha no consumo de energia final para o setor residencial (Figura 2.5). Dados do Censo Nacional de População 
e de Moradia elaborado pelo DANE em 1993, indicam que $18,59 \%$ da população (6.671.259 de pessoas) utilizam a lenha para essa finalidade. Essa cifra é bem menor do que os 35,8\% (10.762.268 de pessoas) da população da Colômbia que dependia deste combustivel em 1985 (Censo DANE 1985). Esses valores, portanto, confirmam uma redução relativa e absoluta da quantidade de pessoas que usam este energético.

É pouco provável que a lenha possa converter-se em um energético substituto da eletricidade para aqueles lares que já usam a energia elétrica para cocção, mas uma política adequada que incentive um uso mais eficiente deste combustivel pode evitar o aumento de usuários interessados em começar a utilizar a eletricidade para cocção.

O Plano Energético Nacional (PEN) (UPME; MME, 1994), define três estratégias para substituir e economizar lenha comercial com fins residenciais: (1) introdução de GLP, (2) promoção e distribuição de fogões mais eficientes e (3) produção e comercialização de briquetes de carvão.

A principal preocupação que motiva uma utilização mais racional da lenha na Colômbia é do tipo ambiental. Desmatamento e degradação de forestas, manifestada em fenômenos conseqüentes como erosão e sedimentação nas águas, o qual incide na destruição do habitat da flora e fauna e na alteração dos cursos de água são os aspectos que mais inquietam os planejadores (UPME; MME, 1994).

Contudo, estima-se que o desmatamento médio na Colômbia entre 1964 e 1987 atingiu niveis de 350.000 ha, dos quais, só $11 \%$ foi devido a atividades energéticas (PAFC -Plan de Acción Forestal para Colombia- apud UPME;MME, 1994). Dai resulta o autor concluir que a questão ambiental não deveria ser vista como a principal preocupação pela utilização da lenha. 
A lenha desempenha um papel muito significativo para as populações pobres das zonas rurais, pois às vezes, constitui a única fonte energética à qual podem ter acesso essas pessoas.

Uma situação de escassez deste energético torna-se um grave problema social, devido ao tipo de população que seria afetada. Aliás, alguns analistas identificaram no problema energético mundial, além da crise do petróleo e a crise no setor elétrico, uma crise da lenha. (GOLDEMBERG et al, 1988a).

De fato, segundo o PEN (UPME;MME, 1994), as reservas de lenha estariam esgotadas daqui a 20 anos, caso continue o processo de desmatamento sem renovação.

O estudo do SIE (1990) para o setor rural determinou os preços da lenha para uso residencial. Esses valores, em dólares de dezembro de 1993, são: cent. US $\$ 2,60 / \mathrm{kg}$ para lenha apropriada e de cent. US $\$ 3,80 / \mathrm{kg}$ para lenha comprada. O custo mensal para uma família média (20,2 hab.-refeição-dia) pela energia gasta utilizando-se a lenha, seria de US\$18 e US\$23 caso usarem lenha apropriada ou comprada, respectivamente.

Os custos da lenha apropriada estão associados ao trabalho humano necessário para recolher o material. Observe-se que melhoras na eficiência dos equipamentos utilizados para a cocção com lenha, redundariam em menores quantidades do energético para realizar o mesmo serviço. Cálculos baseados no estudo do SIE (1990) mostram que a eficiência termodinâmica média é de só $5,5 \%{ }^{30}$. Entretanto, através de uso de fogões, desenhados especialmente para esta finalidade, a lenha pode atingir eficiências de mais de 40\% (GOLDEMBERG et al, 1988b, pág. 49). Isto significa que o custo de 30 São necessárias $232 \mathrm{kcal}$ utéis por habitante-refeição-dia contra as $4.212 \mathrm{kcal}$ que fornecem $1,17 \mathrm{~kg}$
de lenha consumida em média pelo habitante-refeição-dia. 
recolher lenha para uma família média da zona rural poderia ser reduzido para US $\$ 2,48 /$ mês.

Em contrapartida, o custo econômico mensal para fornecer o mesmo serviço (preparo de alimentos), para essa família média do setor rural por meio de eletricidade é de US $\$ 33,80^{31}$.

A conclusão é que uma política de melhoramentos na eficiência de utilização de energéticos de baixo custo, quer seja a lenha ou o carvão, representa uma ótima oportunidade para evitar ou substituir o uso da eletricidade para a cocção na zona rural do país, especialmente em aquelas zonas distantes das zonas urbanas ou de difícil acesso.

\subsection{Gás Liquefeito do Petróleo (GLP)}

Este derivado do petróleo poderá desempenhar, potencialmente, um papel extremadamente importante no programa de massificação de gás no território colombiano, especialmente em zonas fora de influência do gasoduto-tronco La Guajira-Barrancabermeja.

Inicialmente, quando foi definido o programa de "Gás para Mudança" (PERRY, 1987), estava previsto que o GLP fosse o combustivel substituto da eletricidade para a região ocidental da Colômbia (Medellín, Santiago de Cali e o "eixo cafeeiro") e que penetrasse em uma primeira fase, em Santafé de Bogotá, pois logo depois esta cidade seria abastecida de GN dos campos de La Guajira através da operacionalização de um propanoduto entre Barrancabermeja e Bogotá.

31 Calculado a partir de um requerimento de $232 \mathrm{kcal}$ utéis por habitante-refeição-dia, eficiência de conversão de $42,1 \%$ e custos marginais de fornecimento de 8,70 cent US\$ $/ \mathrm{kWh}$. 
Atualmente, com o programa de massificação de gás aprovado pelo CONPES (Consejo Nacional de Política Económica y Social), o GLP estaria voltado para suprir as necessidades energéticas das populações que não seriam atingidas pela rede de gasodutos a ser construído (DNP, 1993b) e (DIAZ DEL CASTILLO, 1992). Isto é, a tendência seria destinar o GLP para pequenas povoações e zonas rurais. As vantagens e desvantagens desta conjuntura que define o programa vai ser analisada posteriormente.

O GLP também desempenhou um papel importante no passado recente, durante o racionamento de energia elétrica. Este energético foi o principal substituto de energia elétrica no setor residencial para o uso final de cocção nas principais cidades da Colômbia. Contudo, a restrição de oferta em algumas delas, obstruiu uma maior penetração do combustivel.
A produção interna de GLP é feita nas refinarias de Cartagena e Barrancabermeja, sob o controle da Ecopetrol com uma capacidade de
produção limitada (da ordem de $18.000 \mathrm{bbl/d}$ ) (COCK, 1991).

Devido à estrutura de preços internos deste combustivel e seus substitutos (óleo combustivel, cru de Castilla ${ }^{32}$, diesel, etc.), existem distorções no consumo. Essa disparidade entre os preços internos e os preços externos (custos de oportunidade) era a principal razão pela qual não eram realizadas importaçōes de GLP para atender a demanda reprimida.

A limitação do consumo era decorrente de um esquema de quotas controlado pelo MME para as distribuidoras privadas (197 no total), mas que logo passou a ser administrado pela Ecopetrol. Isto gerou toda uma série de procedimentos

32 Cru pesado $\left(13,3^{\circ} \mathrm{API}\right)$ com baixo custo de oportunidade por não ser processável nas refinarias existentes na Colômbia. O campo de exploração "Castilla la Nueva" (Meta) fica a $50 \mathrm{~km}$ na direção sudeste de Villavicencio (capital do Departamento do Meta, região oriental da Colômbia) e tem uma
extensão de 19.000 ha (Revista Carta Petrolera, No. 40. mar 1993. pg. 6). 
obscuros devido às influenças e pressões que se exerciam sobre esse organismo (COLGAS; ECONOMISTAS CONSULTORES ASOCIADOS, 1990), (COCK, 1991).

Como decorrência da emergência elétrica (racionamento de eletricidade) entre abril de 1992 e março de 1993, o MME autorizou a importação do combustivel. Todavia, o principal problema era de armazenamento (ao redor de $78.500 \mathrm{bbl}$ somente) (COLGAS; ECONOMISTAS CONSULTORES ASOCIADOS, 1990), o que fez com que a Ecopetrol investisse em torno de MMUS $\$ 18$ para construir tanques em Cartagena (litoral norte). A infraestrutura ficou pronta em dezembro de 1992, mas não existe ainda suficiente capacidade instalada de transporte fluvial e terrestre para levar O GLP até os grandes centros de consumo do interior do país. A administração da Ecopetrol, no entanto, está incentivando o setor privado a participar da logística dos combustiveis (RENDÓN, 1993).

Atualmente, o custo do GLP nacional em refinaria, em dólares de dezembro de 1993 , é de US $\$ 7,47 / \mathrm{bbl}$. Acrescentando US $\$ 13,58 / \mathrm{bbl}$ por transporte e US $\$ 0,87 / \mathrm{bbl}$ destinado aos fondos de manutenção e reposição de cilindros, resulta, sem incluir impostos, o custo total de US\$21,92/bbl (Resolução No.32501 de 27/12/93 do MME apud REVISTA ACOGÁS, 1993), que é o preço de entrega em refinaria ou terminal. Entretanto, o preço médio de importação de GLP, entre janeiro e novembro de 1993 foi de US $\$ 17,79 / \mathrm{bbl}$, valor inferior à média reportada pela Ecopetrol durante esse mesmo período em 1992, que foi de US\$20,50/bbl (ECOPETROL, 1993e).

Os preços atuais do GLP no território nacional estão acordes com as disposições governamentais para os igualar com os preços internacionais CIF em Cartagena, de GLP proveniente da Venezuela, para o qual não é cobrado imposto de nacionalização (ECOPETROL, 1993b). 
O custo econômico do GLP calculado pela Ecopetrol (1993c) em Santafé de Bogotá é de US\$7,90/MMBTU ou US $\$ 29,76 / \mathrm{bbl}$. Porém, com o declínio no preço internacional de derivados do petróleo este custo deve ser inferior àquele valor pois esse, foi calculado assumindo-se a importação de GLP. Para este caso, o custo econômico seria o custo CIF (cost, insurance and freight) do GLP mais os custos marginais de transporte desde porto (Cartagena) até Santafé de Bogotá.

Tabela 3.1

Composição Quimica do GN de Cusiana (1)

\begin{tabular}{|l|c|}
\hline \multicolumn{1}{|c|}{ QUÍMICO } & \% MOLAR \\
\hline $\mathrm{N}_{2}$ & 0,284 \\
$\mathrm{CO}_{2}$ & 3,511 \\
$\mathrm{C}_{1}$ (Metano) & 50,722 \\
$\mathrm{C}_{2}$ (Etano) & 8,950 \\
$\mathrm{C}_{3}$ (Propano) & 5,395 \\
$\mathrm{C}_{4}$ (Butano) & 1,349 \\
$\mathrm{NC}_{4}$ (Iso pentano) & 2,159 \\
$\mathrm{IC}_{5}$ (Iso pentan & 1,092 \\
$\mathrm{NC}_{5}$ & 1,010 \\
\hline
\end{tabular}

(1) Poço petrolero com reservas de GN asociado de $2.600 \mathrm{GPC}\left(73,6 \mathrm{Gm}^{3}\right)$.

Fonte: Gerência de Cusiana, ECOPETROL, 1994

Além disso, com as perspectivas de reservas de GN associado das jazidas de Cusiana e Cupiagua ${ }^{33}$ e segundo as estimativas da Ecopetrol sobre a quantidade de condensados (etano, propano, butano, pentano, etc.) contidos nesse gás (Tabela 3.1), aparecem excelentes oportunidades para o pleno abastecimento da demanda interna de GLP e excedentes para exportação. Desta forma, o custo econômico do GLP deve ser revisado pois, neste caso, seu cálculo seria determinado pelo custo FOB.

A demanda de GLP em 1992 no setor residencial foi de $12.164 \mathrm{bbl} / \mathrm{d}$ (NULE;MME, 1993). A zona urbana consumiu $90 \%$ desse combustivel e a zona rural o restante. O GLP é destinado, quase em sua totalidade, para fins de

33 Poços de petróleo com reservas estimadas de 1.500 bilhões e 500 bilhões de barris de cru, além de gás natural associado em quantia de $2.600 \mathrm{GPC}\left(73,6 \mathrm{Gm}^{3}\right)$ e $1.250 \mathrm{GPC}\left(35,5 \mathrm{Gm}^{3}\right)$
respectivamente. 
cocção. Uma pequena parte (1\%) estima-se que é utilizada para aquecimento de água. O GLP participa com $25,9 \%$ da energia final gasta em cocção para o setor residencial (Figura 3.1).

Segundo os cálculos realizados no Capítulo 2, item 2.3.2, mostrou-se que este combustivel é muito mais eficiente em termos econômicos (para o país como um todo) para cocção do que a eletricidade.

A demanda de eletricidade em cocção para a zona urbana em 1992, 3.514,4 GWh (NULE;MME, 1993), poderia ser substituída com $6.677,6 \mathrm{bbl} / \mathrm{d}$ de GLP, partindo de eficiências de conversão de $42,1 \%$ e $55 \%$ respectivamente. Isto é, a demanda de eletricidade em 1992 para cocção, poderia ser atendida com um aumento de $55 \%$ de disponibilidade de GLP. O custo econômico seria de MMUS $\$ 72,50$ contra MMUS $\$ 305,80$ que custaria para fornecer esse serviço (preparo de alimentos) com eletricidade.

O aumento de consumo de GLP está considerado no plano de massificação de gás. Espera-se que o consumo total para 1996 atinja ainda um nivel de quase $25.000 \mathrm{bbl} / \mathrm{d}$ (DNP, 1993b). Isso significaria um incremento de $50 \% \mathrm{com}$ relação ao consumo total desse combustivel em 1992 (16.690 bbl/d).

Para se dispôr desta oferta necessária, capaz de cobrir a demanda prevista, o plano de gás da Colômbia considerou: a importação de GLP (principalmente da Venezuela), a construção da infraestrutura de armazenamento em Cartagena (já efetuada) e em Bahia Málaga (Pacífico), construção de um poliduto Bahia Málaga-Santiago de Cali e o aumento da capacidade de transporte fluvial e terreste desde Cartagena (DNP, 1993b). A infraestrutura do Pacífico, com um investimento de MMUS\$150 por parte da Ecopetrol (RENDÓN, 1993), reduziria a vulnerabilidade de suprimento do GLP e de 
outros combustiveis caso ocorressem situações de emergência com o centro supridor de Cartagena (região Atlântica).

Essas medidas foram realizadas sob o presuposto de uma produção interna limitada e insuficiente de GLP. Contudo, como foi apresentado antes, a composição química do GN associado de Cusiana mostra uma alta quantidade de condensados que poderiam ser empregados na obtenção de GLP. Aliás, análises preliminares (TECHNOPLAN, 1994) indicam que é viável instalar um extrator de propano e butano de baixa eficiência para se obter o GLP de custo baixo.

Quando foi formulado o "Plano do Gás" pelo Governo da Colômbia, não eram conhecidos os potenciais energéticos dos campos petroliferos Cusiana e Cupiagua (com uma formação geológica similar à de Cusiana). Hoje, o cenário básico da Ecopetrol indica que as reservas do Campo Cusiana são estimadas em 1.500 MMbl de petróleo e $3.000 \mathrm{GPC}\left(85,2 \mathrm{Gm}^{3}\right)$ de Gás. A estimação das reservas de Cupiagua ainda tem grandes incertezas, devido ao fato que este campo ainda está em etapa inicial de caracterização (ECOPETROL, 1993a).

A grandeza das reservas de gás destes campos, sem dúvida, provocará um impacto sensivel na comercialização do GN e do GLP no que se refere a preços, devido ao efeito do esgotamento das reservas no cálculo do custo econômico.

Contudo, sabe-se que o uso do GN de Cusiana só é economicamente atrativo se o petróleo for sido extraído em grandes proporções, pois o GN do campo vai ser reinjetado para melhorar a recuperação de cru. Os estudos contratados pela Ecopetrol, determinaram que reinjetando-se o total do volume de gás produzido, o fator de recuperação do cru é de $60 \%$. Caso não se reinjetar o 
gás, o fator de recuperação desceria a valores em torno de $30 \%$ (ECOPETROL, 1993a).

Todavia, foi aprovado um projeto para se utilizar 20 MMPCD de GN de Cusiana no seu início de exploração. Segundo o balanço demanda-oferta de GN, para o ano 2004, é necessário o fornecimento do combustivel de Cusiana ou de outras fontes diferentes de La Guajira. O plano da Ecopetrol estima uma produção de 300 MMPCD do Campo de Cusiana a partir de 2004.

A proposta desta dissertação apregoa a utilização do GLP que poderia ser obtido a partir dos condensados (principalmente, propano e butano) do gás natural associado do campo Cusiana. Os benefícios desta estratégia seriam:

- Contribuir à consecução do objetivo do Plano de Massificação de Gás, pois como foi demonstrado no Capítulo 2, o GLP é um energético mais econômico para cocção de alimentos do que a eletricidade.

- Adiar a utilização do GN de Cusiana/Cupiagua para depois de 2004 e dispôr depois de grandes volumes, evitando-se assim a redução do fator de recuperação do cru do campo Cusiana.

- Uma ampla oferta de GLP ajudaria a fomentar a "Cultura do Gás" entre as populações que ainda não têm acesso a este energético, pois como é sabido, os custos de instalação para o usuário são bem menores do que os custos com o uso de GN, ○ qual facilitaria a penetração deste último combustivel no futuro.

- Reduzir ou eliminar as importações de GLP realizadas pela Ecopetrol.

- Aumentar a disponibilidade de GN para usos diferentes à cocção, como o uso industrial, termelétrico e de transportes (GNC, Gás Natural Comprimido). 
- Aumentar os volumes de comercialização do GLP para as distribuidoras privadas, aumentando a rentabilidade destas empresas que, de acordo com o estudo de COLGAS (dez. 1990), é atrativa para vendas superiores a $100.000 \mathrm{gal} / \mathrm{mês}(79 \mathrm{bbl} / \mathrm{d}$ ).

- Reduzir o preço do GLP para os usuários, pois a política tarifária atual está baseada nos custos marginais, onde o custo de oportunidade do combustivel é tomado como um valor de referência.

A idéia, então, é instalar em boca de poço um centro de tratamento para extrair os componentes ricos do gás produzido e reinjetar gás seco (com menos condensados) mais o gás produzido que não for tratado. Em geral, este é o procedimento que normalmente é feito quando se precisa utilizar o gás associado para manter a pressão na jazida (SUAREZ; DOBRUSIN, 1992).

A análise de TECNHOPLAN (1994) determinou que as perdas volumétricas de GN de Cusiana, caso se extraia o propano e butano $(8,9 \% \mathrm{~mol})$ desse gás úmido, seriam de só $5,7 \%$. Esta situação não prejudicaria praticamente o fator de recuperação do cru, pois de $60 \%$, desceria para o entorno de $57 \%$, segundo a curva fator de recuperação vs \% GN reinjetado determinada no estudo da Ecopetrol (ECOPETROL, 1993a). No entanto, essa situação extrema não é real, pois a extração dos condensados não é instantânea, senão um processo que dependeria do dimensionamento do centro de tratamento e da taxa de extração dos componentes.

Com base no desenho conceptual desenvolvido no estudo da TECHNOPLAN (1994), a demanda adicional de $10.733 \mathrm{bbl/d}$ de GLP requeridos para substituir toda a eletricidade e cocinol devotados para cocção em 1992 poderia ser atendida processando $400 \mathrm{MMPCD}\left(11,3 \mathrm{MMm}^{3} / \mathrm{d}\right)$ de $\mathrm{GN}, 16 \%$ de todo $\mathrm{GN}$ 
extraído diariamente conjuntamente com o petróleo, numa planta de tratamento de baixa eficiência (menor de $60 \%$ ) e de baixo custo.

O alto teor de GLP (propano e butanos), etano ( $9 \% \mathrm{~mol})$, pentanos $(2,1 \% \mathrm{~mol})$ e outros componentes no gás natural de Cusiana, mostra que convém realizar um estudo mais detalhado sobre a viabilidade econômica e técnica de instalar uma planta de extração de GLP desse gás. De acordo com esses resultados, seria imperioso voltar à re-análise das estratégias do plano de massificação do uso de gás, promovida pelo Governo Nacional e reavaliar o papel do GLP.

Em termos ambientais, o GLP é mais benéfico do que o cocinol por diferentes razões: a emissão de $\mathrm{CO}_{2}$ é menor por kcal produzido, pois o poder calorífico do GLP (16.560 kcal/kg) é superior ao poder calorífico do cocinol $(11.900 \mathrm{kcal} / \mathrm{kg}$ ); não emite SOx (teor de enxôfre do GLP e praticamente de $0 \%$, do cocinol, $0,07 \%$ ); as emissões de particulados e NOx por unidade de volume são também menores $\left(0,223 \mathrm{~kg} / 10^{3} \mid\right.$ e $1,3 \mathrm{~kg} / 10^{3} \mid$ vs $1,2 \mathrm{~kg} / 10^{3}$ e $1,5 \mathrm{~kg} / 10^{3} \mid$ respectivamente).

Contudo, o estudo do JICA (1992) indica que a polução ambiental atual e futura causada por fontes domésticas não é preocupante, mas sim, de fontes do tipo industrial e móveis (transporte).

\subsection{Gás Natural (GN)}

A análise sobre este combustivel é de extrema importância, pois o programa de massificação do uso do gás está baseado em grande parte na utilização do GN no interior do país, que atualmente encontra-se desligado dos grandes centros produtores. 
O programa nasceu como uma iniciativa do MME em 1986 sob o nome de "Gás para Mudança" (PERRY, 1987). Em 1987, foi entregue o estudo de viabilidade do gasoduto central (gasoduto-tronco que traria $\circ \mathrm{GN}$ desde o litoral atlântico até a cidade de Barrancabermeja, onde se encontra o complexo industrial da Ecopetrol - CIB-).

Todos os casos analisados no estudo de viabilidade mostraram a conveniência da construção do gasoduto central (ESTUDIOS TÉCNICOS-NOVACORP INTERNATIONAL, 1987). Todavia, a decisão de construir o gasoduto, já tomada, foi postergada devido à pressão política regionalista do litoral atlântico. A origem desta barreira foram as limitações de reservas provadas em La Guajira que indicavam o esgotamento do recurso da região em menos de 15 anos, tempo mínimo suficiente para se incrementar as reservas mediante novas descobertas (MEJíA, 1992).

Contudo, a situação do setor elétrico foi se agravando e o projeto novamente foi retomado, porém, sob a óptica da possibilidade de se importar GN venezuelano. Os achados de Cusiana, no entanto, adiaram essa alternativa.

Atualmente, o plano de gás, liderado pela estatal Ecopetrol, prevê a utilização do GN em grande escala em cidades da região Andina, para o qual está previsto a construção de uma grande infra-estrutura de transporte e distribuição do combustível. Nas Figuras 3.2 e 3.3 são apresentados os montantes dos investimentos estimados para o programa e um diagrama da rede de gasodutos a ser construido. 
Figura 3.2

Plano de Investimentos do Programa de Massificação de Gás na Colômbia no Período 1993-2015

(Valores em dólares de 1993)

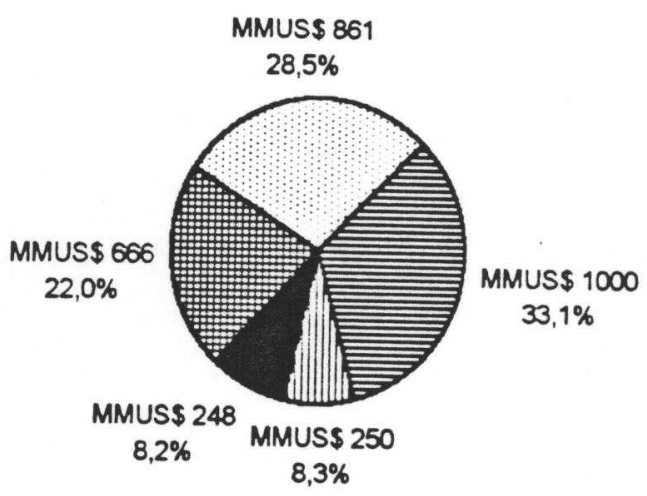

E Conversão usuánios u Conversão Transporte - Estações GNC 田 Distribuição G. Transporte

Fonte: Ecopetrol, 1993c e 1993d.

O investimento total de MMUS $\$ 3.025$, sem dúvida, provocará grandes efeitos macroeconômicos e sociais. A participação de múltiplos atores no financiamento do programa é imprescindivel.

A intenção do Governo é permitir maior participação de capital privado no Programa em todos os componentes da cadeia do GN, exceto a produção, para evitar comprometer os recursos da Nação. Ecopetrol, por exemplo, adjudicará vários dos ramais da rede do gasoduto ao setor privado sob a modalidade de leasing BOMT. Aliás, o trecho do gasoduto central Ballenas (La Guajira)-Barranca, foi ainda adjudicado este ano (1994).

A socialização de grande parte dos custos do programa deverá estar distribuída entre toda a população colombiana, pois a Ecopetrol, como empresa estatal, deverá absorver uma porcentagem do total de investimentos necessários ou assumir garantias para os contratos BOMT realizados. 


\section{RED NACIONAL PROYECTADA DE GAS NATURAL}
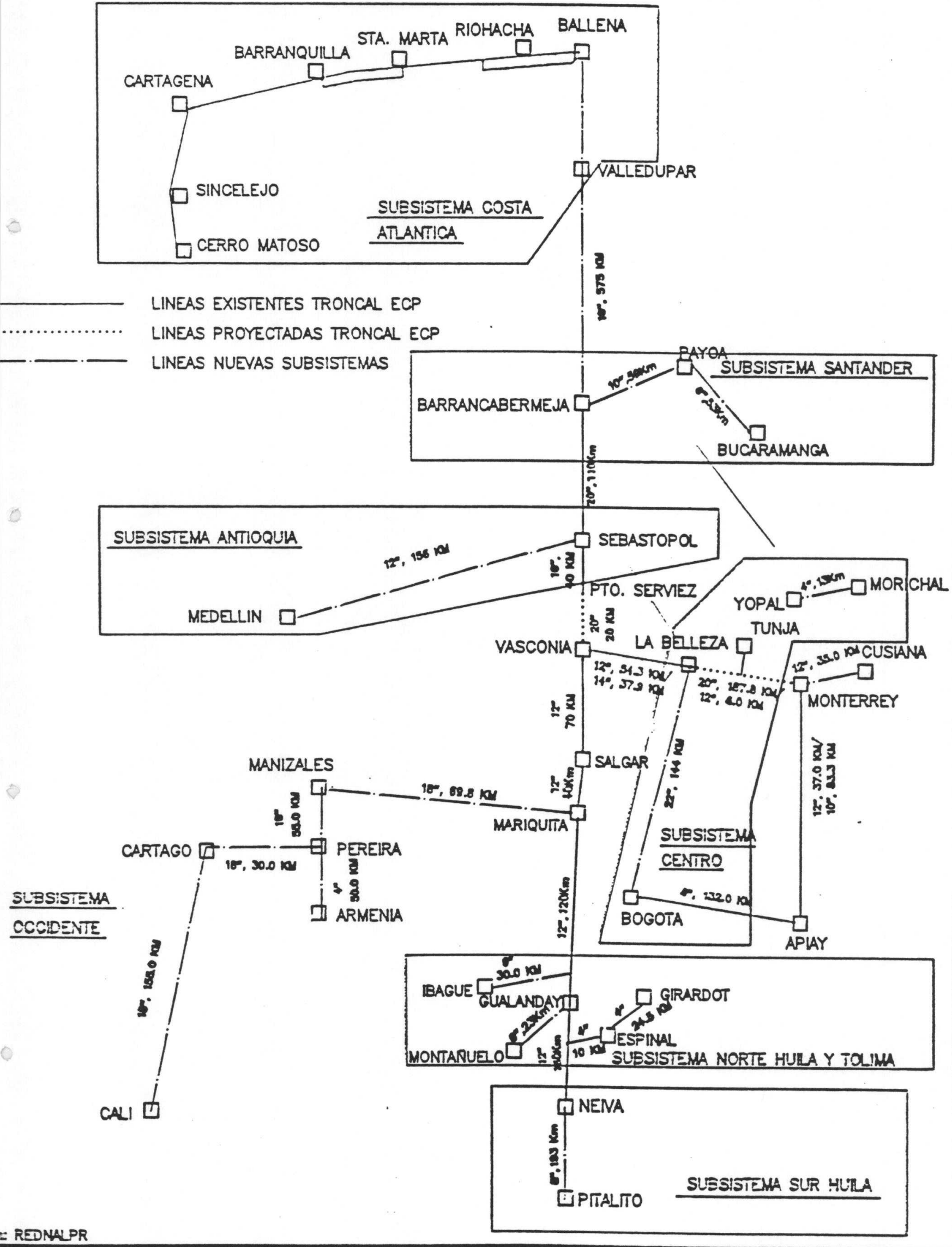

Figura 3.3. Rede de Gasodutos Projetada na Colômbia

Fonte: ECOPETROL, 1993c. 
Contudo, os benefícios esperados do programa (MMUS\$3.977) estarão concentrados $80 \%$ em Santafé de Bogotá e a região Atlântica (Figura 3.4). No primeiro caso, a alta demanda estimada para a cidade de Santafé de Bogotá explica esta participação. A grande alocação de benefícios para a região Atlântica deriva do fato da condição de zona exportadora do combustivel. As reservas de $\mathrm{GN}$ da Colômbia são de $8.300 \mathrm{GPC}\left(230,4 \mathrm{Gm}^{3}\right)$, das quais, $86,8 \%$ estão alojadas em dois campos: Chuchupa (Ballenas, La Guajira) e Cusiana (Casanare), porém, este último só começaria produção depois de 2004.

Figura 3.4

Distribuição dos Benefícios Econômicos Estimados do Programa de Massificação de Gás na Colômbia no Período 1995-2015

(Valores em dólares de 1993)

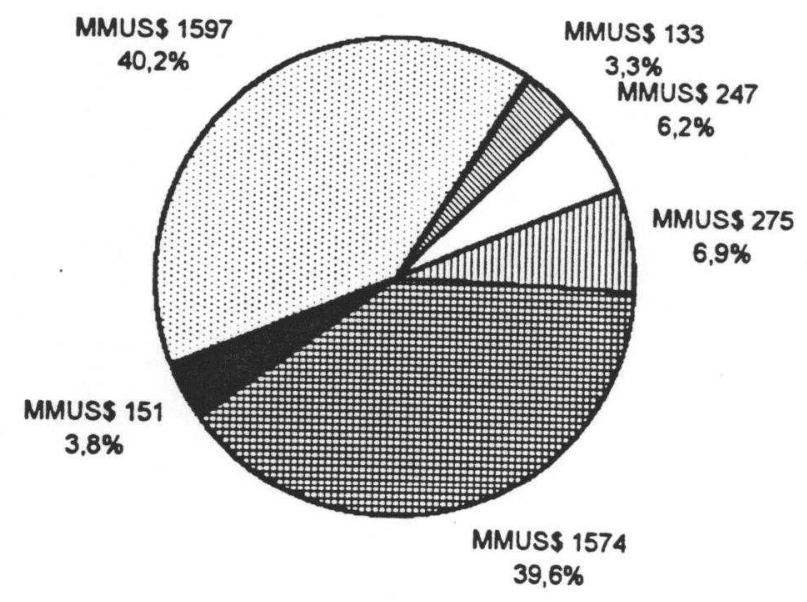

口Ocidente

M Medellin

田Bogotá

- Santander

口 Regiâo Atlántica

Q Outros

Fonte: Ecopetrol, 1993c.

Durante 9 anos, até a entrada de Cusiana, as regiōes envolvidas no programa estariam dependendo fundamentalmente do suprimento do GN de La Guajira ${ }^{34}$. Esse gás deve ser transportado através de um gasoduto central de

34 A rede projetada de gasodutos do programa de massificação de gás interconectaria os campos de produção de La Guajira, Apiay, Santander, Huila e outros menores, mas durante a primeira década do Programa, o campo de Ballenas chegaria a participar com até $93 \%$ do total de produção do país. 
$575 \mathrm{~km}$ de extensão até Barrancabermeja e logo levado aos grandes centros de consumo por intermédio de subsistemas regionais de transporte. No caso de Santafé de Bogotá, que pertence ao subsistema Centro, o GN de Ballenas teria que fazer um percurso de $927 \mathrm{~km}$; para Medellín (subsistema Antioquia) a distância seria de $842 \mathrm{~km}$ e para Santiago de Cali (subsistema Ocidente) de $1.155 \mathrm{~km}$.

As questões acima anotadas mostram que a vulnerabilidade do suprimento para os principais mercados é alta, caso acontecer uma emergência na rede de gasodutos. Uma vantagem é que a probabilidade de falha num gasoduto é muito baixa, o que não acontece, por exemplo, nos sistemas de transmissão de eletricidade. Contudo, não é possivel descartar prováveis ataques terroristas ao longo do gasoduto. Aliás, entre 1986 e abril de 1993 foram reportados 290 incidentes no oleoduto Caño Limón - Coveñas (UPME;MME, 1994). De igual forma, já foram dinamitadas várias vezes as torres do sistema de transmissão de energia elétrica na Colômbia, com conseqüências, às vezes, bastante caóticas.

Sobre essa conjuntura do país, convém pensar em medidas que permitam amenizar os efeitos negativos ante a ocorrência de um desses eventos. Novamente, pode-se trazer à tona o GLP. Uma utilização mais geralizada do GLP para o setor residencial e 0 GN para uso industrial, comercial e termelétrico, permitiria reduzir os impactos sociais adversos por uma emergência desse tipo.

As análises de demanda do GN foram realizadas por EURCOLERG (1992b), e consideraram:

- Dois cenários de projeção: alto e baixo. O cenário alto corresponde a condições ótimas de penetração do GN, sob uma alta disponibilidade do 
combustivel, preço do GN relativamente baixo, concorrente do óleo combustivel e cru de Castilla e alto desenvolvimento do GNC como combustivel para veículos. O cenário baixo, entretanto, pressupõe disponibilidades limitadas do GN e preço alto, pouca substituição de óleo combustivel e cru de Castilla, moderado desenvolvimento nos setores residencial e GNC e nenhum grande consumidor (v.g. termelétricas).

- Divisão geográfica em oito regiões. Daí surgem os subsistemas: Litoral Atlântico, Santander (Bucaramanga e Barrancabermeja), Antioquia (área Metropolitana de Medellin), Centro (Santafé de Bogotá), Norte Huila (Girardot e Espinal), Sul Huila (Neiva, Garzón e Pitalito) e Ocidente (Cali, Ibagué, Cartago, eixo cafetero, Mariquita).

- Oito classes de consumo: residencial, comercial, indústria, geração elétrica, GNC (gás natural comprimido para uso no setor de transportes), Ecopetrol (refinarias), fertilizantes e Petroquímica.

- Os energéticos substituídos para cada classe de consumo. Por exemplo eletricidade, GLP, querosene, gasolina, cocinol, carvão, cru de Castilla, etc.

Quando foi elaborado esse estudo do programa de cooperação energética da Comissão das Comunidades Europeias (CCE) com a República da Colômbia, eram incertas as expectativas sobre o gás da Venezuela (mais caro) e Cusiana-Cupiagua.

Os resultados que hoje estão disponiveis, indicam a possibilidade de abastecimento pleno (alto fator R/P) e eficiente (baixo custo) com as reservas conhecidas. $O$ cenário de demanda que mais se aproxima às condições atuais é, portanto, o cenário "alto". A Figura 3.5 ilustra o prognóstico de demanda residencial de GN e a Figura 3.6 mostra a energia elétrica substituida com GN para esse setor de consumo. 
Figura 3.5

Demanda de Gás Natural no Setor Residencial Colombiano

(Programa de Massificação de Gás)

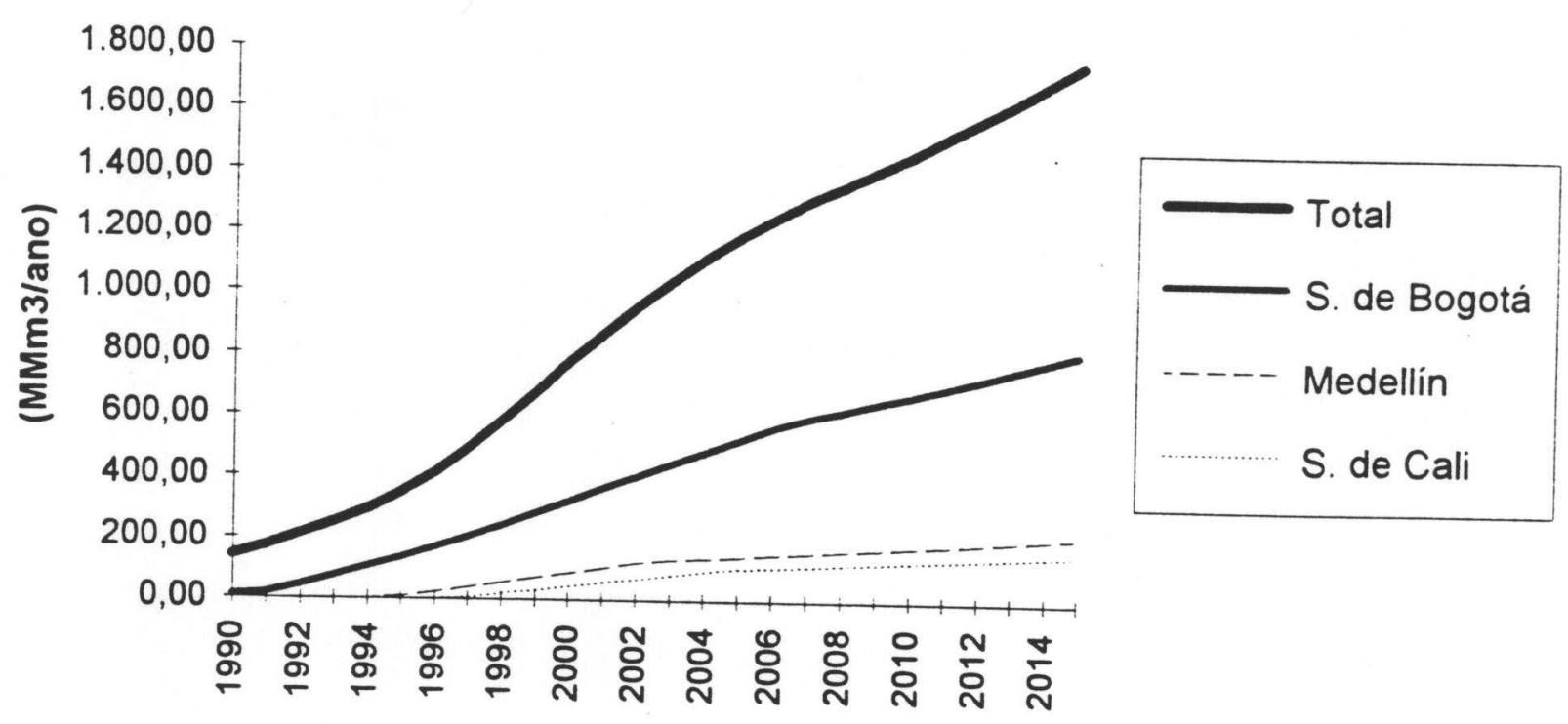

Fonte: EURCOLERG. 1992b

Figura 3.6

Demanda de Eletricidade Substituída com GN

(Programa de Massificação de Gás da Colombia)

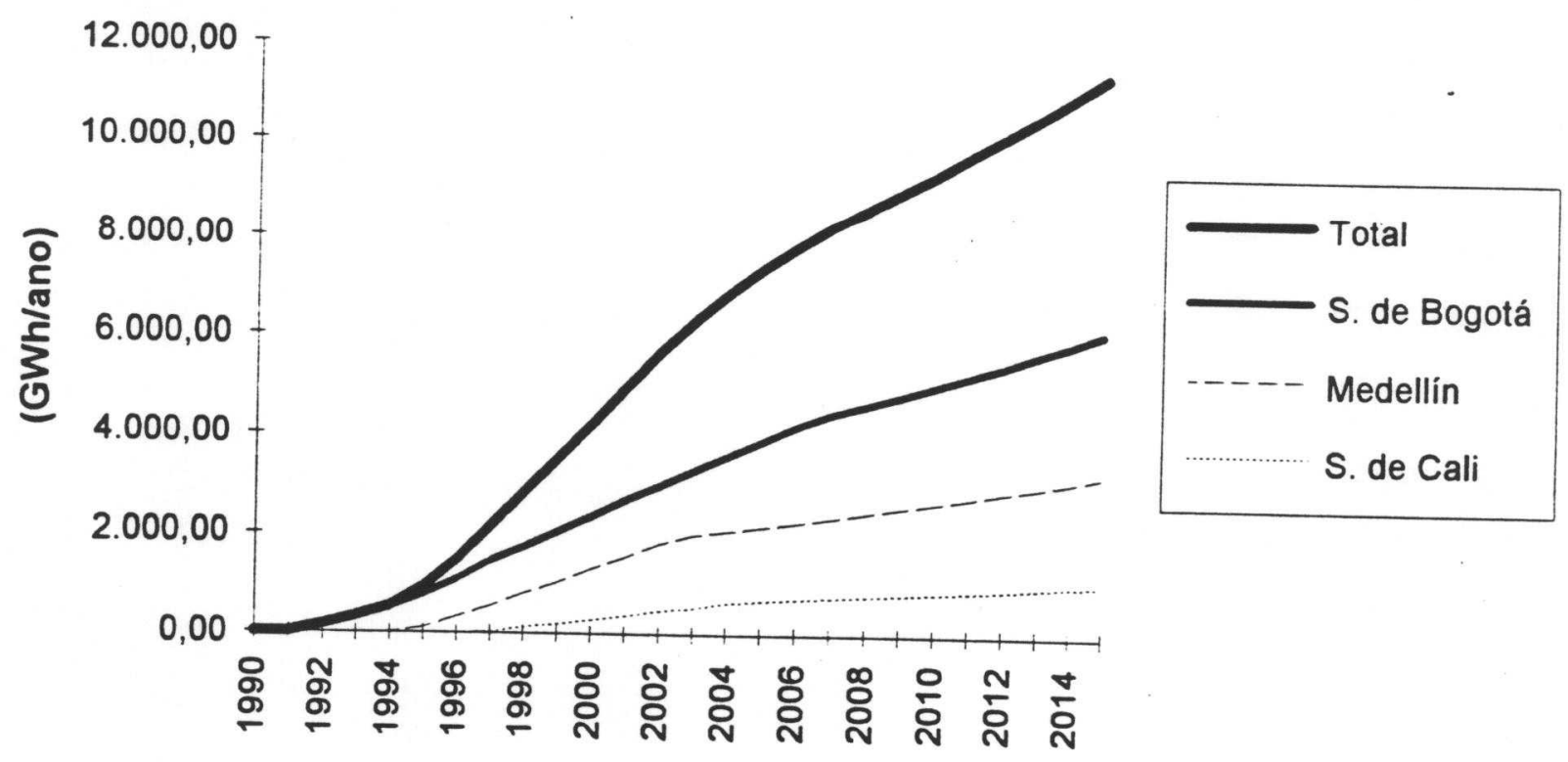

Fonte: Cálculos do autor com base em dados de EURCOLERG,1992b. 
Contudo, as taxas de penetração do GN para o setor residencial da Colômbia vão depender fundamentalmente do preço deste combustivel com relação ao preço dos seus principais substitutos: eletricidade e GLP.

Para determinar a competitividade de um produto em relação aos seus substitutos é utilizada a metodologia dos custos netback ou preços de equilíbrio.

O valor a pagar pela fatura energética de um usuário convertido para o gás natural, deve ser inferior ao valor da fatura antes da conversão, num montante que the permita ao usuário cobrir todos os custos de ligação e conversão de aparelhos e the dê algum incentivo adicional para vencer a normal resistência à mudança.

Os preços de equilibrio do $\mathrm{GN}$ resultam de resto dos preços dos energéticos concorrentes, os custos unitários de conversão, instalação e ligação, para o caso dos usuários que atualmente se utilizam de outro energético. Para novos usuários, o custo netback é a diferença entre o preço do energético concorrente e o extra-custo unitário ocasionado pela utilização de $\mathrm{GN}$ :

A análise mais atualizada deste tipo sobre preços e barreiras tarifárias para a penetração do GN foi realizada em 1993 por Alvaro Santoyo num estudo contratado pela Ecopetrol (SANTOYO, 1993) e que atualmente encontra-se sob avaliação.

O estudo considerou as novas reservas de gás natural de Cusiana e o GLP do mesmo campo, analisou-se do ponto de vista financeiro e econômico a viabilidade de penetração do GN e propôs-se as medidas necessárias e viáveis em matéria de preços e tarifas dos energéticos, assim como subsídios e financiamento dos mesmos. 
O custo econômico médio do GN na boca do poço para os próximos 5 anos, calculado para uma taxa de desconto de $12 \%$ está entre US $\$ 0,72 / \mathrm{MMBTU}$ e US\$ 0,83/MMBTU. O custo financeiro, entretanto, para 1993 é de US\$ 0,82/MMBTU.

A Tabela 3.2 mostra os custos city gate encontrados para os principais mercados do Plano de Gás.

Tabela 3.2

Custos City-Gate do GN para o Programa de Massificação de Gás na Colômbia. (Valores em dólares de 1993)

\begin{tabular}{|l|c|}
\hline \multicolumn{1}{|c|}{ REGIĀO } & CUSTO (US\$/MMBTU) \\
\hline Santafé de Bogotá & 2,01 \\
Eixo Cafeeiro e Valle & 2,47 \\
Medellín & 2,40 \\
Bucaramanga & 1,31 \\
Junto ao gasoduto-tronco & 1,75 \\
\hline
\end{tabular}

Fonte: SANTOYO, 1993.

Santoyo determinou que o GLP, sob condiçōes de oferta sem restrições (o país passaria a ser exportador de propano), é a principal fonte de energia concorrente do GN para usuários de consumos médios do setor residencial. Para os usuários de baixos consumos, a principal fonte competidora seria a eletricidade. Isso, considerando o regime tarifário atual do setor elétrico.

A conclusão anterior do pesquisador é congruente com os resultados encontrados no capitulo anterior desta dissertação. Os altos subsídios para as primeiras faixas de consumo dos estratos sócio-econômicos baixos impede uma penetração efetiva do substituto. 
A sugestão de Santoyo para amenizar o problema, que resulta das elevadas taxas de desconto implícitas dos usuários, é de prover financiamentos tanto da ligação quanto dos custos de conversão.

A afirmação anterior é a solução clássica que se dá para este tipo de barreira. A idéia é diluir $o$ investimento inicial em pequenas parcelas durante um período de tempo suficientemente extenso. Desta forma, os custos de capital são enxergados pelos usuários como custos de operação.

Para um cenário de tarifas de eletricidade alto, isto é, quando forem atingidas as metas das Resoluções 090/91 e 070/93, o menor valor de equilibrio é determinado pelo preço do GLP concorrente, para todos os estratos sócioeconômicos e para todas as cidades, quando o consumo de eletricidade dos usuários é de até $20 \%$ inferior à média.

Medellin é a cidade que teria mais problemas para promover o consumo de GN. A proposta do consultor é efetuar transferências para a empresa distribuidora para que esta possa aguentar financeiramente os subsídios que daria aos usuários de menores recursos.

Felizmente, a empresa distribuidora de GN em Medellín será a mesma empresa que atende o serviço de eletricidade da cidade. Essa vantagem é identificada no fato de que parte dos benefícios esperados com a utilização do GN ou GLP no setor residencial representa uma redução da demanda de eletricidade desse setor, atualmente subsidiado. A mesma empresa distribuidora de energia elétrica seria, então, a mais interessada em conseguir uma maior penetração do substituto.

Nas Empresas Públicas de Medellín (EEPPM), já começaram a prestar o serviço de fornecimento de gás. Inicialmente, implantaram-se projetos piloto, atendidos com GLP numa primeira fase. Em 1995, com a disponibilidade do 
GN de La Guajira, as EEPPM (Gerência do Gás) forneceriam o serviço de gas encanado (EEPPM, 1992) (EEPPM, 1993).

Uma das questões que também afetam a penetração do gás (quer GN, quer GLP) no setor residencial é a segurança. A falta da "cultura de gás" em parte do território colombiano tem levado ao prejulgamento da alta periculosidade destes combustiveis comparado, por exemplo, com a eletricidade.

Pesquisas realizadas na Espanha (MONTENEGRO, 1992), revelam que esses preconceitos não são corretos. As causas de incêndio doméstico, para igual energia consumida, têm as seguintes percentagens:

GLP

Eletricidade $38 \%$

Combustíveis liquidos e sólidos $37 \%$

Gás Natural $15 \%$ $10 \%$

Porém, em termos de acidentes fatais (mortes/10 milhões de pessoas), muda a ordem:

Eletricidade

GLP

Combustiveis liquidos e sólidos Gás natural
47

38

15

12

Segundo as estatísticas levantadas nos últimos 20 anos, em Catalunha (Espanha), no estudo de Montenegro (1992), todos os acidentes fatais decorrentes da utilização de GLP ou GN foram devidos ao não cumprimento das normas de segurança.

Para o caso colombiano, infelizmente, existe um alto risco entre a população de baixa educação de não respeitar as normas de segurança definidas pelos organismos competentes no país. Aliás, entre 1990 e 1993, foram reportados ao CISPROQUIM (Centro de Información de Seguridad sobre Productos 
Químicos) 140 emergências devido a acidentes com GLP (RUEDA, 1993). De acordo com as estatísticas deste centro, as emergências com GLP ostentam o maior número de emergências notificadas.

É responsabilidade institucional, portanto, oferecer aos potenciais usários as informações adequadas de utilização dos combustiveis e equipamentos de uso final, para evitar riscos e consequentemente os prejuízos sociais.

Definitivamente, o GN é de suma importância para a Colômbia, pois além de ser o pilar do Programa de Massificação de Gás, as suas implicações sociais são evidentes, principalmente os seus efeitos macroeconômicos e à distribuição de benefícios para a sociedade.

No entanto, deve-se analisar com cuidado o GLP, agora com uma potencial maior disponibilidade a partir do gás associado de Cusiana, rico em líquidos. Uma redução no custo de oportunidade deste combustivel concorrente do GN, especialmente para uso residencial, pode mudar a participação do $\mathrm{GN}$ no mercado dos energéticos. Do ponto de vista de análise de flexibilidade, uma repartição do mercado residencial mais homogênea entre o GLP. e o GN permitiria reduzir os impactos negativos caso acontecesse uma emergência no abastecimento de um ou outro combustível.

Finalmente, é importante anotar que, felizmente, existe consenso político sobre a necessidade de mudar a atual matriz de consumo de energéticos para o setor residencial, e que a melhor forma para se conseguir esta finalidade, é incentivando a utilização de combustiveis gasosos, dos quais a Colômbia têm abundantes reservas. 


\section{A PROBLEMÁTICA DOS USOS FINAIS DA ELETRICIDADE DESLOCADA DA COCÇÃO}

Este capítulo tem como objetivo analisar as possiveis alternativas de utilização da eletricidade deslocada da cocção elétrica para outros usos finais mais eficientes, não apenas do ponto de vista técnico mas também econômico.

A análise, no entanto, está restrita a três alternativas: (1) Eletrificação do Transporte Ferroviário, (2) Eletrificação do Transporte de Massa e (3) Crescimento Vegetativo da Demanda. Isto é, o enfoque desta parte da dissertação estará voltada, basicamente, para o setor de transportes no modal ferroviário e transporte urbano. $O$ enfoque para o terceiro ponto, crescimento vegetativo da demanda, parte do pressuposto de que não acontecerá nenhuma mudança estrutural no consumo de demanda de eletricidade e que simplesmente a tendência normal de crescimento desta, absorveria os excedentes resultantes da substituição de energia elétrica na cocção por outros energéticos (vide Capítulo 3).

\subsection{Antecedentes}

A escolha do setor de transportes não é fortuita. Em 1992, este setor foi o maior consumidor de energia final na Colômbia, participando de $30 \%$ das 290.434 Tcal totais demandadas na Colômbia. Porém, convém anotar que esse setor demandou $57,9 \%$ do total de energia secundária consumida no pais. Atualmente, esse setor depende inteiramente de derivados do petróleo como fontes energéticas para seu funcionamento. Aliás, das $113.385,9$ Tcal produzidas nas refinarias do país, $57,4 \%$ foram devotadas para o setor de transporte. 
Devido às restrições de oferta interna de derivados, é necessária a importação de alguns derivados do petróleo, principalmente gasolina. Em 1992, foram importados, em média, 35.688 bbl/d desse combustível (NULE;MME, 1993) e $36.309 \mathrm{bbl} / \mathrm{d}$ entre janeiro e novembro de 1993, segundo os dados de ECOPETROL (1993e).

O déficit de gasolina motor no pais é crônico, segundo ilustrado na tendência da curva da Figura 4.1. O abastecimento normal do combustivel é conseguido por meio de produção interna limitada a uns $83.000 \mathrm{bbl} / \mathrm{d}$, importações e, recentemente, mediante contratos de maquilagem ${ }^{35}$ processando cru nacional nas refinarias de Trinidade e Tobago (REVISTA CARTA PETROLERA, 1994).

Figura 4.1

Evolução do Consumo, Produção e Importações de Gasolina Motor na Colômbia

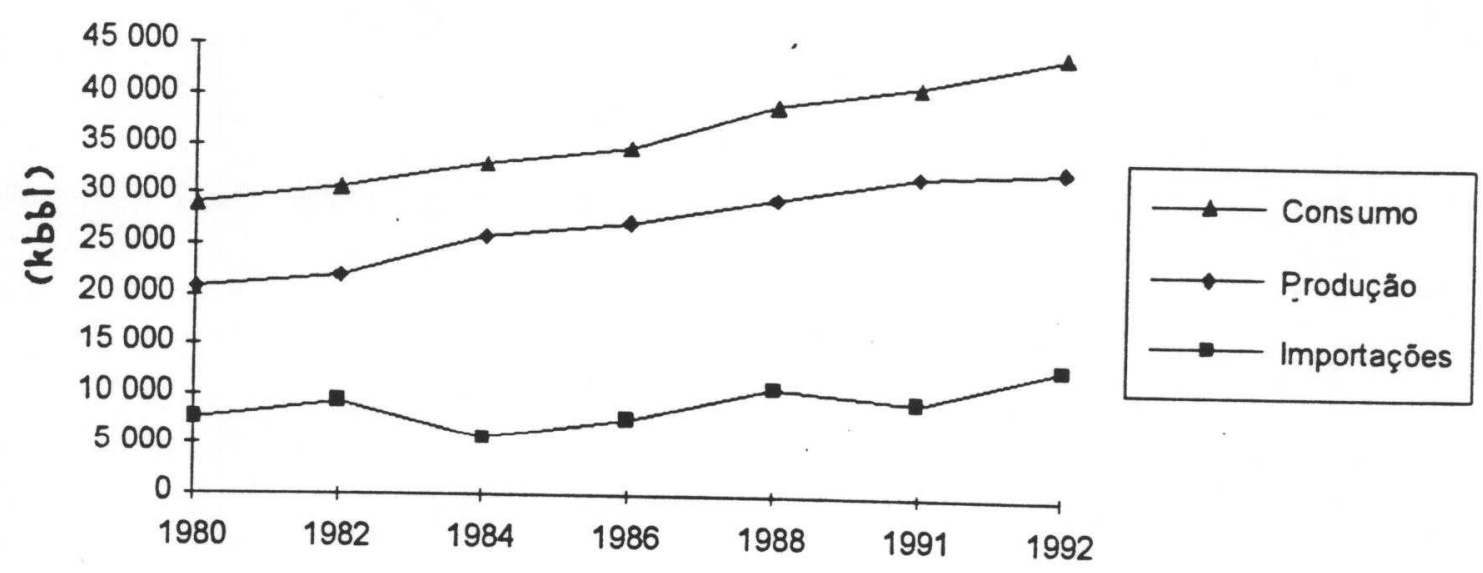

Fonte: MENA;MME, 1990b e NULE;MME, 1993

Contudo, o Governo Nacional procura alternativas pàra reduzir o consumo de gasolina e adiar a construção da projetada refinaria. Os projetos que contribuem para esse objetivo são: utilização de Gás Natural Comprimido (GNC), medidas de conservação e uso da eletricidade como substituto. Os

35 Uma operação comum de maquilagem ou de aperfeiçoamento passivo, consiste fundamentalmente na entrega de matéria prima a uma companhia processadora, a qual devolve ao produtor mercadorias ou bens finalizados. Isto é, o valor agregado é só o trabalho pela manufatura realizada. 
estudos sobre GNC indicam a conveniência de utilização no setor (REVISTA ACOGÁS, n.7, 1993 e ARANGO et al, 1990). Com relação à conservação de energia no setor de transporte, infelizmente, ainda não foi realizado nenhum programa específico. $O$ caso da eletricidade é avaliado em parte nesta dissertação.

Uma análise do ponto do vista dos usos finais, como a que vem a seguir, facilita a identificação dos problemas e oportunidades de solução, pois podese determinar onde se devem realizar os maiores esforços para se obter resultados favoráveis mais rapidamente.

Os combustiveis utilizados pelo setor de transporte na Colômbia são:

- Gasolinas: destinadas basicamente para transporte rodoviário.

- Óleo diesel: seu principal uso é também para o modal rodoviário, mas com alguma participação no transporte marítimo, fluvial e ferroviário.

- Querosene: utilizado para aviação.

- Óleo combustivel: uso nos modais marítimo e ferroviário.

Contudo, em termos de Teracalorias, os principais energéticos são a gasolina e o diesel (Figura 4.2 e Tabela 4.1). A participação destes combustiveis nos diferentes modos de transporte (rodoviário, ferroviário, fluvial e maritimo) que os utilizam, é apresentada nas Figuras 4.3 e 4.4. Relativamente, o transporte rodoviário consome a maior parte das gasolinas e do óleo diesel utilizados no setor de transportes da Colômbia, mas em valores absolutos, a gasolina contribui em $85,4 \%$ das necessidades energéticas do transporte rodoviário. 
Tabela 4.1

Evolução do Consumo de Derivados do Petróleo pelo Setor de Transportes na Colômbia (Tcal)

\begin{tabular}{|r|r|r|r|r|r|}
\hline \multicolumn{1}{|c|}{ ANO } & GASOLINAS & DIESEL & QUEROSENE & \multicolumn{1}{c|}{$\begin{array}{c}\text { ÓLEO } \\
\text { COMBUSTIVEL }\end{array}$} & $\begin{array}{r}\text { NÃO } \\
\text { ENERGÉTICOS (1) }\end{array}$ \\
\hline 1980 & $31.477,1$ & $6.262,9$ & $4.455,5$ & 483,8 & 667,2 \\
1981 & $32.524,0$ & $6.189,0$ & $5.059,3$ & 343,1 & 674,8 \\
1982 & $33.323,2$ & $6.530,9$ & $5.507,4$ & 382,6 & 655,1 \\
1983 & $34.659,0$ & $7.263,1$ & $5.147,1$ & 294,5 & 723,8 \\
1984 & $36.571,1$ & $7.322,0$ & $4.438,2$ & 167,8 & 699,8 \\
1985 & $38.193,0$ & $7.547,6$ & $4.598,7$ & 207,2 & 621,8 \\
1986 & $38.834,8$ & $7.795,1$ & $4.157,2$ & 178,2 & 581,3 \\
1987 & $42.055,0$ & $6.993,4$ & $4.469,5$ & 461,6 & 850,9 \\
1988 & $41.892,5$ & $7.849,7$ & $4.478,6$ & 106,6 & $1.067,3$ \\
1989 & $42.265,2$ & $7.912,1$ & $4.511,9$ & 110,3 & $1.099,0$ \\
1990 & $44.288,1$ & $9.576,4$ & $5.183,1$ & 152,0 & $1.489,7$ \\
1991 & $46.770,4$ & $9.758,4$ & $5.477,5$ & 127,5 & 833,6 \\
1992 & $49.252,6$ & $9.940,3$ & $5.771,8$ & 102,9 & 177,5 \\
\hline
\end{tabular}

(1) Corresponde a lubrificantes e asfaltos produzidos nas refinarias.

Figura 4.2

Evolução do Consumo de Derivados do Petróleo no Setor de Transportes na Colômbia
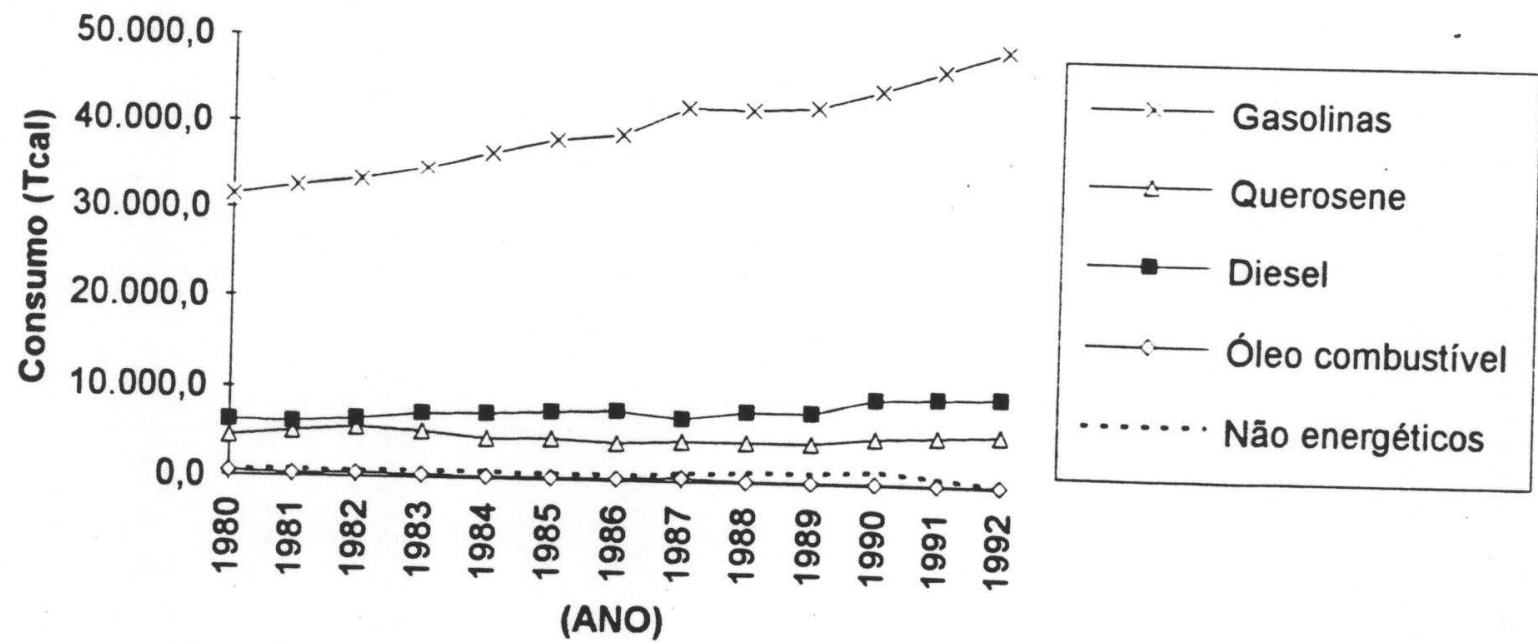

Fonte: MENA;MME, 1990b e NULE;MME, 1993. 
Figura 4.3

Consumo de Gasolinas no Setor de Transportes da Colômbia

Participação Relativa em 1992

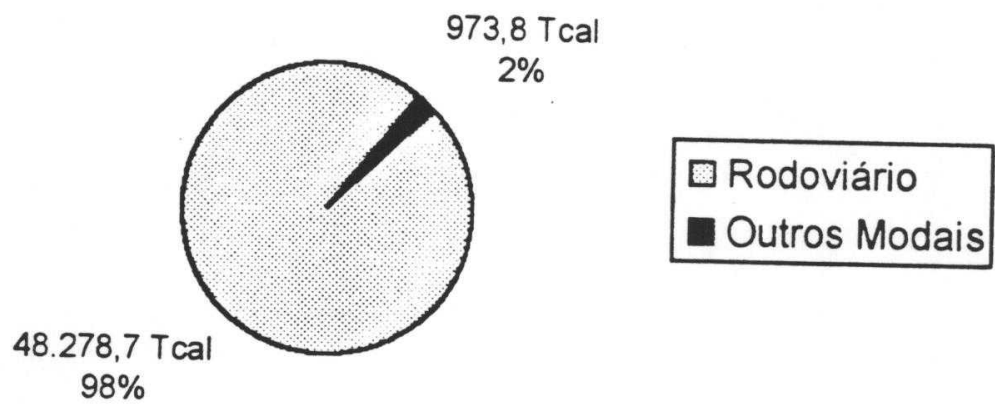

Fonte: Cálculos do autor com base em dados de NULE:MME. 1993

Figura 4.4

Consumo de Óleo Diesel no Setor de Transportes da Colômbia

Participação Relativa em 1992

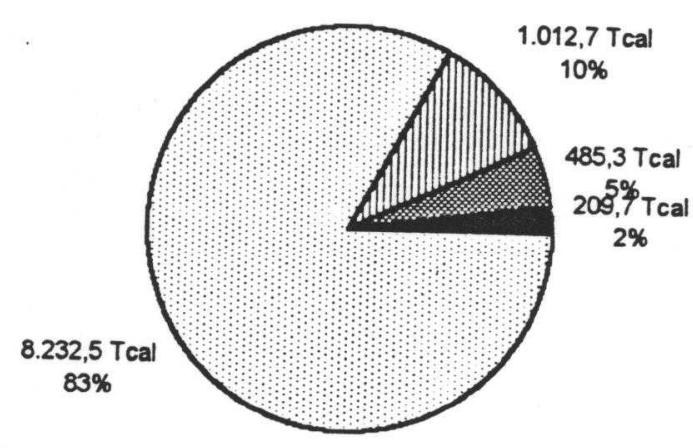

QRodoviário m Marítimo Rluvial

Ferroviário

Fonte: Cálculos do autor com base em dados de NULE; MME, 1993.

Agora, de acordo com as Figuras 4.5 e 4.6, conclui-se que:

- O principal uso da gasolina no transporte rodoviário é para mobilização de passageiros, pois segundo as estimativas do MME, $76 \%$ do consumo desse energético foi para essa finalidade. 
- O óleo diesel, entretanto, tem sua principal utilização para o transporte de carga. Aliás, a maior parte da frota de carga em 1993 (em torno de 158.000 caminhões) funciona com esse combustivel, conseqüência da renovação acelerada desses veículos nestes últimos anos. De fato, a taxa de crescimento anual da frota de carga em 1993 foi do 13\% (SUPLEMENTO Especial EL TIEMPO, 28 feb. 1994).

As Figuras 4.7 a 4.10 mostram os usos finais das gasolinas e do óleo diesel no transporte rodoviário de passageiros e de carga. No caso das gasolinas, o consumo é compartilhado em partes iguais pelo serviço público e serviço privado, porém, com os preços subsidiados do combustivel, os benefícios sociais não estão igualmente distribuidos. Para o diesel, no entanto, o consumo está mais concentrado no serviço público. Nesse caso, a frota privada consome $22 \%$ do diesel enquanto $78 \%$ é consumido pelo serviço de transporte público de passageiros.

Devido ao problema técnico que apresentaria o uso da eletricidade, a penetração deste energético só é considerada para o transporte urbano de passageiros, mais especificamente, em sistemas coletivos de transporte público e para transporte ferroviário. Segundo as análises apresentadas anteriormente, os combustiveis que seriam substituídos são as gasolinas (transporte rodoviário) e o óleo diesel (transporte rodoviário e transporte ferroviário).

Com relação à eficiência de conversão, o setor de transportes mostra o menor valor, seguido pelo setor residencial. Em 1992, a energia final gasta por esse setor foi de 65.553,9 Tcal contra 10.191,1 Tcal que se estima como energia útil (NULE;MME, 1993). Essa baixíssima eficiência, $15,5 \%$, é devida principalmente ao reduzido rendimento que têm os equipamentos utilizados no setor. 
Figura 4.5

Consumo de Gasolinas no Transporte Rodoviário em 1992 por Tipo de Serviço na Colômbia

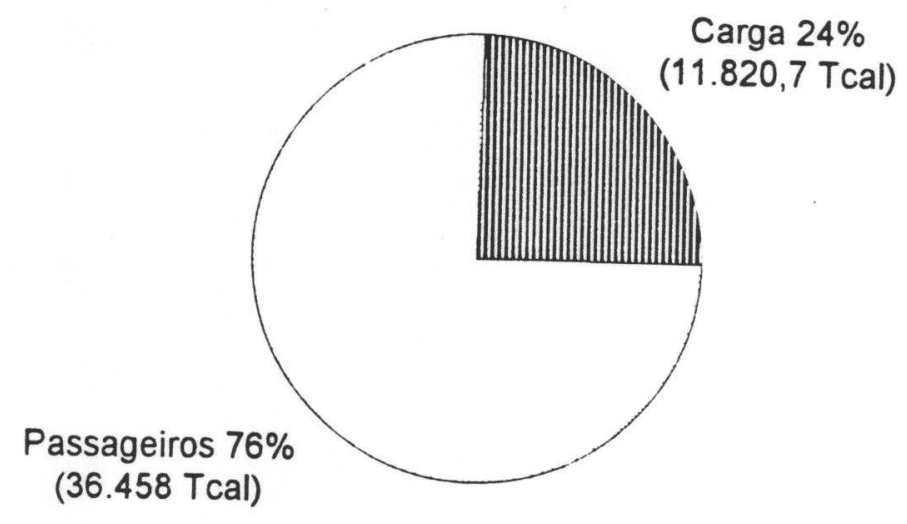

Figura 4.6

Consumo de Diesel no Transporte Rodoviário em 1992 por Tipo de Serviço na Colômbia

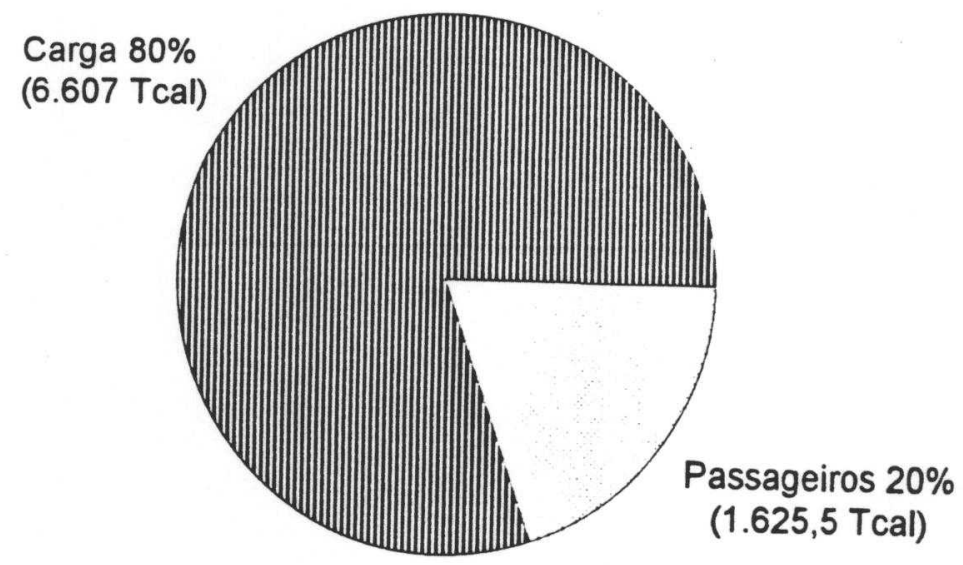

Fonte: NULE;MME, 1993 
Figura 4.7

Consumo de Gasolinas no Transporte Rodoviário de Passageiros em 1992

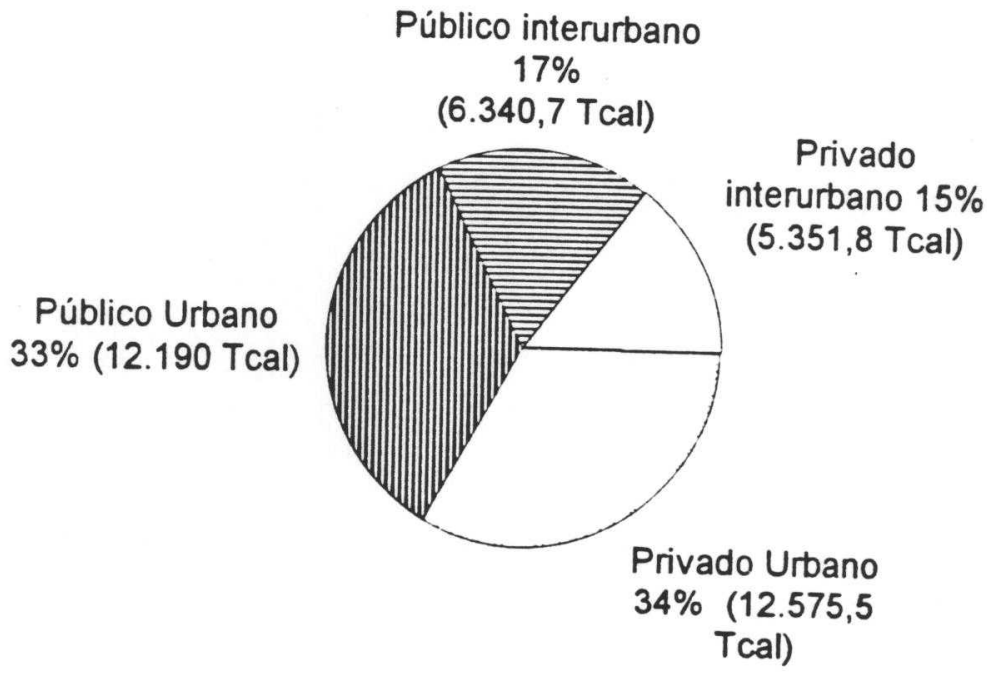

Figura 4.8

Consumo de Diesel no Transporte Rodoviário de Passageiros em 1992

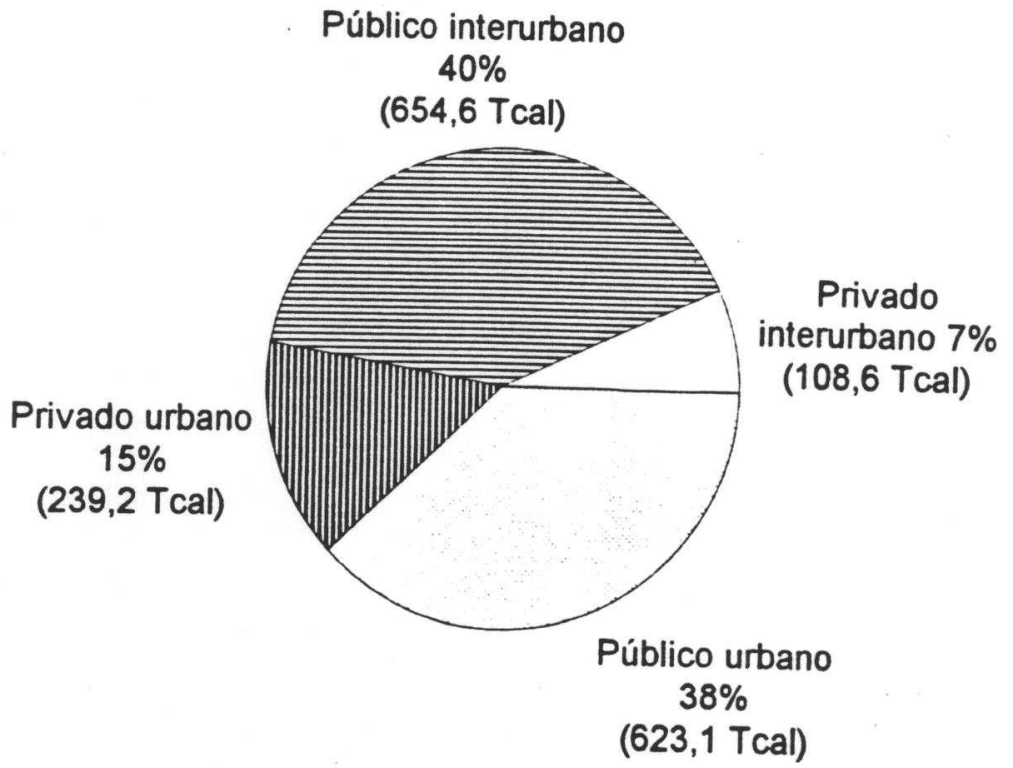

Fonte: NULE;MME, 1993 
Figura 4.9

Consumo de Gasolinas no Transporte Rodoviário de Carga em 1992

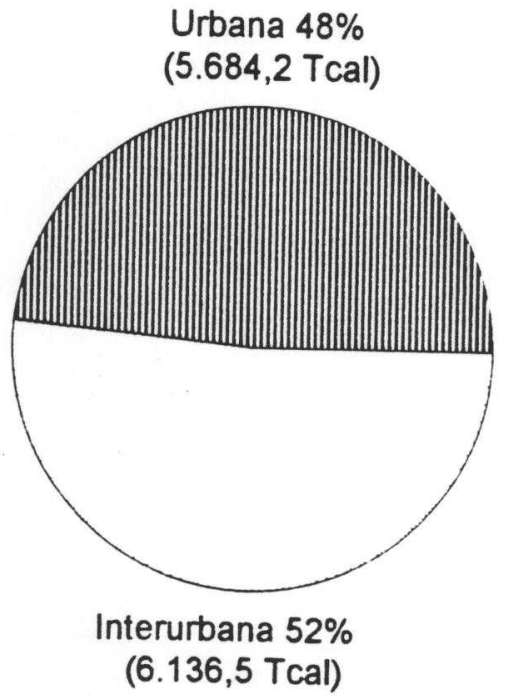

Figura 4.10

Consumo de Diesel no Transporte Rodoviário de Carga em 1992

Interurbana $87 \%$

$(5.720,2 \mathrm{Tcal})$

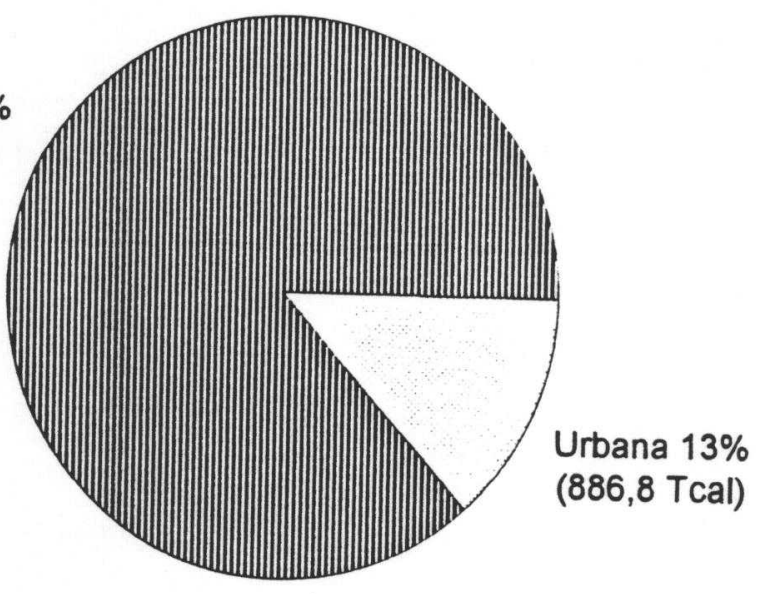

Fonte: NULE;MME, 1993 
As alternativas que vão ser apresentadas nos próximos itens, envolvem tecnologias eficientes para movimentação dos sistemas de transporte coletivos de passageiros ou carga, mediante a utilização de eletricidade.

Os problemas mais sérios de transporte urbano estão nas principais urbes da Colômbia: Santafé de Bogotá e a zona metropolitana do Vale de Aburrá (que compreende a fusão geográfica dos municipios de Medellin, Envigado, Itagüí, La Estrella, Sabaneta, Bello, Copacabana e Girardota). Essas cidades do interior do país são, por sua vez, os lugares onde se espera uma maior substituição da energia elétrica por GN ou GLP para cocção doméstica a curto e médio prazo. Isso facilitaria a disponibilidade de oferta de eletricidade para o setor de transportes, principalmente em forma de capacidade de fornecimento de potência.

Esta dissertação, porém, não visa efetuar um estudo exaustivo do setor de transportes na Colômbia, mas, realizar uma análise de carater global da energia consumida e identificar as vantagens e desvantagens de se utilizar a eletricidade para participar como fonte energética alternativa e de contribuir com idéias e sugestões sobre o plano de transportes que atualmente elabora esse Ministério na Colômbia.

\subsection{Eletrificação do Setor Ferroviário}

O sistema ferroviário da Colômbia teve o seu começo em 1915, com a construção de uma linha entre Santiago de Cali e o porto de Buenaventura (Oceano Pacífico). Na década de 1920, foram terminadas as linhas Santafé de Bogotá-Salgar e Medellin-Puerto Berrio que logo depois seriam complementadas com a ferrovia do Atlântico até a cidade de Santa Marta (BID, 1982), (ETMVA;ADEMINAS, 1993). 
No entanto, o sistema ferroviário atual não é muito diferente. A rede ferroviária da Colômbia consiste de duas linhas-tronco, com $1.461 \mathrm{~km}$ de extensão. Essas linhas são Santafé de Bogotá-Santa Marta, com conexões a Medellín e Bucaramanga e Santiago de Cali-Buenaventura. Estas linhas não estão interligadas devido a inundaçōes do rio Cauca que aconteceram em 1973 e destruiram a via de interconexão (BID, 1982) e (FNC, 1988).

Em 1992, foram transportadas 242.917 kton-km de carga paga, enquanto em 1974 que foi o ano em que se atingiu o máximo volume mobilizado por meio de ferrovias, foram quase $1.400 .000 \mathrm{kton}-\mathrm{km}$ (DANE). Existem no pais somente 59 locomotivas e, destas, 18 são utilizadas para dar manutenção ${ }^{36}$.

Além disso, as condiçōes topográficas da Colômbia desfavorecem o serviço ferroviário. Em torno de $20 \%$ do sistema existente foi construído sobre terrenos muito abruptos, portanto, com altas inclinações e pequenos raios de curvatura que complicam a operação do sistema. Segundo FERROVIAS (Empresa Colombiana de Vias Férreas), as velocidades médias dos trens são muito baixas $(18 \mathrm{~km} / \mathrm{h})$ e apresentam um alto índice de descarrilamentos $(9,1 \%)^{37}$.

Essas condições de operação do sistema ferroviário são simplesmente um reflexo da caótica situação institucional, administrativa, financeira e operativa em que se encontra neste setor. O sistema ferroviário era controlado pela empresa FNC (Ferrocarriles Nacionales de Colombia) que foi liquidada segundo o Decreto-Lei 1586 de 1989 (MOPT -Ministerio de Obras Públicas y Transporte-, 1990). Esse Decreto-Lei formou parte de um conjunto de leis que 36 DNP. Informações Gerais sobre Transporte Ferroviário. Comunicação Pessoal. Depto. de Infra-
estrutura e Energia, Div. Transporte. Mar. 1994.

37 O índice de descarrilamentos é definido como a relação entre o número de vezes que uma unidade sai do seu trilho e o número total de viagens de serviços. 
visaram modernizar o setor ferroviário, com a finalidade de recuperar o sistema.

O embasamento institucional da nova estrutura do sistema ferroviário consiste na separação de funções do Estado e do setor privado. A intenção do Governo é pôr o sistema ferroviário em condições similares aos outros modos de transporte. Desta forma o Estado assume os custos relacionados com a via, colocando-la a disposição de operadores, quer empresas mixtas, quer empresas privadas.

FERROVIAS (Empresa Colombiana de Vias Férreas), empresa industrial e comercial do Estado, é a nova entidade encarregada da recuperação, manutenção, expansão, regulamentação e coordenação do tráfego da rede ferroviária. Seus recursos provém da coleta de pedágios e impostos sobre a gasolina.

\section{A empresa STF (Sociedad Colombiana de Transporte Ferroviario S.A.),} formada com capital mixto (inicialmente, o Estado com $51 \%$ das ações e o resto para o setor privado), é atualmente a principal operadora da rede. Em 1993, esta empresa estimou suas perdas por MMUS\$6, mas espera investir em 1994 MMUS\$16 para reparações de equipamentos. A meta de toneladas a transportar em 1994 é de 1.300.000 (SUPLEMENTO especial EL TIEMPO, 2802-94). Para efeitos de comparação, em 1974 foram transportadas 3.400 .000 ton, isto é, 2,6 vezes o volume de carga esperado ainda para este ano.

Como pode-se notar, o sistema ferroviário da Colômbia é ainda bastante incipiente, a pesar de já existir uma estrutura institucional definida. Além disso, 
segundo entrevistas realizadas com FERROVIAS ${ }^{38}$, os esforços financeiros para o curto e médio prazos das empresas envolvidas no setor estarão levando à recuperação do sistema atual. Disto resulta que FERROVIAS não está considerando dentro de seu plano de expansão a eletrificação parcial ou total do sistema.

A experiência internacional mostra que só são eletrificadas as ferrovias em países que dispõem de energia elétrica de baixo custo (v.g. hidrelétricas), onde não existe diesel e nos países que têm um grande tráfego de passageiros ou carga (TOGNO, 1982). Infelizmente, os volumes de carga transportados na rede nacional são muito baixos. Em 1990, ano em que foi liquidada a empresa FNC, a carga mobilizada por ferrovias representou somente $4 \%$ do volume total de carga movimentada na Colômbia.

Um dos fatores que mais incidiram na restrição de volume de carga a se transportar de trem é o tamanho da bitola da rede nacional. Segundo um estudo elaborado pelo MIT (Massachusetts Institute of Technology) em 1975 (durante a década em que foi atingida a máxima utilização da rede), foi identificado como principal problema do sistema ferroviário colombiano o fato da estreita bitola utilizada $(914 \mathrm{~mm})$, limitando a velocidade e o transporte de grandes cargas (BID, 1982).

A anterior consideração mostra que, mesmo a Colômbia que coloca energia elétrica de baixo custo à disposição, a eletrificação das ferrovias só seria viável para vias com bitola padrão $(1.435 \mathrm{~mm})$ e grandes volumes de carga a transportar. A médio prazo, é impensável que o país invista na remodelação da infra-estrutura atual, pois as prioridades estão enfocadas na recuperação da

38 Entrevistas celebradas em março de 1994 com pessoal executivo: Dr. Bernardo Moreno (Vicepresidente de Operações), Dr. Iván Darío Almeyda (Diretor de Acordos Operacionais) e o Dr. Jaime Alberto Suarez (Diretor de Equipamentos e Segurança). 
deteriorada rede existente. Contudo, no passado, existiram analistas que já haviam recomendado a eletrificação de trechos da rede ferroviária nacional (PRADA, 1961), mas com base em estudos superficiais que não garantiam o sucesso econômico do novo sistema.

No entanto, é conveniente que, para novas expansões do sistema ferroviário seja reavaliada a utilização de bitola estreita e começe a se introduzir o uso de bitola padrão. Além das vantagens anotadas anteriormente pela maior velocidade operacional e maiores volumes de carga que se poderiam atingir, está o fato da disponibilidade de equipamentos. A adoção de novo equipamento e de peças de reposição para bitola de $914 \mathrm{~mm}$ é bem mais difícil do que para equipamento padronizado e com grande disponibilidade no mundo todo. As expansões e remodelações de trechos importantes da rede ferroviária podem ser realizadas acrescentado um terceiro trilho, o que permitiria a compatibilidade entre os equipamentos.

Porém, na Colômbia, existe um caso que merece um estudo mais aprofundado com relação à possibilidade de eletrificação. Em 1990, foram produzidas 13 milhões de toneladas de carvão no complexo mineiro de El Cerrejón (La Guajira, zona setentrional da Colômbia), mas com um potencial de produção de 15 milhões de toneladas por ano (MENA; MME, 1990a). Todo o carvão produzido é exportado e é transportado através de uma ferrovia privada de $150 \mathrm{~km}$ com bitola padrão $(1.435 \mathrm{~mm})$ entre a mina e o porto. Essa ferrovia está situada numa zona plana e semi-desértica, sem maiores obstáculos geográficos. Até 1992, o sistema elétrico que atendia o complexo de EI Cerrejón era relativamente vulnerável, pois pertence ao sistema do litoral atlântico, outrora, altamente deficitário de eletricidade. Com a interconexão elétrica Cuestecitas (Colômbia)-Cuatricentenario (Venezuela) ${ }^{39}$, em 1992, o 39 Interconexão realizada através de uma linha de transmissão a $230 \mathrm{kV}$ e $125 \mathrm{~km}$ e com uma
capacidade efetiva inicial de $100 \mathrm{MW}$ de potência. 
serviço de energia elétrica para o complexo mineiro, que se alimenta da subestação Cuestecitas, tornou-se garantido.

O estudo feito por ALSTON (1984) para o BM determinou que existem muitos parâmetros que influenciam o valor do tráfego crítico anual para o qual a eletrificação da ferrovia é economicamente viável. Esse valor é sensivel, entre outros fatores, ao custo de oportunidade de capital, ao custo dos investimentos, preço dos energéticos, e nível de consumo energético e tipo de terreno. Análises de sensibilidade realizadas por Alston, mostram que esse volume critico de carga pode estar entre 5 e 22 milhões de toneladas brutas por ano, faixa na qual se encaixa o caso da ferrovia de El Cerrejón.

\subsection{Eletrificação de Sistemas de Transporte de Massa (STM)}

A eletrificação de STM está relacionado com a utilização da eletricidade em sistemas coletivos de transporte urbano. A adequada prestação desse serviço público é motivo de preocupação de planejadores e instâncias políticas pelas implicações sociais a elas associadas.

Segundo ACEVEDO e BOCAREJO (1993), existem dois fenômenos complementares para se descrever a situação atual do tráfego urbano na Colômbia: um, é o congestionamento generalizado em várias zonas das cidades e em muitas horas do dia; o outro, é a desorganização.

O congestionamento é devido ao excesso de demanda sobre a oferta vial e a desorganização é devida tanto às deficiências da infra-estrutura (vias em má estado, semáforos estragados, etc.) quanto da incapacidade das autoridades de coordenar e manter a fluidez do sistema.

As análises sobre projetos de eletrificação de STM visam ajudar à solução do primeiro problema, pois como foi definido no estudo de ACEVEDO e 
BOCAREJO (1993), a política de transporte deve-se fundamentar em dois propósitos complementares: Dar prioridade ao transporte público no uso da infra-estrutura vial escassa e ao desestímulo à utilização indiscriminada do carro particular nas vias em horários de congestionamento. 0 segundo problema, entretanto, deve ser resolvido principalmente na esfera institucional, ○ qual não é tema desta dissertação.

No entanto, é sabido que os problemas mais graves de transporte urbano acontecem nas principais cidades do país. Alguns deles, produto da inexistência de um planejamento urbano efetivo. A metodologia para a realização dos planos tem sido intuitiva, guiada mais pelos critérios subjetivos dos funcionários de turno, sem ter rigorosamente em conta os fatores determinantes do crescimento da cidade e da localização das diferentes atividades de acordo com as variáveis econômicas (ACEVEDO; BOCAREJO, 1993).

As oportunidades de eletrificação de STM estão sendo analisadas para Santafé de Bogotá e Medellín, Santiago de Cali e Pereira. Desenvolveram-se planos de transporte coerentes, baseados em diretrizes que definiram os estudos de planejamento urbano e de transporte, conforme a parâmetros e métodos modernos de análise (THOMPSON, 1983).

Nesta dissertação, vão ser considerados dois tipos de projetos de STM que utilizam a eletricidade para sua movimentação: Tróleibus e sistemas de transporte de massa sobre trilhos. Estes últimos envolvem os VLT (Veículos Leves sobre Trilhos, "pré-metrô", ou metrô leve), o metrô e trem suburbano.

As informações mais sistemáticas e completas sobre sistemas de transporte urbano foram analisadas por ARMSTRONG-WRIGHT no seu trabalho para o 
(velocidades médias em torno de 30 a $35 \mathrm{~km} / \mathrm{h}$ ), podem transportar até 70.000 passageiros por hora por rota e por sentido.

Estes sistemas rápidos, possuem um elevado nivel tecnológico, normalmente inexistente em cidades de paises em desenvolvimento, e que pode gerar uma dependência de especialistas e equipamentos estrangeiros, principalmente nos primeiros anos de funcionamento.

As receitas derivadas das passagens raras vezes cobrem os custos totais do sistema. Alguns sistemas conseguem recuperar os custos de funcionamento, incluída a depreciação, mas a maioria precisa de consideráveis subsídios para cobrir os custos de capital e de operação.

Os sistemas de trens suburbanos funcionam sobre vias compartilhadas com trens de passageiros interurbanos e trens de carga. Porém, é necessário melhorar a rede ferroviária mediante eletrificação, construção de calçadas melhoradas, novos trilhos, sistemas de controle e sinalização e material rodante novo.

Na Tabela 4.2 é apresentada uma comparação qualitativa dos diferentes STM. A Tabela 4.3 e 4.4 , mostram os custos de infra-estrutura, equipamento e veículos para essas alternativas. A Tabela 4.5 mostra os custos de operação típicos para estes sistemas e a Tabela 4.6 apresenta o custo total de acordo com os dados de ARMSTRONG-WRIGHT (1987).

Os custos de operação são bastante representativos nos sistemas de ônibus, enquanto para STM sobre trilhos predominam os custos de capital. 
Tabela 4.2

Comparação de Diferentes Alternativas de Sistemas de Transporte de Massa

\begin{tabular}{|c|c|c|c|c|c|c|c|c|c|}
\hline SISTEMA & $\begin{array}{l}\text { Pass./h } \\
\text { por pista }\end{array}$ & $\begin{array}{l}\text { Reserva de } \\
\text { capacidade }\end{array}$ & $\begin{array}{c}\text { Velocidade } \\
\mathrm{km} / \mathrm{h} \\
\end{array}$ & Regularidade & Flexibilidade & $\begin{array}{l}\text { Poluição } \\
\text { atmosférica }\end{array}$ & Ruido & $\begin{array}{l}\text { Intrusão } \\
\text { visual } \\
\end{array}$ & Segurança \\
\hline \multicolumn{10}{|l|}{ - Ónibus: } \\
\hline Tráfego mixto & 15000 & Ruim & 12 & Ruim & Excelente & Alta & Médio & Bom & Regular \\
\hline Com prioridades & 20000 & Ruim & 18 & Regular & Boa & Média & Médio & Bom & Regular \\
\hline Em troncais & 36000 & Ruim & 25 & Regular & Regular & Baixa & Baixo & Bom & Boa \\
\hline -Troléibus em troncais & 36000 & Ruim & 25 & Regular & Deficiente & Muito baixa & Baixo & Média & Boa \\
\hline \multicolumn{10}{|l|}{$\begin{array}{l}\text {-Sistemas sobre trilhos } \\
\text { VLT }\end{array}$} \\
\hline VLT & 36000 & Regular & 30 & Boa & Deficiente & Muito baixa & Médio & Média & Boa \\
\hline Metró de superficie & 70000 & Satisfactória & 30 & Excelente & Deficiente & Muito baixa & Alto & Alta & \\
\hline Metró em viaduto & 70000 & Satisfactória & 30 & Excelente & Deficiente & Muito baixa & & Alta & Muito boa \\
\hline Metrô subterráneo & 70000 & Satisfactória & 30 & Excelente & Deficiente & Muito baixa & Muito baixo & Nula & Muito boa \\
\hline Trem suburbano & 72000 & Satisfactória & 45 & Excelente & Deficiente & Muito baixa & Médio & Bom & Boa \\
\hline
\end{tabular}

Fonte: ARMSTRONG-WRIGHT, 1987 e INECO-SOFRETUR-C.S. apud GUHL et al, 1992. 
Tabela 4.3

Custos de Infraestrutura e de Equipamentos dos Sistemas de Transporte de Massa (1)

(Valores em milhões de dólares de dezembro de 1993) (2)

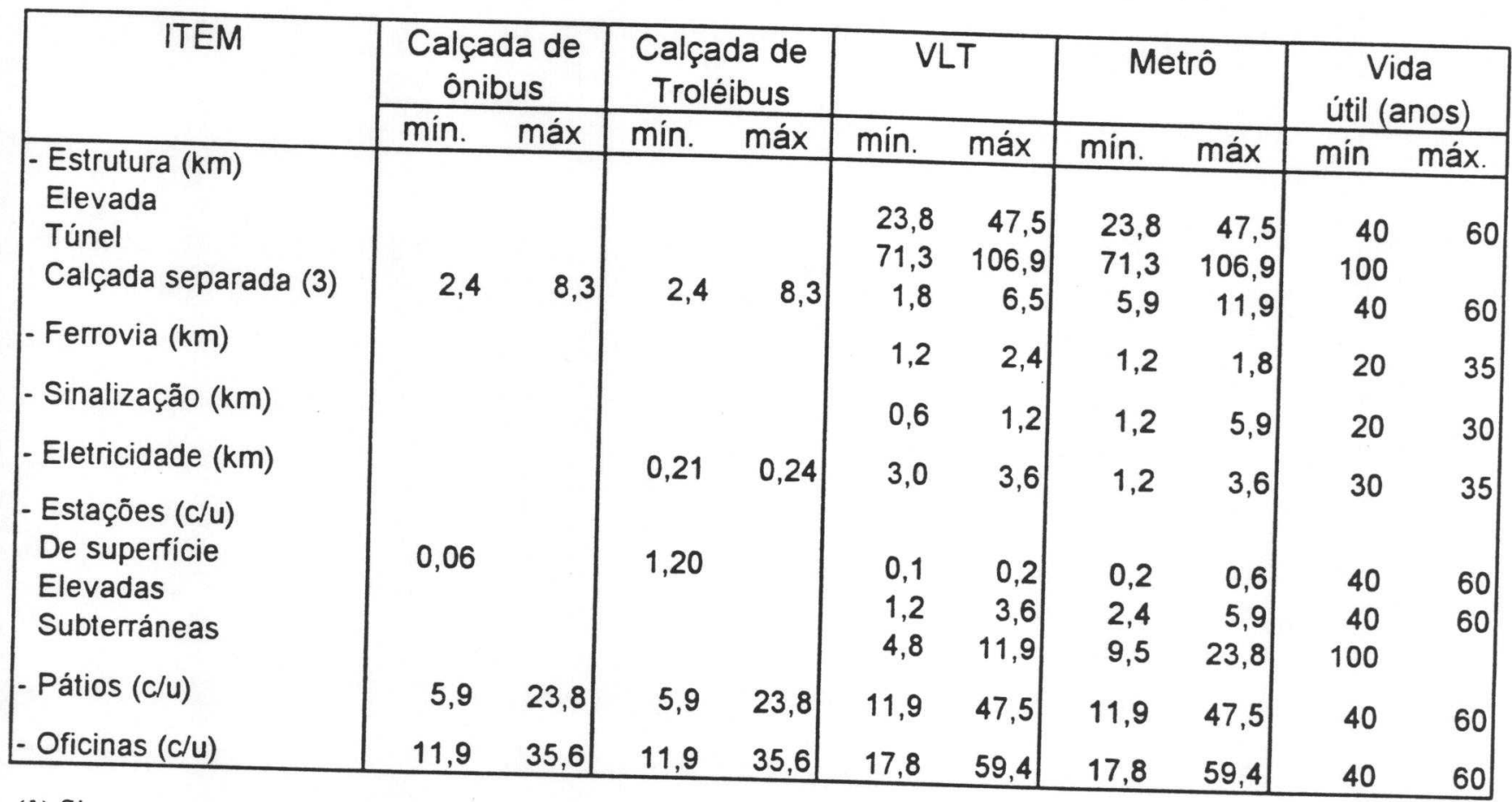

(1) Sistemas para avenidas de duas pistas ou ferrovias de duas vias

(2) Cálculo realizado deflacionando-se os valores originais segundo o indice de inflação externa publicado por DNP

(3) Nas calçadas separadas, assume-se que a construção é a nivel do solo com cruzamentos em diferente nivel

Fonte: ARMSTRONG-WRIGHT, 1987

Tabela 4.4

Custos dos Veículos Utilizados em STM

(Valores em US\$ de 1993) (1)

\begin{tabular}{|c|c|c|c|c|}
\hline \multirow[b]{2}{*}{ Veículo } & \multicolumn{2}{|c|}{ Capacidade } & \multirow{2}{*}{\begin{tabular}{|c|}
$\begin{array}{c}\text { Preço de compra } \\
\text { sem impostos } \\
\text { (US\$) }\end{array}$ \\
\end{tabular}} & \multirow[b]{2}{*}{ Vida útil (anos) } \\
\hline & Assentos & Total & & \\
\hline Mini-ônibus & 12 & 18 & 29.693 & 8 \\
\hline Ónibus pequeno & 20 & 30 & 47.508 & 10 \\
\hline Ónibus comum & 40 & 80 & 59.386 & 12 \\
\hline Ónibus grande & 50 & 100 & 95.017 & 15 \\
\hline Troléibus comum & 37 & 112 & 260.000 & 20 \\
\hline Troléibus articulado & 43 & 180 & 470.000 & 20 \\
\hline Unidade de VLT & 50 & 300 & 800.000 & 25 \\
\hline Unidade de metrô & 50 & 350 & 1.000 .000 & 30 \\
\hline
\end{tabular}

Fontes:

1- ARMSTRONG-WRIGHT, 1987

2- HENRIQUES, 1985 apud BALASSIANO, 1991

3- Catálogos de MAFERSA 
Tabela 4.5

Custos de Operação Unitários dos Sistemas de Transporte de Massa (STM)

(Valores em dólares de dezembro de 1993) (1)

\begin{tabular}{|l|c|c|}
\hline \multirow{2}{*}{ STM } & \multicolumn{2}{|c|}{ Custo por Passageiro-km } \\
\cline { 2 - 3 } & $(\mathrm{min})$. & $(\mathrm{max})$ \\
\hline Ônibus & 0,02 & 0,10 \\
Tranvia & 0,02 & 0,10 \\
Trem leve & 0,10 & 0,12 \\
Trem rápido & 0,12 & 0,18 \\
\hline
\end{tabular}

Tabela 4.6

Custos Totais Unitários dos Sistemas de Transporte de Massa (STM)

(Valores em dólares de dezembro de 1993) (1)

\begin{tabular}{|l|c|c|}
\hline \multirow{2}{*}{\multicolumn{1}{|c|}{ STM }} & \multicolumn{2}{|c|}{ Custo por Passageiro-km } \\
\cline { 2 - 3 } & $(\mathrm{min})$. & $(\mathrm{max})$ \\
\hline Ônibus & 0,02 & 0,06 \\
Ônibus, pista reservada & 0,02 & 0,06 \\
Ônibus, via reservada & 0,02 & 0,10 \\
Tranvia & 0,04 & 0,12 \\
Trem leve & 0,12 & 0,18 \\
Trem rápido de superficie & 0,12 & 0,18 \\
Trem rápido em viaduto & 0,14 & 0,24 \\
Trem rápido subterrâneo & 0,18 & 0,30 \\
\hline
\end{tabular}

(1) Os valores originais, em dólares de 1985, foram deflacionados utilizando os índices de inflaçâo externa publicados pelo DNP.

Fonte: ARMSTRONG-WRIGHT, 1987 
Finalmente, como anotam GUHL et al (1992), as alternativas tecnológicas de transporte não são excludentes. É possivel combinar diferentes sistemas de acordo com as necessidades e com as vantagens comparativas de cada uso, para conseguir satisfazer uma demanda heterogênea otimizando-se as condições operacionais e econômicas.

Os projetos considerados para as cidades de Santafé de Bogotá e Medellin estão baseados em estudos e propostas elaboradas por organismos ou especialistas do setor. Não é intenção do autor formular novas alternativas, pois esse tipo de trabalho necessitaria análises profundas de outras questões que fogem do escopo desta dissertação.

\subsubsection{Projetos de Eletrificação de STM em Santafé de Bogotá}

Basicamente, são dois projetos que em estudos prévios foram analisados para esta cidade: o sistema de tróleibus e os STM sobre trilhos, fundamentalmente o caso do metrô.

\section{Tróleibus}

Os projetos que contemplam este tipo de transporte visam sua utilização para troncais exclusivas para ônibus, ou por meio da revitalização do antigo sistema já desativado.

O caso da utilização deste sistema para troncais já foi recomendado por ACEVEDO e MARTíNEZ apud GUHL et al (1992). A aplicação a mais curto prazo seria para a troncal da Caracas, principal eixo de tráfego da cidade. 
A troncal da Caracas é o projeto de maior extensão e maior capacidade (passageiros/hora/pista) jamais emprendido no mundo segundo o BIRF 40 . Ademais, é o primeiro em contar com um número e um comprimento de pontos tão importante. A Tabela 4.7 mostra as principais caracteristicas do sistema a ser implantado.

O projeto de tróleibus consistiria na incorporação dessas unidades como meio de transporte na troncal, conforme foi inicialmente apresentado no estudo de ACEVEDO e MARTÍNEZ ${ }^{41}$. A característica do projeto estaria afim com a experiência internacional que mostra a inconveniência no uso do tróleibus quando empregado em vias de tráfego mixto (BALASSIANO, 1991).

Para efeitos de análise, pode-se estabelecer um cenário extremo que contemple a utilização exclusiva de tróleibus na troncal. Esta condição permitiria estabelecer as ordens de magnitude de demanda de energia elétrica deste projeto e sua economicidade com relação aos ônibus convencionais a gasolina que atualmente são empregados nessa via.

O segundo projeto a considerar é o denominado "Projeto Tróleibus Bogotá S.A.", iniciativa da empresa EDTU (Empresa Distrital de Transporte Urbano de Bogotá), atualmente em processo de liquidação. O objetivo do projeto era de reativar o sistema de tróleibus que há vários anos operava essa empresa, mas esta vez sob controle de uma sociedade de capital mixto, $60 \%$ do setor privado e $40 \%$ do distrito capital (EDTU, 1991).

A EDTU tem ativos avaliados comercialmente em torno de MMUS\$29. Parte desse imobilizado é formado por 250 unidades de tróleibus, oito subestações 40 BIRF I. Plan Integral de Transporte Urbano, Estudio de Factibilidad de la Troncal de la Caracas.
1991 apud GUHL et al, 1992.

41 ACEVEDO, J.; MARTÍNEZ, W. Análisis preliminar de un Servicio Troncal de Transporte a lo Largo de la Avenida Caracas en Bogotá. 1987 apud GUHL et al, 1992. 
elétricas, oficinas, pátios, peças de reposição, etc. O projeto apresentado pela EDTU consiste em implantar uma rede de tróleibus em Santafé de Bogotá através de 10 rotas predefinidas. Para essa finalidade, devem ser recuperados 220 tróleibus soviéticos e romenos, 7 subestaçōes, $27,1 \mathrm{~km}$ de rede elétrica, construidas mais 7 subestações, $64,6 \mathrm{~km}$ de novas redes elétricas e novas oficinas.

\section{Tabela 4.7}

Características Principais do Projeto da Troncal da Caracas em Santafé de Bogotá

\begin{tabular}{ll|}
\hline Comprimento: & $16,4 \mathrm{~km}$ \\
No. de pistas: & 8 (2 exclusivas para ônibus e 2 para tráfego em \\
Largura das pistas de ônibus: & $6,2 \mathrm{~m}$ a $6,4 \mathrm{~m}$ \\
Largura das pistas de tráfego geral: & $5,8 \mathrm{~m}$ a $6 \mathrm{~m}$ \\
Distância entre pontos: & inferior a $500 \mathrm{~m}$ \\
No. de pontos zona norte: & 20 \\
No. de pontos zona sul: & 32 \\
Comprimento dos pontos: & 190 a $240 \mathrm{~m}$ divididos em 4 grupos de rotas \\
Capacidade máxima: & 20.000 pass./h/pista \\
No. de ônibus: & 400 a 500 por hora \\
Velocidade de operação: & $14 \mathrm{~km} / \mathrm{h}$ para ônibus \\
& $19 \mathrm{~km} / \mathrm{h}$ para automóveis \\
Investimento real zona sul : & $(1990)$ MMUS $\$ 5$ \\
Investimento estimado zona norte: & $(1990)$ MMUS $\$ 7,10$ \\
Custo de operação anual (1): & $(1990)$ MMUS $\$ 0,36$ \\
Custos de manutenção anual: & $(1990)$ MMUs $\$ 0,14$ \\
\hline (1) Custo do pessoal encarregado do controle (150 pessoas). \\
\hline
\end{tabular}


Os resultados financeiros do projeto mostraram uma taxa interna de retorno (TIR) de 12,4\%, para uma vida útil de 10 anos e investimentos de MMUS\$16,3 Observe-se que essa TIR é relativamente baixa, considerando-se 0 fato de que a avaliação é de curto prazo, sem novas expansões ou reposições do equipamento onde os novos investimentos teriam de ser efetuados com preços altos e reais e não como valores residuais.

Outra questão não afim com as políticas de transporte eficiente é a definição das rotas do tróleibus. Todas as vias selecionadas pertencem a tráfego mixto, isto é, podem circular tanto veículos de serviço público quanto particular e não foram aproveitadas avenidas que estão sendo condicionadas como vias exclusivas de ônibus (sistema de troncais), como a avenida Caracas, a Carrera $10^{\mathrm{a}}$, a Calle 80 e parte da Calle $68^{42}$ (ACEVEDO; BOCAREJO, 1993). (Vide mapa da Figura 4.11).

A utilização das unidades de tróleibus, ainda recuperáveis, da extinta EDTU pode ser avaliada para o caso de seu uso no projeto da troncal da Caracas. A seguir analisa-se esse projeto.

Este projeto leva a uma série de benefícios ambientais, econômicos e sociais, pois permite reduzir as emissões de poluentes, aumentam as vendas de eletricidade, são reduzidos o consumo de gasolina e os custos de manutenção e operação de veículos, aumentam as velocidades médias das viagens e podem ser adiadas expansōes da infra-estrutura vial da cidade.

42 A nomenclatura do sistema vial das cidades da Colômbia é mediante dígitos e nomes para algumas avenidas ou ruas (chamadas calles quando vão na direção leste-oeste e carreras para a direção nonte-
sul) mais importantes. 


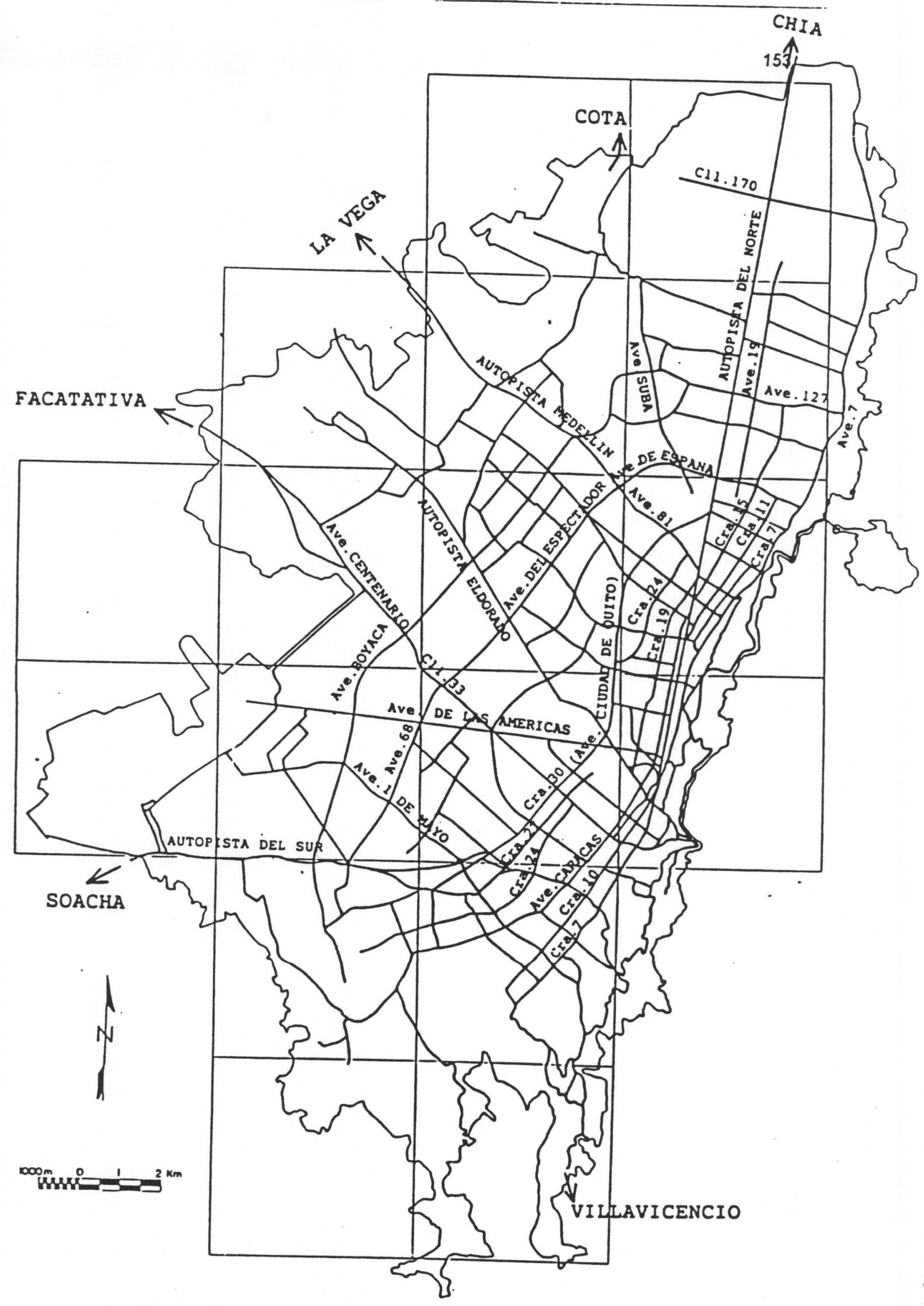

Figura 4.11. Rede das Principais Vias da Cidade de Santafé de Bogotá 
A altitude sobre o nível do mar de Santafé de Bogotá, em torno de $2.600 \mathrm{~m}$, é um fator que desfavorece ambientalmente a cidade. A baixa pressão atmosférica ocaciona maiores emissões de poluentes pela combustão incompleta da frota de veículos da cidade, quase toda a gasolina e bastante antiga.

Segundo as análises e medições realizadas pelo JICA (1992), em Santafé de Bogotá, as concentrações de $\mathrm{CO}$ (monóxido de carbono) e $\mathrm{O}_{3}$ (ozônio) superam os niveis toleráveis estabelecidos pela lei (Decretos 2 de 1982 e 2206 de 1983). Contudo, as concentrações de $\mathrm{SO}_{2}$ (dióxido de enxôfre) e $\mathrm{NO}_{2}$ (dióxido de nitrogênio) são altas em alguns lugares da cidade. As projeções feitas por essa agência (JICA, 1992) mostram que essas concentrações de poluentes serão maiores. A Tabela 4.8 apresenta os valores atuais de poluição atmosférica da cidade assim como o valor estimado para o ano 2001 e as normas de qualidade ambiental de cada poluente.

Tabela 4.8

Concentrações Máximas de Poluentes Atmosféricos em. Santafé de Bogotá

\begin{tabular}{|l|c|l|l|}
\hline \multicolumn{1}{|c|}{ POLUENTE } & $\begin{array}{c}\text { NORMA DE } \\
\text { QUALIDADE }\end{array}$ & $\begin{array}{c}\text { NIVEL MAXIMO } \\
\text { MEDIDO } \\
(1991)\end{array}$ & $\begin{array}{c}\text { NIVEL MÁXIMO } \\
\text { ESTIMADO } \\
(2001)\end{array}$ \\
\hline CO (monóxido de carbono) & $3,6 \mathrm{ppm}$ & $6,96 \mathrm{ppm}$ & $9,6 \mathrm{ppm}$ \\
$\mathrm{SO}_{2}$ (dióxido de enxôfre) & $38,2 \mathrm{ppb}$ & $32,3 \mathrm{ppb}$ & $43,7 \mathrm{ppb}$ \\
$\mathrm{NO}_{2}$ (dióxido de nitrogênio) & $53,2 \mathrm{ppb}$ & $40,4 \mathrm{ppb}$ & $50,0 \mathrm{ppb}$ \\
$\mathrm{HC}$ (hidrocarbonetos) & $0,5 \mathrm{ppmC}$ & $6 \mathrm{ppmC}$ & - \\
MP (material particulado) & $100 \mu \mathrm{gg} / \mathrm{m}^{3}$ & $59,3 \mathrm{\mu g} / \mathrm{m}^{3}$ & - \\
\hline
\end{tabular}

Fonte: JCA, 1992.

setor de transportes é o único responsável pela emissão de $\mathrm{CO}$ e $\mathrm{HC}$, mas tem uma alta participação nos niveis de poluição por SOx e NOx. Em termos 
absolutos, os principais poluidores do setor de transporte são os carros particulares. A cidade tem um parque automotor de uns 600.000 veículos (ACEVEDO; BOCAREJO, 1993), desses, 15.693 são de serviço coletivo, 2,6\% da frota da cidade, mas realizam o $90,1 \%$ das viagens na urbe. O problema de poluição tende a se agravar, pois as taxas de cescimento anual da frota são de $10 \%$.

A Tabela 4.9 mostra as emissões de poluentes e a responsabilidade dos diferentes setores econômicos da cidade.

O projeto de tróleibus para a troncal da Caracas teria um potencial capaz de tirar de serviço 500 ônibus que funcionam a gasolina. Para determinar a redução de emissões de poluentes é necessário inicialmente calcular algumas características de operação destes veículos.

Tabela 4.9

Quantidade de Emissões de Poluentes Atmosféricos e Responsabilidade dos Diferentes Setores Econômicos de Santafé de Bogotá.

(Dados medidos ou estimados para 1991)

\begin{tabular}{|l|c|c|c|c|c|}
\hline \multicolumn{1}{|c|}{ SETOR } & SOX & NOx & Poeira & CO & HC \\
\hline Industria e Comércio & $6.504(82)$ & $1.688(15)$ & $2.198(95)$ & - & \\
\hline Transportes: & & & & & \\
Veiculos particulares & $496(6,3)$ & $5.039(44)$ & - & $149.237(52)$ & $12.039(61)$ \\
Ónibus & $475(6,0)$ & $2.644(23)$ & - & $100.545(35)$ & $5.781(29)$ \\
Caminhóes & $298(3,8)$ & $1.567(14)$ & - & $38.651(13)$ & $2.025(10)$ \\
& & & & & \\
Subtotal & $1.269(16)$ & $9.250(82)$ & - & $288.433(100)$ & $19.845(100)$ \\
\hline Aviaçåo & $29(0,4)$ & $114(1)$ & & - & - \\
\hline Residencial & $84(1)$ & $254(3)$ & $105(5)$ & - & \\
\hline TOTAL & $7.886(100)$ & $11.306(100)$ & $2.303(100)$ & $288.433(100)$ & $19.845(100)$ \\
\hline
\end{tabular}

Fonte: ЛСА, 1992

A velocidade média dos ônibus (ou tróleibus) nessa troncal, estima-se em torno de 14 a $20 \mathrm{~km} / \mathrm{h}$. Como a troncal tem uma extensão de $16,4 \mathrm{~km}$, os dois 
sentidos podem ser cobertos em duas horas. Segundo isso, o percurso máximo que poderia realizar cada unidade seria de $393,6 \mathrm{~km}$. Contudo, o número de viagens que normalmente efetua um ônibus é bem inferior à máxima capacidade. Com base em estudos realizados há vários anos atrás, pode-se calcular um fator de carga do sistema em $41 \%$ (Figura 4.12). As horas de ponta do sistema acontecem nos perídos das 7:00 às 10:00, das 12:00 às 15:00 e das 17:00 às 20:00 (GUHL et al, 1992). Infelizmente, não existem estudos recentes sobre a curva de carga diária de transportes para as principais cidades do pais.

Figura 4.12

Curva de Carga Típica Diária de Transporte Urbano na Colômbia

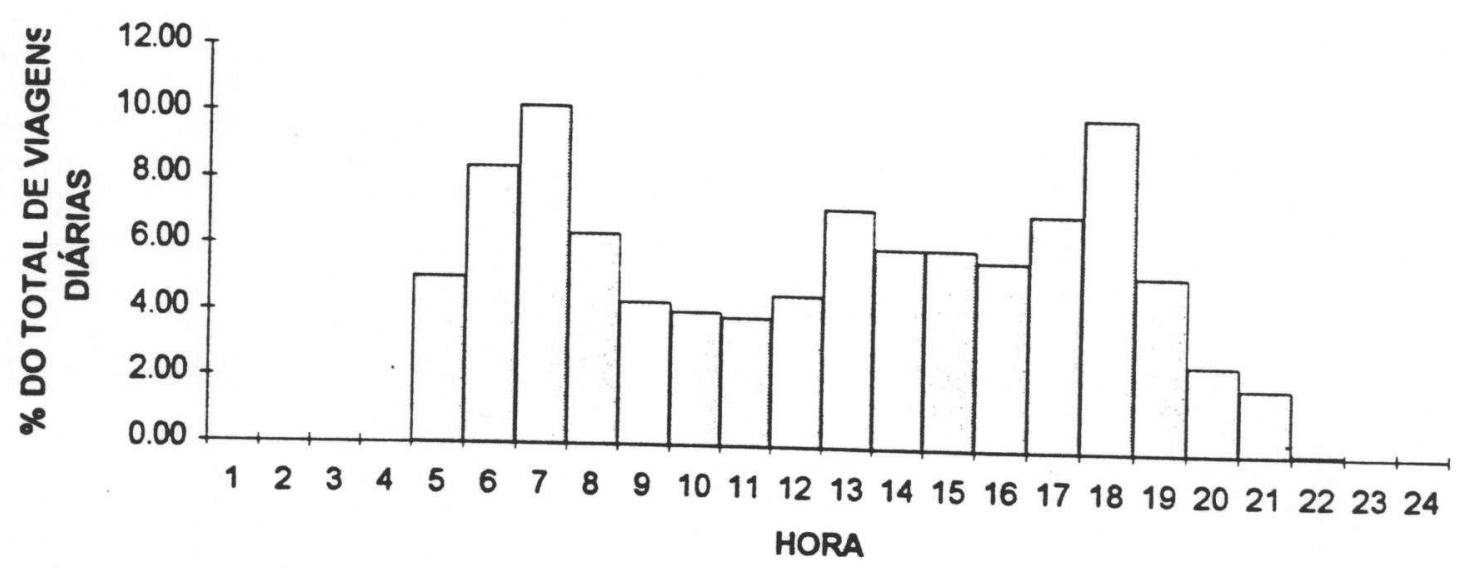

Fonte: Planeación Metropolitana de Medellin, 1978.

Desta forma, então, o percurso anual da frota de ônibus seria de 29,5 milhões de $\mathrm{km}$. $\mathrm{O}$ volume de emissões dos veículos é função da velocidade média deles. Para uma velocidade média de $15 \mathrm{~km} / \mathrm{h}$ as emissões específicas para ônibus comum a gasolina são (JICA, 1992):

HC

$13,38 \mathrm{~g} / \mathrm{km}$

CO

$229,04 \mathrm{~g} / \mathrm{km}$

NOx

$4,39 \mathrm{~g} / \mathrm{km}$

SOx

$0,59 \mathrm{~g} / \mathrm{km}$ 
Assim sendo, a utilização de tróleibus ao invés de ônibus na troncal da Caracas significaria uma redução da emissão de poluentes de até:

$\mathrm{HC}$ 394,2 ton/ano

CO $\quad 6.745,2$ ton/ano

NOx $\quad 127,8$ ton/ano

SOx $\quad 17,4$ ton/ano

Com base nos niveis medidos em 1991 (JICA, 1992), é possivel determinar os impactos positivos calculando-se as reduções percentuais de emissão de poluentes atmosféricos do total da frota de ônibus, do setor de transportes e para a cidade toda. Esses cálculos são apresentados na Tabela 4.10

Tabela 4.10

Redução Percentual das Emissões de Poluentes Atmosféricos pela Substituição de Ónibus por Tróleibus na Troncal da Caracas em Santafé de Bogotá. (Ano base de comparação: 1991).

\begin{tabular}{|l|c|c|c|c|}
\hline \multicolumn{1}{|c|}{ SETOR } & SOx & NOx & CO & HC \\
\hline Total Ónibus & $3,7 \%$ & $4,8 \%$ & $6,7 \%$ & $6,8 \%$ \\
\hline Setor de Transportes & $1,4 \%$ & $1,4 \%$ & $2,3 \%$ & $2,0 \%$ \\
\hline Total cidade & $0,2 \%$ & $1,1 \%$ & $2,3 \%$ & $2,0 \%$ \\
\hline
\end{tabular}

Fonte: Cálculos do autor com base em dados do JICA, 1992.

Os valores anteriores mostram um efeito positivo bastante significativo com relação aos impactos ambientais do projeto. Avaliações econômicas sobre o custo da poluição ambiental em Santafé de Bogotá e outras cidades da Colômbia deverão ser realizadas num futuro próximo, como uma forma de internalizar esses custos ambientais neste tipo de projetos. Sabe-se, por exemplo, que houve um incremento notório no número de consultas hospitalares devido a doenças pulmonares a partir de 1985 (JICA, 1992). Isso tem um custo social, representado no orçamento familiar devotado para cobrir esse tipo de despesas, no tempo de trabalho perdido em licenças e 
incapacidades e no custo decorrente da infra-estrutura física e de pessoal necessários para atender os pacientes.

Para se determinar a viabilidade econômica e financeira do projeto de tróleibus é utilizada a metodologia de preços netback ou de equilibrio (vide seção 3.4). A idéia é encontrar o valor limite para o qual o preço da eletricidade vendida para cada unidade de tróleibus permite que a sua utilização seja competitiva com relação aos ônibus a gasolina. Neste sentido, o objetivo é encontrar o preço da eletricidade para o qual o custo do veículo anualizado por $\mathrm{km}$ e por passageiro sejam iguais.

O esquema institucional que aqui se propõe, consiste em que a rede elétrica, subestações de retificação e demais componentes, sejam propriedade de uma empresa do município ou a mesma concessionária de energia elétrica da cidade. Os veículos, entretanto, seriam do setor privado, em forma similar como acontece hoje na Colômbia com todos os veículos de transporte coletivo.

O setor público, portanto, teria a responsabilidade de manter e operar a infraestrutura física necessária para que o setor privado colocasse as unidades de tróleibus na rede.

Contudo, o preço de equilíbrio é calculado para dois cenários de preços das unidades de tróleibus: um cenário alto, onde o preço desses veículos é o valor atual de uma unidade nova e um cenário baixo, onde são aproveitadas as unidades de tróleibus que estão fora de serviço na EDTU ${ }^{43}$. Também, é feita uma análise de sensibilidade em função da taxa de desconto e do preço do energético concorrente, neste caso, a gasolina motor.

43 A EDTU possui 250 tróleibus desativados. Segundo um dossiê dessa instituição em liquidação (EDTU, 1991), é possivel recuperar 220 unidades para serem leiloados por um valor total estimado
de MMCol\$6.724,8 (1991 MMUS\$1). 
Os dados básicos de custos para os ônibus são determinados com base na pesquisa realizada em 1990 pelo INTRA (Instituto Nacional de Transporte) (GUHL et al, 1992). Esses valores são apresentados na Tabela 4.11. Para avaliar esses custos em dezembro de 1993, os valores segundo o IPC (Índice de Preços ao Consumidor) são deflacionados, excetuando-se os custos de combustivel e de capital.

O custo de capital para ônibus é calculado anualizando-se o investimento (US\$100.000) durante a vida útil (12 anos) a uma taxa de desconto dada. 0 custo de combustivel é calculado a partir do consumo específico de $0,179 \mathrm{gal} / \mathrm{km}$ (ACEVEDO; BOCAREJO; 1993). O percurso anual de uma unidade é estimada em $58.902 \mathrm{~km}$.

No caso do tróleibus, o consumo especifico empregado para os cálculos foi de $2,5 \mathrm{kWh} / \mathrm{km}$, que é o valor médio para o sistema de tróleibus no Brasil (SERRA, 1982) e (GEIPOT, 1987 apud BALASSIANO, 1991). O custo de capital foi calculado anualizando-se o investimento (US\$260.000 ou US\$64.000) durante uma vida útil de 20 anos ou 10 anos respectivamente. Este último valor é devido ao fato que os tróleibus empregados não são novos. Os custos de manutenção foram assumidos como sendo igual a $50 \%$ dos custos para este tipo de ônibus e o custo de lubrificantes é zero.

Além da sensibilidade à taxa de desconto, os valores netback são determinados parametricamente para dois preços do combustivel concorrente. Um primeiro caso é identificado para o preço da gasolina vigente em 1993, 0,68 US\$/gal (OLADE, 1994); e um segundo caso é assumindo um preço similar ao internacional, de um país também exportador de petróleo, como o México, 1,38 US\$/gal (OLADE, 1994) 
O resultado para os dois cenários de preços de tróleibus, sob as hipóteses anteriores, é ilustrado nas Figuras 4.13 e 4.14 .

Pode-se observar que o preço netback é altamente sensivel à taxa de desconto utilizada e também ao preço da gasolina. Valores intermédios do preço deste combustivel, como possiveis impostos (de até $20 \%$ ), podem ser então extrapolados entre os dois limites aqui definidos.

Para o caso em que o preço do tróleibus é alto, isto é, novo, o preço netback reduze-se à medida que aumenta a taxa de desconto do investidor. Em outras palavras, começa a ser mais difícil, do ponto de vista tarifário, a penetração do tróleibus. Isto se explica pelo fato de que no caso do tróleibus, o custo de capital é o fator mais importante nos custos totais do veículo. Para o ônibus, porém, a parcela de custos de operação é a mais significativa, daí o valor netback ser tão sensivel ao preço do combustivel.

Note-se na Tabela 4.11 que, em 1990, os custos de operação representavam $70,1 \%$ dos custos totais do veículo, e só a parcela dos combustíveis, $22,9 \%$ dos custos totais.

Para o cenário de preços baixos dos tróleibus, devido à utilização das unidades atualmente inativas da EDTU, a situação inverte-se. O resultado é lógico, pois neste caso o investimento no tróleibus é menor do que o investimento num ônibus novo. 
Tabela 4.11

Custos de Operação e Capital dos Ônibus (Valores em US\$ de dezembro de 1990) (1)

\begin{tabular}{|l|r|r|}
\hline \multicolumn{1}{|c|}{ ITEM } & \multicolumn{1}{|c|}{$\begin{array}{c}\text { Onibus } \\
\text { US\$/km }\end{array}$} & $\begin{array}{c}\text { \% do custo } \\
\text { total }\end{array}$ \\
\hline - Custos variáveis: & 0,09 & 22,92 \\
Combustiveis & 0,01 & 1,93 \\
Lubrificantes & 0,03 & 7,55 \\
Pneus & 0,06 & 14,58 \\
Manutenção & 0,04 & 11,24 \\
Salários e beneficios & 0,01 & 1,65 \\
Serviços de estação & 0,23 & 59,87 \\
& & \\
Subtotal & 0,01 & 1,67 \\
- Custos Fixos & 0,00 & 0,08 \\
Garagem & 0,01 & 2,08 \\
Impostos & 0,02 & 6,45 \\
Administração & 0,04 & 10,28 \\
Seguros & 0,27 & \\
Subtotal & & \\
\hline Total custos de Operação & 0,12 & 29,15 \\
\hline - Custos de Capital: & & \\
Recuperação de capital & 0,12 & \\
\hline Total custos de Capital & & \\
\hline Receita requerida & 0,39 & 100,00 \\
\hline
\end{tabular}

(1) Calculados com base nos dados originais em Col\$ de 1990 e uma taxa representativa de câmbio em 31-12-90 de Col\$568.70/US\$

Fonte: INTRA, 1990 apud GUHL et al, 1992 
Figura 4.13

Valor Netback (de Equilibrio) Financeiro da Eletricidade a ser Utilizada no

Sistema de Tróleibus (Valores em US\$ de 1993)

- Cenário de Preços Altos dos Tróleibus (US\$260.000/unidade)-

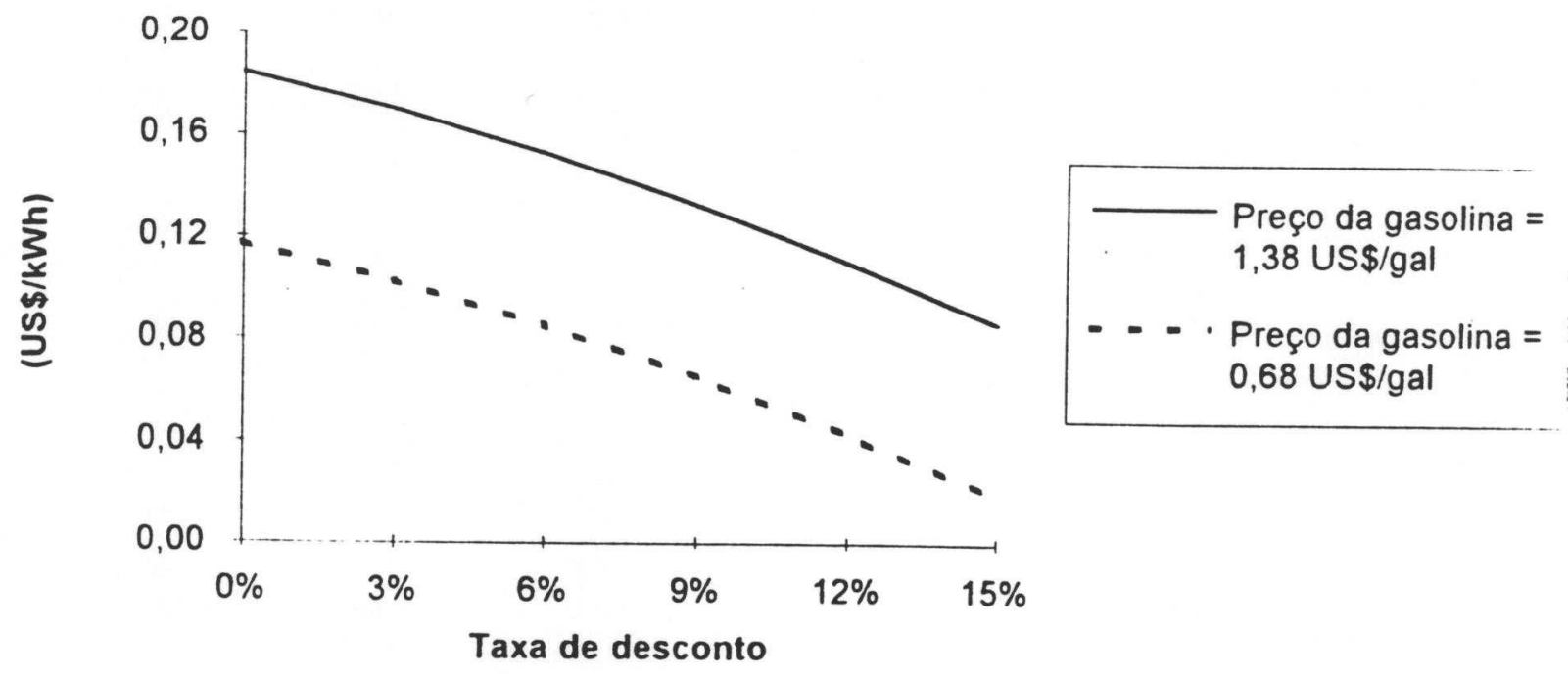

Figura 4.14

Valor Netback (de Equilibrio) Financeiro da Eletricidade a ser Utilizada no

Sistema de Tróleibus (Valores em US\$ de 1993)

- Cenário de Preços Baixos dos Tróleibus (US\$64.000/unidade)-

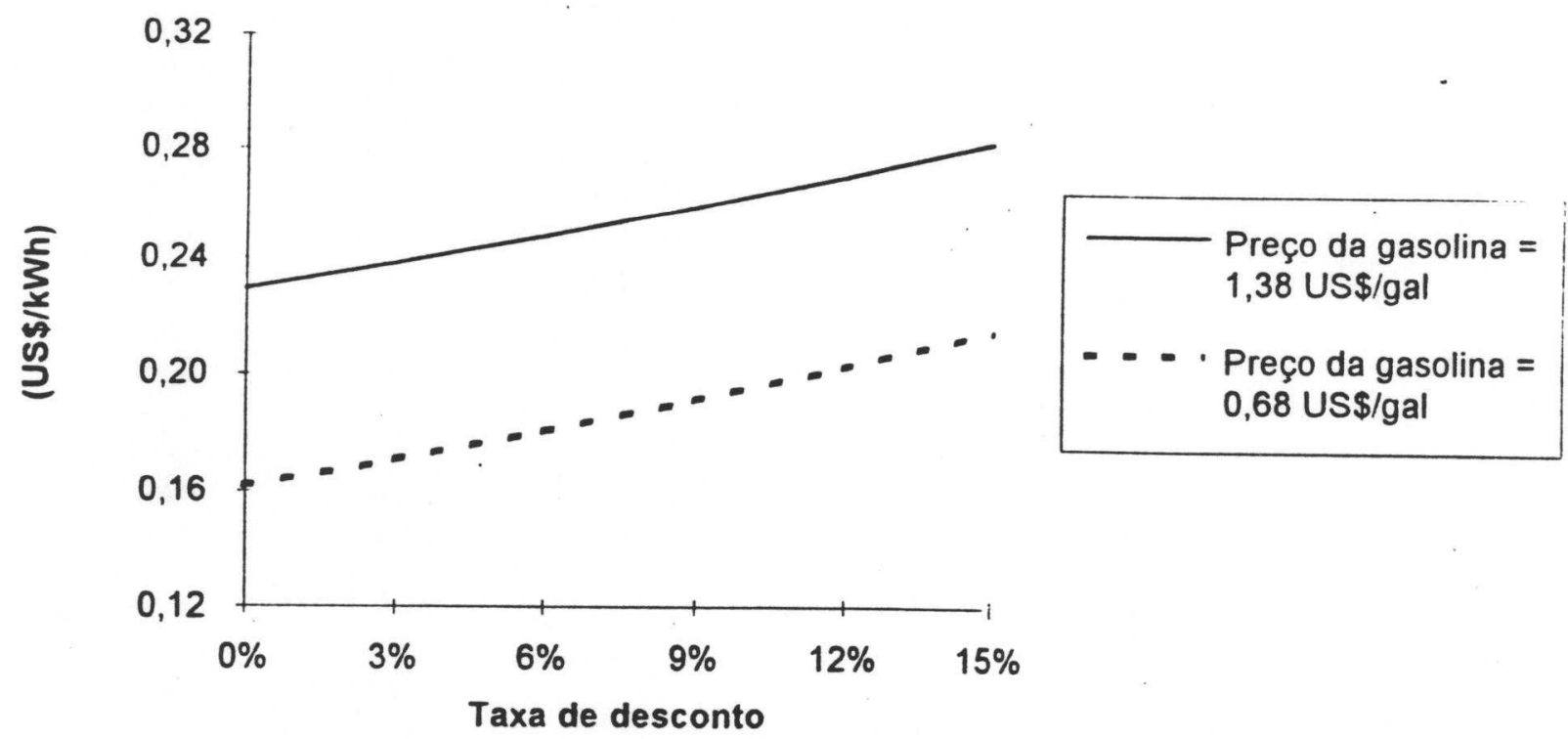

Fonte: Cálculos do autor com base em dados da EDTU,1991 e do INTRA, 1990 apud GUHL et al, 1992. 
A existência dos dois cenários pode ser analisado do ponto de vista da teoria marginalista da economia. $O$ custo de curto prazo pela utilização de tróleibus é baixo devido à disponibilidade de recursos com baixo custo de oportunidade, mas a longo prazo, quando as reposições dos equipamentos ou expansões teriam de ser realizadas, o custo marginal é alto. Isto é, a unidade adicional de tróleibus a ser comprada deve ser realizada com um custo de oportunidade elevado.

Por outro lado, para se determinar a viabilidade do sistema, tem de ser calculado o custo econômico da infraestrutura física e de operação da rede de alimentação para os tróleibus e ser comparado com o preço de equilíbrio. Se o custo econômico unitário for inferior ao preço de equilíbrio, o projeto é economicamente viável.

O custo da infraestrutura é determinado anualizando-se o custo total de cada componente (rede elétrica, subestações) de acordo com a sua vida útil e acrescentando-se a componente de custos A\&M e uma margem de imprevistos. (Tabela 4.12). O custo unitário (US\$/kWh) é calculado dividindose o custo anualizado total pela demanda de energia anual esperada, a qual é função do número de tróleibus na rede e da intensidade de uso dos mesmos.

O custo de operação da rede é determinada a partir do custo marginal de fornecimento de eletricidade para o nivel de tensão em que funcionará. Estes sistemas operam em tensōes de $600 \mathrm{Vcc}$, retificadas em subestações de média tensão ( $1 \mathrm{kV} \leq \mathrm{U}<30 \mathrm{kV}$ ). Para este nivel, os custos marginais são de 0,04 US $\$ / k W h$ em energia e 135,96 US $\$ / k W$-ano para a componente de potência.

O custo de operação é então função da característica de carga do sistema. 0 fator de carga do sistema de transporte e o fator de coincidência deste com a 
ponta do sistema elétrico de distribuição determinam, portanto, o custo de operação equivalente por kWh consumido.

Tabela 4.12

Cálculo dos Custos do Sistema de Alimentação para a Rede de Tróleibus na Troncal da Caracas em Santafé de Bogotá

(Valores em US\$ de dezembro de 1993)

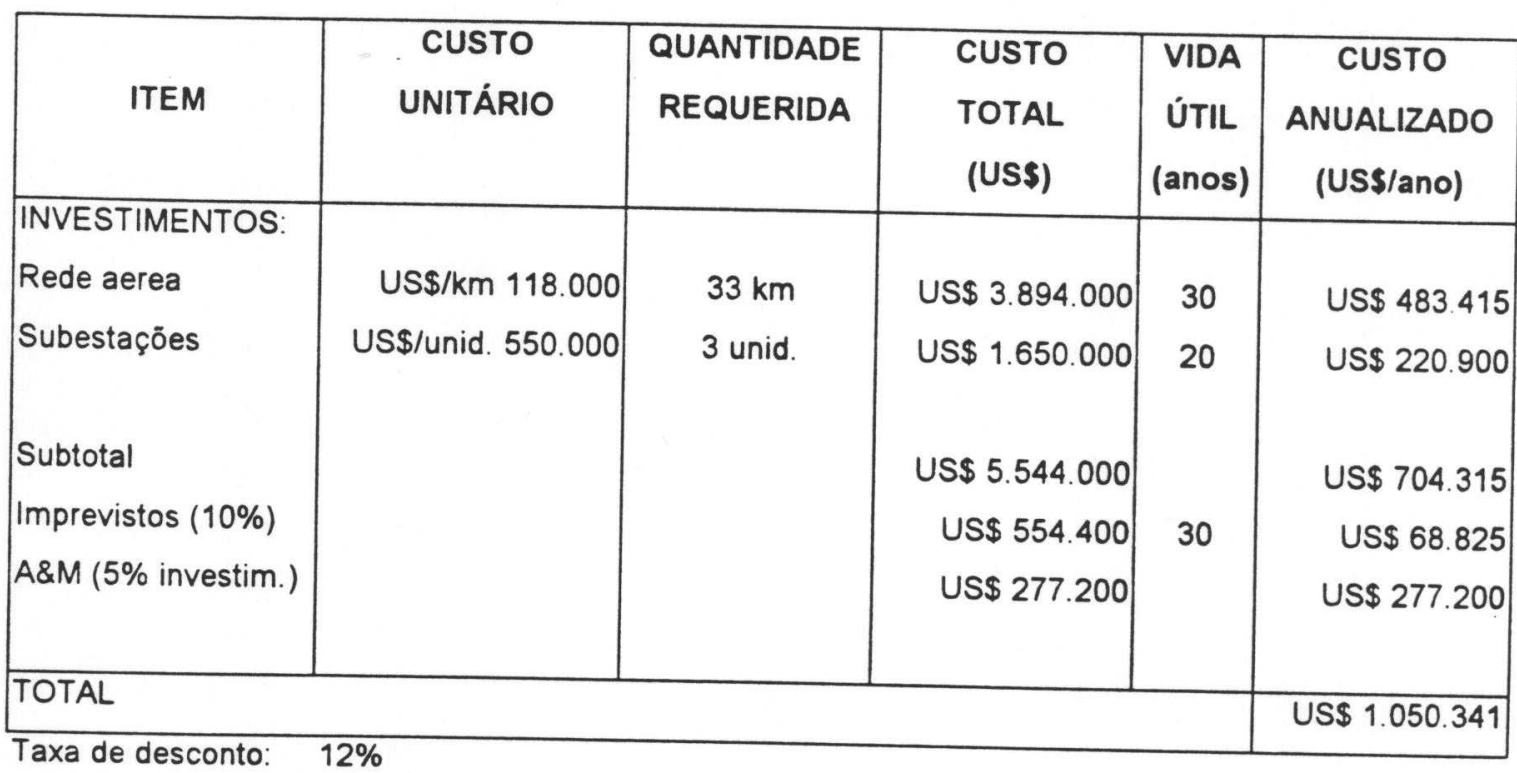

Fonte: Cálculos do autor com base em dados de ARMSTRONG-WRIGHT, 1987 e EDTU, 1991

A ponta do sistema de transporte mostra uma defasagem de mais ou menos uma hora em relação à ponta do sistema elétrico de distribuição. Isto significa que, caso se utilizar uma estrutura tarifária binômia convencional, o sistema de tróleibus poderia ser penalizado injustamente, pois se the estaria responsabilizando por uma demanda de potência maior do que aquela que realmente acontece na hora de ponta do sistema (19:00).

A estrutura tarifária para uma sistema deste tipo, não deve inviabilizar indiscriminadamente a sua operação, mas também não deve dar sinais errôneos do verdadeiro custo da eletricidade para se evitar introduzir distorções econômicas. 
A Figura 4.15 ilustra o custo econômico resultante das premisas antes anotadas para uma taxa de desconto de $12 \%$. Pela incidência que tem no custo o número de tróleibus que se estariam servindo da infraestrutura instalada, é realizada uma análise de sensibilidade à penetração destes veículos no sistema. A percentagem de penetração é definida como o valor relativo em que foi atingida a meta de colocação de tróleibus na rede. Em termos de capacidade de mobilização de passageiros, 500 ônibus a gasolina são equivalentes a 357 tróleibus, pois a lotação deles é de 80 e 112 passageiros respectivamente (ARMSTRONG-WRIGHT, 1987 e Catálogos da fábrica MAFERSA). A meta, portanto, para a qual a percentagem de penetração de tróleibus é de 100\%, é 357 unidades.

Também, foi realizada uma análise paramétrica com relação ao fator de carga do sistema. É lógico que não vão estar circulando durante todas as horas do dia a totalidade de veículos na troncal, dai ser necessário introduzir um fator de utilização da rede em função do número de viagens médias realizadas pelos veículos. Os resultados mostram uma alta sensibilidade do custo a este parâmetro. Análises de demanda mais detalhadas para as viagens realizadas na troncal da Caracas devem ser consequentemente analisadas.

Comparando-se os custos econômicos ilustrados na Figura $4.15 \mathrm{com}$ os preços de equilíbrio da eletricidade, apresentados nas Figuras 4.13 e 4.14 , pode-se então concluir que:

- As barreiras tarifárias são significativas para a penetração de uso dos tróleibus na troncal da Caracas. Para altos custos de oportunidade do dinheiro dos potenciais investidores, não é viável a utilização destes veículos na rede, quando o preço de compra dos tróleibus é alto. 
- Devido ao fato que o custo final de ônibus é muito sensivel ao custo do combustivel, aumentos no preço da gasolina podem favorecer sensivelmente a economicidade dos tróleibus. As políticas de desmonte de subsidios ou de sobretaxas para esse combustivel poderiam beneficiar a viabilidade do projeto em questão.

Figura 4.15

Custo Económico de Infra-estrutura - Operaçầo do Sistema de Alimentaçăo Eletrica para os Trobleibus na Troncal da Caracas em Santaft de Bogoti. (Valores em USS de dezambro de 1993)

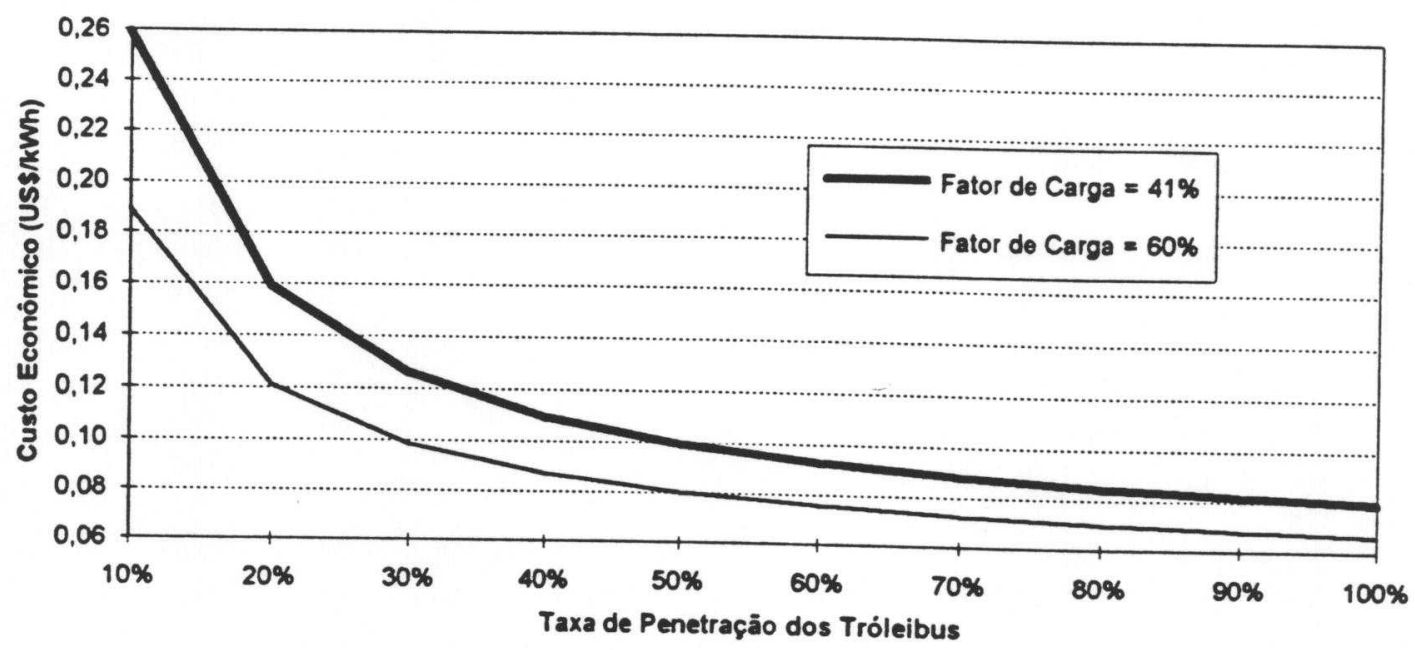

Fonte: Cálculos do autor com base em dados da EDTU (1991).

- A utilização das unidades inativas de tróleibus da empresa EDTU são uma opção atrativa para o investidor privado e o organismo que fosse proprietário da rede de alimentação, pois além de mostrar menores custos de capital, permite reduzir os custos de energia. Para a empresa dona da rede esta é uma opção interessante para superar as barreiras iniciais de colocação de unidades e desta forma asegurar um alto fator de penetração dos tróleibus.

- As avaliaçōes preliminares mostram que o custo econômico unitário (US $\$ / k W h$ ) para o sistema de alimentação elétrica dos veículos, aumenta exponencialmente a medida que diminui o número de tróleibus funcionando 
na rede. Nestes casos, onde a taxa de penetração é baixa, é conveniente que os tróleibus sejam utilizados mais regularmente durante o dia do que as unidades a gasolina (maior custo de operação e menor custo de capital), visando um maior fator de carga, melhorando-se a economicidade do sistema de tróleibus.

Contudo, a quantidade de eletricidade que seria utilizada por este sistema é pequena se comparada com a energia elétrica que seria deslocada da cocção. Aliás, as vendas estimadas de eletricidade para o projeto são de $52,6 \mathrm{GWh}$ que representa $1,5 \%$ e $0,72 \%$ da demanda de eletricidade em 1992 do setor residencial e total, respectivamente, para a cidade de Santafé de Bogotá. A gasolina economizada é de 120,6 kbbl/ano, 1,1\% do consumo estimado por ACEVEDO e BOCAREJO (1993) de gasolina da frota veicular dessa cidade.

Assim, não se pode esperar que esta alternativa se apresenta como forte candidata para recepcionar a eletricidade deslocada da cocção.

\section{STM sobre Trilhos}

O primeiro estudo sobre a definição de um STM sobre trilhos para Santafé de Bogotá foi realizado pelo consórcio hispano-franco-colombiano, INECOSOFRETU-CS em $1980^{44}$, como resposta às recomendações que sobre esse assunto fizeram outros estudos contratados pela administração distrital. (GUHL et al, 1992).

Esse estudo propôs a implantação de uma rede de Metrô de $92,8 \mathrm{~km}$, composta por três linhas centrais e duas periféricas que cobriam os corredores

44 INECO-SOFRETU-CS. Estudio de Factibilidad y Realización de un Sistema de Transporte Masivo para Bogotá, ago. 1981. 20v. apud GUHL et al, 1992. 
de alta demanda, visando terminá-las no ano 2000. Também, propunha uma linha prioritária de 23,6 km que entraria em operação em 1986. (Figura 4.16).

Com base na demanda prevista para o ano 2000, o estudo considerou que os sistemas de ônibus com via exclusiva e o VLT não poderiam satisfazer a demanda, por limitações de capacidade. Análises realizadas por GUHL e PACHÓN (1991) mostraram que essa demanda foi superestimada assim como os benefícios do projeto, pois a TIR determinada no estudo era de $14 \%$, para investimentos de MMUS\$3.754 (dólares de 1981). Uma atualização do projeto, efetuada pela empresa espanhola INECO em 199245 , acharam que a TIR seria de $3,6 \%$ anual.

Contudo, foi o projeto de metrô, baseado na reabilitação dos corredores de trem da cidade e levado a cabo principalmente por iniciativa do Governo Nacional, que chegou a um estado bastante avançado dando a impressão de que a sua realização parecesse iminente.

O projeto, proposta de uma firma italiana, constaria de uma rede de $46,4 \mathrm{~km}$ que seria desenvolvida em três fases. $75 \%$ do projeto seria construído sobre os corredores do trem. Diferente do projeto de INECO-SOFRETU-CS, a rede de Metrô proposta não teria nenhum trecho subterrâneo. Os custos, em dólares de 1987, foram estimados em MMUS\$1.360 46. A Figura 4.17 mostra um diagrama do projeto proposto.

45 INECO. Metro de Bogotá: Actualización Estudio de Factibilidad. 1992 apud GUHL et al, 1992.

46 MOPT. Rehabilitación del Șistema de Corredores Férreos de la Sabana de Bogotá para Adaptarlo a Transporte Masivo de Población. 1990. apud GUHL, 1992. 


\section{Figura 4.16}

Projeto do Metrô em Santafé de Bogotá Proposto no Estudo do Consórcio INECO-SOFRETU-CS em 1981

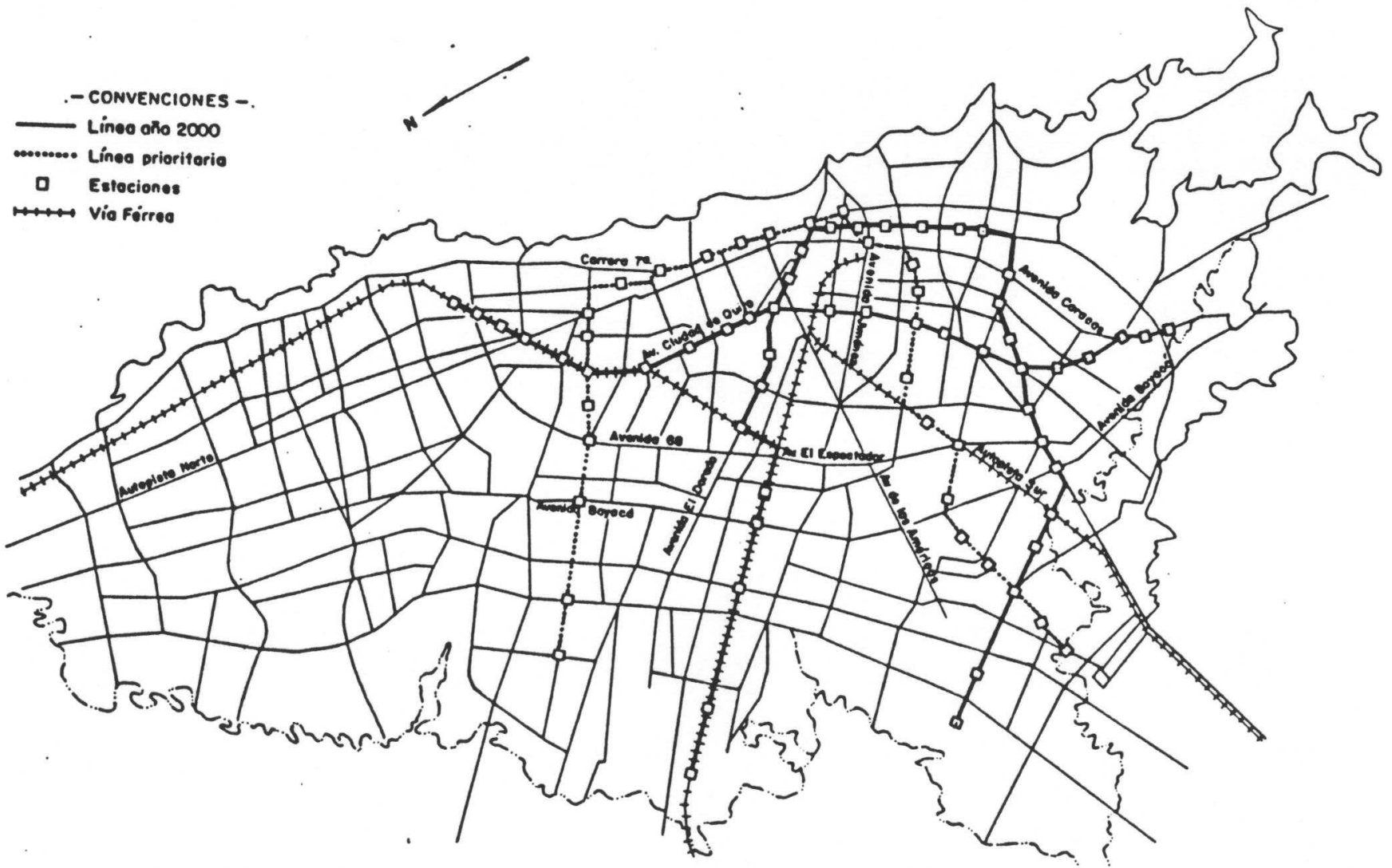




\section{Figura 4.17}

Projeto de Metrô em Santafé de Bogotá Proposto no Estudo de Reabilitação das Ferrovias Urbanas em 1986

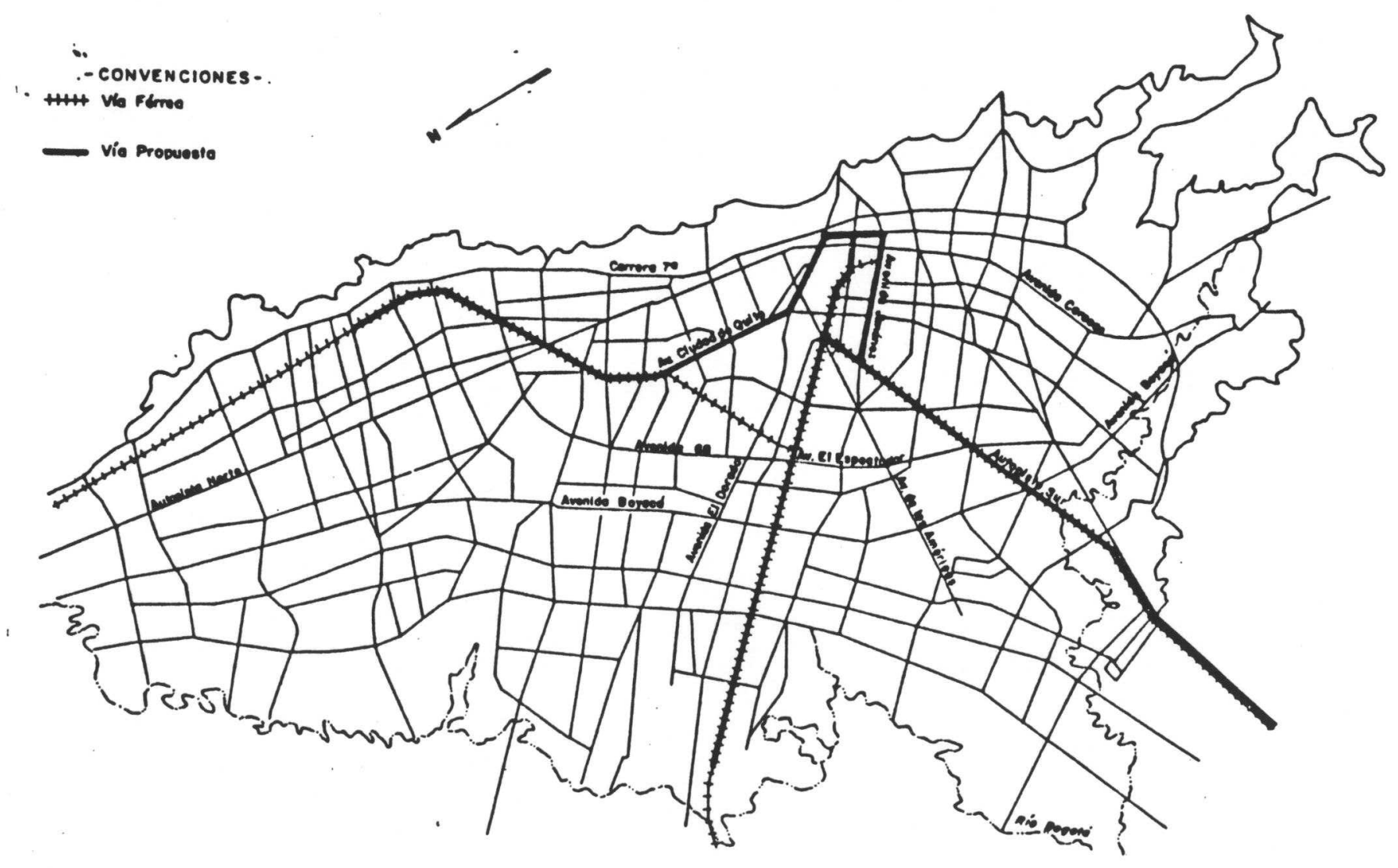


Surpreendentemente, o estudo de viabilidade deste projeto não considerou necessário calcular benefícios diferentes correspondentes aos de tempos economizados pelos usuários e também não mostrou nenhum indicador econômico, quer TIR, quer VPL (Valor Presente Líquido) que mostrasse a justificação sócio-econômica do projeto (GUHL et al, 1992).

Avaliações exaustivas foram logo desenvolvidas para se avaliar o projeto. Foram contratados quatro estudos, três com especialistas colombianos e mais um com um estrangeiro ${ }^{47}$.

Todos os estudos mencionados coincidem em mostrar a inconveniência do projeto, pois dificilmente vão-se obter os benefícios necessários para compensar os enormes custos do sistema, que a juizo dos especialistas, foram sub-estimados. A TIR do projeto teria valores negativos nas condições mais prováveis dos casos (em torno de $-6,2 \%$ a $-10,5 \%$ ). Financeiramente provocaria estragos para os recursos do Distrito.

Os resultados dos estudos confirmam a longa experiência internacional neste tipo de projetos. Os STM do tipo metrô não são viáveis financeiramente, mesmo para cobrir os custos operacionais. É necessária, às vezes, transferências financeiras ${ }^{48}$ do tipo subsídios.

47 Os estudos que permitiram tomar a decisão de abandonar o projeto foram:

GUHL. Ernesto; PACHÓN, Alvaro. Estudio de Evaluación del Sistema Férreo en la Sabana de
Bogotá. feb.1991 ACEVEDO, Jorge; SALAZAR, Manual. Evaluación del Proyecto de Contrucción de un Metro para
Bogotá. mar. 1991 URRUTIA, Miguel; VALENCIA, Catalina. Comparación de la Inversión en el Metro y en Gasto
Social en Bogotá. mar. 1991. KAIN, John. Análisis de las Propuestas para el Metro de Bogotá. may. 1991.

48 HALCROW FOX and ASSOCIATES. Study of Mass Rapid Transit in Developing Countries. Transport and Road Research Laboratory, The Overseas Unit, 1989 apud GUHL; PACHÓN, 1991. 
O custo da energia para este tipo de projetos não é uma variável que permita determinar contundentemente a viabilidade do sistema. O custo de capital, é sim, o fator que mais influi na economicidade deste STM.

Todavia, é possivel que o projeto de metrô para a cidade de Santafé de Bogotá seja retomado num futuro próximo, pois o presidente da República que acabou de ser eleito, Dr. Ernesto Samper P., tem dentro de seu programa de governo a construção do metrô para esta cidade. Se as pressões presidenciais conseguem dar início a esse projeto, poder-se-ia novamente repetir o caso do Metrô de Medellín.

A demanda de eletricidade seria da ordem de algumas dezenas de MW, cifra pequena com relação à demanda máxima da maior cidade colombiana.

Finalmente, deve-se notar que o fato de se poder incrementar as vendas de energia elétrica para a concessionária, não é razão suficiente para aprovar um projeto que se mostra pouco atrativo quando analisado num contexto mais global. Existem projetos de STM que, com menores investimentos podem também ajudar a solucionar, durante um horizonte de tempo adequado, o problema de tráfego nesta cidade. Os projetos de troncais exclusivas para ônibus, com TIR da ordem de 20\% (ACEVEDO; SALAZAR, 1991), são exemplos de alternativas deste tipo, e como foi demonstrado anteriormente, a utilização de ônibus elétricos (tróleibus) podem representar uma opção interessante do ponto de vista ambiental, econômico e social.

\subsubsection{Projetos de Eletrificação de STM em Medellín}

O caso de Medellín é especial com relação à seleção de um ou vários projetos de STM., pois praticamente o projeto do Metrô, atualmente em andamento, condicionou a evolução da infra-estrutura vial da cidade. 
O projeto do Metrô de Medellín foi mais uma decisão política presidencial do que técnica. O estudo de viabilidade de 1979, elaborado por uma firma estrangeira, convenceu às instâncias políticas da região sobre a necessidade de um sistema de transporte de massa para a cidade de Medellín.

O estudo de viabilidade (ETMVA, 1979) pré-selecionou três sistemas: 0 tróleibus, o VLT e um sistema pesado de transporte sobre trilhos, o metrô. Este estudo, porém, recomendou a adoção de um trem elétrico pesado, considerado como uma alternativa técnica superior aos ônibus, tróleibus e VLT, pois resultava mais rentável e adequada para altas demandas, mais flexivel e com maior capacidade.

A comparação das diferentes alternativas tecnológicas foi realizada, no entanto, sob bases precárias: em primeiro lugar porque, segundo a suposta demanda, só o metrô poderia satisfazê-la; em segundo lugar, porque estes supostos de demanda não foram examinados criticamente. As comparações tecnológicas foram realizadas superficialmente e só consideraram-se qualitativamente, sem chegar a estimativas exatas dos seus diferentes desempenhos (ACEVEDO et al, 1993).

O estudo de viabilidade estimou uma taxa interna de retorno (TIR) do sistema de $13,6 \%$, mostrando um projeto auto-sustentável, economicamente. As crises financeiras vividas nos últimos anos evidenciou o crasso erro de se tomar a decisão de construir esse projeto que nunca contou com os estudos de engenharia detalhada para se revisar as conclusões do estudo de viabilidade, porque para agilizar a decisão, foi adjudicado sob condiçōes duvidosas.

Análises detalhadas sobre a evolução deste projeto são apresentadas por exemplo em "El Metro de Medellín, una llusión Costeada por todos los 
Colombianos" dos pesquisadores e especialistas J. Acevedo, J.C. Salazar e W. Castañeda (1993).

A demanda de eletricidade deste sistema já foi prevista no plano de expansão das EEPPM. As subestações para alimentar o Metrô de Medellín estarão ligadas a um sistema de cabos próprios colocados ao longo da linha. A tensão destes circuitos será de $13,2 \mathrm{kV}$, obtida do sistema das EEPPM de $110 \mathrm{kV}$, por meio de 3 subestações transformadoras de 31,5 MVA capazes de fornecer suficiente energia elétrica para as 9 subestações de tração (subestações retificadoras a $1,5 \mathrm{kVcc}$ ) e as subestações de passageiros (ETMVA; ADEMINAS, 1993). A potência máxima estimada que demandará o sistema está entre 25 e $35 \mathrm{MW}$, isto é, em torno de $3 \%$ da potência da hora de ponta (19:00) do sistema elétrico de Medellin em 1992.

O projeto de Metrô de Medellín é formado por duas linhas, A e B. A linha "A", que é a mais importante, cruza o Vale de Aburrá no sentido norte-sul passando pelo centro da cidade, desde Niquia (Município de Bello) até o município de Itagüi, integrando 19 estações ao longo de $23 \mathrm{~km}$. A linha "B", de $6 \mathrm{~km}$, é formada por 6 estações e cobre a zona ocidental da cidade de Medellín. (Figura 4.18).

É sabido que o Metrô não constituirá uma solução total ao problema de transporte de massa do Vale de Aburrá, portanto, dever-se-á complementar com outros sistemas de transporte mais flexiveis que permitam uma prestação ótima do serviço de transporte público. Para esta finalidade, está-se desenvolvendo desde 1988 um programa inter-institucional denominado Sistema Integrado de Transporte (SIT) (ACEVEDO et al, 1993), no qual participam o escritório de Planejamento Metropolitano, a Secretaria de Tráfego e Transporte, a ETMVA e um grupo de assessores brasileiros. O mapa da Figura 4.19 ilustra o esquema integrado de transporte para a cidade de 
Medellin, no qual basicamente são criadas novas rotas de ônibus para complementar a demanda do Metrô.

O programa SIT é em essência uma adaptação para a área Metropolitana de Medellin da metodologia utilizada em outros países. Em São Paulo, por exemplo, foi elaborado um Plano Metropolitano de Transporte Integrado (PMTI) pela Secretaria de Estado dos Transportes Metropolitanos cujo objetivo é desenvolver uma verdadeira rede metropolitana de transporte coletivo, integrando os diferentes modais de transporte (ferrovias, ônibus, tróleibus e metrô) na região da Grande São Paulo (CARRARO, 1993).

A expansão de corredores exclusivos para ônibus é uma alternativa que se apresenta sempre nestes tipos de integração. Os ônibus, que são sistemas de média capacidade, servem de conexão entre zonas da área Metropolitana sem acesso aos grandes STM, como é o caso do Metrô.

Para o caso de Medellín, pode-se pensar em corredores exclusivos de tróleibus, como o analisado para Santafé de Bogotá (troncal da Caracas). A análise econômica seria semelhante, pois os preços dos insumos do setor são iguais nestas cidades, porém, a penetração dessas unidades seria mais complicada pelo fato de não existir unidades de tróleibus de baixo custo para Medellín. A análise econômica mostrou que o preço de equilibrio tende a tornar a eletricidade não competitiva para esse caso. A viabilidade do sistema provavelmente dependerá da possibilidade de transferências, via subsídios, para a empresa ou concessionária proprietária da infra-estrutura de alimentação elétrica dos veículos. 
Figura 4.18

Linhas em Construção do Metrô de Medellin

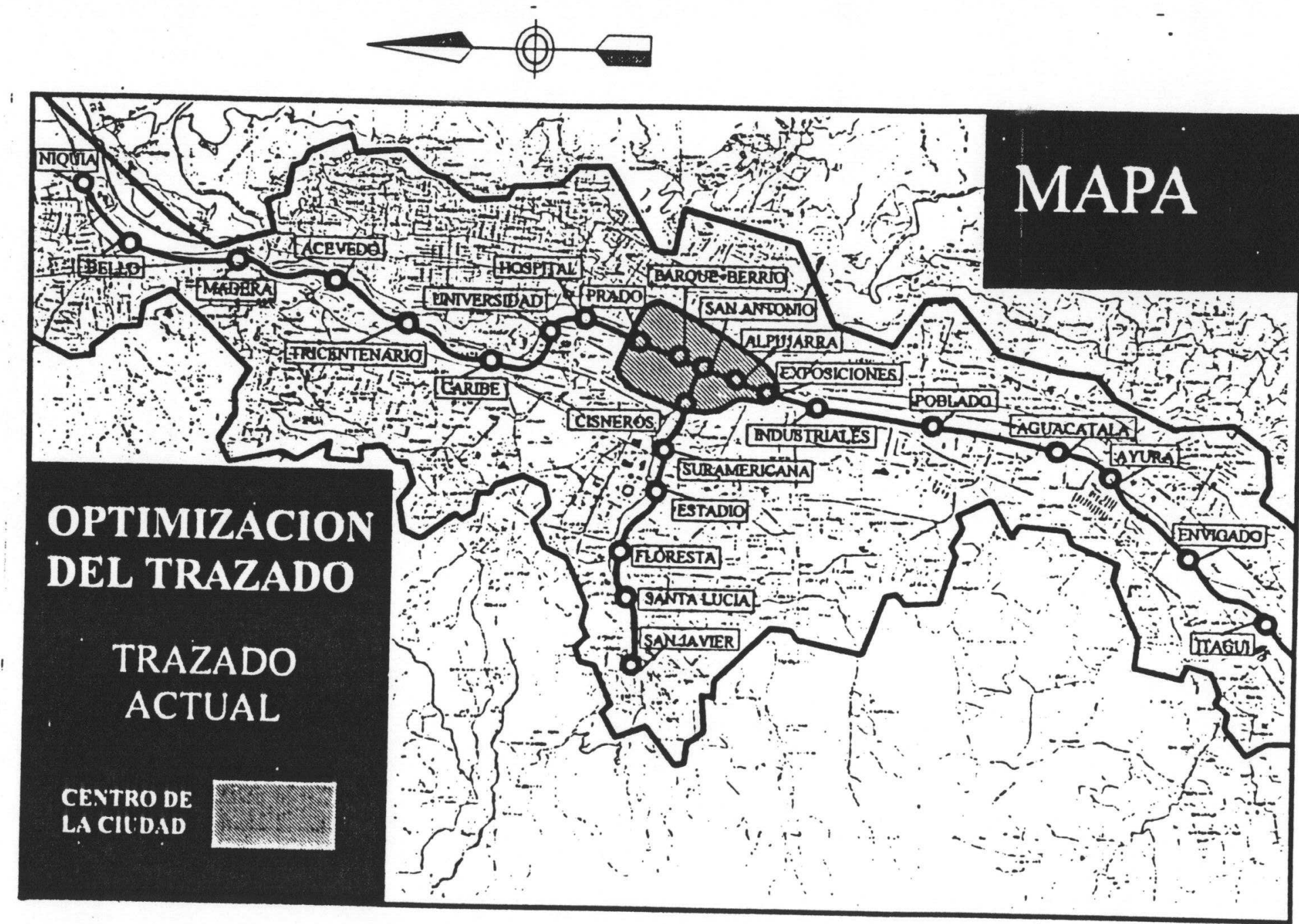


Entretanto, parece ser bastante difícil retirar uma boa percentagem da frota de ônibus que atualmente fazem percursos similares aos que teria o Metrô. Aliás, este ano (1994), as empresas de ônibus (todas são privadas) realizaram uma greve em conseqüência da modificação de suas rotas pela Secretaria de Tráfego da cidade.

Cerca de $92 \%$ das rotas urbanas de Medellin são radiais, de modo que o centro da cidade é o lugar mais congestionado do municipio e mais poluido com relação às emissões próprias do setor de transporte. Medições realizadas em 1991 pelo Instituto Metropolitano de Saúde de Medellín (METROSALUD), determinaram niveis de $\mathrm{CO}$ de até 76,6 ppm em algumas zonas do centro da cidade enquanto as normas de qualidade do ar estipulam niveis máximos de 13 ppm (PLANEACIÓN METROPOLITANA, 1991).

Outras soluções estão sendo estudadas. Existe, por exemplo, o projeto de "bus ligero" (DIAZ, 1993), que é uma adaptação do sistema implantado em Curitiba (Brasil), sob a denominação de ligeirinho (REVISTA Via Urbana, 1993). Este sistema, bem sucedido, consiste em definir rotas que operam entre dois lugares distantes com grande demanda e estações de embarque do tipo tubular e compra antecipada do bilhete. Opçōes deste tipo podem ser utilizadas no futuro para interligar algumas zonas da cidade com estações do metrô.

As oportunidades de eletrificação do setor de transportes em Medellín são, portanto, escassas. Isso, se se descontar o caso do Metrô, projeto já definido há vários anos atrás. Porém, de acordo com o interesse mostrado pelo Departamento de Vias e Transportes do escritório de Planejamento 
Metropolitano ${ }^{49}$, não devem ser desprezadas a priori alternativas como os corredores exclusivos de tróleibus para complementar o mercado do Metrô.

\subsection{Crescimento Vegetativo da Demanda}

A análise para esta alternativa vai estar baseada nas estimativas de demanda de gás para o setor residencial, elaborados por EURCOLERG (1992b). As projeções de demanda de GN foram apresentadas no Capitulo 3 (Figura 3.5).

A metodologia da análise é a seguinte:

- Determinar as prospectivas de crescimento da demanda de energia elétrica caso não acontecer nenhuma penetração do GN ou GLP.

- Determinar as prospectivas de crescimento da demanda de energia elétrica com base nas projeções de demanda de GN realizadas por EURCOLERG (1992b).

- Calcular a demanda de energia elétrica (em energia e potência) economizada durante o horizonte de tempo das projeções.

- Discutir as implicações sócio-econômicas dos resultados.

Os dois primeiros pontos são ilustrados nas Figuras 4.20 a 4.27. As projeções são mostradas tanto em termos de energia (GWh) quanto em potência (MW) para o sistema elétrico interligado nacional e para os três principais mercados do país, os quais envolvem as três maiores cidades colombianas (Santafé de Bogotá, Medellín e Santiago de Cali). 49 Segundo entrevista celebrada em fevereiro de 1994 com o Eng. Gabriel Diaz Rivera, responsável
pelo desenho de rotas e análises do transporte da cidade. 
Figura 4.20

Cenários de Crescimento da Demanda de Energia Elétrica na Colômbia considerando ou não o Programa de Massificação de Gás

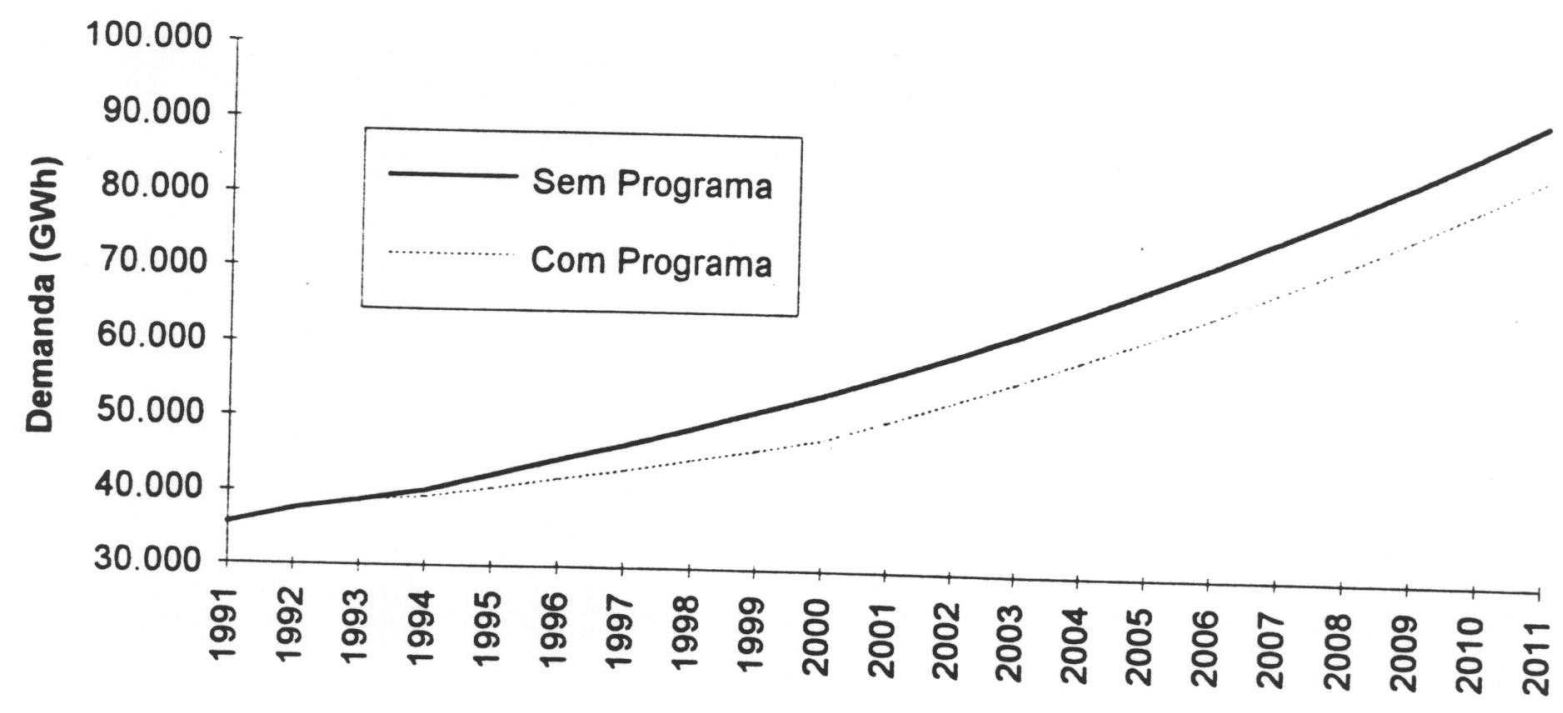

Figura 4.21

Cenários de Crescimento da Demanda de Potência Elétrica na Colômbia considerando ou não o Programa de Massificação de Gás

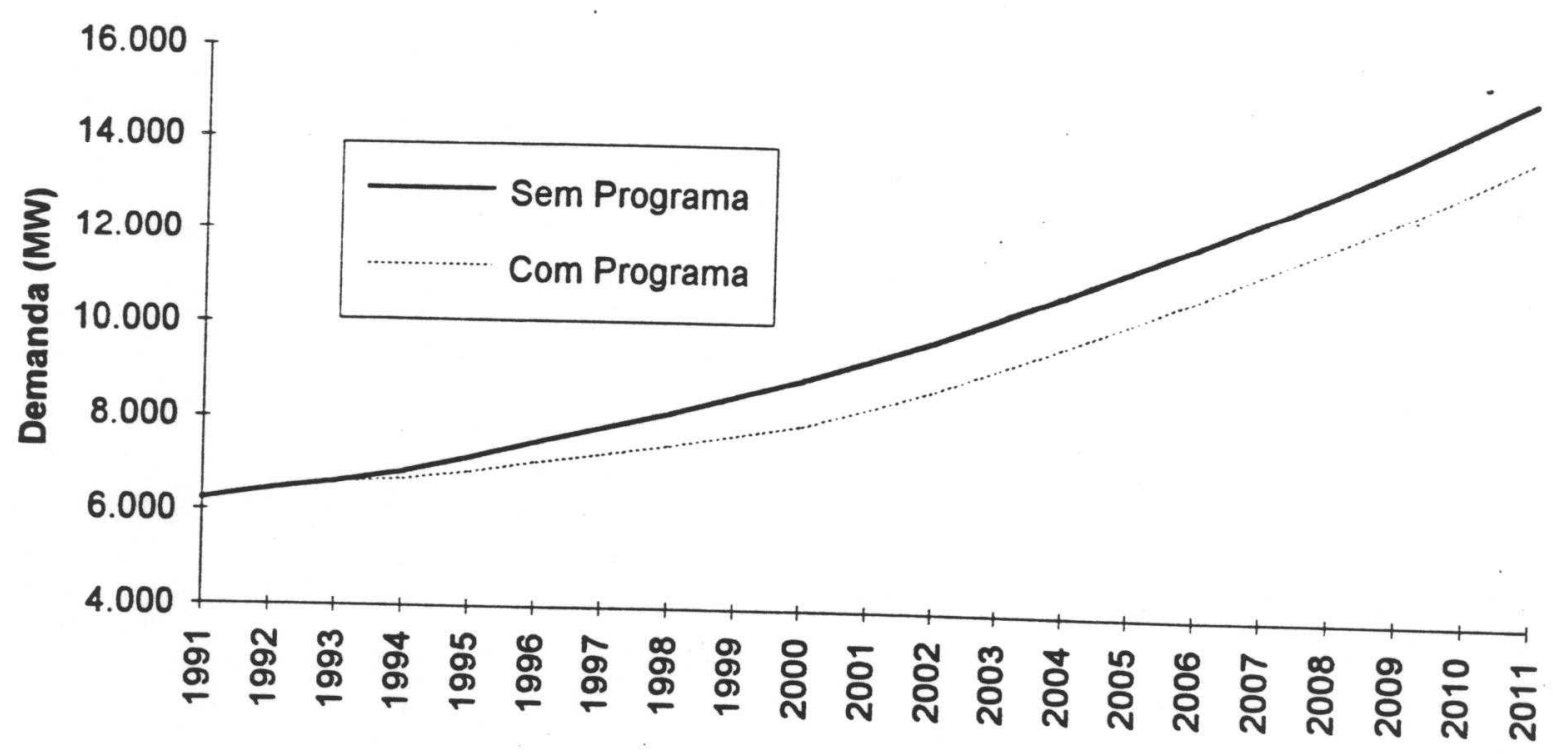

Fonte: Projeções de demanda utilizadas no plano de expansão elétrica de ISA, 1993b. 
Figura 4.22

Cenários de Crescimento da Demanda de Energia Elétrica no Mercado de EEB (1) considerando ou não o Programa de Massificação de Gás

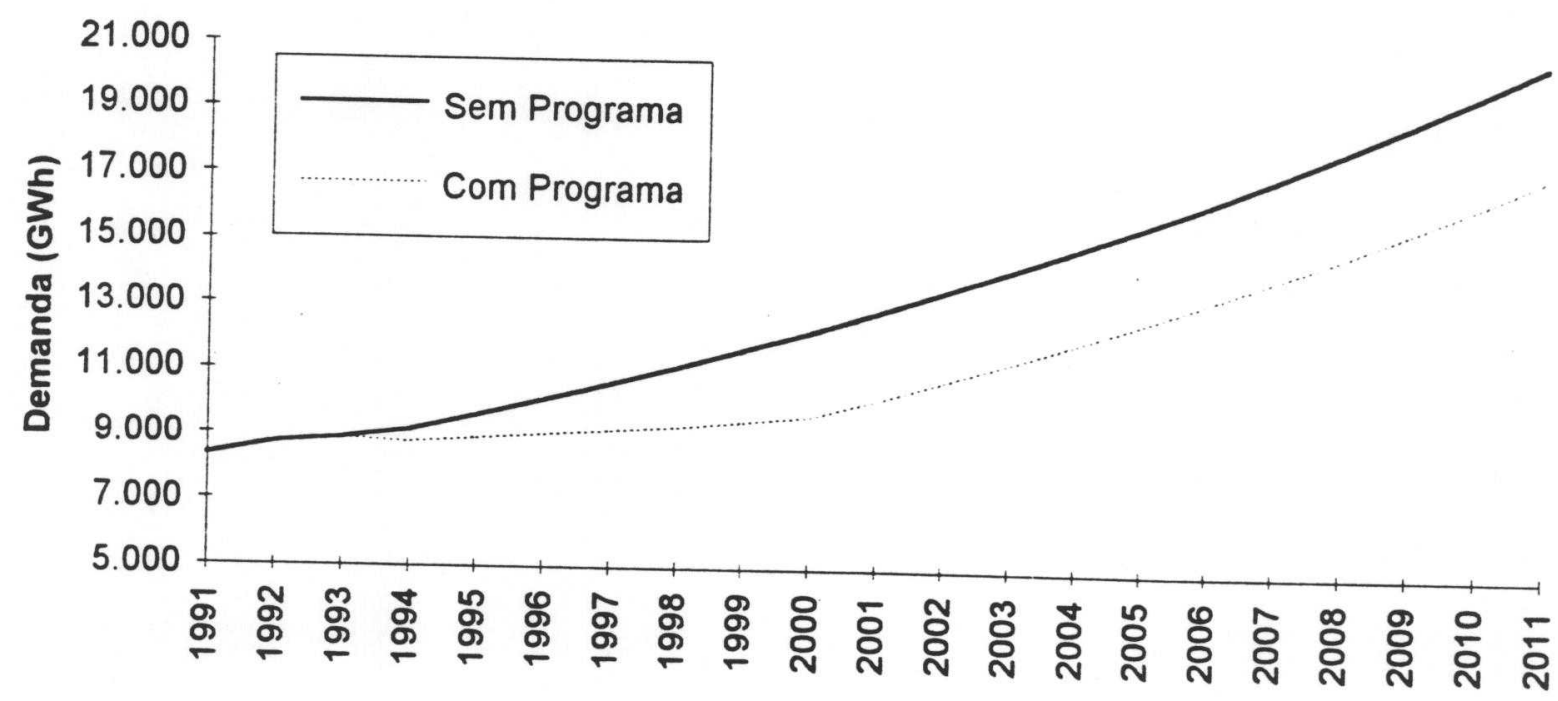

Figura 4.23

Cenários de Crescimento da Demanda de Potência Elétrica no Mercado de EEB (1) considerando ou não o Programa de Massificação de Gás

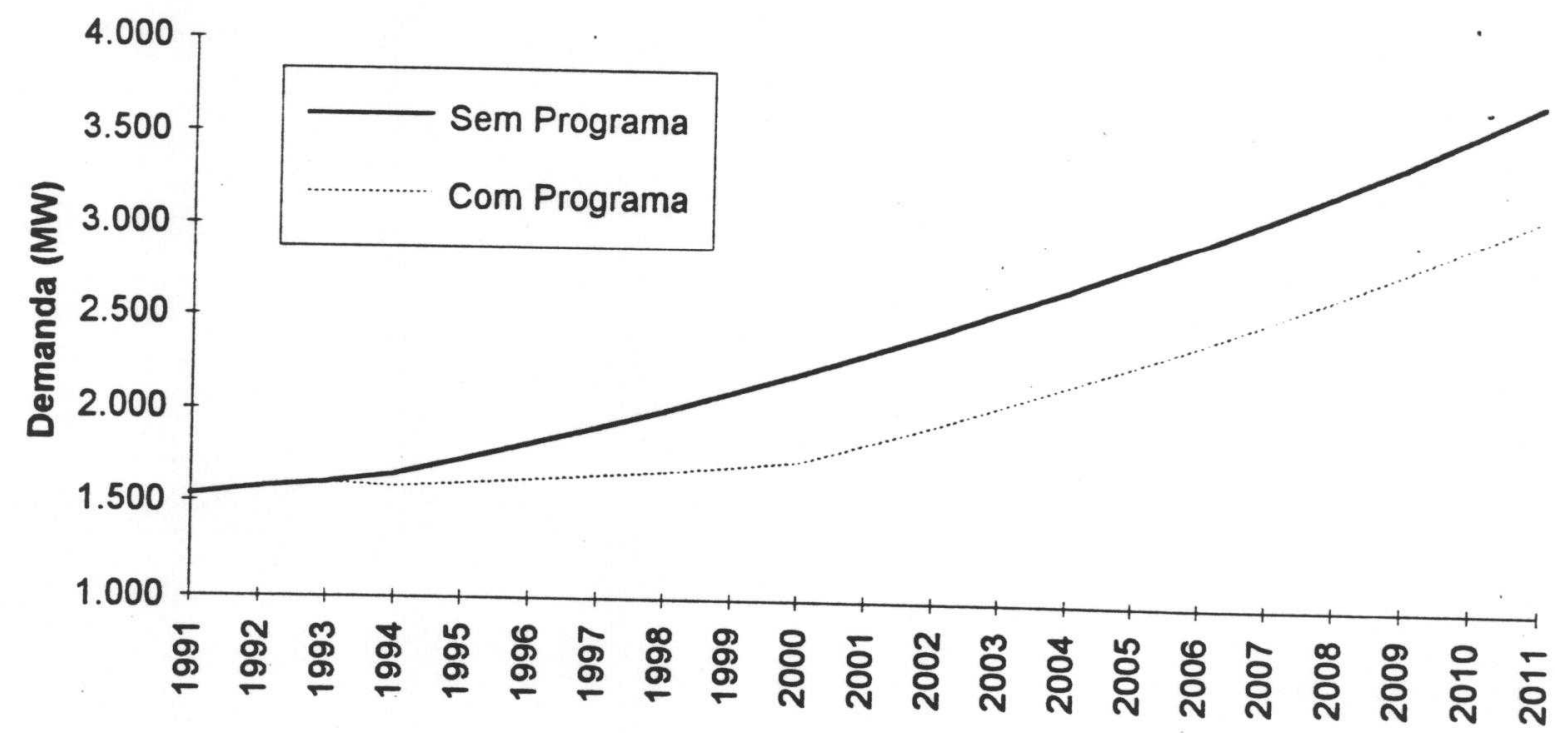

(1) Mercado própio da Empresa de Energia de Bogotá, incluindo os mercados industriais de Álcalis e Ecopetrol.

Fonte: Projeções de demanda utilizadas no plano de expansão elétrica de ISA, 1993b. 
Figura 4.24

Cenários de Crescimento da Demanda de Energia Elétrica no Mercado de EEPPM (1) considerando ou não o Programa de Massificação de Gás

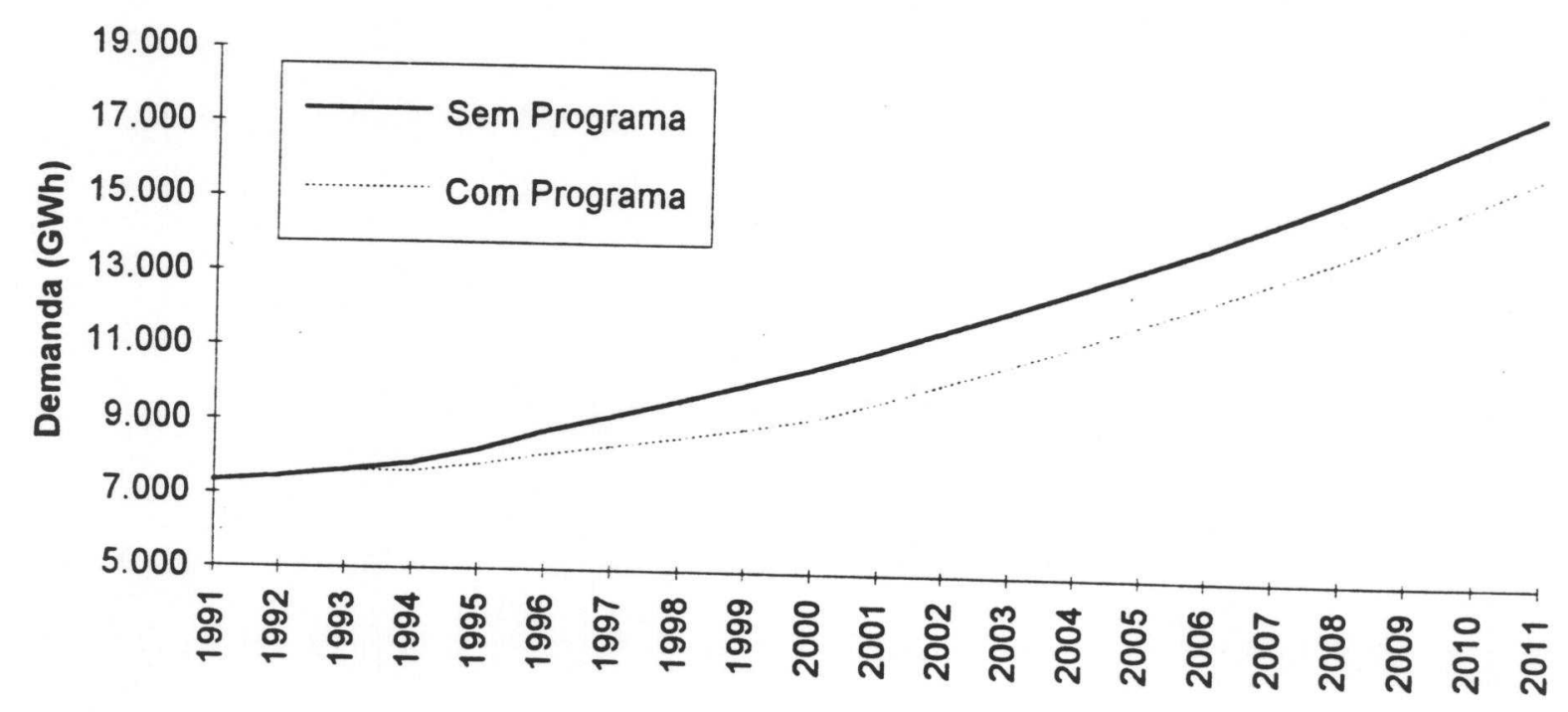

Figura 4.25

Cenários de Crescimento da Demanda de Potência Elétrica no Mercado de EEPPM (1) considerando ou não o Programa de Massificação de Gás

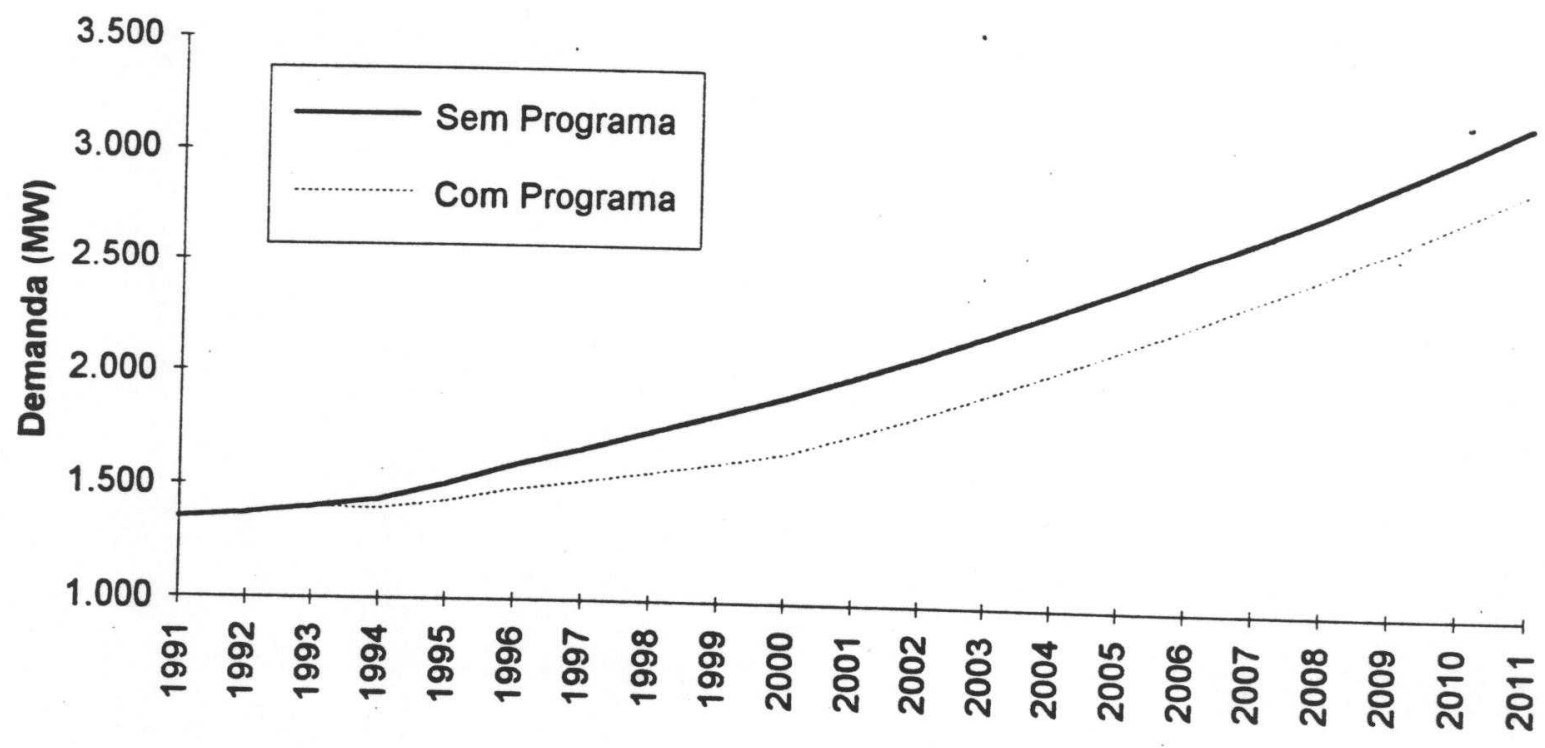

(1) Mercado próprio das Empresas Públicas de Medellin e vendas em bloco à Empresa de Energia de Antioquia (EADE) e à Eletrificadora do Chocó (zona pacífica).

Fonte: Projeções de demanda utilizadas no plano de expansão elétrica de ISA, 1993b. 
Figura 4.26

Cenários de Crescimento da Demanda de Energia Elétrica no Mercado de CVC (1) considerando ou não o Programa de Massificação de Gás

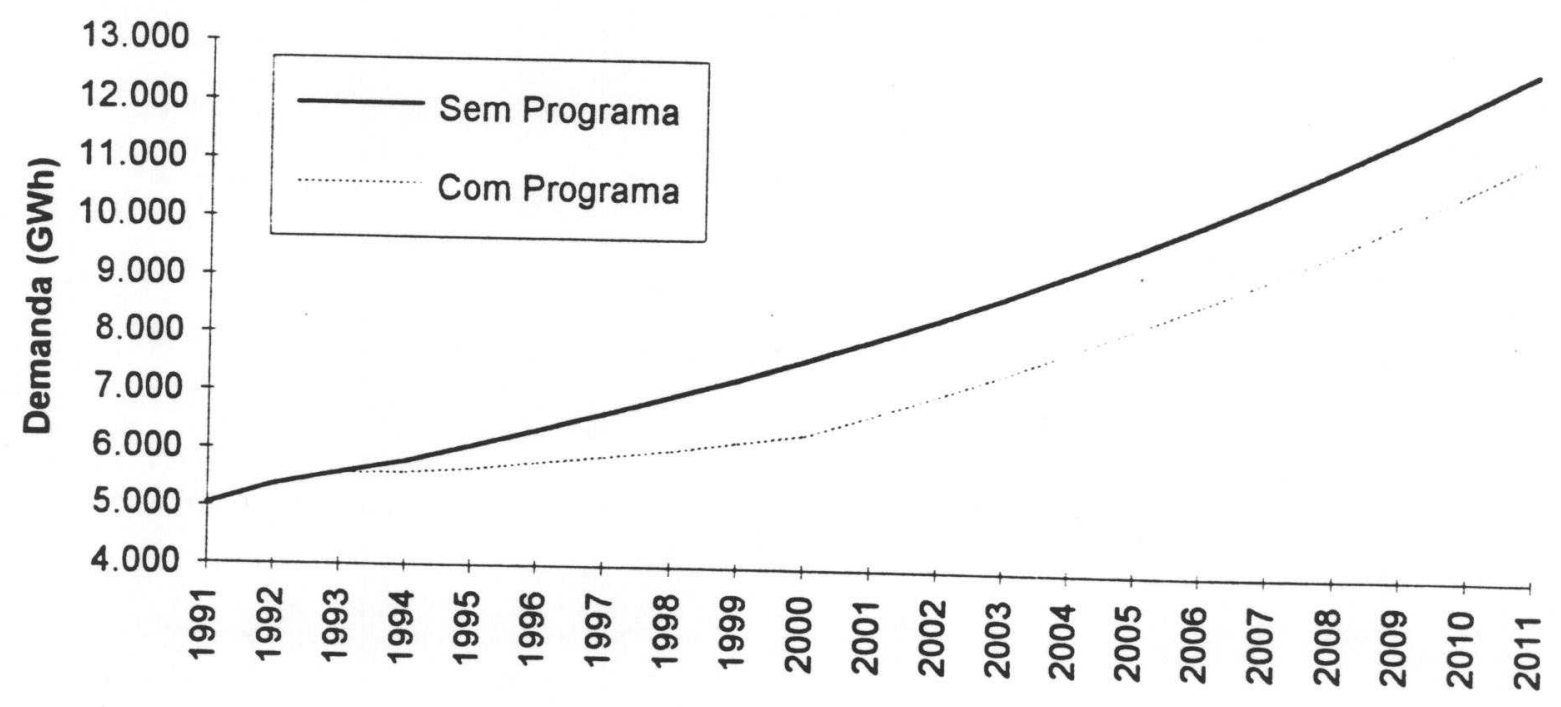

Figura 4.27

Cenários de Crescimento da Demanda de Potência Elétrica no Mercado de CVC (1) considerando ou não o Programa de Massificação de Gás

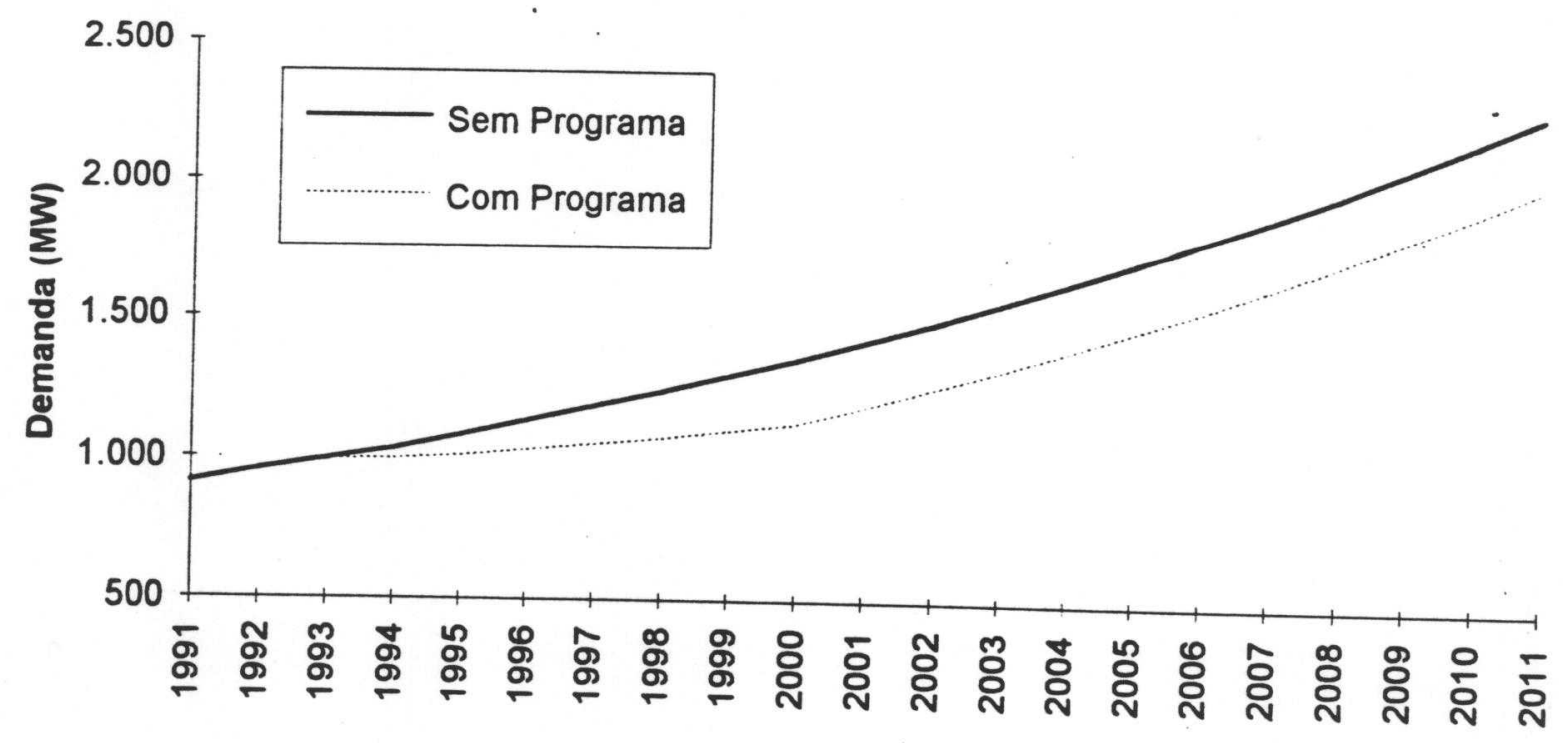

(1) Mercado do departamento do Valle (sudoeste do país)

Fonte: Projeções de demanda utilizadas no plano de expansão de ISA, 1993b. 
As curvas apresentadas correspondem a dois cenários de crescimento da demanda de eletricidade diferenciados entre si considerando-se ou não a penetração do programa de massificação de gás do Governo Nacional.

O cenário de demanda base é o calculado por ISA (1992b) a partir do seu modelo econométrico que considera basicamente três variáveis: Macroeconomia (PIB), demografia (No. de usuários) e decisões de política energética (por exemplo preço dos substitutos).

O cenário que considera o programa de massificação do uso do gás, está baseado na proposta do DNP sobre alta penetração do combustivel substituto. Convém anotar que este cenário foi considerado no plano de expansão elétrica de ISA (1993b), mas o cenário de referência desse estudo foi baseado numa menor penetração do programa de gás.

Nesta dissertação é analisado o cenário de alta penetração de substitutos por diferentes razões. Em primeiro lugar, as grandes descobertas de reservas de GN associado em Cusiana e Cupiagua, além de ser um gás rico em líquidos, reduzirá os custos econômicos do combustivel, pois aumentou-se o horizonte de esgotamento dele no pais. O cenário de "referência" (até então o mais provável) utilizado para as análises de expansão é agora pessimista, já que os custos econômicos do GN foram calculados supondo a importação do combustivel da Venezuela. Em segundo lugar, é tarefa do Governo, por meio das suas instituições descentralizadas, garantir que o programa de massificação de gás seja um sucesso, pois estão em jogo milhões de dólares investidos e que devem ser adequadamente recuperados para garantir a utilização ótima dos recursos da Nação. 
As demandas de energia e potência elétricas economizadas são ilustradas nas Figuras 4.28 e 4.29 , tanto para o sistema elétrico total quanto para os três principais mercados que seriam alvo do programa de massificação de gás.

De acordo com as estimativas do programa de massificação de gás, espera-se que a maior taxa de crescimento na penetração dos combustiveis substitutos (GN e GLP) aconteça até o ano 2000. A partir desse ano, começaria um processo de saturação.

As maiores economias de energia e potência vão ser concentradas em Santafé de Bogotá, Medellin e Santiago de Cali e suas áreas vizinhas. O programa de massificação, sob este cenário, permite reduzir para o ano 2000 a demanda de potência para a concessionária EEB (Empresa de Energia de Bogotá) em $462 \mathrm{MW}$ e para os mercados de EEPPM (área metropolitana de Medellín e vendas em bloco para o Departamento de Antioquia e Chocó) e CVC (Departamento do Valle del Cauca) de 243 MW e 225 MW respectivamente. A demanda do sistema interligado nacional teria uma redução de $982 \mathrm{MW}$.

Os crescimentos de demanda, quando considerado o programa de massificação de uso do gás, podem ser vistos como deslocamentos temporais do crescimento da demanda sem ter em conta penetração dos substitutos.

Para o caso do sistema total, o deslocamento é de dois anos. Isto é, o crescimento da demanda sem programa de substituição adiado dois anos é similar ao crescimento da demanda com programa de substituição. Para o caso do mercado de EEB o deslocamento é de quatro anos, para EEPPM é 2,5 anos e para CVC é de 3 anos. 
Figura 4.28

\section{Projeção das Economias em Energia Elétrica pela Penetração do \\ Programa de Massificação de Gás na Colômbia}

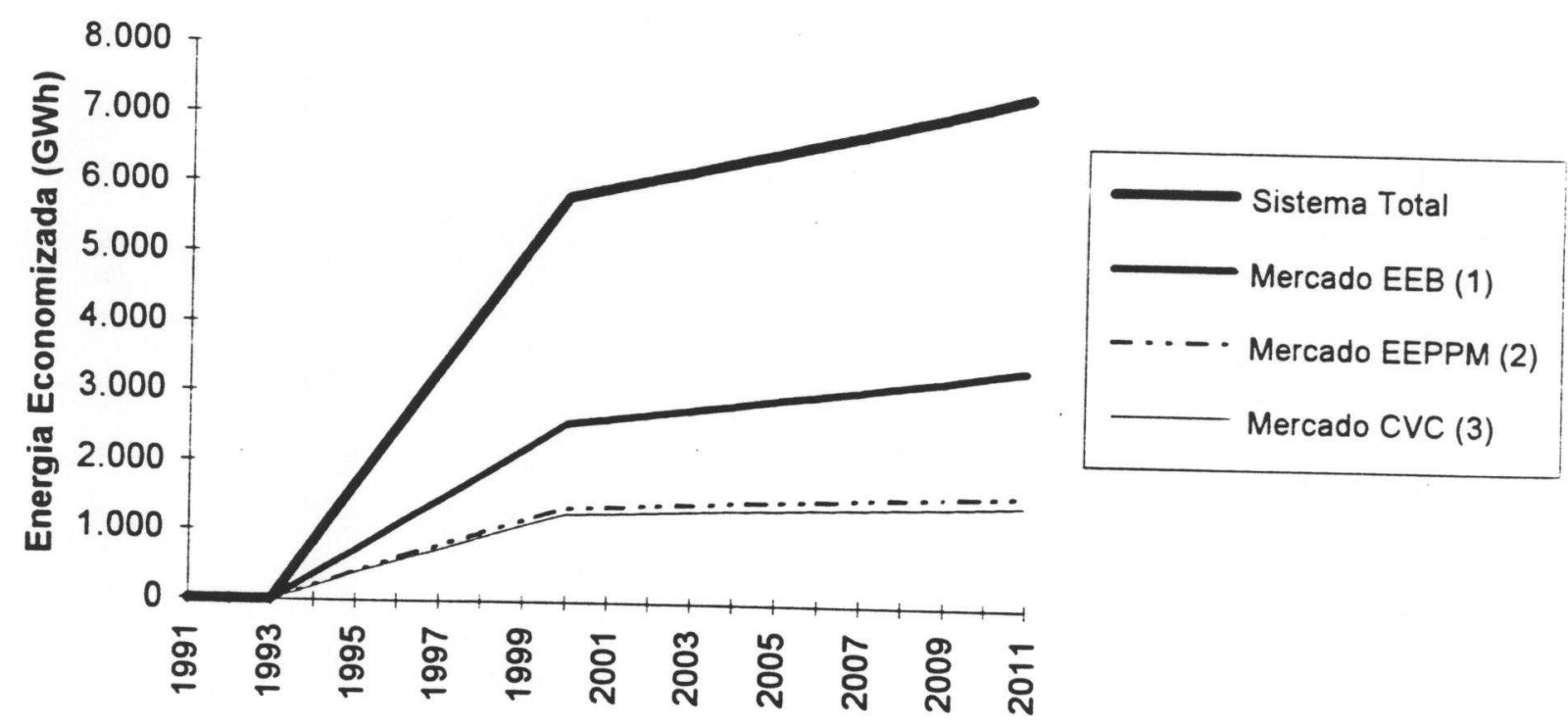

Figura 4.29

Projeção das Economias em Potência Elétrica pela Penetração do Programa de Massificação de Gás na Colômbia

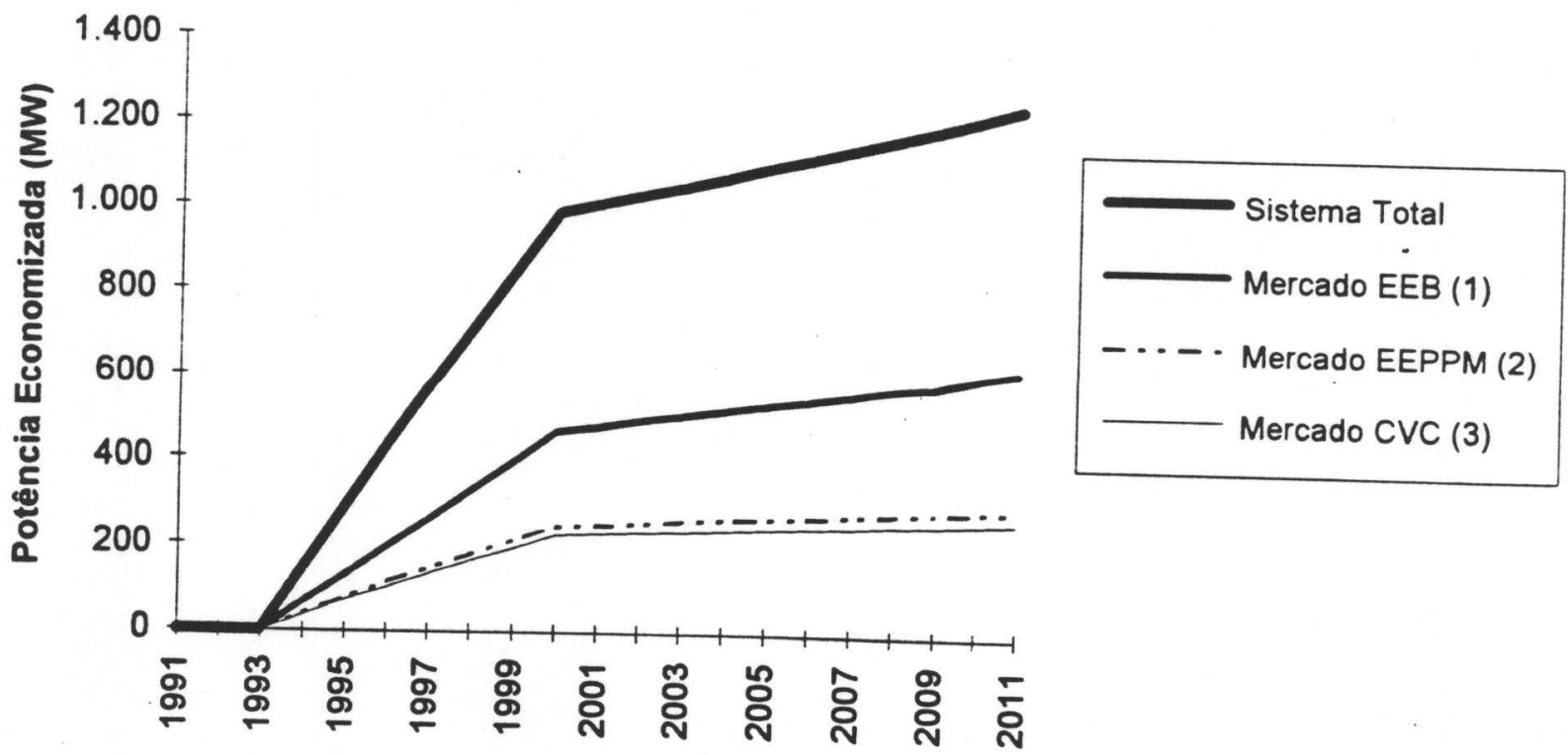

(1) Mercado próprio da Empresa de Energia de Bogotá, incluindo os mercados industriais de Álcalis e Ecopetrol.

(2) Mercado próprio das Empresas Públicas de Medellín e vendas em bloco à Empresa de Energia de Antioquia
(EADE) e à Eletrificadora do (3) Mercado do departamento do Valle (su Fonte: Cálculos do autor com base nas projeções de demanda utilizadas no plano de expansão elétrica de ISA,
1993b. 


\begin{abstract}
Esses valores encontrados são importantes porque mostram que a penetração do programa de massificação de gás permite adiar investimentos nos sistemas elétricos do país com todas as vantagens financeiras decorrentes dai derivadas.
\end{abstract}

Como era de se esperar, o sistema elétrico de Santafé de Bogotá seria o mais beneficiado com o programa em termos de provocar o adiamento das necessidades de expansão da rede elétrica, devido ao fato que praticamente não se precisariam novas obras por um período de quatro anos. Esse periodo é similar ao horizonte de planejamento de curto prazo dos sistemas de distribuição (ISA, 1992a), no qual são definidas as obras a se construir.

As reduções para o ano 2000 da demanda de energia e potência para o sistema interligado colombiano significam economias anuais de MMUS\$254 50 Essas economias traduzem-se em alivios financeiros para o setor elétrico, devido ao adiamento de custosos investimentos em novas usinas, linhas de transmissão, subestações de transformação, redes de distribuição, etc.

O crescimento vegetativo da demanda, é então, uma alternativa interessante do ponto de vista financeiro para as concessionárias de energia elétrica, pois além de simples (não é necessário gerenciar nenhum tipo de projeto, ao invés das outras alternativas: eletrificação de ferrovias e eletrificação de transporte de massa), representa a opção mais plausivel para o curto prazo (até o ano 2000).

Para o ano 2000, a estrutura de vendas do setor elétrico teria uma mudança notória com relação à estrutura atual. O setor residencial, que em 1992

50 O custo marginal a nivel de geração para o sistema elétrico colombiano em dólares de dezembro de 1993 é de 31 US\$/MWh em energia e 75,60 US\$/kW-ano em potência (CRE, 1993). 
representava $47 \%$ das vendas do setor, passaria a $38 \%$ e o setor industrial a $37 \%$, mostrando desta forma que o programa de massificação de uso de gás permitiria a médio prazo a restruturação favorável das vendas do setor elétrico colombiano. (Figura 4.30).

Figura 4.30

Composição Estimada das Vendas de Eletricidade para o ano 2000

(Cenário de alta penetração do Programa de Massificação de Gás)

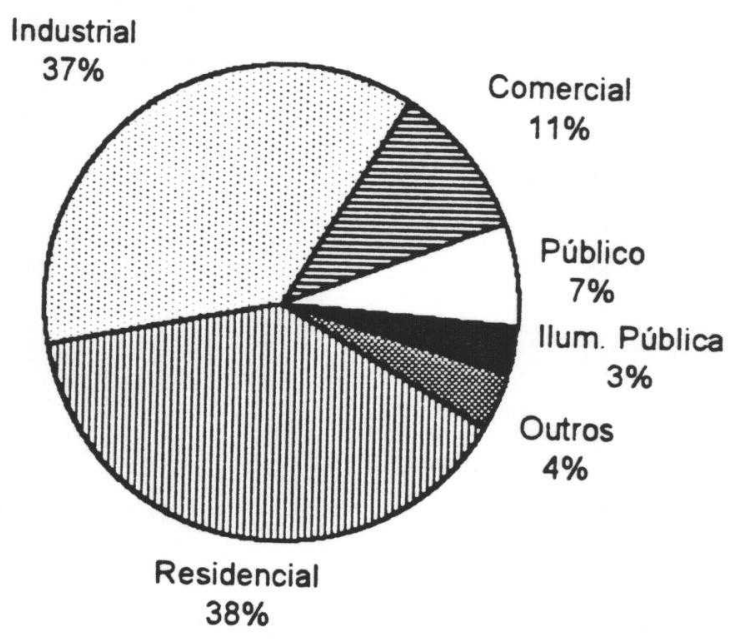

Fonte: Cálculos do autor com base em dados de ISA, 1992b. 


\section{CONCLUSÕES E RECOMENDAÇÕES}

\subsection{Conclusões}

O setor elétrico colombiano apresenta atualmente uma difícil situação financeira, causada principalmente pela insolvência econômica das concessionárias de energia elétrica. Insolvência que é devida, entre outros fatores, à estrutura de vendas do setor.

O setor residencial é o principal consumidor de energia elétrica, com participação de $47 \%$ e demanda uma quarta parte da energia final do país. Esta estrutura é devida principalmente ao fato do intensivo uso da eletricidade para atividades de cozimento de alimentos (cocção). Foi determinado que, na média, $33 \%$ da energia elétrica está voltada para cocção na zona urbana do país. Dita estrutura seria somente comparável com a matriz energética da Costa Rica, no hemisfério ocidental.

A estrutura tarifária vigente na Colômbia outorga subsídios para a maioria dos usuários residenciais, levando à utilização inadequada de recursos. do país devido à ausência de sinalização econômica correta. A atualização tarifária é imprescindivel para se conseguir uma boa penetração do gás natural conforme reza o do Programa de Massificação de Gás.

Foi estimado que $11 \%$ da produção de energia elétrica na Colômbia é destinada para atender o serviço de cocção. Porém, o aspecto crucial, do ponto de vista energético, da cocção, está nas necessidades de potência elétrica, dado o fator de coincidência na ponta do sistema deste uso final. Cálculos realizados permitiram determinar que a responsabilidade deste uso final na ponta do sistema elétrico nacional pode chegar a 27\% (1.666 MW). 
Estimou-se que o custo anual da utilização de eletricidade em cocção é da ordem de MMUS $\$ 490$. Esses custos não são repassados completamente aos usuários, devido aos baixos níveis tarifários para os setores menos ricos da população. Desta forma, são dados enormes subsídios que menosprezam as finanças das concessionárias. Em cidades como Santafé de Bogotá e Medellin, por exemplo, calcularam-se subsídios de MMUS\$171 e MMUS\$ 81 .

Avaliando-se o custo econômico da cocção do ponto de vista de usos finais, centrado no serviço requerido (calor) e não no volume de energia demandado, encontra-se que a forma mais econômica para realizar a cocção de alimentos é utilizando-se gás. Do ponto de vista do usuário, esse resultado é também válido, excetuando-se o caso quando o preço da eletricidade é muito baixo (como acontece para alguns setores da população).

Socialmente, o setor da população de menores recursos do pais será mais sensivel à política de atualização dos níveis tarifários do setor residencial. Cálculos apresentados nesta dissertação mostram que as parcelas médias de orçamento familiar devotadas para o pagamento da fatura de eletricidade podem chegar a níveis de $14 \%$, enquanto para usuários de boa situação econômica, a percentagem no orçamento familiar não supera $2,8 \%$.

As mesmas características do sistema tarifário atual tendem a indicar que, os usuários de maiores rendas sejam os principais interessados na substituição da eletricidade para cocção e não os usuários mais pobres. Porém, para as concessionárias de energia elétrica o interesse é inverso. Esse paradoxo será solucionado por meio de políticas de incentivos (por exemplo financiamento dos equipamentos de uso final) para os setores mais pobres da população. 
Em geral, o usuário que reduzir o consumo de eletricidade para cocção vai experimentar, em termos relativos, uma redução maior no faturamento de energia elétrica. Isso devido à estrutura tarifária atual, na qual os níveis tarifários aumentam conforme a faixa de demanda superior.

Não existe uma diferença muito marcante entre a participação de energéticos utilizados para o uso final cocção na zona urbana do pais. O GLP é o principal, seguido da eletricidade, a lenha, o cocinol (gasolina), o GN, ○ querosene e carvão mineral. Mostra-se que o uso da energia elétrica, mesmo não sendo o principal energético para cocção na zona urbana, conduz às piores conseqüências sócio-econômicas para o país.

Nesta dissertação mostra-se que os combustiveis com maiores vantagens para substituir a eletricidade devotada para cocção são o GLP, ○ GN e Carvão. $O$ cocinol, entretanto, deve ser também substituído por energéticos mais seguros e econômicos. Estimou-se que uma demanda adicional de $1.480 \mathrm{kbbl} / \mathrm{ano}$ de GLP $(24,4 \%$ de incremento da oferta interna) é necessária para eliminar o uso desse perigoso energético.

O carvão mineral, em forma de briquetes, pode ser uma alternativa interessante do ponto de vista econômico para substituir eletricidade e lenha em cocção para as zonas rurais carboníferas da Colômbia. É importante acompanhar durante os próximos anos o desenvolvimento da primeira empresa que fabricará, a partir de 1995, os briquetes no Departamento de Antioquia.

Políticas de melhoramentos na eficiência de utilização de energéticos de baixo custo, lenha ou carvão, representa uma ótima oportunidade para evitar ou substituir o uso da eletricidade para a cocção na zona rural do país, especialmente em zonas distantes dos centros urbanos ou locais de dificil acesso. 
A utilização de condensados do GN associado de Cusiana permitiria adiar as necessidades de oferta de GN para depois de 2004 e dispôr ainda de maiores volumes de GN de Cusiana para reinjetar, evitando assim, uma redução do fator de recobro de cru do campo. Também, poder-se-iam evitar importações de GLP; ajudar a fomentar a cultura do gás, graças ao menor custo de instalação para o usuário quando comparado com o GN; aumentar a disponibilidade de $\mathrm{GN}$ para usos diferentes de cocção, como o uso industrial, termelétrico e de transportes; aumentar os volumes de comercialização para distribuidores; e facilitar a penetração em mercados geograficamente isolados.

Uma das maiores vantagens para se fomentar a substituição de energia elétrica por outros energéticos mais baratos para a sociedade é o apoio e a consciência política que existe no país para isso. A decisão, já tomada, para construir um gasoduto central de $575 \mathrm{~km}$ para trazer o $\mathrm{GN}$ das jazidas de La Guajira (zona setentrional da Colômbia) para os grandes centros consumidores é um passo claro e convincente da vontade nacional para ajudar a solucionar este problema.

Porém, deve-se pensar em medidas que permitam amenizar os efeitos negativos ante a ocorrência de uma falha ou de atentados na rede de gasodutos. Uma repartição do mercado residencial mais homogênea entre o GLP e o GN, que também poderia ter uso industrial, comercial e termelétrico, permitiria reduzir impactos sociais adversos por uma emergência desse tipo.

Uma falha no gasoduto-tronco criar-se-ia uma situação de grande inconveniência à população por se tratar de usar GN em cocção. Neste sentido, o GLP também apresenta vantagens.

No futuro, quando forem atingidas as metas de atualização de tarifas elétricas para o setor residencial, o GLP será o principal energético 
concorrente do GN. Caso deixar que as forças do mercado operem sobre este setor, provavelmente o GLP penetraria na faixa da população de menores rendas, enquanto o GN seria utilizado por usuários de maiores rendas.

Provavelmente, as reduções de demanda de eletricidade pelo setor residencial na Colômbia redundarão no adiamento do aumento de oferta e não na conquista de novos e importantes mercados para a eletricidade. As oportunidades de eletrificação do setor de transportes na Colômbia não são muito numerosas, e as que existem não provocariam um aumento isolado sensivel na demanda atual de eletricidade de modo a compensar os excedentes que poderiam advir da cocção não elétrica. Por exemplo, a utilização de tróleibus na Troncal da Caracas em Santafé de Bogotá, que seria o projeto mais viável de se implantar a curto prazo, demandaria $52 \mathrm{GWh} / a n o$, apenas $1,5 \%$ da demanda de energia elétrica utilizada em cocção em 1992.

As reduções para o ano 2000 da demanda de energia e potência para o sistema interligado colombiano significam economias anuais de MMUS\$254. Essas economias traduzem-se em alivios financeiros para o setor elétrico, devido ao adiamento de custosos investimentos em novas usinas, linhas de transmissão, subestações de transformação, redes de distribuição, etc.

Os projetos considerados para eletrificação no setor de transportes são, entretanto, opções interessantes quando analisados individualmente. Estudos mais aprofundados e em detalhe podem ser levados a cabo para os projetos de eletrificação da ferrovia de El Cerrejón (complexo de mineração de carvão em La Guajira) e para a implantação de tróleibus em vias exclusivas (somente de ônibus) nas grandes cidades do país (Santafé de Bogotá e Medellin). 
Conforme estudos internacionais, a linha ferroviária de El Cerrejón pode ser um projeto de eletrificação de ferrovia viável economicamente, devido ao enorme volume de carga (até 15 milhões de ton/ano) que é mobilizada nos $150 \mathrm{~km}$ da rede.

Uma análise preliminar realizada nesta dissertação mostrou que existem interessantes vantagens pela utilização de tróleibus em vias exclusivas. Considerou-se um esquema de funcionamento no qual a infra-estrutura física (rede) e vias fossem de uma entidade governamental, enquanto os veículos seriam de particulares.

As barreiras tarifárias são significativas para a penetração do uso dos tróleibus na troncal da Caracas em Santafé de Bogotá. Para altos custos de oportunidade do dinheiro dos potenciais investidores, não é viável a utilização devido ao alto custo de capital dos tróleibus. Este custo de capital das unidades é, portanto, o principal obstáculo para sua utilização por parte do setor privado.

Devido ao custo final de transporte por ônibus ser muito sensivel ao custo do combustivel, aumentos no preço da gasolina podem favorecer apreciavelmente a economicidade dos tróleibus. As políticas de desmonte de subsidios ou de sobretaxas para esse combustivel poderiam beneficiar a viabilidade do projeto em questão.

A utilização das unidades inativas de tróleibus da empresa bogotana em liquidação, EDTU, são uma opção atrativa para o investidor privado e o organismo que for proprietário da rede de alimentação, pois além de mostrar menores custos de capital, permite reduzir os custos de energia. Para a empresa dona da rede, esta é uma opção interessante para superar as barreiras iniciais de colocação de unidades e desta forma assegurar um alto fator de penetração dos tróleibus. 
Avaliações preliminares mostram que o custo econômico unitário (US\$/kWh) para o sistema de alimentação elétrica dos veículos, aumenta exponencialmente à medida que diminui o número de tróleibus funcionando na rede. Nos casos onde a taxa de penetração é baixa, é conveniente que os tróleibus sejam utilizados mais regularmente durante o dia do que as unidades a gasolina (maior custo de operação e menor custo de capital), visando um maior fator de carga visando melhorar a economicidade do sistema de tróleibus.

Análises de sistemas de transporte de massa pesados, como o metrô, contêm muitos fatores que devem ser considerados e que 0 fato de poder incrementar as vendas de energia elétrica para a concessionária, não é razão suficiente para aprovar projetos que se mostram pouco atrativos quando analisados num contexto mais integral. Existem projetos de sistemas de transporte de massa que, com menores investimentos podem também ajudar a solucionar, durante um horizonte de tempo adequado, o problema de tráfego de algumas cidades. Os projetos de troncais exclusivas para ônibus, com taxas internas de retorno da ordem de $20 \%$, são exemplos de alternativas deste tipo. E como foi demonstrado na dissertação, a utilização de ônibus elétricos (tróleibus) podem representar uma opção interessante do ponto de vista ambiental e social, mas contém inerentes desvantagens econômicas dado, entre os fatores, o fato de apresentar baixos fatores de capacidade e altos investimentos. Além do que, a quantidade de eletricidade que seria consumida é desprezivel perante o montante da energia que poderia ser liberada na substituição da eletricidade por combustiveis fluidos (GLP e GN).

Em suma, a presente análise mostrou que a utilização da energia elétrica deslocada da cocção não encontra receptáculo favorável no transporte elétrico, tanto sob o ponto de vista quantitativo como geográfico. 0 principal 
"uso" econômico-estratégico desta energia encontra lugar no crescimento vegetativo natural da demanda de energia elétrica da Colômbia.

\subsection{Recomendações}

Devem ser revistos ou elevados os niveis de eficiência das resistências elétricas produzidas no país. O organismo competente, o ICONTEC, deverá atuar para essa finalidade. Melhoras nos rendimentos térmicos desses elementos trazem benefícios de curto prazo para o setor elétrico, pois a vida útil relativamente curta das resistências $(5.000 \mathrm{~h})$, permite que seja realizada uma renovação destes componentes num horizonte de tempo não muito grande.

O alto teor de GLP (propano e butanos), etano, pentanos e outros componentes no gás natural associado do novo campo petrolífero de Cusiana (Departamento de Casanare), mostra que convém realizar um estudo mais detalhado sobre a viabilidade econômica e técnica de se instalar uma planta de tratamento desse gás. De acordo com esses resultados, seria imperioso voltar a re-analisar as estratégias contidas no plano de massificação do uso de gás, impulsionado pelo Governo Nacional e, assim, rever o papel do GLP. Notícias recentes, determinaram achados de novos poços petrolíferos (Vulcanera), com similares estruturas geológicas às de Cusiana, permitindo assim, reforçar essa tese.

Nesta dissertação foi mostrado que a utilização de GLP para fins domésticos não representa problema para a comercialização do $\mathrm{GN}$, pois este último combustível pode ser também utilizado em outros setores produtivos. No entanto, é importante que sejam feitos estudos sistêmicos sobre a utilização do GN para geração termelétrica no interior do país e para o setor de transporte (GNC). 
É bastante importante que seja realizado um estudo detalhado sobre os custos ambientais decorrentes dos niveis de poluição atmosférica causados por fontes móveis (setor de transporte) em Santafé de Bogotá. A internalização desses custos na valorização de energéticos utilizados nesse setor podem melhorar a economicidade de projetos que se utilizem de energéticos menos agresivos para o meio ambiente, como é o caso dos tróleibus. Nesta dissertação foi demonstrado que, para os preços atuais da gasolina (subsidiada), não é viável financeiramente a implantação desse tipo de veículo para a cidade mais poluida do pais, mas para preços superiores da gasolina, o projeto pode tornar-se interessante levando em conta os custos ambientais. 


\section{REFERÊNCIAS BIBLIOGRÁFICAS}

ACEVEDO, J.; BOCAREJO, J.P. Bases de Una Politica Integral de Transporte Urbano en Colombia. Informe Final, IFT-264. Departamento Nacional de Planeación. Santafé de Bogotá, oct. 1993.

ACEVEDO, J.; SALAZAR, J.C.; CASTAÑEDA, W. El Metro de Medellín, Una llusión Costeada por Todos los Colombianos. FONADE, Instituto SER de Investigación. Santafé de Bogotá, may. 1993.

ALVAREZ G.,J. G. Investigación sobre Producción Colombiana de Electrodomésticos. International Energy Initiative. Medellín, mar. 1994.

ALSTON, L. L. Railways and Energy. World Bank Staff Working Papers No. 634. Washington, 1984.

ARANGO, F. et al. Estudio de Factibilidad del Uso del GNC como fuente Alterna de Energía para el Transporte Público de Pasajeros en el Valle de Aburrá. Medellin, 1990. Trabalho de Graduação - Facultad de Economía, Universidad Cooperativa de Colombia.

ARMSTRONG-WRIGHT, A. Sistemas de Transporte Público Urbano; Directrices para el Examen de Opciones. Doc. Técnico do Banco Mundial. No. 52S. Washington, ene. 1987.

BALASSIANO, R. Alternativas Tecnológicas para o Ónibus Urbano: Avaliação do Ónibus a Gás Natural Comprimido, do Tróleibus e de seus Impactos Ambientais Atmosféricos. Rio de Janeiro, 1991. 193p. Dissertação (Mestrado) - COPPE, Universidade Federal de Rio de Janeiro.

BANCO INTERAMERICANO DE DESARROLLO. El Impacto de los Costos de Energia sobre el Transporte en América Latina. Colombia, nov. 1982.

BITU, R.; BORN, P. Tarifas de Energia Elétrica. Companhia Força e Luz Cataguazes-Leopoldina. Brasil, 1994.

BÓA NOVA, A. C. Energia e Classes Sociais no Brasil. Ed. Loyola. São Paulo, 1985. 
BRUGMAN, A.; DELGADO, J.; ACOSTA, A. Beneficios Históricos del Uso del Gas Natural en el Pais y Perspectivas para su Aprovechamiento en la Costa Atlántica. Santafé de Bogotá, may. 1990.

CARRARO, U. Sistema Integrado de Transporte Urbano da Região Metropolitana de São Paulo, SITU/RMSP. I Congresso Internacional de Transportes Metropolitanos sobre Trilhos. São Paulo, dez. 1993.

CHAin A., C. Ajuste de Modelos de Proyección de la Demanda Energética de Sector Transporte. Ministerio de Minas y Energía de Colombia. Santafé de Bogotá, mar. 1993.

COCK L., J.E. Elementos para Mejorar el Ordenamiento Institucional del Sector del Gas en Colombia. Seminario Internacional: Organización Institucional del Sector del Gas: La Experiencia Internacional. Santa Marta, dic. 1991.

\section{COLGAS-ECONOMISTAS CONSULTORES ASOCIADOS. La} Comercialización del GLP en Colombia: Organización y Rentabilidad. Informe Final. Santafé de Bogotá, dic. 1990.

COMISIÓN NACIONAL DE ENERGÍA. Estudio de Eficiencia Energética en los Sectores Residencial, Comercial y Oficial: Informe Final de Consultores. Programa ESMAP. Santafé de Bogotá, jun. 1992.

CONGRESO SOBRE LA MASIFICACIÓN DEL USO DE COMBUŚTIBLES GASEOSOS, Medellin, jul. 1992. Conclusiones y Comentarios. Medellin, ACIEM, jul. 1992.

CORPORACIÓN AUTÓNOMA DEL CAUCA; EMPRESAS MUNICIPALES DE CALI; UNIVERSIDAD DEL VALLE. Proyecto Demanda y Oferta de Energéticos en el Suroccidente Colombiano: Informe de Encuesta de Hogares Sector Residencial. Santiago de Cali, ene. 1993.

DEPARTAMENTO NACIONAL DE PLANEACIÓN; JUNTA NACIONAL DE TARIFAS. Boletin Mensual de Tarifas. Jun. 1991.

DEPARTAMENTO NACIONAL DE PLANEACIÓN. Nuevos Espacios para la Inversión Privada en Colombia: Documento DNP-2648-UDE-Diex. Santafé de Bogotá, mar. 1993a. 
DEPARTAMENTO NACIONAL DE PLANEACIÓN. Plan de Gas; Estrategia para el Desarrollo del Programa de Gas: Documento MINMINASECOPETROL-DNP-2646-UINF-DIMEN. Santafé de Bogotá, mar. 1993b.

DEPARTAMENTO NACIONAL DE PLANEACIÓN. Resoluciones de la Junta Nacional de Tarifas de Servicios Públicos: Gaceta DNP. No. 81. Santafé de Bogotá, 31 de may. 1993c.

DIAZ DEL CASTILlO G., H. Plan de Desarrollo del Programa de Masificación del Gas. Ecopetrol. Seminario sobre Masificación del Uso de Combustibles Gaseosos, ACIEM. Medellin, julio de 1992.

DIAZ R., G. Estudio de Factibilidad "El Bus Ligero" para la Ciudad de Medellin. Departamento Administrativo de Planeación Metropolitana, Sección de Vias y Transporte. Medellín, mar. 1993.

EMPRESA COLOMBIANA DE PETROLEOS. Estudio de Comercialidad Contratos de Asociación Santiago de Atalayas y Tauramena. Campos Cusiana y Cupiagua: Manejo y Aprovechamiento del Gas. Santafé de Bogotá, jun. 1993a.

EMPRESA COLOMBIANA DE PETROLEOS. EI Plan de Masificación de Gas; Evaluación y Perspectivas: Documento MINMINAS-ECOPETROL. Santafé de Bogotá, ago. 1993b.

EMPRESA COLOMBIANA DE PETROLEOS, Vicepresidencia de Transporte y Abastecimiento, Gerencia Plan de Gas. Plan de Acciones de Ecopetrol para la Masificación del Gas Natural. Santafé de Bogotá, nov. 1993c.

EMPRESA COLOMBIANA DE PETROLEOS, Vicepresidencia de Transporte $y$ Abastecimiento. Proyectos de Inversión. Santafé de Bogotá, nov. 1993d.

EMPRESA COLOMBIANA DE PETROLEOS. Indicadores de la Industria Petrolera. Santafé de Bogotá, dic. 1993e.

EMPRESA COLOMBIANA DE PETROLEOS, División de Gas Natural y Combustibles Domésticos. Información General sobre el Plan de Masificación de Gas Natural. Santafé de Bogotá , feb. 1994a.

EMPRESA COLOMBIANA DE PETROLEOS. Programa de Sustitución de Cocinol. Santafé de Bogotá, ene. 1994b. 
EMPRESA DE TRANSPORTE MASIVO DEL VALLE DE ABURRÁ; ADEMINAS. Curso General de Ferrocarriles. Medellín, may. 1993.

EMPRESA DE TRANSPORTE MASIVO DEL VALLE DE ABURRÁ. Tren Metropolitano: Selección del Sistema y su Factibilidad Técnica y Económica. Medellín, sep. 1979. v.1.

EMPRESA DISTRITAL DE TRANSPORTE URBANO. Proyecto Trolebús Bogotá S.A. Santafé de Bogotá, jul. 1991.

EMPRESAS PÚBLICAS DE MEDELLíN, Unidad del Gas. Propuesta de Estructura Tarifaria para el GLP: Proyectos piloto del programa de gas. Medellin, jun. 1992.

EMPRESAS PÚBLICAS DE MEDELLín, Unidad del Gas. Proyecto para la Distribución de Gas Natural por Red en el Valle de Aburrá. Medellin, may. 1993.

ESTUDIOS TÉCNICOS; NOVACORP INTERNATIONAL. Estudio de Factibilidad del Gasoducto Central: Informe Final. Santafé de Bogotá, nov. 1987. v.2.

EURCOLERG. Gestión de Carga Eléctrica: Resumen Ejecutivo. Santafé de Bogotá, nov. 1992a.

EURCOLERG. Plan Gas; Mercado Potencial del Gas: Escenarios de Demanda por Sector y Región. Santafé de Bogotá, 1992b. v.3.

FERROCARRILES NACIONALES DE COLOMBIA. Red Férrea Nacional. Unidad de Planeación. 1988.

GOLDEMBERG, J.; JOHANSSON, T.; REDDY, A.; WILLIAMS, R. Energy For a Sustainable World. Wiley Eastern Limited. New Delhi, 1988a. 517p.

GOLDEMBERG, J.; JOHANSSON, T.; REDDY, A.; WILLIAMS, R. Energia para o Desenvolvimento. Trad. de José R. Moreira. São Paulo, T. A. Queiroz, 1988b. 101p.

GUHL, E.; PACHÓN, A. Estudio de Evaluación del Sistema Férreo en la Sabana de Bogotá. Bogotá, feb. 1991. 
GUHL, E. et al. Transporte Masivo en Bogotá. DNP, FONADE, UNIANDES Santafé de Bogotá, jun. 1992.

INSTITUTO COLOMBIANO DE NORMAS TÉCNICAS. Norma Colombiana 2 661; Electrotecnia: Resistencias Eléctricas Tubulares. Santafé de Bogotá, nov. 1989.

INTERCONEXIÓN ELÉCTRICA S.A.; CORPORACIÓN ELÉCTRICA DE LA COSTA ATLÁNTICA. Caracterización de la Carga del Sistema Eléctrico de la Costa Atlántica. Oficina de Planeación. Documento ISA-OPUN 16/04/91 056E. Medellin, abr. 1991.

INTERCONEXIÓN ELÉCTRICA S.A.; CENTRO DE INVESTIGACIONES PARA EL DESARROLLO INTEGRAL. Eficiencia Térmica en Electrodomésticos. Documento SC-D-162. Medellín, ene. 1992.

INTERCONEXIÓN ELÉCTRICA S.A. Estructura de Costos del Sistema Eléctrico Colombiano: Referencia. Doc. ISA-OPUN 11/11/86 139E. Medellin, nov. 1986.

INTERCONEXIÓN ELÉCTRICA S.A.. Manual de Planeamiento de Sistemas Eléctricos de Distribución. Grupo Sistemas de Distribución. Medellín, $1992 a$.

INTERCONEXIÓN ELÉCTRICA S.A.. Proyecciones Regionales de Ventas y Demandas de Energía y Potencia 1992-2011. Doc. ISA-OP-E-10. Medellín, jul. 1992b.

INTERCONEXIÓN ELÉCTRICA S.A. Sector Eléctrico Colombiano: Información General. Oficina de Planeación. Doc OP-E-02. Medellín, feb. $1993 a$.

INTERCONEXIÓN ELÉCTRICA S.A.. Plan de Expansión de Referencia Generación-Transmisión, Revisión: Resumen Ejecutivo. Medellin, 1993b.

INTERCONEXIÓN ELÉCTRICA S.A. Indices de Pérdidas de Energia: Metodología de Cálculo. Gerencia Centro Nacional de Despacho. Documento ISA-CND-94-069. Medellin, 2 mar. 1994. 
JAPAN INTERNATIONAL COOPERATION AGENCY. The Study on Air Pullution Control Plan in Santa Fe de Bogota City Area. Santafé de Bogotá, feb. 1992.

LOPERA V., A. et al. El Gas: Una Alternativa Energética: Gestión de Conocimiento para la Masificación del Gas en Colombia. Medellín, 1992. Dissertação (Mestrado) - Programa de Gestión Tecnológica, Universidad Pontificia Bolivariana.

MEJÍA F., E. Consideraciones del Corpes de la Costa Atlántica Respecto a la Construcción del Gasoducto Central y al Programa Gas para el Cambio. Congreso del Uso de Combustibles Gaseosos. Medellín, jul. 1992.

MEJÍA VILLEGAS S.A; SANTOYO, A. Plan Maestro para la Distribución de Gas Natural: Anexo 8: Parque Automotor en Medellín. Informe Final. EEPPM. Medellin, 1992. v.1. T.1.

MENA, M.; MME. Memorias al Congreso Nacional. Santafé de Bogotá, 1990a.

MENA, M.; MME. Memorias al Congreso Nacional; Anexo Histórico. Santafé de Bogotá, 1990b.

MINISTERIO DE OBRAS PÚBLICAS Y TRANSPORTE. Invitación a Participar en la STF (Sociedad Colombiana de Transporte Ferroviario S.A.) Dentro de la Nueva Estructura Institucional del Transporte Ferroviario en Colombia. Santafé de Bogotá, abr. 1990.

MONTENEGRO F., L. La Seguridad del Gas, de Otras Energia, de Otras Actividades: Una Comparación Significativa. XVIII Asamblea Nacional del Gas, España, 1992.

MUNASINGHE, M.; WARFORD, J. J. Electricity Pricing. The Johns Hopkins University Press. Baltimore, 1982.

MUNICIPIO DE MEDELLíN, Planeación Metropolitana, División Planeación Física. Análisis Sobre los Aspectos Ambientales del Valle de Aburrá. Medellin, jun. 1991.

NULE A., G.; MME. Memorias al Congreso Nacional 1992-1993. Santafé de Bogotá, jul. 1993. 
OLADE. Manual Latinoamericano y del Caribe para el Control de Pérdidas Eléctricas. Santafé de Bogotá, ago. 1990.

OLADE. Sistema de Información Económico Energética. Quito, 1994.

OLADE; CCE. Proyecto Manejo de la Demanda y Uso Racional de Energía en el Istmo Centroamericano: Etapa 4. Plan de Acción e Identificación de Medidas en la Ciudad de Costa Rica. Quito, sep. 1993.

PERRY R., G. Gas para el Cambio. MME. Santafé de Bogotá. 1987.

POVEDA R., G. Gas de Carbón para Colombia. Seminario sobre Masificación del Uso de Combustibles Gaseosos, ACIEM. Medellín, jul. 1992.

PRADA C., J.J. Electrificación del Ferrocarril de Antioquia. Anales de Ingeniería. v.65, n.735/737, p. 35-45, 1961.

REDDY K. N., A. Barriers to Improvements in Energy Efficiency. Energy Policy. dec. 1991.

RENDÓN, J.M. Gas para Todos. Carta Petrolera, Ecopetrol. n. 40, mar. 1993.

RESTREPO S., J.C.; MME. Memorias al Congreso Nacional 1991-1992. Santafé de Bogotá, jun. 1992. T.1.

REVISTA ACOGAS. Santafé de Bogotá, n.7, nov.- dic. 1993.

REVISTA CARTA PETROLERA. Santafé de Bogotá, n. 46. 1994.

REVISTA VIA URBANA. Rio de Janeiro, nov. 1993.

RUEDA O., R. V. Emergencias con GLP y otros Productos Quimicos Reportadas al CISPROQUIM. Acogás. n.7, nov-dec. 1993.

SANTOYO C., A.. Estudio de Precios y Barreras Tarifarias a la Penetración del Gas Natural en el Centro del Pais: Informe Final. ECOPETROL. Santafé de Bogotá, abr. 1993. v.1. 
SERRA, C. Contribuição do Metrô para a Economia de Energia no Transporte de Passageiros no Municipio de São Paulo. São Paulo, jul. 1982.

SISTEMA DE INFORMACIÓN ENERGÉTICA; MINISTERIO DE MINAS Y ENERGIA. Usos y Consumos de Energía en los Sectores Residencial Rural, Comercio e Industria. Santafé de Bogotá, mar. 1990.

SUPLEMENTO Especial : Transporte de Carga. El Tiempo, Santafé de Bogotá, 28 feb. 1994.

SUAREZ, C. E.; DOBRUSIN, A. J. Economía del Gas. Instituto de Economía Energética. San Carlos de Bariloche, 1992.

TECHNOPLAN. Thermoelectric Alternatives for Colombia. International Energy Initiative. Sao Paulo, jun. 1994.

THOMSON, J. M. Toward Better Urban Transport Planning in Developing Countries. World Bank Staff Working Papers No. 600. Washington, 1983.

TOGNO, F.M. Ferrocarriles. México, 1982.

UNIDAd DE PLANEAmiento MINERO-energético; MME. Plan Energético Nacional, PEN. Santafé de Bogotá, may. 1994. 


\section{LISTA DE FIGURAS}

Figura

Descrição

Página

1.1 Comparação entre Tarifas Setoriais e Custos Marginais de Longo Prazo (CMLP)

1.2 Comparação entre Tarifas e Custos Marginais de Longo

Prazo (CMLP) por Empresas e para o Sistema Nacional

1.3 Projeções Financeiras do Setor Elétrico Colombiano. 1991-2000

1.4 Mapa da República da Colômbia

2.1 Evolução da Demanda de Energia Final na Colômbia. 1975-1992

2.2. Taxas de Crescimento Anual da Demanda Final de Energia Setorial na Colômbia. 1981-1992

2.3 Evolução da Participação Relativa no Consumo Energético dos Principais Setores Consumidores. 19751992

2.4 Evolução da Eficiência Energética dos Principais Setores de Consumo Colombianos. 1980-1992 (Energia Útil/Energia Final)

2.5 Evolução da Participação dos Energéticos no Consumo de Energia Final Residencial

2.6 Evolução Histórica da Demanda de Eletricidade na Colômbia

Eletricidade na Colômbia. 1975-1992

Histogramas de Freqüência Relativa dos
Residenciais Segundo Estrato Sócio-Econômico

2.9 Participação Energética no Setor Residencial Urbano Colombiano 1992

2.10 Curva de Carga Diária Típica do Sistema Elétrico Colombiano 
2.11 Curva de Distribuição Percentual Diária de Usuários da Cocção Elétrica em Santiago de Cali para o Estrato Sócio-Econômico 1

2.12 Curva de Distribuição Percentual Diária de Usuários da Cocção Elétrica em Santiago de Cali para o Estrato Sócio-Econômico 2

2.13 Curva de Distribuição Percentual Diária de Usuários da Cocção Elétrica em Santiago de Cali para o Estrato Sócio-Econômico 3

2.14 Curva de Distribuição Percentual Diária de Usuários da Cocção Elétrica em Santiago de Cali para o Estrato Sócio-Econômico 4

2.15 Curva de Distribuição Percentual Diária de Usuários da Cocção Elétrica em Santiago de Cali para o Estrato Sócio-Econômico 5

2.16 Curva de Distribuição Percentual Diária de Usuários da Cocção Elétrica em Santiago de Cali para o Estrato Sócio-Econômico 6

2.17 Participação Energética no Setor Residencial Rural Colombiano. 1992

2.18 Evolução do Índice de Perdas do Sistema Elétrico Colombiano

2.19 Desagregação Estimada de Perdas de Energia Elétrica. na Colômbia em 1992

2.20 Produção Anual de HACEB de Resistências Tubulares para Fogões Elétricos

2.21 Avaliação Econômica do Custo por $k W(t)-h$ Útil na Cocção, Segundo Horas de Uso Diário e Equipamento Utilizado. Taxa de Desconto: $5 \%$

2.22 Avaliação Econômica do Custo por $k W(t)-h$ Útil na Cocção, Segundo Horas de Uso Diário e Equipamento Utilizado. Taxa de Desconto: $8 \%$

2.23 Avaliação Econômica do Custo por $k W(t)-h$ Útil na Cocção, Segundo Horas de Uso Diário e Equipamento Utilizado. Taxa de Desconto: $12 \%$ 
2.24 Avaliação Econômica do Custo por $k W(t)-h$ Útil na Cocção, Segundo Horas de Uso Diário e Equipamento Utilizado. Taxa de Desconto: $15 \%$

2.25 Avaliação Financeira do Custo por $k W(t)-h$ Útil na Cocção, Segundo Preço da Eletricidade e Equipamento Utilizado. Taxa de Desconto: 3.3\%. Horas de Uso Diário: $4 \mathrm{~h}$

2.26 Avaliação Financeira do Custo por $k W(t)-h$ Útil na Cocção, Segundo Preço da Eletricidade e Equipamento Utilizado. Taxa de Desconto: 10\%. Horas de Uso Diário: $4 \mathrm{~h}$

2.27 Avaliação Financeira do Custo por $k W(t)-h$ Útil na Cocção, Segundo Preço da Eletricidade e Equipamento Utilizado. Taxa de Desconto: $15 \%$. Horas de Uso Diário: $4 \mathrm{~h}$

2.28 Avaliação Financeira do Custo por $k W(t)-h$ Útil na Coç̧ão, Segundo Preço da Eletricidade e Equipamento Utilizado. Taxa de Desconto: $30 \%$. Horas de Uso Diário: $4 \mathrm{~h}$

3.1 Participação dos Diferentes Energéticos no Consumo Final de Energia na Cocção Residencial da Zona Urbana da Colômbia (Ano 1992)

3.2 Plano de Investimentos do Programa de Massificação de Gás na Colômbia no Período 1993-2015. (Valores em dólares de 1993)

3.3 Rede de Gasodutos Projetada na Colômbia

3.4 Distribuição dos Benefícios Econômicos Estimados do Programa de Massificação de Gás na Colômbia no Período 1995-2015. (Valores em dólares de 1993)

3.5 Demanda de Gás Natural no Setor Residencial Colombiano. (Programa de Massificação de Gás)

3.6 Demanda de Eletricidade Substituida com GN. (Programa de Massificação de Gás da Colômbia)

4.1 Evolução do Consumo, Produção e Importações de Gasolina Motor na Colômbia 
4.3 Consumo de Gasolinas no Setor de Transportes da 132 Colômbia. Participação Relativa em 1992

4.4 Consumo de Óleo Diesel no Setor de Transportes da 132 Colômbia. Participação Relativa em 1992

4.5 Consumo de Gasolinas no Transporte Rodoviário em 134 1992 por Tipo de Serviço na Colômbia

4.6 Consumo de Óleo Diesel no Transporte Rodoviário. em 134 1992 por Tipo de Serviço na Colômbia

4.7 Consumo de Gasolinas no Transporte Rodoviário de 135 Passageiros em 1992

4.8 Consumo de Diesel no Transporte Rodoviário de 135 Passageiros em 1992

4.9 Consumo de Gasolinas no Transporte Rodoviário de 136 Carga em 1992

4.10 Consumo de Diesel no Transporte Rodoviário de Carga 136 em 1992

4.11 Rede das Principais Vias da Cidade de Santafé de 153 Bogotá

4.12 Curva de Carga Típica Diária de Transporte Urbano na 156 Colômbia

4.13 Valor Netback (de Equilibrio) Financeiro da Eletricidade a ser Utilizada no Sistema de Tróleibus (Valores em US\$ 162 de 1993). Cenário de Preços Altos dos Tróleibus (US $\$ 260.000 /$ unidade)

4.14 Valor Netback (de Equilibrio) Financeiro da Eletricidade a ser Utilizada no Sistema de Tróleibus (Valores em US\$ 162 de 1993). Cenário de Preços Baixos dos Tróleibus (US\$ 64.000/unidade)

4.15 Custo Econômico da Infra-estrutura e Operação do Sistema de Alimentação Elétrica para os Tróleibus na 166 Troncal da Caracas em Santafé de Bogotá. (Valores em US $\$$ de dezembro de 1993)

4.16 Projeto do Metrô em Santafé de Bogotá Proposto no Estudo do Consórcio INECO-SOFRETU-CS em 1981 
4.17 Projeto do Metrô em Santafé de Bogotá Proposto no Estudo de Reabilitação das Ferrovias Urbanas em 1986

4.18 Linhas em Construção do Metrô de Medellín

4.19 Sistema Integrado de Transporte (SIT) para Medellín

4.20 Cenários de Crescimento da Demanda de Energia Elétrica na Colômbia Considerando ou não o Programa de Massificação de Gás

4.21 Cenários de Crescimento da Demanda de Potência Elétrica na Colômbia Considerando ou não o Programa de Massificação de Gás

4.22 Cenários de Crescimento da Demanda de Energia Elétrica no Mercado de EEB Considerando ou não o Programa de Massificação de Gás

4.23 Cenários de Crescimento da Demanda de Potência Elétrica no Mecado de EEB Considerando ou não o Programa de Massificação de Gás

4.24 Cenários de Crescimento da Demanda de Energia Elétrica no Mercado de EEPPM Considerando ou não o Programa de Massificação de Gás

4.25 Cenários de Crescimento da Demanda de Potência Elétrica no Mercado de EEPPM Considerando ou não o Programa de Massificação de Gás

4.26 Cenários de Crescimento da Demanda de Energia Elétrica no Mercado de CVC Considerando ou não o Programa de Massificação de Gás

4.27 Cenários de Crescimento da Demanda de Potência Elétrica no Mercado de CVC Considerando ou não o Programa de Massificação de Gás

4.28 Projeção das Economias em Energia Elétrica pela Penetração do Programa de Massificação de Gás na Colômbia

4.29 Projeção das Economias em Potência Elétrica pela Penetração do Programa de Massificação de Gás na Colômbia 
4.30 Composição Estimada das Vendas de Eletricidade para o ano 2000. (Cenário de Alta Penetração do Programa de Massificação de Gás) 


\section{LISTA DE TABELAS}

Tabela

Descrição

Página

2.1 Demanda de Energia Final na Colômbia

2.2 Participação Setorial na Demanda de Energia Final na Colômbia. (Porcentagem)

2.3 Taxas de Crescimento Anual da Demanda de Energia Final na Colômbia. (Porcentagem)

2.4 Demanda de Energia Útil na Colômbia (Teracalorias)

2.5 Eficiência no Uso Energético na Colômbia (Energia útil/Energia final). (Porcentagem)

2.6 Evolução do Consumo de Energéticos no Setor Residencial 1980-1992. (Tcal)

2.7 Evolução da Participação dos Energéticos no Consumo Residencial 1980-1992. (Porcentagem)

2.8 Evolução do Consumo de Eletricidade na Colômbia 19751992 (GWh)

2.9 Evolução da Participação Setorial nas Vendas de Eletricidade na Colômbia 1975-1992

2.10 Participação do Setor Residencial no Total de Consumo de Eletricidade. Ano 1992

2.11 Parâmetros e Fatores de Ponderação Utilizados para Estratificação Sócio-Econômica na Colômbia

2.12 Distribuição Percentual dos Usuários Residenciais Segundo Estrato Sócio-Econômico

2.13 Nivel de Renda Familiar Segundo Estrato SócioEconômico

2.14 Distribuição Percentual do Consumo Residencial de Energéticos Segundo o Estrato Sócio-Econômico para a Cidade de Santafé de Bogotá 
2.15 Distribuição Percentual do Consumo Residencial de Energéticos Segundo o Estrato Sócio-Econômico para a Cidade de Medellín

2.16 Distribuição Percentual do Consumo Residencial de Energéticos Segundo o Estrato Sócio-Econômico para a Cidade de Santiago de Cali

2.17 Distribuição Percentual do Consumo Residencial de Energéticos Segundo o Estrato Sócio-Econômico para a Cidade de Barranquilla

2.18 Usos Finais da Eletricidade no Setor Residencial em Santafé de Bogotá. Porcentuais de Consumo para um Usuário Médio

2.19 Usos Finais da Eletricidade no Setor Residencial em Medellín. Porcentuais de Consumo para um Usuário Médio

2.20 Usos Finais da Eletricidade no Setor Residencial em Santiago de Cali. Porcentuais de Consumo para um Usuário Médio

2.21 Usos Finais da Eletricidade no Setor Residencial em Barranquilla. Porcentuais de Consumo para um Usuário Médio

2.22 Usos Finais da Eletricidade no Setor Residencial em Santafé de Bogotá. Consumos Médios por Usuário (kWh/mês)

2.23 Usos Finais da Eletricidade no Setor Residencial em Medellín. Consumos Médios por Usuário (kWh/mês)

Usos Finais da Eletricidade no Setor Residencial em Santiago de Cali. Consumos Médios por Usuário

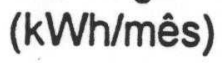

2.25 Usos Finais da Eletricidade no Setor Residencial em Barranquilla. Consumos Médios por Usuário (kWh/mês)

2.26 Estrutura de Consumo de Energia Elétrica para a Cidade de Medellín, Segundo Avaliação das Empresas Públicas de Medellin

2.27 Estrutura de Consumo de Energia Elétrica para a Cidade de Santiago de Cali, Segundo Estudo CVC-EMCALI-UV 
2.28 Potências Efetivas Instaladas para o Atendimento da Cocção Elétrica por Usuário em Santiago de Cali. (kW)

2.29 Potências Máximas Diversificadas para Cocção Elétrica por Usuário Médio em Santiago de Cali. (kW)

2.30 Tarifas de Energia Elétrica na Colômbia (Cent US $\$ / \mathrm{kWh} / \mathrm{mês})$. Valores em centavos de dólar de dezembro de 1993

2.31 Custos de Referência para Usuários a Nivel de Distribuição Secundária (< $1 \mathrm{kV}$ ). (Cent US $\$$ de dezembro de 1993)

2.32 Comparação Percentual entre as Tarifas Residenciais de Eletricidade e os Custos Econômicos de Referência para a Colômbia. (Valores em dólares de dezembro de 1993)

2.33 Paralelo entre as Estruturas dos Sistemas Elétricos da Colômbia e da Costa Rica. Valores para o Ano de 1992

2.34 Cálculo do Fator de Carga do Uso Final Cocção em Santiago de Cali

2.35 Subsídios Anuais Implícitos nas Tarifas Residenciais de Energia Elétrica em Santafé de Bogotá, Medellin, Santiago de Cali e Barranquilla. (Valores em US\$ de dezembro de 1993)

2.36 Custo Anual da Eletricidade Consumida em Cocção por um Usuário Médio em Santafé de Bogotá, Medellin,. Santiago de Cali e Barranquilla. (Valores em US\$ de dezembro de 1993)

2.37 Custos Totais Anualizados para um Usuário Médio Decorrentes da Cocção Elétrica em Santafé de Bogotá, Medellin, Santiago de Cali e Barranquilla. (Valores em US $\$$ de dezembro de 1993)

2.38 Cálculo Econômico do Custo pelo Serviço Calor para a Cocção. (Valores em US\$ constantes de dezembro de 1993)

2.39 Cálculo Financeiro do Custo pelo Serviço Calor para a Cocção. (Valores em US\$ constantes de dezembro de 1993) 
2.40 Parcela Familiar Orçamentária Devotada ao Pagamento da Fatura Elétrica Média Mensal em Santafé de Bogotá, Medellin, Santiago de Cali e Barranquilla. (Valores em US $\$$ de dezembro de 1993)

2.41 Efeito na Redução Marginal de Consumo de Eletricidade na Fatura Mensal de Energia Elétrica Residencial em Santafé de Bogotá, Medellín, Santiago de Cali e Barranquilla. (Valores em US $\$$ de dezembro de 1993)

3.1 Composição Química do GN de Cusiana

3.2 Custos City-Gate do GN para o Programa de Massificação de Gás na Colômbia. (Valores em dólares de 1993)

4.1 Evolução do Consumo de Derivados do Petróleo no Setor de Transportes na Colômbia

4.2 Comparação de Diferentes Alternativas de Sistemas de Transporte de Massa

4.3 Custos de Infra-estrutura e de Equipamentos dos Sistemas de Transporte de Massa. (Valores em milhöes de dólares de dezembro de 1993)

4.4 Custos dos Veículos Utilizados em Sistemas de Transporte de Massa. (Valores em US\$ de 1993)

4.5 Custos de Operação de Sistemas de Transporte de Massa

4.6 Custos Totais de Sistemas de Transporte de Massa

4.7 Características Principais do Projeto da Troncal da Caracas em Santafé de Bogotá

4.8 Concentrações Máximas de Poluentes Atmosféricos em Santafé de Bogotá

4.9 Quantidade de Emissões de Poluentes Atmosféricos e Responsabilidade dos Diferentes Setores Econômicos de Santafé de Bogotá. (Dados Medidos ou Estimados para 1991)

4.10 Redução Percentual das Emissões de Poluentes Atmosféricos pela Substituição de Ónibus por Tróleibus na Troncal da Caracas em Santafé de Bogotá. (Ano base de comparação: 1991) 
4.11 Custos de Operação e Capital dos Ónibus. (Valores em US\$ de dezembro de 1990)

4.12 Cálculo dos Custos do Sistema de Alimentação para a 164 Rede de Tróleibus na Troncal da Caracas em Santafé de Bogotá. (Valores em US $\$$ de dezembro de 1993) 